\title{
Mesenchymal stromal cells to induce tolerance to solid organ transplantation
}

Citation for published version (APA):

Casiraghi, F. (2015). Mesenchymal stromal cells to induce tolerance to solid organ transplantation.

[Doctoral Thesis, Maastricht University]. Maastricht University. https://doi.org/10.26481/dis.20150422fc

Document status and date:

Published: 01/01/2015

DOI:

$10.26481 /$ dis.20150422fc

Document Version:

Publisher's PDF, also known as Version of record

\section{Please check the document version of this publication:}

- A submitted manuscript is the version of the article upon submission and before peer-review. There can be important differences between the submitted version and the official published version of record.

People interested in the research are advised to contact the author for the final version of the publication, or visit the DOI to the publisher's website.

- The final author version and the galley proof are versions of the publication after peer review.

- The final published version features the final layout of the paper including the volume, issue and page numbers.

Link to publication

\footnotetext{
General rights rights.

- You may freely distribute the URL identifying the publication in the public portal. please follow below link for the End User Agreement:

www.umlib.nl/taverne-license

Take down policy

If you believe that this document breaches copyright please contact us at:

repository@maastrichtuniversity.nl

providing details and we will investigate your claim.
}

Copyright and moral rights for the publications made accessible in the public portal are retained by the authors and/or other copyright owners and it is a condition of accessing publications that users recognise and abide by the legal requirements associated with these

- Users may download and print one copy of any publication from the public portal for the purpose of private study or research.

- You may not further distribute the material or use it for any profit-making activity or commercial gain

If the publication is distributed under the terms of Article $25 \mathrm{fa}$ of the Dutch Copyright Act, indicated by the "Taverne" license above, 


\title{
MESENCHYMAL STROMAL CELLS TO INDUCE TOLERANCE TO SOLID ORGAN TRANSPLANTATION
}

\author{
ACADEMIC DISSERTATION
}

To obtain the degree of Doctor at the Maastricht University,

on the authority of the Rector Magnificus, Prof. dr. L.L.G. Soete, in accordance with the decision of the Bord of Deans, to be defended in public on Wednesday April 22 $2^{\text {nd }} 2015$ at 12:00 hrs

$$
\text { by }
$$

Federica Casiraghi 


\section{Supervisor}

Prof.dr. K.L.M. Leunissen, Maastricht University

\section{Cosupervisor}

Prof.dr. G. Remuzzi, Mario Negri Institute, Bergamo, Italy

\section{Assessment committee}

Prof.dr. M.G.J. Tilanus (chairman)

Dr. M. Christiaans

Prof.dr. M.H.V. De Baets

Prof.dr. L. Hilbrands, Radboud Universitair Medisch Centrum Nijmegen

Prof.dr. J.J. Homan van der Heide, Academisch Medisch Centrum Amsterdam 
To my Father 


\section{CONTENTS}

Chapter 1. Introduction and objectives of the thesis

Chapter 2. Pretransplant Infusion of Mesenchymal Stem Cells Prolongs the Survival of a Semiallogeneic Heart Transplant through the Generation of Regulatory T Cells Journal of Immunology 2008; 181: 3933-3946.

Charter 3. Autologous Mesenchymal Stromal Cells and Kidney Transplantation:

A Pilot Study of Safety and Clinical Feasibility

Clinical Journal of American Society of Nephrology 2011; 6: 412-422

Chapter 4. Localization of mesenchymal stromal cells dictates their immune or proinflammatory effects in kidney transplantation

American Journal of Transplantation 2012; 12:2373-83

Chapter 5. Mesenchymal stromal cells and kidney transplantation:

pretransplant infusion protects from graft dysfunction while

fostering immunoregulation

Transplant International 2013; 26:867-78

Chapter 6. Immunomodulatory effects of mesenchymal stromal cells

in solid organ transplantation

Current Opinion in Organ Transplantation 2010, 15: 731-737.

Chapter 7. Mesenchymal stromal cells to promote solid organ

transplantation tolerance

Current Opinion in Organ Transplantation 2013, 18:51-58.

Chapter 8. General discussion and conclusions

Chapter 9. Summary

Chapter 10.Valorisation of the research

References

Curriculum Vitae

Acknowledgements 
CHAPTER 1

INTRODUCTION AND OBJECTIVES 


\section{INTRODUCTION}

\section{The unmet needs of organ transplantation}

Since the birth of the field, progress in transplantation medicine has been rapid. The introduction of newer immunosuppressive agents and improvements in surgical techniques and ancillary care have made transplantation a routine and preferred therapy for end-stage renal, cardiac, hepatic, and pulmonary failure; pancreatic transplantation provides similar benefits for diabetic patients (1). Although these immunosuppressive drugs have dramatically improved the life of transplant recipients over the past 30 years, two notable problems remain. First, these drugs are associated with significant toxicities. They include both the toxicities of immunosuppression itself (enhanced risk of opportunistic infections and selected malignancies), and side effects unrelated to immunosuppression (e.g., nephrotoxicity of calcineurin inhibitors, hypertension and cardiovascular disease resulting from use of corticosteroids). Second, although the array of currently available drugs and biologic agents has proven very successful in the prevention and treatment of acute rejection, similar success has not been achieved in preventing chronic graft dysfunction (often termed chronic rejection) and extending long-term graft survival (2-6). Given these circumstances, the scientific discussion at most transplantation immunology meetings are dominated by designing effective ways to induce transplantation tolerance. 'Transplantation tolerance' describes a state in which a donor is 'accepted' without chronic immunosuppressive therapy, while the remainder of the immune system is left intact $(7,8)$. Thus, lack of a pathogenic response to the alloantigen is specific, and the recipient is capable of responding to potentially pathogenic microorganisms and malignancies. Tolerance does not imply the absence of an immune response. Indeed, there is abundant evidence for active immunoregulatory mechanisms, which may operate to maintain transplant tolerance (8).

\section{Mechanisms of rejection to solid organ allografts}

The immune response to an allograft is an ongoing process involving components of both innate and adaptive immune system, starting from the time of reperfusion (9). Local tissue damage and ischemia/reperfusion injury initiate the production of damage-associated molecular patterns (DAMPs) including reactive oxygen species, heat shock proteins and heparan sulphate that bind to pattern recognition receptors (PRR) expressed by innate immune cells. The sensing of DAMPs by PRR results in the production of proinflammatory cytokines, chemokines and the rapid expression of P-selectin by endothelial cells $(10,11)$. These events identify the transplant as a site of injury and inflammation modifying the activation status, permeability and viability of endothelial cells lining 
the vessels, triggering the release of soluble molecules, including antigens from the graft, inducing the production of acute phase proteins such as complement factors, stimulating the migration of donor-derived antigen-presenting cells (APC) from the transplant to recipient lymphoid tissues and triggering the recruitment of inflammatory leukocytes into the graft $(12,13)$.

The presentation of alloantigens by APC, mainly dendritic cells (DC), and their recognition by recipient $\mathrm{T}$ cells initiate the adaptive immune response, the key player in graft destruction (14).

In transplantation, priming of recipient $\mathrm{T}$ cells with antigen can occur on three distinct pathways (15). The first is the direct pathway in which donor DC present in the graft act as passenger leukocytes. In the context of a proinflammatory environment these cells mature and migrate to secondary lymphoid organs where they prime host $\mathrm{T}$ cells. The second is the indirect allorecognition pathway in which recipient DC capture, process and present alloantigens as peptides on their host Major Histocompatibility Complex (MHC) molecules and then prime T cells (16). The third pathway is the semi-direct allorecognition, characterized by the dual ability of recipient DC to present intact donor MHC molecules acquired by cell-to-cell contact of fusion with donor exosomes and to internalize and process donor $\mathrm{MHC}$ as peptides on recipient $\mathrm{MHC}$ molecules (17). Antigen presentation through the direct pathway of allorecognition plays a dominant role in initiating the adaptive immune response to a MHC-mismatched transplant. However, because there are a finite number of passenger leukocytes transferred within a transplanted organ, the role of the direct pathway in allograft rejection diminishes with time as eventually only other types of donor cells, such as endothelial cells remain in the graft to stimulate direct pathways $\mathrm{T}$ cells. Importantly the indirect pathway of allorecognition is available for antigen presentation for as long as the graft remains in situ, and therefore becomes the dominant mode of allorecognition long-term. The significance of the semi-direct pathway of allorecognition in the context of rejection remains to be elucidated (18).

As a consequence of allorecognition, antigen specific signals deliver to T cells through the T-Cell Receptor (TCR-CD3). Signals through TCR-CD3 alone are not sufficient to fully activated naïve T cells. A second essential signal is provided by the interaction of costimulatory molecules with their ligands. Costimulatory molecules can essentially be divided into two families: the B7 family which is best characterized by the T-cell costimulatory molecules CD28 and CD152 (CTLA4) and the Tumor Necrosis Factor (TNF)/TNF receptor family of which the prototype receptor-ligand pair are CD40 and CD154 (CD40L) (19). Signal transduction through TCR and costimulatory pathways then lead to "signal 3", represented by generation of large amount of proliferative cytokines, mainly Interleukin (IL)-2, which in turn promotes cell cycle progression and initiates the clonal expansion and differentiation of activated T cells (18). 
After activation, depending on the microenvironment and additional signals, naïve alloreactive $\mathrm{CD}^{+} \mathrm{T}$ cells acquire helper function (Th). Different $\mathrm{Th}$ subsets exist, each with unique transcription factor and cytokine signature referred to as Th1, Th2 and Th17. In a proinflammatory environment, naïve $\mathrm{CD}^{+} \mathrm{T}$ cells differentiated mainly into Th1 and Th17cells. Th1 cells that express the transcription factor Tbet and secrete Interferon- $\gamma$ (IFN- $\gamma$ ) and IL-2, are involved in cytototoxic T lymphocyte (CTL) priming, stimulation of the B cell humoral response and activation of other cell type such as NK cells. Th17 cells characterized by the expression of ROR $\gamma \mathrm{T}$, secrete IL-17. IL-17 stimulates the production of proinflammatory cytokines leading to the recruitment of neutrophils and macrophages to the graft. There is evidence that Th17 cells and also IL-17producing $\mathrm{CD}^{+} \mathrm{T}$ cells have the capacity to play a role in rejection, particularly in the absence of a Th1 response (20). Alloantigen-specific $\mathrm{CD}^{+} \mathrm{T}$ cells, after differentiation in CTL migrate to the graft where they recognize target cells via their allogeneic MHC class I molecules. Killing by CTLs is mediated mainly by the secretion of perforin, granzyme B or by the Fas/FasL pathway (18).

$\mathrm{T}$ cells come in two general flavours: naïve and memory (21). Naïve $\mathrm{T}$ cells mount primary responses to foreign antigens not previously encountered by the host. They are present at a low frequency for any given antigen, have a relatively high stimulation threshold and can only be activated within secondary lymphoid tissues. Memory $\mathrm{T}$ cells in contrast, mount a secondary immune response to antigens previously encountered by the individual. Memory $\mathrm{T}$ cells are longlived lymphocytes that exist at a greater frequency for previously encountered antigens than their naïve counterparts, have a low stimulation threshold, a high proliferative capacity and they are less dependent on costimulation for activation. Moreover, although the activation of naïve $\mathrm{T}$ cells is clearly dependent on encountering antigen presented by professional APC within secondary lymphoid tissues, memory $\mathrm{T}$ cells can be activated within the transplanted organ itself, and, importantly, their activation may or may not require professional APC or the costimulatory stimuli that they provide $(22,23)$.

A significant proportion of memory $\mathrm{T}$ cells, either pre-existing or de-novo generated is present in human patients and can directly attack grafted organs, threatening transplant survival (23). In transplant setting, blood transfusion, pregnancy, or prior transplant all lead to the induction of donor specific memory T cells (23). Other mechanisms include heterologous immunity and homeostatic proliferation. Heterologous immunity is defined as the ability of memory $\mathrm{T}$ cells specific for a microbial antigen to cross-react with allogeneic MHC molecules through direct recognition. A major implication of heterologous immunity is that in humans in an open environment plus a normal history of vaccination and infections, pathogen-specific memory $\mathrm{T}$ cells that are potentially reactive to transplant antigens are likely to be numerous $(22,24)$. Homeostatic proliferation occurs 
in lymphopenic conditions and in the absence of antigenic stimulus. Mechanistically, homeostatic proliferation is mediated primarily by the availability of cytokines, especially IL-7 and IL-15, in the lymphopenic hosts. Homeostatic proliferation converts naive T cells directly to memory phenotype. This is a clinically relevant issue in transplantation as induction therapies with T-cell depleting agents are commonly used in transplant patients to reduce the mass of alloreactive $\mathrm{T}$ cells. After depletion therapies, residual $\mathrm{T}$ cells rapidly proliferate and acquire a memory phenotype that spontaneously skew toward a Th1 phenotype. This response may lead to an expanded memory pool in transplant recipients $(25,26)$. In animal models, memory $\mathrm{T}$ cells alone are sufficient to trigger rejection; they are among the first cell types infiltrating the grafts (27), this "second set" rejection is extremely difficult to inhibit. Indeed, current immunosuppressive drugs that are effective at inhibiting naïve $\mathrm{T}$ cells have minimal effects at preventing memory $\mathrm{T}$ cell-mediated rejection. So far, it is known that $\mathrm{CD}^{+}$memory $\mathrm{T}$ cells are resistant to steroid, deoxyspergualin and sirolimus. In contrast, calcineurin inhibitors, such as Cyclosporine A and Tacrolimus, inhibit their in-vitro activation and proliferation. However, there is a strong correlation between the presence of pretransplant alloreactive memory $\mathrm{T}$ cells and acute rejection episodes that occurred despite tacrolimus-based and sirolimus-based therapies. The poor transplant outcomes in patients with high memory $\mathrm{T}$ cell frequency suggest that the in-vivo efficacy of conventional immunosuppression drugs in containing memory $\mathrm{T}$ cells is limited (28-31). Thus, the success of future toleranceinducing therapies will demand rational development of combinatory novel strategies that target generation, homeostasis and effector functions of memory $\mathrm{T}$ cells.

\section{Mechanisms of tolerance to solid organ allografts}

Tolerance inducing strategies in experimental animals take advantage of natural mechanisms by which the immune system prevents self-reactivity and autoimmune diseases. Thus, like natural tolerance, transplant tolerance is achieved through two main mechanisms, not necessarily mutually exclusive: deletional mechanisms (actually in the thymus and in the periphery) in which donor reactive T-cell clones are destroyed, and non-deletional/immuno-regulatory mechanisms (including anergy, immune-deviation, active suppression-regulation) (32).

Central tolerance has been exploited in transplantation by the induction in the recipient of hematopoietic chimerism after infusion of donor hematopoietic stem cells (33). To date the only reports of successfully "intentionally induced" tolerance in humans come from protocols involving bone marrow and kidney transplants from the same donors (34-39). Basically, these strategies foresee severe conditioning regimens of lymphoid irradiation, cytotoxic drugs, immunosuppressants and $\mathrm{T}$ cell-depleting antibodies before donor stem cell infusion and kidney transplantation. 
However, the risk of infections and aplasia and ultimately death associated with the conditioning regimens may outweigh the potential benefit of tolerance - particularly when considering the excellent short-term outcomes currently achieved with conventional immunosuppression in organ transplantation - and makes further efforts mandatory for achieving acceptable relative risk/benefit ratio in clinical practice.

Mechanisms of peripheral tolerance rely mainly of active down-regulation and physiologic termination of the allospecific $\mathrm{T}$ cell immune response. We now recognize that transplantation of MHC incompatible graft triggers the activation of graft destructive effector $\mathrm{T}$ cells and graft protective regulatory $\mathrm{T}$ cells (Tregs); it is the balance of such opposing subsets that ultimately determines the fate of an allotransplant (40).

Regulatory $\mathrm{T}$ cells are a subset of $\mathrm{CD}^{+} \mathrm{T}$ cells that are defined by constitutively high expression of the transcription factor forkhead-box P3 (FOXP3) (41). FOXP3 ${ }^{+}$Treg can be divided into two groups: those that leave the thymus as naïve Tregs, also known as natural Tregs, and those that are derived in the periphery when $\mathrm{CD}^{+} \mathrm{T}$ cells are activated under tolerogenic conditions, also known as induced Tregs (42). Human $\mathrm{CD}^{+} \mathrm{FOXP}^{+}$Tregs are better characterized by the combination of the markers $\mathrm{CD} 127^{-/ \text {low }} \mathrm{CD} 25^{\text {high }} \mathrm{CD} 4^{+}$, since in humans FOXP3 can also be induced transiently and at low level in recently activated $\mathrm{CD}^{+} \mathrm{T}$ cells (43). When Tregs are activated in an antigen-MHC dependent manner they suppress many type of immune cells ranging from dendritic cells to the downstream effector $\mathrm{CD}^{+}$and $\mathrm{CD}^{+} \mathrm{T}$ cells, including memory $\mathrm{T}$ cells (even though more Tregs are required to control their function (44)). The precise mechanisms are not yet clear but include direct cell-to-cell contact between Tregs and an effector cells, secretion and signalling of cytokines such as transforming-growth-factor- $\beta$ (TGF- $\beta$ ), IL-2, IL-10 (45).

The concept of reprogramming the peripheral immune system toward a state of transplantation tolerance was firmly established in mice with the discovery that a combination of blocking antibodies against CD4 and CD8 receptors could induce tolerance to allogeneic skin graft (46). Tolerance was induced without the need for stable chimerism, was found to be independent of the thymus and was also dominant - able to resist the infusion of large number of naïve $\mathrm{T}$ cells, which was a strong pointer to the presence of active immune regulation rather than any deletion of donorreactive $\mathrm{T}$ cells (47). Since then and after the discovery of the Treg specific transcription factor FOXP3, Tregs have been the focus of intense investigations that provide compelling evidence of the crucial role of Tregs, either natural or induced or both in inducing and maintaining tolerance to solid organ allografts $(44,48,49)$. Thus, reprogramming the immune system toward Treg could represents a promising strategy for tolerance induction. 


\section{Mesenchymal stromal cells}

Mesenchymal stem cells were discovered four decades ago and were originally described as marrow-derived, nonhematopoietic cells that form colonies of fibroblastic nature (50). Later, these cells were found to have multilineage differentiation potential in bone, adipose tissue and cartilage both in-vitro and after transfer in-vivo (51), rising the idea that, in addition to the previously recognized hematopoietic stem cells, a second type of stem cells, non hematopoietic in nature, could be found within the bone marrow stroma. This idea was later reformulated (and to a some degree distorted (52)) into the current concept of Mesenchymal Stem Cells (53). The term Mesenchymal Stem Cells was later used to describe a wide variety of connective tissue cells from many tissues (adipose tissue, peripheral blood, fetal liver, lung, amniotic fluid, chorionic villi of the placenta, and umbilical cord blood and wall) with varying proliferation and differentiation potential and whose true stemness should be established by stringent in-vivo assays. The isolation of "Mesenchymal Stem Cells" by in-vitro expansion of plastic-adherent cells, from any sources, yields a mixture of cells which are very heterogeneous between different laboratories. Position paper from the International Society of Cellular Therapy (ISCT) (54) has attempted to unify the terminology and proposed the term "Multipotent Mesenchymal Stromal Cells (MSC)" that should include the source in the terminology, i.e., "bone-marrow MSC", "adipose derived-MSC" or others. In addition, ISCT has also provided the following minimum criteria for defining human MSC: i) plasticadherent under standard culture conditions; ii) positive for CD105, CD73 and CD90 expression and negative for expression of CD11b, CD14, CD34, CD45, CD79a and HLA-DR surface markers; iii) under specific stimulus, cells should differentiate in-vitro into osteocytes, adipocytes and chondrocytes (54).

The possibility that MSC exert functions other than those of stem or progenitor cells is supported by initial studies showing that MSC down-regulated $\mathrm{T}$ cell effector functions. MSC inhibited the proliferation and activation of $\mathrm{T}$ cells in co-culture experiments $(55,56)$, arrested activated $\mathrm{T}$ cells in the G0/G1 phase of the cell cycle, decreased their production of IFN- $\gamma$ and IL-2, and downregulated CTL-mediated cytotoxicity (57-59). The inhibition is not MHC-restricted (60) and targets both naïve and effector/memory $\mathrm{CD}^{+}$and $\mathrm{CD}^{+} \mathrm{T}$ cells (61-63). MSC also favour the emergence of Tregs $(64,65)$ and drive $\mathrm{CD}^{+} \mathrm{T}$ cells $(62)$, including fully differentiated Th17 (66), into cells with regulatory phenotype and function. Moreover, MSCs converted APC in an inhibitory or suppressor phenotype via cell-to-cell contact, thus locking DC (67-71) as well as macrophages (72-74) into a regulatory APC thereby favouring peripheral tolerance. Inhibition of immune cells rely essentially on a combinational effect from many immunosuppressive factors: TGF- $\beta$, Prostaglandin- $\mathrm{E}_{2}\left(\mathrm{PGE}_{2}\right)$, Nitric Oxide (NO) and IL-10, indoleamine 2 3-dioxygenase (IDO), 
HLAG-5 have been proposed as mediators of MSC-induced T-cell suppression and Treg expansion, while MSC use IL-6, Macrophage colony-stimulating factor (M-CSF) in addition to $\mathrm{PGE}_{2}$ and IL10 to suppress APC maturation. These molecules are minimally expressed in resting MSC unless they are primed or "licensed" by several inflammatory cytokines (75). Recently, the Tumornecrosis-factor- $\alpha$-Stimulated gene 6 protein (TSG-6) has been reported as the most relevant MSCderived factor involved in the interaction between MSC and macrophages/APC $(76,77)$.

In animal models, MSCs have been extensively studied in immune disease models such as graftversus-host disease (GvHD), experimental autoimmune encephalomyelitis, collagen-induced arthritis, type 1 diabetes, and systemic lupus erythematosus (SLE) (78-83) with beneficial effects of MSCs on T helper (Th)1-driven diseases. The success of MSCs in modulating immune responses in preclinical studies have prompted exploration of MSCs in clinical settings. Currently, there are 92 registered clinical trials evaluating the potential of MSC based cell therapy worldwide (ClinicalTrials.gov, http://clinicaltrials.gov/). In initial small pilot studies MSCs have been successfully applied to revert GvHD in patients receiving bone marrow transplantation, especially in patients diagnosed with severe steroid resistance (84-86). Similarly, in SLE and Crohn's disease patients, both autologous and allogeneic MSCs were able to suppress inflammation and reduce damage to kidneys and bowel, supposedly by induction of regulatory $\mathrm{T}$ cells in patients (87-90).

Collectively, the emerging data suggest that MSCs dampen effector T cell response, including memory cells, while promoting the emergence of Tregs. By skewing this balance MSC hold great promise as immunomodulatory cell therapy for tolerance induction in organ transplantation. 


\section{OBJECTIVES OF THE THESIS}

Based on the above evidence, a number of studies either in experimental models of solid organ transplantation or in kidney transplant recipients were designed and performed in this thesis with the aim to establish the tolerogenic potential of MSC, their mechanisms of action as well as safety of infusion eventually finding out the best cell infusion protocol to be applied in large clinical transplantation.

The tolerogenic potential of MSC has been first evaluated in a murine model of semi-allogeneic heart (B6C3 heart in B6 recipient mice) transplantation (Chapter 2). Either donor-derived or recipient-derived MSC isolated from the bone marrow were infused in unconditioned mice before transplantation. The effect of either single vs double pre-transplant MSC infusion as well as the effect of the site of MSC injection (portal vs tail vein) were evaluated in this model. The mechanism by which MSC induced tolerance was also studied through ex-vivo experiments. Results show that donor-derived MSC were effective in prolonging heart graft survival when infused into the portal vein 7 days before surgery. Combining a further i.v. injection of MSC 1 day before transplantation to the portal vein infusion of MSC did not result in additional effect on graft survival. The same tolerogenic potential was shared by recipient-derived MSCs when given by tail vein infusion pretransplantation. Both donor-derived and recipient-derived MSCs mediated their immunomodulation by the generation of donor-specific Tregs in recipient animals.

These results provided the basis for the design of a safety and clinical feasibility pilot study of autologous bone-marrow derived MSC in transplant recipients of kidneys from a living donor. Invitro studies were first performed to establish the impact of rabbit anti-thymocyte globulin (RATG) as well as maintenance immunosuppressive drugs on MSC immunosuppressive properties. Based on these experiments the infusion of autologous MSC was set after transplantation. Results of the first two patients are reported in Chapter 3. This work showed that post-transplant MSC infusion induced a transient renal insufficiency characterized, at histological analysis, by an inflammatory infiltrate of neutrophils and complement C3 deposition but no evidence of graft rejection. It was hypothesized that the subclinical inflammatory environment of the graft in the few days postsurgery could have favoured the prevalent intragraft recruitment and activation of the infused MSC promoting a proinflammatory environment with eventual acute renal dysfunction. This hypothesis has been confirmed back into a murine kidney transplant model (Chapter 4) showing that a single administration of syngeneic MSC before (one day before surgery) but not after renal transplantation avoided the acute deterioration of graft function, while maintaining the immunomodulatory effects associated with MSC treatment, including a marked Treg expansion. 
These experimental findings did represent a gain of knowledge to further implement our clinical protocol, aimed at creating favourable conditions for MSC-promoting immunomodulation avoiding any possible side-effects associated with cell infusion. In two subsequent living-related kidney transplant recipients bone-marrow derived autologous MSC were infused pre-transplant (day-1). Results, reported in Chapter 5, showed that pre-transplant infusion of MSC no longer negatively affect kidney graft while maintaining MSC-immunomodulatory properties.

Finally, Chapters 6 and 7 are review chapters aimed at making the focus on the more recent acquaintance on MSC immunomodulatory effects in-vivo in experimental transplant models as well as in early clinical experiences in kidney transplantation, and discuss topics of crucial importance for the future clinical use of MSC as immunotherapy in solid organ transplantation. 
CHAPTER 2

Pretransplant Infusion of Mesenchymal Stem Cells Prolongs the Survival of a Semiallogeneic Heart Transplant through the Generation of Regulatory $T$ Cells

F. Casiraghi, N. Azzollini, P. Cassis, B. Imberti, M. Morigi, D. Cugini, R.A. Cavinato, M. Todeschini, S. Solini, A. Sonzogni, N. Perico, G. Remuzzi and M. Noris

published in: Journal of Immunology 2008; 181: 3933-3946. 


\title{
Pretransplant Infusion of Mesenchymal Stem Cells Prolongs the Survival of a Semiallogeneic Heart Transplant through the Generation of Regulatory $T$ Cells ${ }^{1}$
}

\author{
Federica Casiraghi,** Nadia Azzollini, ${ }^{* *}$ Paola Cassis, ${ }^{*}$ Barbara Imberti, ${ }^{*}$ Marina Morigi, \\ Daniela Cugini,** Regiane Aparecida Cavinato, ${ }^{* *}$ Marta Todeschini, ${ }^{* *}$ Samantha Solini, ${ }^{* *}$ \\ Aurelio Sonzogni, ${ }^{\dagger}$ Norberto Perico, ${ }^{* *}$ Giuseppe Remuzzi, $* *$ and Marina Noris ${ }^{2} * *$
}

In this study, we investigated whether mesenchymal stem cells (MSC) had immunomodulatory properties in solid organ allotransplantation, using a semiallogeneic heart transplant mouse model, and studied the mechanism(s) underlying MSC tolerogenic effects. Either single (portal vein, day -7) or double (portal vein, day -7 and tail vein, day -1 ) pretransplant infusions of donor-derived B6C3 MSC in B6 recipients induced a profound T cell hyporesponsiveness and prolonged $\mathrm{B} 6 \mathrm{C} 3$ cardiac allograft survival. The protolerogenic effect was abrogated when donor-derived MSC were injected together with $\mathrm{B} 6 \mathrm{C} 3 \mathrm{hematopoietic} \mathrm{stem}$ cells (HSC), suggesting that HSC negatively impact MSC immunomodulatory properties. Both the induction (pretransplant) and the maintenance phase ( $>100$ days posttransplant) of donor-derived MSC-induced tolerance were associated with $\mathrm{CD}^{+} \mathrm{CD}^{+}{ }^{+} \mathrm{Foxp3}^{+}$Treg expansion and impaired anti-donor Th1 activity. MSC-induced regulatory $\mathrm{T}$ cells (Treg) were donorspecific since adoptive transfer of splenocytes from tolerant mice prevented the rejection of fully MHC-mismatched donor-specific secondary allografts but not of third-party grafts. In addition, infusion of recipient-derived B6 MSC tolerized a semiallogeneic B6C3 cardiac allograft, but not a fully MHC-mismatched BALB/c graft, and expanded Treg. A double i.v. pretransplant infusion of recipient-derived MSC had the same tolerogenic effect as the combined intraportal/i.v. MSC infusions, which makes the tolerogenic protocol applicable in a clinical setting. In contrast, single MSC infusions given either peritransplant or 1 day after transplant were less effective. Altogether these findings indicate that MSC immunomodulatory properties require HSC removal, partial sharing of MHC Ags between the donor and the recipient and pretransplant infusion, and are associated with expansion of donor-specific Treg. The Journal of Immunology, 2008, 181: 3933-3946.

$\mathrm{T}$ ransplantation is regarded as the only therapeutic choice for the end-stage failure of several organs; however, the prolonged acceptance of transplanted organs requires long-term use of combinations of immunosuppressive drugs. This treatment risks infection and a range of side effects, which, along with the inexorable chronic allograft injury, limit the life of the transplanted organs and the patients (1). The most appealing solution to these problems is the induction of transplantation tolerance, defined as lifelong, donor-specific unresponsiveness without the need of chronic immunosuppression (2). In recent years, several clinically relevant tolerance-induction regimens have been reported in experimental models. Many of these approaches incorporate infusion with either mature cells or stem cells (3-7).

\footnotetext{
*Transplant Research Center, "Chiara Cucchi De Alessandri \& Gilberto Crespi," Ranica, ${ }^{\dagger}$ Department of Medicine and Transplantation, Ospedali Riuniti, and ${ }^{*}$ Mario Negri Institute for Pharmacological Research, Bergamo, Italy

Received for publication June 19, 2007. Accepted for publication July 14, 2008.

The costs of publication of this article were defrayed in part by the payment of page charges. This article must therefore be hereby marked advertisement in accordance with 18 U.S.C. Section 1734 solely to indicate this fact.

${ }^{1}$ This study was partially supported by a grant from Foundation ART for Research on Transplantation and from Banca Aletti (Milan, Italy). D.C. received fellowships from Cavaliere. Grana in memory of Libera Dossi Grana and from Fondazione ART. P.C., R.A.C., and S.S. received a fellowship from Fondazione ART.

${ }^{2}$ Address correspondence and reprint requests to Dr. Marina Noris, Mario Negri Institute for Pharmacological Research, Via Camozzi 3, 24020 Ranica (Bergamo),
} Italy. E-mail address: noris@marionegri.it
Mesenchymal stem cells (MSC) ${ }^{3}$ produce the stromal matrix, which constitutes the bone marrow microenvironment, and support the growth of hematopoietic progenitor cells $(8,9)$. Potential interest to transplant medicine derives from the observation that MSC are immunoprivileged and display immunosuppressive capacities $(10,11)$. Due to low expression of MHC class II (MHCII) in unstimulated conditions (12-14) and absence of costimulatory molecules such as B71, B72, CD40, and CD40L on the cell surface $(13,15,16)$, MSC escape the immune system and therefore could be infused into an allogeneic host without being rejected, eventually avoiding the need of conditioning regimen $(12,17)$. In vitro studies with human $(13,14,16,18-20)$, baboon (21), rat (22), and murine (23-26) MSC have shown that they prevent $\mathrm{T}$ cell responses to cellular and to nonspecific mitogenic stimuli, targeting both naive and memory $\mathrm{CD}^{+}{ }^{+}$and $\mathrm{CD}^{+} \mathrm{T}$ cells $(13,25)$. Moreover, in vitro MSC-induced $\mathrm{T}$ cell suppression occurs independently of MHC matching with either stimulatory cells or responder lymphocytes in a MLR $(21,23)$ in a dose-dependent manner (13).

Notwithstanding the considerable amounts of in vitro data supporting the nonimmunogenicity and immunomodulatory effects of MSC, scanty and conflicting data are available on the immunomodulatory capacities of these cells in vivo. Allogeneic MSC infusion slightly prolonged skin allograft survival in immunocompetent baboons (21), prevented the rejection of allogeneic B16

\footnotetext{
${ }^{3}$ Abbreviations used in this paper: MSC, mesenchymal stem cell; HSC, hematopoietic stem cell; BM, bone marrow; Foxp3, forkhead box p3; Treg, regulatory $\mathrm{T}$ cell; MHCII, MHC class II; MST, median survival time; AU, arbitrary unit.
}

Copyright $(2008$ by The American Association of Immunologists, Inc. 0022-1767/08/\$2.00 
melanoma cells in immunocompetent $\mathrm{C} 3 \mathrm{H}$ mice (23), and attenuated graft-versus-host disease in mice (27) and in humans $(28,29)$. In mice, administration of autologous MSC also prevented the development of autoimmune encephalomyelitis (30). On the contrary, MSC infusion failed to prevent graft rejection (22) or did result in a very modest prolongation of graft survival $(31,32)$ in fully MHC-mismatched vascularized heart transplant models in rodents.

The present study was designed 1) to investigate the effectiveness of MSC in promoting immunosuppression/tolerance in the context of vascularized solid organ transplantation in a mouse model of semiallogeneic heart transplantation; 2) to dissect the mechanism(s) underlying the potential MSC tolerogenic effects in vivo with a main focus on the role of regulatory $\mathrm{T}$ cells (Treg); and 3) to find out the best tolerogenic MSC infusion protocol.

\section{Materials and Methods \\ Mice}

Male and female inbred C57BL/6 (B6, H-2 $\left.{ }^{\mathrm{b}}\right),(\mathrm{C} 57 \mathrm{BL} / 6 \times \mathrm{C} 3 \mathrm{H}) \mathrm{F}_{1}(\mathrm{~B} 6 \mathrm{C} 3$, $\left.\mathrm{H}-2^{\mathrm{b}, \mathrm{k}}\right), \mathrm{C} 3 \mathrm{H}\left(\mathrm{C} 3, \mathrm{H}-2^{\mathrm{k}}\right)$, and BALB/c $\left(\mathrm{H}-2^{\mathrm{d}}\right)$ mice were purchased from Charles River Laboratories. Animal care and treatment were conducted in conformity with the institutional guidelines that are in compliance with national (DL n.116, GU suppl 40, 18 febbraio 1992, Circolare no. 8, GU 14 luglio 1994) and international laws and policies (European Economic Community Council Directive 86/609, OJL 358, December 1997; National Institutes of Health Guide for the Care and Use of Laboratory Animals, U.S. National Research Council, 1996). Animals were housed in a constant temperature room with a 12-h dark/12-h light cycle and fed a standard diet.

\section{MSC isolation and expansion}

Bone marrow (BM) was obtained from 2-mo-old B6C3 or B6 mice. Briefly, mice were killed and femurs and tibias were aseptically removed. $\mathrm{BM}$ was flushed from the shaft of the bone with DMEM (Sigma-Aldrich) containing 5\% FCS (Invitrogen) and then filtered through a 100- $\mu \mathrm{m}$ sterile filter to produce a single-cell suspension. MSC were recovered from BM by their tendency to adhere tightly to the plastic culture dish and were isolated as previously described (33). Filtered BM cells were plated in DMEM $/ 10 \%$ FCS and allowed to adhere for $6 \mathrm{~h}$. Adherent cells were then cultured for 2-3 wk with medium change every 3 days. Thereafter, primary MSC cultures were collected and immunodepleted of CD45 $5^{+}$and $\mathrm{CD} 11 \mathrm{~b}^{+}$ cells. After blocking with PBS/0.5\% BSA, cells were incubated for 20 min with rat anti-mouse CD45 and rat anti-mouse CD11b Abs $\left(0.2 \mu \mathrm{g} / 10^{6}\right.$ cells; Caltag Laboratories), washed, and then incubated with goat anti-rat $\mathrm{IgG}$ magnetic microbeads (Miltenyi Biotec). $\mathrm{CD} 45^{-} \mathrm{CD} 11 \mathrm{~b}^{-}$MSC were then isolated by a MACS system (Miltenyi Biotec). FACS analysis (FACSort; BD Biosciences) on purified MSC confirmed the absence of $\mathrm{CD} 45$ and $\mathrm{CD} 11 \mathrm{~b}$ expression ( $>95 \% \mathrm{CD}^{2} 5^{-} \mathrm{CD} 11 \mathrm{~b}^{-}$cells). MSC properties to differentiate toward osteoblasts, adipocytes, and chondroblasts in vitro have been routinely assayed as previously described (33).

\section{Hematopoietic stem cell (HSC) isolation}

For HSC isolation, total BM cells were incubated with rat anti-mouse mAbs specific for the following lineage markers: CD4, CD8, CD45R/ B220, CD11b, Gr-1, and Ter-119 (Caltag Laboratories). After washing, labeled cells were incubated with magnetic microbeads and depleted by magnetic cell sorting (Miltenyi Biotec) as previously described (33). The obtained lineage-negative cells $\left(\mathrm{Lin}^{-}\right)$were then incubated with rat antimouse CD117 (c-Kit) PE conjugate (Caltag Laboratories). Positive cells were then isolated by cell sorting (FACSAria; BD Biosciences) to obtain purified $\mathrm{Lin}^{-} \mathrm{c}-\mathrm{Kit}^{+}$HSC preparations $(97 \%)$.

\section{Detection of donor MSC in recipient tissues}

For in vivo tracking experiments, male B6C3 or B6 MSC were labeled with PKH26 according to the manufacturer's protocol (Red Fluorescence Cell Linker Kit; Sigma-Aldrich) and infused into B6 mice. Labeling efficacy was found to be $>90 \%$ by FACS analysis. At sacrifice, single-cell suspensions were obtained from spleen, lymph nodes (cervical, mesenteric, and iliac), thymus, bone marrow, and blood and analyzed by FACS for the presence of PKH26-labeled MSC. As negative controls, single-cell suspensions from naive mice $(n=3)$ were run in parallel. From each sample, 500,000 cells were analyzed and the number of events falling in the PKH26 fluorescence window was recorded. No positive events were found in the
PKH26 fluorescence window with negative control cells. The total number of PKH $26^{+}$cells in each tissue was calculated by relating the number of $\mathrm{PKH} 26^{+}$events in 500,000 cells to the total number of cells in each tissue and the percentage of PKH $26^{+}$MSC/total MSC infused was calculated as follows: number of $\mathrm{PKH} 26^{+}$cells in each tissue/total number of infused PKH26-labeled MSC $(500,000) \times 100$.

To evaluate MSC engraftment in the liver and lungs, the organs from $\mathrm{PKH} 26^{+}$MSC-infused mice were fixed in paraformaldehyde, impregnated with sucrose, and rapidly frozen. Tissues were then sectioned on a cryostat $(8 \mu \mathrm{m})$, fixed with acetone, stained with 4',6-diamidino-2-phenylindole (1 $\mu \mathrm{g} / \mathrm{ml}$; Sigma-Aldrich), and analyzed by fluorescence confocal microscopy. For each tissue, three nonconsecutive sections were analyzed and $\mathrm{PKH} 26^{+}$cells in each section were counted. Results are expressed as mean number of $\mathrm{PKH} 26^{+}$cells per section.

\section{Heterotopic heart transplant}

$\mathrm{B} 6 \mathrm{C} 3, \mathrm{C} 3$, or $\mathrm{BALB} / \mathrm{c}$ hearts were transplanted into the abdomen of $\mathrm{B} 6$ recipients (34). Mice were anesthetized by inhalation of isofluorane (Abbott Laboratories). Donor hearts were perfused with chilled, heparinized saline via the inferior vena cava and harvested after ligation of the superior vena cava and pulmonary veins. The aorta and pulmonary artery of donor hearts were anastomosed to the abdominal aorta and inferior vena cava of recipient mice, respectively, using a microsurgical technique. Recipients were kept on a warming blanket and under a heating lamp to recover postoperatively. Ischemic time during the surgical procedure was routinely $30 \mathrm{~min}$. Graft survival was followed by palpation at least three times per week. Rejection was defined by complete cessation of palpable contraction confirmed by direct visualization.

\section{Graft histology}

Fragments of cardiac allografts were fixed in $10 \%$ neutral formalin, embedded in paraffin, sectioned, and stained with H\&E. Sections were examined microscopically and graded (from mild to severe) for acute rejection changes: presence of vasculitis, infarction, lymphocytic infiltration, thrombosis, and hemorrhage. The development of chronic rejection was evaluated by the presence of vessels, including coronary arteries and arterioles, affected by obliterative vasculopathy.

\section{Adoptive cell transfer}

Spleen cells or electronically sorted splenic $\mathrm{CD}^{+} \mathrm{T}$ cells, $\mathrm{CD} 4^{+} \mathrm{T}$ cell subsets, and $\mathrm{CD} 8^{+} \mathrm{T}$ lymphocytes were obtained from mice with longterm graft survival, from infused and naive mice. Cells were then diluted in PBS and injected into the tail vein of naive mice the day before heart transplantation. No immunosuppressive drugs were given to the animals.

\section{$M L R$ and proliferation studies}

Spleen cell suspensions were obtained by passing the spleen through a $70-\mu \mathrm{m}$ cell stainless steel strainer and the erythrocytes were depleted by hypotonic lysis. $\mathrm{CD} 4^{+} \mathrm{T}$ cells were isolated using mouse $\mathrm{CD} 4^{+} \mathrm{T}$ cell isolation kit (Miltenyi Biotec) and used as responders $\left(0.5 \times 10^{6}\right.$ cells $)$ in the MLR. Either 4000-rad irradiated splenocytes or irradiated mesenchymal stem cells $\left(0.5 \times 10^{6}\right.$ cells $)$ were used as stimulators. Cells were resuspended in complete RPMI 1640 supplemented with $10 \%$ heat-inactivated FCS and antibiotics (Invitrogen) or in conditioned medium from primary MLR with MSC. MLR were conducted in 96-well plates and cells were cultured for $72 \mathrm{~h}$. Cell proliferation was determined by pulsing the cells with $\left[{ }^{3} \mathrm{H}\right]$ thymidine during the last $14-16 \mathrm{~h}$ of culture and measuring the radioactivity incorporated by liquid scintillation counting. Proliferative response was expressed as $\Delta \mathrm{cpm}$ by subtracting the cpm recorded in the control syngeneic combination from the $\mathrm{cpm}$ of allogeneic combinations.

$\mathrm{T}$ cell proliferation in response to anti-CD3/anti-CD28 Abs was assessed by coating $96-w e l l$ flat-bottom plates with anti-CD3 $\mathrm{mAb}(0.5 \mu \mathrm{g} / \mathrm{well}$, hamster anti-mouse CD3, clone 7D169; Serotec) overnight at $4^{\circ} \mathrm{C}$. Wells were then washed and spleen cells $\left(0.5 \times 10^{6} /\right.$ wells $)$ were added with 0.2 $\mu \mathrm{g} / \mathrm{well}$ anti-CD28 mAb (hamster anti-mouse CD28, clone 37.51.1; Caltag Laboratories). For experiments studying the induction of anergy, 100 IU/ml IL-2 (mouse rIL-2; BD Biosciences) was added to the wells. Cell proliferation was determined by pulsing the cells with $\left[{ }^{3} \mathrm{H}\right]$ thymidine during the last $14-16 \mathrm{~h}$ of culture and measuring the radioactivity incorporated by liquid scintillation counting. Proliferative response was expressed as cpm.

\section{Flow cytometry analysis}

Mesenchymal cell surface phenotypic analysis was performed by flow cytometric analysis using FACSort. The following Abs were used: FITCconjugated mouse anti-mouse H-2K ${ }^{\mathrm{b}}$, R-PE-conjugated rat anti-mouse I-A/ 
I-E (BD Biosciences), R-PE-conjugated rat anti-mouse CD44 (clone IM7; Biolegend), and R-PE-conjugated rat anti-mouse CD86 (clone GL1; BD Biosciences). FITC-conjugated rat anti-mouse CD4 (clone CT-CD4; Caltag Laboratories), allophycocyanin-conjugated rat anti-mouse CD25 $\mathrm{mAb}$ (Biolegend), R-PE- conjugated rat anti-mouse CD $8 \alpha / \mathrm{Lyt}-2 \mathrm{mAb}$ (Southern Biotechnology Associates), and R-PE-conjugated anti-mouse/rat forkhead box p3 (Foxp3) staining set (clone FJK-16s; eBioscience) were used for splenocyte phenotypic analysis and cell sorting (FACSAria; BD Biosciences). To block nonspecific binding, a 30-min preincubation with $5 \%$ rat serum was performed. All stainings include negative controls with isotype Abs. Light scattering parameters were set to exclude dead cells and debris.

\section{Real-time quantitative PCR for Foxp3, IFN- $\gamma$, and IL-10 in cardiac allograft tissues}

Total RNA was obtained from cardiac tissue by homogenization followed by TRIzol extraction (Invitrogen). RNA was treated with DNase and reverse transcribed to cDNA by Superscript II (Invitrogen). Quantitative realtime PCR was performed on a TaqMan Applied Biosystems Prism 5700 Sequence Detection System with Power SYBR Green Master Mix and the following specific primers: mouse Foxp3 (GenBank sequence NM_054039): forward (300 nM) 5'-GCG AAA GTG GCA GAG AGG TAT T-3'; reverse (300 nM) 5'-TTC CAA GTC TCG TCT GAA GGC-3'; mouse IFN- $\gamma$ (GenBank sequence NM_008337): forward (300 nM) 5'TGA ATT CAT GAG TAT TGC CAA GT-3'; reverse (300 nM) 5'-GCT TCC TGA GGC TGG ATT CC-3'; and mouse IL-10 (GenBank sequence NM_010548): forward (300 nM) 5'-CGG CTG AGG CGC TGT C-3'; reverse (300 nM) 5'-TGC CTT GCT CTT ATT TTC ACA GG-3'; $G A P D H$ served as housekeeping gene. The $\triangle \Delta C$ t equation was used to compare the target gene expression in each sample with the expression in control mouse lymph nodes taken as calibrator (set to 1 arbitrary unit)

\section{Immunohistochemical analysis}

We analyzed in situ intragraft $\mathrm{CD} 4^{+} \mathrm{T}$ cells by an immunofluorescence technique on frozen tissue sections. Cardiac sections $(8 \mu \mathrm{m})$ were cut with a cryostat, air-dried, and fixed with acetone. We incubated the sections with the Abs: FITC-conjugated rat anti-mouse CD4 (100 $\mu \mathrm{g} / \mathrm{ml}$, clone RM4-5; BD Pharmingen) and rat anti-mouse Foxp3 mAbs $(20 \mu \mathrm{g} / \mathrm{ml}$, clone MF333F; Alexis) followed by Cy3-conjugated goat anti-rat IgG $(6 \mu \mathrm{g} / \mathrm{ml}$; Jackson ImmunoResearch Laboratories). The double immunofluorescence staining was analyzed by an inverted confocal laser scanning microscope (LS 510 Meta; Zeiss). The numbers of total single- and/or double-positive cells were counted in at least 10 randomly selected high-power fields. For each animal, the total $\mathrm{CD}^{+}$cell counts and the percentage of $\mathrm{CD} 4^{+}$Foxp $^{+}$on $\mathrm{CD}^{+}$were calculated.

\section{ELISPOT assays}

ELISPOT assays were performed using BD ELISPOT mouse IFN- $\gamma$ and IL-10 reagents. Responder splenocytes were placed in 96-well ELISPOT plates (Millipore) precoated with capture anti-IFN- $\gamma$ or anti-IL-10 Ab at the concentration of $100,000 /$ well for IFN- $\gamma$ or $250,000 /$ well for IL-10 assays. The same number of stimulator cells (irradiated splenocytes) from $\mathrm{B} 6 \mathrm{C} 3, \mathrm{BALB} / \mathrm{c}$, and B6 (self-combination) mice were added to the wells and the plates were incubated at $37^{\circ} \mathrm{C}$ in $5 \% \mathrm{CO}_{2}$ for $48 \mathrm{~h}$. Aliquots of responder splenocytes were also incubated with medium alone (negative controls). Each combination was run in triplicate wells. The assays were then conducted according to the manufacturer's instructions. The resulting spots were counted on a computer-assisted Immunospot image analyzer (Aelvis ELISPOT Scanner System). Results are the mean value of spots/ per 100,000 (IFN- $\gamma$ ) or spots per 250,000 (IL-10) recipient splenocytes stimulated with $\mathrm{B} 6 \mathrm{C} 3$ or $\mathrm{BALB} / \mathrm{c}$ cells after subtracting spots in negative controls (usually 2 or less).

\section{Statistical analysis}

Data are reported as mean \pm SEM. Survival data were compared using the log-rank test. All of the other data were analyzed by ANOVA. Differences with a $p<0.05$ were considered significant.

\section{Results}

\section{MSC characterization}

MSC, isolated from BM by their adherence to plastic, consisted of a heterogeneous cell population with a spindle-shaped morphology. At this stage, FACS analysis of MSC preparation revealed a $15-35 \%$ of contaminating cells that expressed CD45 and CD11b hematopoietic markers. After further purification by MACS, $>95 \%$ of cells were $\mathrm{CD}_{4} 5^{-} \mathrm{CD} 11 \mathrm{~b}^{-}$. Murine $\mathrm{CD} 45^{-} \mathrm{CD} 11 \mathrm{~b}$ MSC expressed low levels of MHC class I and MHCII and were positive for CD44 (on average 44\%) and negative for CD86, as shown in Fig. $1 A$.

\section{MSC are not immunogenic and suppress $T$ cell proliferation in vitro}

As shown in Fig. $1 B$, murine MSC themselves did not elicit a proliferative response by allogeneic $\mathrm{CD}^{+} \mathrm{T}$ cells. Indeed, B6 $\mathrm{CD}^{+}{ }^{+} \mathrm{T}$ cell proliferation against $\mathrm{B} 6 \mathrm{C} 3 \mathrm{MSC}$ was negligible and significantly lower than the proliferation induced by mature splenocytes from B6C3 mice.

B6C3 MSC added at a 1:10 ratio (MSC:CD4 ${ }^{+} \mathrm{T}$ cells) to naive MLR cultures significantly reduced the proliferative response of allogeneic B6 $\mathrm{CD}^{+} \mathrm{T}$ cells to splenocytes from the same MSC donor strain (Fig. 1B). B6C3 MSC at the same concentration also significantly lowered the proliferation of allogeneic B6 $\mathrm{CD} 4^{+} \mathrm{T}$ cells elicited by third-party splenocytes from BALB/c mice (Fig. $1 B)$. When naive MLR were repeated in the presence of conditioned medium (diluted 1/10) collected from the above MSC-MLR cocultures, the $\mathrm{CD} 4^{+} \mathrm{T}$ cell proliferative alloresponse was not affected, whereas $20-30 \%$ reduction was observed with conditioned medium diluted 1/5 (Fig. 1B). These results would suggest that in our experimental conditions the MSC immunomodulatory effect was mainly cell-contact dependent.

To test whether MSC were capable of suppressing the proliferation of autologous $\mathrm{CD} 4^{+} \mathrm{T}$ cells in MLR as well, graded doses of B6 MSC were added to a naive MLR with $\mathrm{B} 6 \mathrm{CD}^{+}{ }^{+} \mathrm{T}$ cell responders and B6C3 splenocytes as stimulators. For comparison, additional MLR with graded doses of B6C3 MSC added to allogeneic $\mathrm{B} 6 \mathrm{CD}^{+}{ }^{+} \mathrm{T}$ cell responders and $\mathrm{B} 6 \mathrm{C} 3$ splenocyte stimulators were performed. MSC were able to suppress the proliferation of both allogeneic and autologous $\mathrm{CD} 4^{+} \mathrm{T}$ cells to alloantigens in a dose-dependent manner and to a comparable extent (Fig. 1C).

\section{In vivo tissue distribution of MSC}

We next evaluated in vivo the distribution of either allogeneic B6C3 or syngeneic B6 PKH26-labeled MSC $\left(0.5 \times 10^{6}\right)$ infused either in the portal vein or in the tail vein of B6 mice. After 1, 7, and 21 days, single-cell suspensions were obtained from bone marrow, thymus, spleen, lymph nodes, and blood and analyzed by FACS for the presence of PKH $26^{+}$MSC. The tissue distribution and the degree of engraftment of allogeneic MSC was similar to those of syngeneic MSC both after tail vein and after portal vein injection (Fig. 2A). FACS analysis of blood from mice in all experimental group did not reveal any $\mathrm{PKH}_{2} 6^{+}$cells (data not shown). In both syngeneic and allogeneic combinations, infusion via tail vein was associated with higher percentages of MSC localizing in secondary lymphoid tissues as compared with intraportal injection. Indeed, 1 day after tail vein injection, $\sim 12-19 \%$ of the overall $\mathrm{PKH} 26^{+}$MSC infused localized in the spleen and $4-5 \%$ localized in lymph nodes, as compared with $5-7 \%$ and $1.4 \%$ found in spleen and lymph nodes of mice given the cells via the portal vein. On the other hand, the amount and distribution of MSC in bone marrow and thymus were not influenced by the site of injection (Fig. 2A). Seven and 21 days after infusion, $\mathrm{PKH} 26^{+}$ MSC were hardly or not detectable in bone marrow and lymphoid tissues of recipient animals, either in allogeneic or in syngeneic settings (Fig. 2A), irrespectively from the site of injection.

We next evaluated MSC engraftment in lungs and livers by fluorescence microscopy. After intraportal injection of either allogeneic or syngeneic $\mathrm{PKH} 26^{+}$MSC, approximately six to eight cells per section and four to five cells per section were detected in 
A
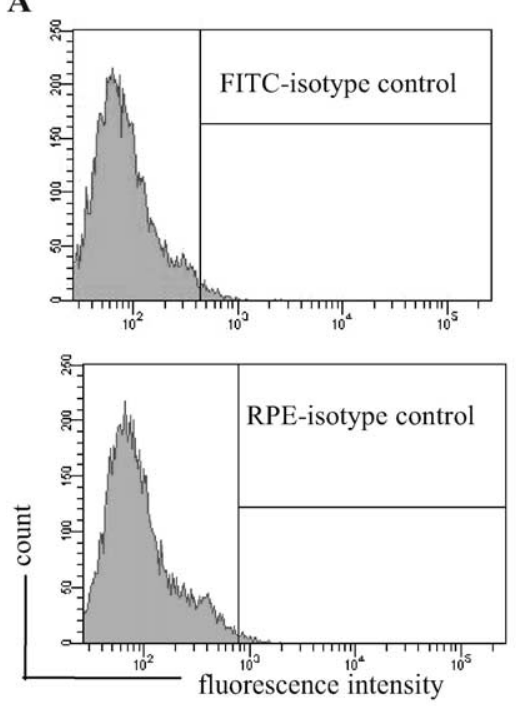
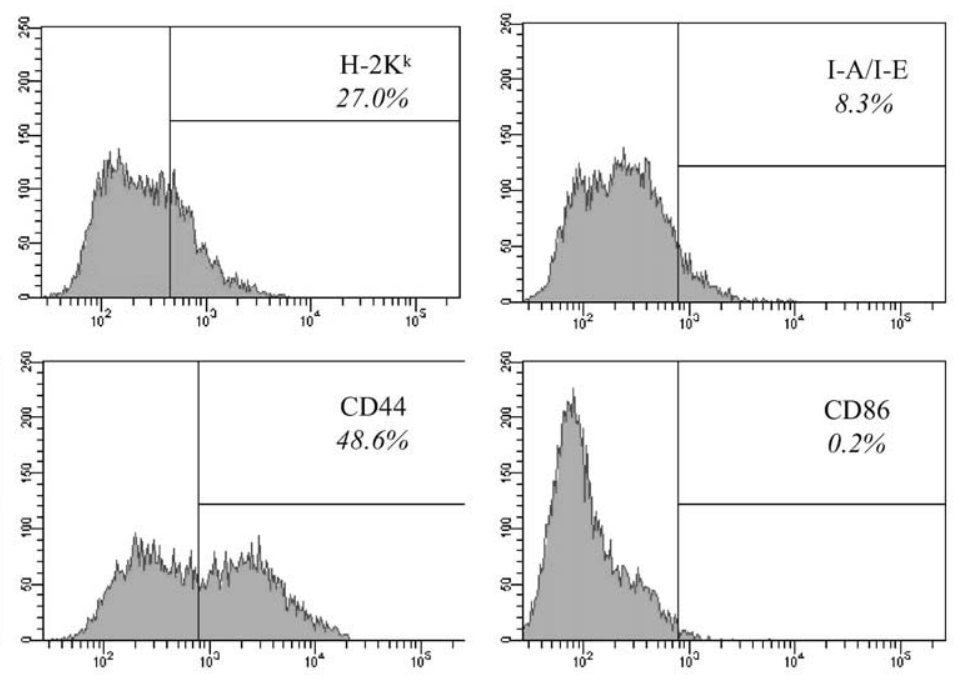
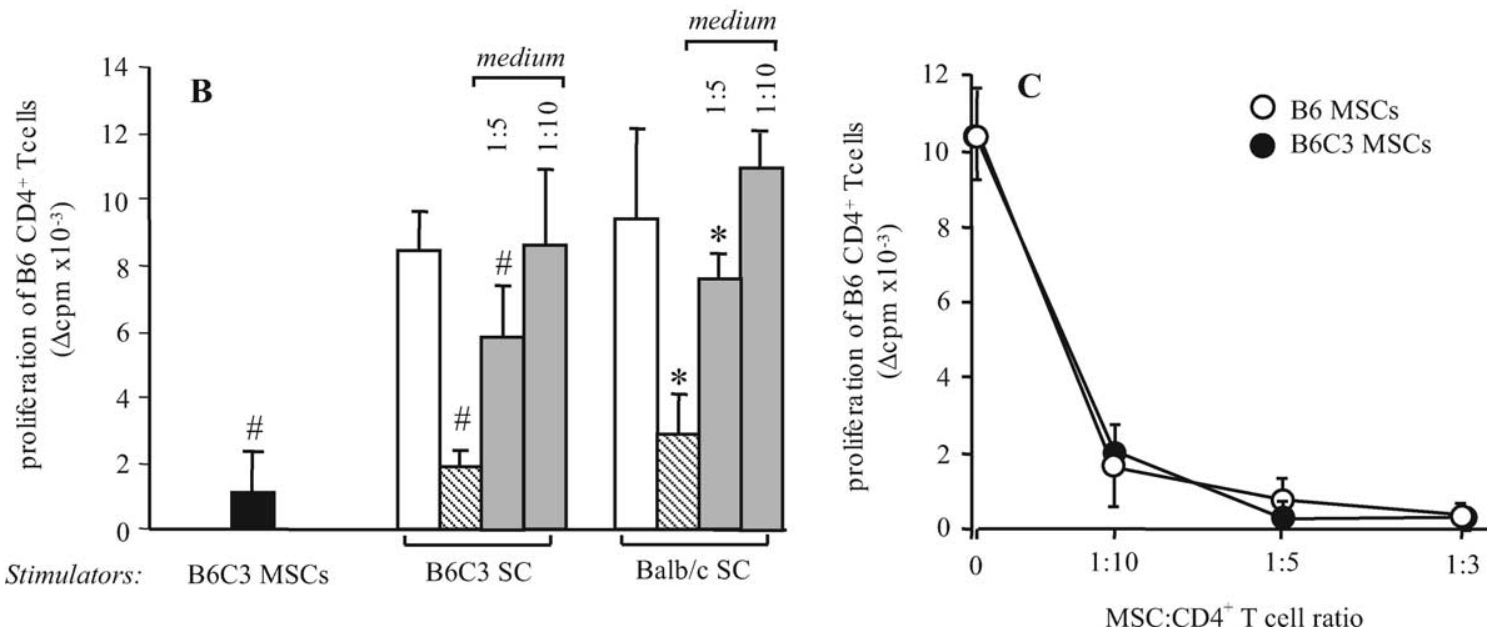

FIGURE 1. MSC are not immunogenic and suppress $\mathrm{T}$ cell proliferation in vitro. $A$, Expression of $\mathrm{H}-2 \mathrm{~K}, \mathrm{I}-\mathrm{A} / \mathrm{I}-\mathrm{E}, \mathrm{CD} 44$, and $\mathrm{CD} 86$ in $\mathrm{CD} 45^{-} \mathrm{CD}^{-} 1 \mathrm{~b}^{-}$ MSC. Representative FACS histograms and the percentage of positive cells with the indicated mAbs are shown. $B$, Effect of MSC on T cell proliferative response. Responders B6 CD4 ${ }^{+} \mathrm{T}$ cells $\left(0.5 \times 10^{6}\right)$ were stimulated for 3 days with an equal number of irradiated B6C3 MSC ( $\square$ ) or with irradiated (4000-rad) allogeneic B6C3 or BALB/c splenocytes ( $\square$ ). Proliferative responses of naive B6 CD4 ${ }^{+} \mathrm{T}$ cells against B6C3 or BALB/c splenocytes were also

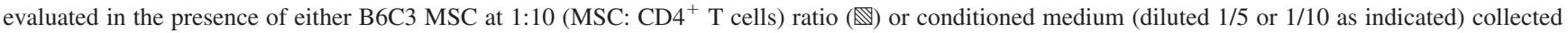
from a naive MLR run in the presence of $\mathrm{B} 6 \mathrm{C} 3 \mathrm{MSC}$ (圈). $C, \mathrm{~B} 6 \mathrm{CD} 4^{+} \mathrm{T}$ cells were cultured in MLR with allogeneic $\mathrm{B} 6 \mathrm{C} 3$ splenocytes in the presence of graded doses of B6 MSC (O) or B6C3 MSC (๑). Proliferative results were expressed as $\Delta$ cpm by subtracting cpm of syngeneic MLR from allogeneic combinations. Results are mean $\pm \mathrm{SE}$ of three independent experiments. SC, Spleen cells; \#, $p<0.05$ vs B6C3 spleen cells; $*, p<0.05$ vs BALB/c spleen cells.

the liver 1 and 7 days after infusion, respectively (Fig. 2, B-D). Lower but detectable numbers of allogeneic and syngeneic MSC were found in the liver 1 day after tail vein injection, whereas at 7 days PHK26-labeled MSC were negligible $(p<0.05$ vs portal vein infusion; Fig. $2 B$ ). No $\mathrm{PKH} 26^{+} \mathrm{MSC}$ were found in lungs from mice receiving either syngeneic or allogeneic MSC via the portal vein (Fig. 2B). Few positive cells were found in lungs at 1 day (Fig. 2, $B$ and $E$ ) but not at 7 days after tail vein injection. No $\mathrm{PKH} 26^{+}$MSC cells were found in liver and lungs taken 21 days after infusion in any experimental group (data not shown).

To evaluate the distribution and compartmentalization of MSC after transplantation, additional mice received double infusion (portal vein, day -7 ; tail vein, day -1 ) of either allogeneic B6C3 or syngeneic B6 PKH26-labeled MSC $\left(0.5 \times 10^{6}\right.$ each infusion $)$ and were transplanted with a $\mathrm{B} 6 \mathrm{C} 3$ heart at day 0 or left untreated. Tissues were collected and analyzed 7 days later (i.e., 15 days after the first MSC infusion). As shown in Fig. 2A, both allogeneic and syngeneic MSC were hardly detectable or even absent in bone marrow and lymphoid tissues, with no apparent difference between transplanted and untransplanted animals studied at the same time point. Few $\mathrm{PKH} 26^{+}$cells were found in the livers of either transplanted or untransplanted mice (Fig. $2 B$ ), whereas MSC were virtually absent in lung tissues (Fig. 2B).

\section{Donor-derived MSC infusion prolongs the survival of a semiallogeneic heart transplant}

To evaluate whether MSC had immunomodulatory effects in vivo, we infused $\mathrm{B} 6 \mathrm{C} 3\left(\mathrm{H}-2^{\mathrm{b}, \mathrm{k}}\right)$ MSC $\left(0.5 \times 10^{6}\right)$ into the portal vein of semiallogeneic B6 $\left(\mathrm{H}-2^{\mathrm{b}}\right)$ mice. Injection into the portal vein was done on the basis of previous studies showing that the liver is a privileged organ for donor allogeneic mature (splenocytes) or stem cell (bone marrow or embryonic stem cells) engraftment and development of tolerance $(5,35-37)$. Seven days later, mice were sacrificed and splenocytes isolated to perform MLR assays. CD4 ${ }^{+}$ $\mathrm{T}$ cells from the spleen of MSC-infused mice had a reduced MLR proliferative response toward either donor B6C3 or third-party 
A \% PKH26 ${ }^{+}$MSC/total MSC infused (FACS analysis)

\begin{tabular}{|c|c|c|c|c|c|c|c|c|c|}
\hline & & \multicolumn{3}{|c|}{ Tail vein ${ }^{a}$} & \multicolumn{3}{|c|}{ Portal vein ${ }^{a}$} & \multirow{2}{*}{ Transplanted $^{\mathrm{b}}$} & \multirow{2}{*}{ Untransplanted $^{\mathrm{b}}$} \\
\hline \multicolumn{2}{|c|}{ days after MSC infusion } & 1 & 7 & 21 & 1 & 7 & 21 & & \\
\hline \multirow[t]{2}{*}{ Bone marrow } & allo MSC & $1.8 \pm 0.8$ & $0.0 \pm 0.0$ & $0.0 \pm 0.0$ & $3.2 \pm 0.8$ & $0.0 \pm 0.0$ & $0.4 \pm 0.1$ & $0.0 \pm 0.0$ & $0.1 \pm 0.0$ \\
\hline & syn MSC & $1.7 \pm 0.4$ & $0.2 \pm 0.2$ & $0.0 \pm 0.0$ & $2.9 \pm 0.4$ & $0.2 \pm 0.2$ & $0.0 \pm 0.0$ & $0.0 \pm 0.0$ & $0.3 \pm 0.1$ \\
\hline \multirow[t]{2}{*}{ Thymus } & allo MSC & $3.1 \pm 0.9$ & $0.0 \pm 0.0$ & $0.6 \pm 0.8$ & $2.7 \pm 1.1$ & $0.8 \pm 1.0$ & $0.0 \pm 0.0$ & $0.2 \pm 0.3$ & $0.0 \pm 0.0$ \\
\hline & syn MSC & $1.3 \pm 0.0$ & $0.0 \pm 0.0$ & $0.0 \pm 0.0$ & $2.7 \pm 1.2$ & $0.2 \pm 0.2$ & $0.0 \pm 0.0$ & $0.0 \pm 0.0$ & $0.0 \pm 0.0$ \\
\hline \multirow[t]{2}{*}{ Lymph nodes } & allo MSC & $5.0 \pm 0.4 \S$ & $0.0 \pm 0.0$ & $0.5 \pm 0.4$ & $1.4 \pm 0.9$ & $0.7 \pm 1.0$ & $0.0 \pm 0.0$ & $0.7 \pm 0.6$ & $0.4 \pm 0.2$ \\
\hline & syn MSC & $3.7 \pm 0.3 \S$ & $0.0 \pm 0.0$ & $0.0 \pm 0.0$ & $1.4 \pm 0.6$ & $0.0 \pm 0.0$ & $0.0 \pm 0.0$ & $0.0 \pm 0.0$ & $0.0 \pm 0.0$ \\
\hline \multirow[t]{2}{*}{ Spleen } & allo MSC & $19 \pm 1.4 \S$ & $0.0 \pm 0.0$ & $0.0 \pm 0.0$ & $4.7 \pm 1.9$ & $0.9 \pm 0.5$ & $0.4 \pm 0.2$ & $0.0 \pm 0.0$ & $0.0 \pm 0.0$ \\
\hline & syn MSC & $12 \pm 5.0$ & $0.0 \pm 0.0$ & $0.0 \pm 0.0$ & $7.2 \pm 3.0$ & $0.0 \pm 0.0$ & $0.0 \pm 0.0$ & $0.0 \pm 0.0$ & $1.2 \pm 0.7$ \\
\hline
\end{tabular}

B PKH26 ${ }^{+}$MSC counts in livers and lungs (fluorescence microscopy)

\begin{tabular}{|c|c|c|c|c|c|c|c|}
\hline & & \multicolumn{2}{|r|}{ Tail vein ${ }^{a}$} & \multicolumn{2}{|c|}{ Portal vein $^{a}$} & \multirow{2}{*}{$\begin{array}{c}\text { Transplanted }^{\mathrm{b}} \\
15\end{array}$} & \multirow{2}{*}{ Untransplanted ${ }^{\mathrm{b}}$} \\
\hline & SC infusion & 1 & 7 & 1 & 7 & & \\
\hline Liver & $\begin{array}{l}\text { allo MSC } \\
\text { syn MSC }\end{array}$ & $\begin{array}{l}2.6 \pm 0.7 \S \\
4.3 \pm 0.3 \S\end{array}$ & $\begin{array}{l}1.5 \pm 0.3 \S \\
0.5 \pm 0.4 \S\end{array}$ & $\begin{array}{l}6.8 \pm 1.3 \\
8.3 \pm 1.2\end{array}$ & $\begin{array}{l}5.3 \pm 0.9 \\
4.3 \pm 0.3\end{array}$ & $\begin{array}{l}2.0 \pm 1.3 \\
2.0 \pm 1.0\end{array}$ & $\begin{array}{l}2.0 \pm 1.3 \\
2.3 \pm 0.8\end{array}$ \\
\hline Lung & $\begin{array}{l}\text { allo MSC } \\
\text { syn MSC }\end{array}$ & $\begin{array}{l}3.0 \pm 1.3 \\
2.5 \pm 1.0\end{array}$ & $\begin{array}{l}0 \pm 0 \\
0 \pm 0\end{array}$ & $\begin{array}{l}0 \pm 0 \\
0 \pm 0\end{array}$ & $\begin{array}{l}0 \pm 0 \\
0 \pm 0\end{array}$ & $\begin{array}{c}0.8 \pm 1.0 \\
0 \pm 0\end{array}$ & $\begin{array}{l}0 \pm 0 \\
0 \pm 0\end{array}$ \\
\hline
\end{tabular}
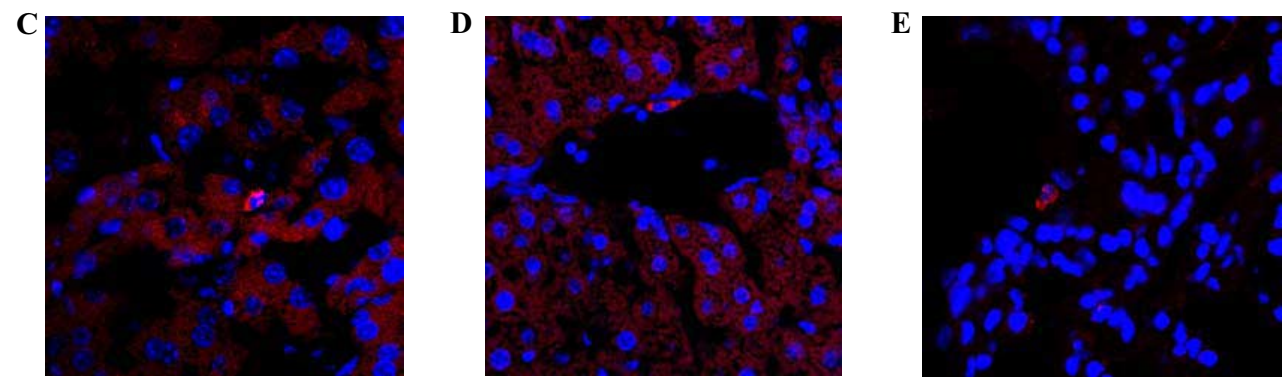

FIGURE 2. In vivo tissue distribution of MSC. FACS $(A)$ and fluorescence microscopy ( $B$, confocal) analysis of PKH26 ${ }^{+}$MSC in recipient tissues after tail vein or portal vein injection of allogeneic and syngeneic MSC in naive or transplanted mice. ${ }^{a} 500,000$ PKH26-labeled B6C3 (allo MSC) or B6 MSC ( syn MSC) were infused into the tail vein or into the portal vein of B6 mice. After 1, 7, and 21 days $\left(n=3\right.$ each) mice were killed. ${ }^{b}$ Additional mice received a double infusion of allogeneic MSC or syngeneic MSC (500,000 at day -7 , portal vein; 500,000 at day -1 , tail vein, $n=3$ each) and were transplanted with a B6C3 heart at day 0 or left untreated. Seven days later (15 days after the first MSC infusion), mice were killed. At sacrifice, single-cell suspensions were obtained from bone marrow, thymus, lymph nodes, and spleen and analyzed by FACS. The total number of PKH $26^{+}$cells in each tissue and the percentage of $\mathrm{PKH} 26^{+}$MSC/total MSC infused were calculated as described in Materials and Methods. Liver and lung sections were analyzed by confocal microscopy for the presence of PKH $26^{+}$cells in three nonconsecutive sections. Results are expressed as mean number of PKH $26^{+}$cells per section. $\S, p<$ 0.05 vs portal vein at the corresponding time point. $C-E$, Representative images of histological analysis of $\mathrm{B} 6 \mathrm{C} 3 \mathrm{PKH} 26^{+} \mathrm{MSC}$ (red cell) in recipient liver $1(C)$ and 7 days $(D)$ after intraportal infusion. E, Representative image of PKH26 ${ }^{+}$MSC in recipient lung 1 day after tail vein infusion. Original magnification, $\times 400$. allo, Allogeneic; syn, syngeneic.

$\mathrm{BALB} / \mathrm{c}\left(\mathrm{H}-2^{\mathrm{d}}\right)$ stimulators as compared with the response of $\mathrm{CD}^{+} \mathrm{T}$ cells from naive mice run in parallel (Fig. $3 A$ ). When splenocytes from infused mice were stimulated with anti-CD3/antiCD28 Abs, they were unable to proliferate (Fig. $3 B$ ) even in the presence of a high dose of IL-2 (Fig. 3B), indicating that MSC administration induced profound $\mathrm{T}$ cell hyporesponsiveness.

Based on striking inhibition of in vitro and ex vivo $\mathrm{T}$ cell activation by MSC, we sought to address whether MSC infusion had tolerogenic properties in a murine model of solid organ transplantation using the semiallogeneic combination of B6C3 donor hearts in B6 recipients. Experimental groups are shown in Table I. Donor-derived B6C3 MSC $\left(0.5 \times 10^{6}\right)$ were intraportally injected in mice 7 days before transplantation (group 1). To evaluate the possible contribution of donor BM cells other than MSC in inducing long-term graft acceptance, an additional group of mice receiving intraportal donor total BM cells $\left(0.5 \times 10^{6}\right.$, group 2$)$ was studied. No immunosuppression was given to recipient mice.

Untreated B6 recipients (group 4) rejected a B6C3 heart within 13 days (Table I and Fig. 4A). Mice receiving an intraportal infu- sion of donor MSC showed a significant ( $p<0.05$ vs untreated mice) prolongation of graft survival. Of note, in $33 \%$ of MSCinfused recipient mice, graft survival reached more than 100 days, indicating that graft acceptance was achieved in a subgroup of allograft recipients. At variance, slightly accelerated cardiac allograft rejection was observed in group 2 mice given donor total $\mathrm{BM}$ cells ( $p<0.05$ vs untreated mice; Table I and Fig. $4 A$ ).

To evaluate whether a single infusion into a peripheral vein was effective in prolonging heart graft survival like portal vein infusion, naive B6 mice (group 3) received $0.5 \times 10^{6} \mathrm{~B} 6 \mathrm{C} 3 \mathrm{MSC}$ into the tail vein 7 days before a cardiac B6C3 transplant. All mice rejected their cardiac graft within 15 days (Table I and Fig. 4A). These results suggest that liver is the favored site for tolerance induction by MSC $(5,35-37)$.

In an attempt to enhance the in vivo tolerogenic properties of $\mathrm{MSC}$, recipient B6 mice were given two doses of $0.5 \times 10^{6} \mathrm{~B} 6 \mathrm{C} 3$ MSC: an intraportal injection 7 days and an i.v. injection (tail vein) 1 day before transplantation of a $\mathrm{B} 6 \mathrm{C} 3$ heart (group 5). Mice receiving two injections of donor total BM cells (group 6) were also 

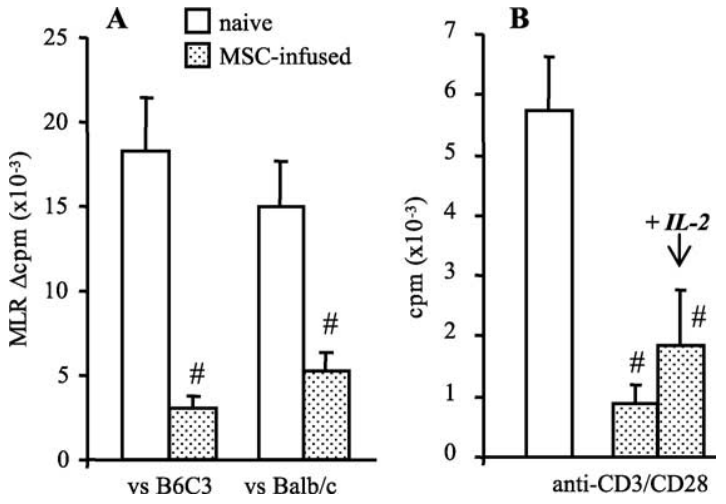

FIGURE 3. Splenocytes from B6 mice receiving B6C3 MSC infusion display hyporesponsiveness ex vivo. A, Isolated $\mathrm{CD}^{+} \mathrm{T}$ cells $\left(0.5 \times 10^{6}\right)$ from either naive $(\square, n=5)$ or B6C3 MSC-infused B6 mice (sacrificed 7 days after infusion, 䁔, $n=5$ ) were cultured for 3 days with irradiated (4000-rad) B6C3, BALB/c or syngeneic B6 splenocytes. MLR proliferative results (mean $\pm \mathrm{SE}$ ) are expressed as $\Delta \mathrm{cpm}$ by subtracting cpm of syngeneic MLR from allogeneic combinations. \#, $p<0.05$ vs naive mice. $B$, Results of anti-CD3/anti-CD28 mAb stimulation of total splenocytes from naive ( $\square, n=5$ ) or B6C3 MSC-infused B6 mice (畨, $n=5$ ). IL-2 was added at a concentration of $100 \mathrm{U} / \mathrm{ml}$. Results are mean \pm SE. \#, $p<$ 0.05 vs naive.

studied as controls. The double dose of donor MSC resulted in significant prolongation of heart allograft survival as compared with that observed after two injections of total BM cells or in untreated recipients (Table I and Fig. 4B). There was, however, no significant difference in graft survival between animals given one or two MSC injections.

Histological analysis of rejected not beating allografts $(n=2)$ taken 9-10 days after transplant from untreated B6 recipients of a B6C3 heart revealed an intense interstitial mononuclear cell infiltrate, many apoptotic and degenerating myocytes, scattered areas of hemorrhage, and total or subtotal vascular luminal obliteration (Fig. 5A). A similar histological picture was found in nonbeating allografts taken at 10-12 days after transplant from the subgroup of donor MSC-infused mice that rejected their grafts $(n=2$ from group 1 in Table I; Fig. 5B). Grafts obtained at $>100$ days after transplantation from donor-derived MSC-tolerized mice $(n=3)$ demonstrated mild, diffuse mononuclear cell infiltrate, viable myocytes but also showed moderate signs of chronic allograft vasculopathy (Fig. 5C), indicating that MSC infusion did not prevent chronic rejection.
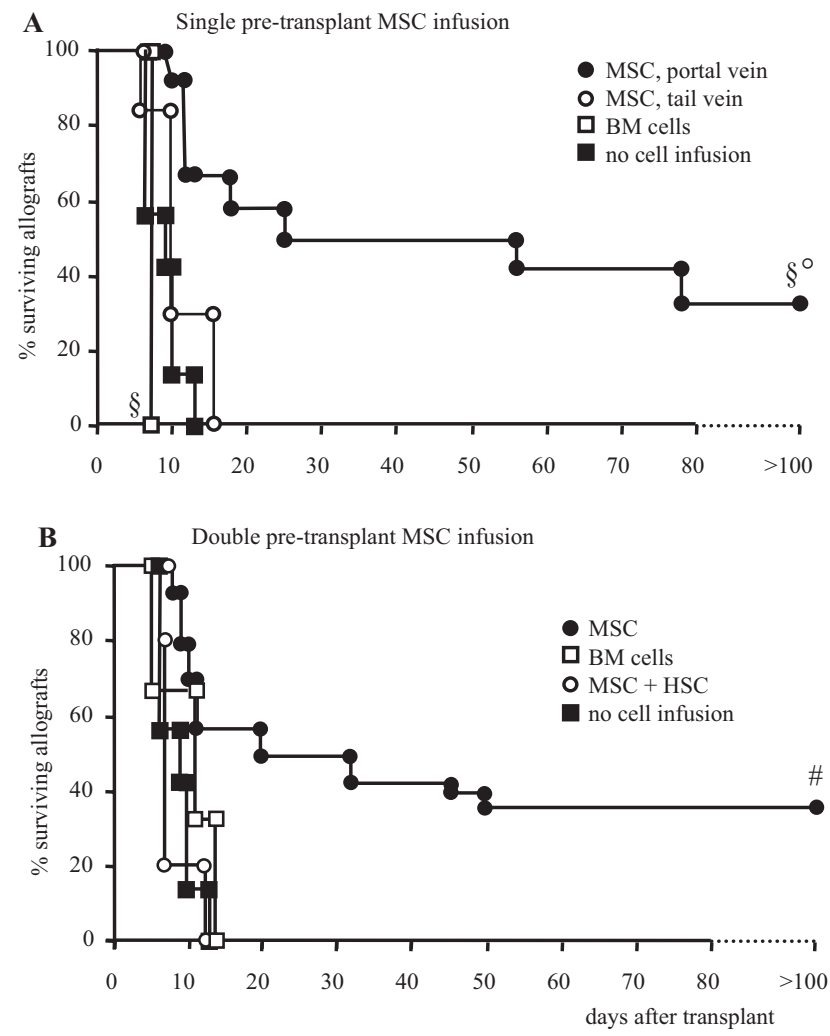

FIGURE 4. Donor MSC induce long-term cardiac allograft survival. $A$, Either B6C3 MSC (portal vein, $n=12$; tail vein, $n=6$ ) or total BM cells (portal vein, $n=3$ ) were injected into recipient $\mathrm{B} 6\left(\mathrm{H}-2^{\mathrm{b}}\right)$ mice 7 days before cardiac $\mathrm{B} 6 \mathrm{C} 3\left(\mathrm{H}-2^{\mathrm{b}, \mathrm{k}}\right)$ transplantation. Untreated $\mathrm{B} 6$ mice $(n=7$, no cell infusion) rejected $\mathrm{B} 6 \mathrm{C} 3$ cardiac grafts within 13 days. Only donor MSC infusion into the portal vein induced a significant prolongation of cardiac allograft survival. $\S, p<0.05$ vs no cell infusion; $\bigcirc, p<0.05$ vs total BM cell infusion and MSC tail vein. $B, \mathrm{~B} 6$ recipients of $\mathrm{B} 6 \mathrm{C} 3$ cardiac grafts received two pretransplant infusions (portal vein at day -7 and tail vein at day -1 before surgery) of donor MSC $(n=14)$, total BM cells $(n=$ $3), \mathrm{MSC}+\mathrm{Lin}^{-} \mathrm{c}-\mathrm{Kit}^{+} \mathrm{HSC}(n=5)$ or no cell infusion $(n=7)$. Only mice receiving donor MSC showed prolonged survival of cardiac allografts while recipients of total $\mathrm{BM}$ cells or MSC plus $\mathrm{Lin}^{-} \mathrm{c}-\mathrm{Kit}^{+} \mathrm{HSC}$ promptly rejected $\mathrm{B} 6 \mathrm{C} 3$ cardiac grafts. \#, $p<0.05$ vs no cell infusion, total $\mathrm{BM}$ cells, and MSC + HSC.

\section{Donor-derived HSC antagonize MSC tolerogenic effects}

MSC isolated using a plastic adherence method from rodent BM usually contain heterogeneous cell populations including HSC $(38,39)$.

Table I. Experimental groups and heart graft survival

\begin{tabular}{|c|c|c|c|c|c|c|}
\hline Group & Heart & Recipient $^{a}$ & Site and Timing & Injected Cells & Graft Survival (Days) & MST \\
\hline 1 & B6C3 & B6 & Portal vein, day -7 & B6C3MSC & $10,12 \times 3,18,25,56,78,>100 \times 4$ & $40^{b, c}$ \\
\hline 2 & B6C3 & B6 & Portal vein, day -7 & B6C3 BM & $7 \times 3$ & $7^{c}$ \\
\hline 3 & B6C3 & B6 & Tail vein, day -7 & B6C3MSC & $8,10 \times 3,15 \times 2$ & 10 \\
\hline 4 & B6C3 & B6 & Untreated & & $9 \times 3,10,12 \times 2,13$ & 10 \\
\hline 5 & $\mathrm{~B} 6 \mathrm{C} 3$ & B6 & Portal vein, day -7 ; tail vein, day -1 & B6C3MSC & $\begin{array}{l}8,9 \times 2,10,11 \times 2,20,32,50 \\
\quad>100 \times 5\end{array}$ & $26^{c, d}$ \\
\hline 6 & B6C3 & B6 & Portal vein, day -7 ; tail vein, day -1 & B6C3 BM & $8,11,14$ & 11 \\
\hline 7 & B6C3 & B6 & Portal vein, day -7 ; tail vein, day -1 & $\mathrm{~B} 6 \mathrm{C} 3 \mathrm{MSC}+\mathrm{HSC}^{e}$ & $7,8 \times 3,13$ & 8 \\
\hline
\end{tabular}

${ }^{a}$ Recipient B6 mice received $0.5 \times 10^{6} \mathrm{~B} 6 \mathrm{C} 3$ cell infusion.

${ }^{b} p<0.05$ vs groups 2 and 3 .

${ }^{c} p<0.05$ vs group 4.

${ }^{d} p<0.05$ vs groups 6 and 7 .

${ }^{e} \mathrm{Lin}^{-} \mathrm{c}-\mathrm{Kit}^{+} \mathrm{HSC}\left(0.25 \times 10^{6}\right)$ were injected with MSC. 

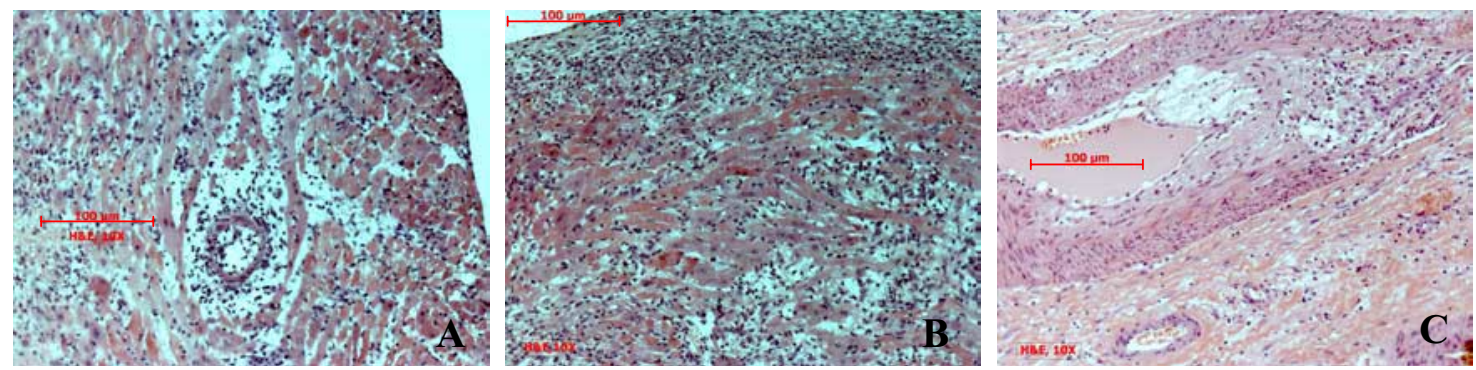

FIGURE 5. Histological analysis of cardiac graft tissues. Representative images of grafts harvested from rejecting untreated mice 10 days after transplantation $(A)$, from donor MSC-infused mice acutely rejecting the graft 10 days after transplantation $(B)$, and from donor MSC-tolerized mice $>100$ days after transplantation $(C)$.

To evaluate whether MSC and HSC could exert either synergistic or antagonistic effects on tolerance induction, an additional group of B6 mice received two injections of $0.5 \times 10^{6} \mathrm{~B} 6 \mathrm{C} 3 \mathrm{MSC}$ plus $0.25 \times 10^{6} \mathrm{~B} 6 \mathrm{C} 3 \mathrm{Lin}^{-} \mathrm{c}-\mathrm{Kit}^{+} \mathrm{HSC}$ (group 7) given 7 days (portal vein) and 1 day (tail vein) before $\mathrm{B} 6 \mathrm{C} 3$ heart transplantation. No prolongation of cardiac allograft survival was observed with the combined cell treatment, indicating that HSC do not synergize but instead hamper the in vivo tolerogenic properties of MSC (Table I and Fig. 4B). The presence of residual hematopoietic cells in MSC preparations may at least in part explain failure of some studies in showing an immunomodulatory effect of MSC in organ transplantation in rodents (22).

\section{Donor-derived MSC induce in vivo formation of Treg}

To clarify whether MSC infusion induced the formation of Treg, adoptive transfer experiments were performed. Forty million splenocytes obtained from B6 mice sacrificed 7 days after intraportal infusion of $0.5 \times 10^{6} \mathrm{~B} 6 \mathrm{C} 3 \mathrm{MSC}$ were given i.v. to B6 naive mice 1 day before donor B6C3 heart transplantation. As shown in Fig. 6, all B6 mice adoptively transferred with splenocytes from B6C3 MSC-treated mice showed prolongation of donor B6C3 cardiac allograft survival ( $p<0.05$ vs naive recipients) that was indefinite in $60 \%$ of animals.

We next investigated whether Treg had also a role in the maintenance phase of MSC-induced tolerance. To this purpose, mice with long-term graft survival ( $>100$-day survival of a B6C3 heart) by either intraportal or combined intraportal and tail vein $\mathrm{B} 6 \mathrm{C} 3$

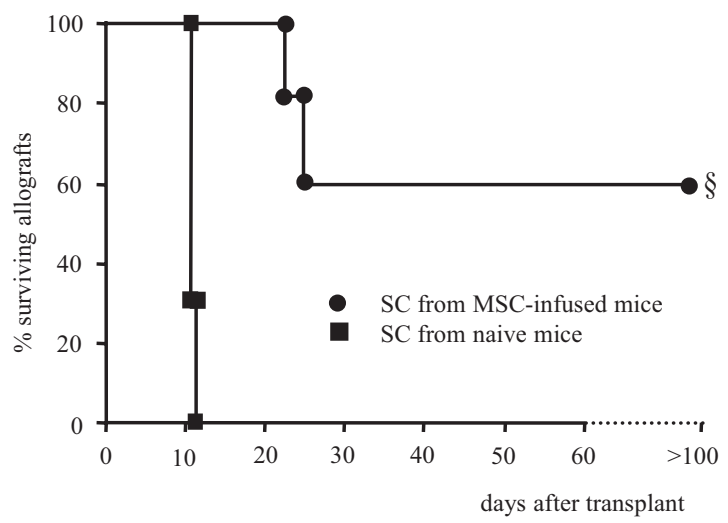

FIGURE 6. Splenocytes from donor MSC-infused mice transfer tolerance into naive mice. Survival time of cardiac grafts in naive B6 mice adoptively transferred with splenocytes $\left(40 \times 10^{6}\right)$ from B6C3 MSC-infused mice sacrificed 7 days after cell injection are shown. Donor B6C3 hearts had prolonged survival $(n=5)$ as compared with donor B6C3 $(n=$ 3) hearts in B6 mice receiving naive splenocytes. $\S, p<0.05$ vs B6 mice given naive splenocytes.
MSC infusion were used as splenocyte donors for adoptive transfer experiments. Naive B6 mice receiving splenocytes $\left(40 \times 10^{6}\right.$ i.v. $)$ from mice with long-term graft survival the day before transplantation of a $\mathrm{B} 6 \mathrm{C} 3$ heart had significant prolongation of graft survival ( $p<0.05$ vs mice receiving naive splenocytes; Table II). Four of five mice had indefinite ( $>100$ days) survival of the allograft (Table II). Notably, spleen cells from these secondary transplanted mice were able to transfer tolerance to other naive B6 mouse recipients of a new $\mathrm{B} 6 \mathrm{C} 3$ heart (Table III). Once these latter animals were tolerant for more than 100 days, their splenocytes transferred tolerance to additional naive recipients (Table III), further documenting the infectious properties of MSC-induced Treg (40). To document the donor-specificity of Treg, naive B6 mice receiving splenocytes from animals tolerizing a $\mathrm{B} 6 \mathrm{C} 3$ heart were transplanted with fully allogeneic donor-specific C3 hearts. Two of three mice showed a prolongation of heart survival (Table II). In contrast, naive B6 mice receiving splenocytes from animals tolerized to a B6C3 heart promptly rejected a fully allogeneic thirdparty BALB/c heart (Table II).

Altogether these data indicate that both the induction and the maintenance phase of pretransplant donor MSC infusion-induced graft acceptance were associated with the formation of Treg. Of note, Treg isolated during the maintenance phase of MSC-induced tolerance were donor specific.

Different subsets of $\mathrm{T}$ cells with regulatory properties have been reported in literature, including $\mathrm{CD} 4{ }^{+} \mathrm{CD} 25^{+}$Treg, $\mathrm{CD} 4^{+} \mathrm{CD} 25^{-}$ Treg, and certain $\mathrm{CD}^{+} \mathrm{T}$ cell subsets, which may be induced in vivo by protolerogenic strategies (41).

Additional experiments were done to identify the subset of Treg responsible for $\mathrm{MSC}$-induced infectious tolerance. $\mathrm{CD}^{+}$and

Table II. Results of adoptive transfer experiments with spleen cells or splenic T cell subpopulations from mice made tolerant by donor MSC to a B6C3 heart $^{a}$

\begin{tabular}{lllc}
\hline \hline & Heart & Graft Survival (Days) & MST \\
\hline Cell injection & & & \\
Tolerant splenocytes & B6C3 & $69,>100 \times 4$ & $>100^{b}$ \\
CD4 ${ }^{+}$T cells & B6C3 & $>100 \times 3$ & $>100^{b}$ \\
CD4 ${ }^{+}$CD25 ${ }^{+}$T cells & B6C3 & $>100 \times 3$ & $>100^{b}$ \\
CD4 ${ }^{+}$CD25 $5^{-}$T cells & B6C3 & $14,27,38$ & 27 \\
CD8 ${ }^{+}$T cells & B6C3 & $13,15,14$ & 14 \\
Tolerant splenocytes & C3 & $11,>40 \times 2$ & $>40^{b}$ \\
Tolerant splenocytes & BALB/c & $8,8,11$ & 8 \\
Naive splenocytes & B6C3 & $11,12,12$ & 12 \\
Naive splenocytes & C3 & $7,7,7$ & 7 \\
Naive splenocytes & BALB/c & $8,9,10$ & 9 \\
\hline
\end{tabular}

${ }^{a} \mathrm{~B} 6 \mathrm{C} 3$ and $\mathrm{C} 3$ donor and $\mathrm{BALB} / \mathrm{c}$ third-party hearts were transplanted into B6 recipients the day after splenocyte or splenic $\mathrm{T}$ cell subpopulation injection.

${ }^{b} p<0.05$ vs naive splenocytes. 
Table III. Survival of B6C3 heart transplants after serial adoptive transfers of splenocytes

\begin{tabular}{ccc}
\hline \hline Group & Source of Adoptively Transferred Splenocytes & Heart Survival (Days) \\
\hline 1 (first adoptive transfer) & B6 recipient taken at $>100$ days after B6C3 MSC infusion and primary & $>100 \times 3$ \\
B6C3 heart transplant & Group 1 taken $>100$ days after B6C3 secondary heart transplant & $>100 \times 3$ \\
(second adoptive transfer) & Group 2 taken $>100$ days after B6C3 tertiary heart transplant & $>100 \times 3$ \\
\hline
\end{tabular}

$\mathrm{CD}^{+} \mathrm{T}$ cell subpopulations from splenocytes of mice with longterm graft survival were sorted and transferred into naive B6 animals the day before transplantation. Six million total $\mathrm{CD} 4^{+} \mathrm{T}$ cells, $1.5 \times 10^{6} \mathrm{CD} 4^{+} \mathrm{CD} 25^{+} \mathrm{T}$ cells, $2.5 \times 10^{6} \mathrm{CD} 4^{+} \mathrm{CD} 25^{-} \mathrm{T}$ cells, and $4 \times 10^{6} \mathrm{CD}^{+} \mathrm{T}$ cells, that correspond to the number of cells in each subset isolated by sorting $40 \times 10^{6}$ total splenocytes from mice with long-term graft survival, were infused i.v. Results are summarized in Table II. Naive B6 mice receiving either total $\mathrm{CD} 4{ }^{+} \mathrm{T}$ cells or $\mathrm{CD} 4{ }^{+} \mathrm{CD} 25^{+} \mathrm{T}$ cells from mice with long-term graft survival had indefinite survival of the cardiac B6C3 allograft, whereas mice infused with $\mathrm{CD} 8^{+} \mathrm{T}$ cells acutely rejected the donor heart within 15 days (Table II). Mice given $\mathrm{CD} 4{ }^{+} \mathrm{CD} 25^{-} \mathrm{T}$ cells showed a slight prolongation of cardiac allograft survival, but eventually rejected the graft within 38 days.

To confirm the phenotype of MSC-induced Treg, we stained splenocytes from mice, made tolerant to $\mathrm{B} 6 \mathrm{C} 3$ hearts by $\mathrm{B} 6 \mathrm{C} 3$ MSC infusion, with anti-CD4, anti-CD25, and anti-Foxp3 Abs. We found a higher percentage of cells that coexpressed CD4, $\mathrm{CD} 25$, and Foxp3 in splenocytes from MSC-tolerized mice than in naive mice (Fig. 7, $A$ and $B, p<0.05$ vs naive mice).
Real-time PCR of Foxp3 mRNA and immunohistochemical analysis of $\mathrm{CD}^{+}{ }^{+} \mathrm{FoxP}^{+}$cells were also performed in cardiac allograft tissues to document Treg recruitment at the graft site. Foxp3 mRNA levels were higher in MSC-tolerized heart allografts than in rejected grafts from untreated recipients (Fig. 8A). Approximately $30 \%$ of $\mathrm{CD}^{+}$cells in beating heart allografts taken at 9-10, 21, and $>100$ days posttransplantation (Fig. 8, $C$ and $D$ ) from mice tolerized by donor MSC infusion expressed Foxp3. By contrast, few $\mathrm{CD}^{+}$cells in rejected nonbeating heart allografts from untreated mice showed a positive staining for FoxP3 (Fig. 8, $B$ and $D ; p<0.05$ vs MSC tolerized).

We next investigated whether expansion of Treg in mice with long-term graft survival was associated with a Th1/Th2 shift. The frequencies of anti-donor IFN- $\gamma$-producing splenocytes from mice studied at $>100$ days after transplant were lower than those from untreated mice rejecting their graft at 7-10 days after transplant (Fig. 7C). The frequency of IFN- $\gamma$-producing splenocytes against $\mathrm{BALB} / \mathrm{c}$ was comparable in both groups (Fig. $7 C$ ). In contrast, the frequency of anti-donor IL-10- producing splenocytes was comparable in MSC-tolerized (11.5 \pm 4.4 spots/250.000 responders,
FIGURE 7. Expansion of $\mathrm{CD}^{+}$ $\mathrm{CD} 25^{+} \mathrm{Foxp}^{+}$Treg and reduced $\mathrm{T}$ cell alloreactivity in the spleen of MSC-tolerized mice. A, Phenotypic analysis was performed on spleen cells isolated from naive $(n=3, \square)$ and from B6 mice recipient of a $\mathrm{B} 6 \mathrm{C} 3$ heart tolerized either by donor-derived B6C3 MSC ( $>100$ days posttransplantation, $n=3, \square$ ) or by recipient-derived B6 MSC $(>100$ days posttransplantation, $n=3, \mathbb{Q}$ ), by flow cytometric analysis using anti-CD4, antiCD25, and anti-Foxp3 mAbs. The percentages of splenic $\mathrm{CD} 4^{+} \mathrm{CD} 25^{+}$ Foxp $3^{+}$cells are shown. \#, $p<0.05$ vs naive. $B$, Representative dot plots of $\mathrm{CD} 25^{+} \mathrm{Foxp}^{+}$cells on gated splenic $\mathrm{CD} 4{ }^{+} \mathrm{T}$ cells from donor MSC-tolerized mice or naive mice. The percentages of $\mathrm{CD}_{25}{ }^{+} \mathrm{FoxP}^{+}{ }^{+}$cells on gated $\mathrm{CD} 4{ }^{+} \mathrm{T}$ cells are given in the boxes. $C$, Frequency of alloreactive $\mathrm{T}$ cells from donor MSCtolerized mice ( $>100$ days posttransplantation, $n=7, \square$ ) or untreated B6 mice rejecting a $\mathrm{B} 6 \mathrm{C} 3$ heart $(n=5$, 畻) by ELISPOT for IFN- $\gamma$ following exposure to donor (vs B6C3) and third-party (vs $\mathrm{BALB} / \mathrm{c}$ ) alloantigens. The frequencies of IFN- $\gamma$-specific T cells were plotted as spots per 100,000 splenocytes. Splenocytes from naive mice were also incubated with donor or third-party stimulators as controls $(n=4$, control range, horizontal gray bars). $\bigcirc, p<0.05$ vs rejecting.
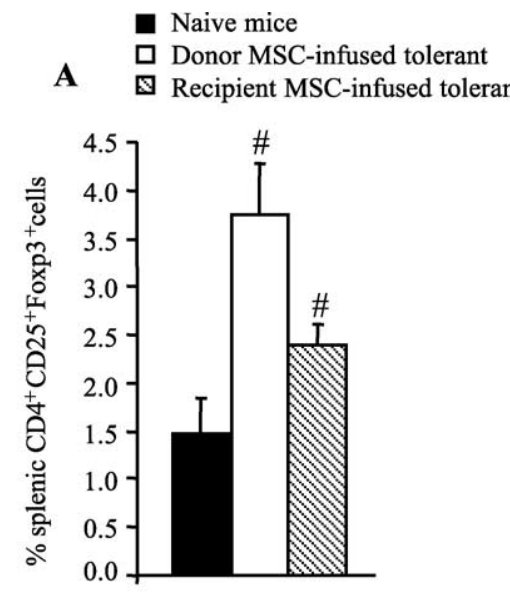

C

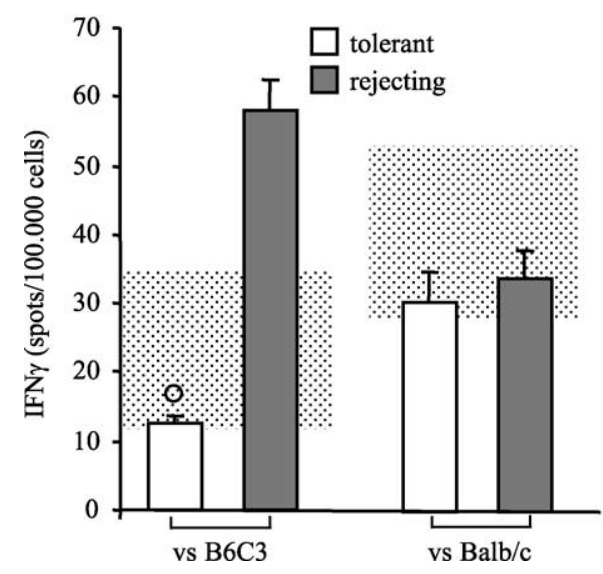

B

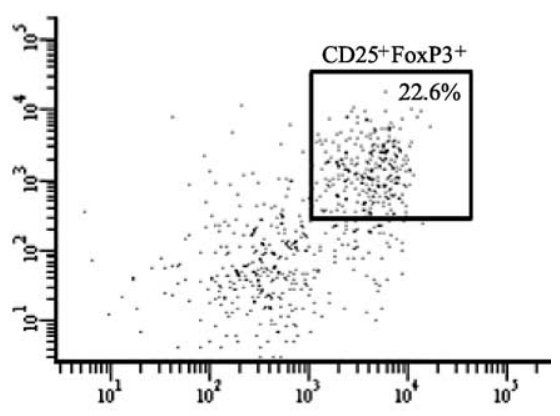

naive

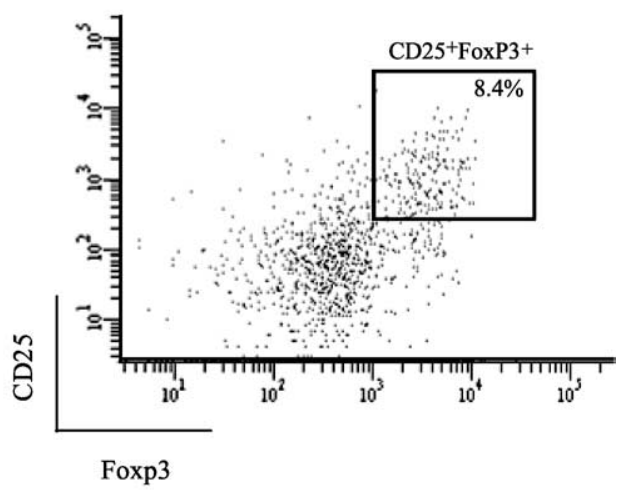


A

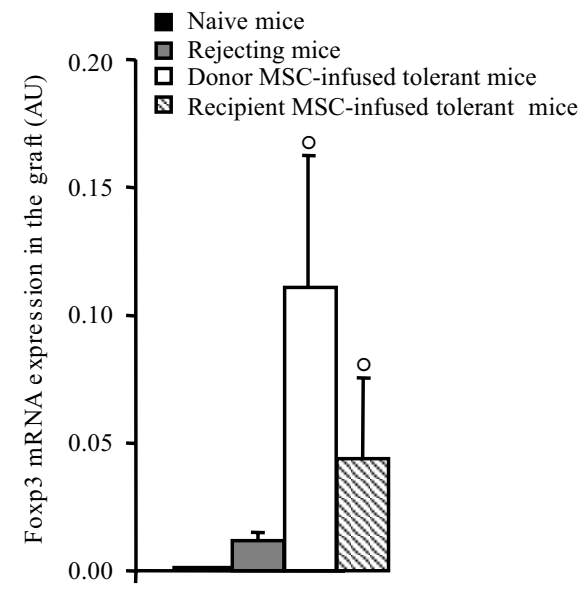

B

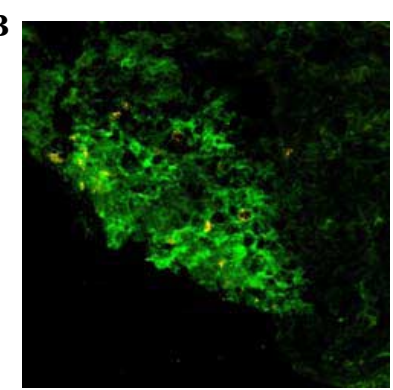

E

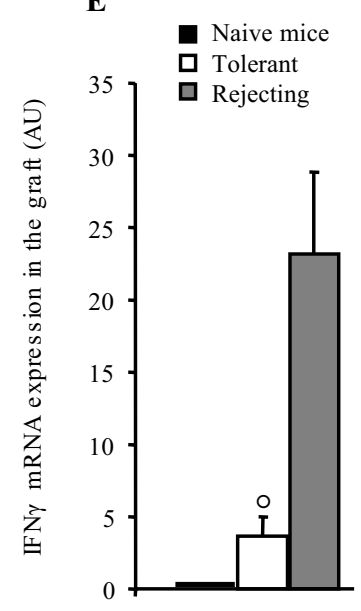

C

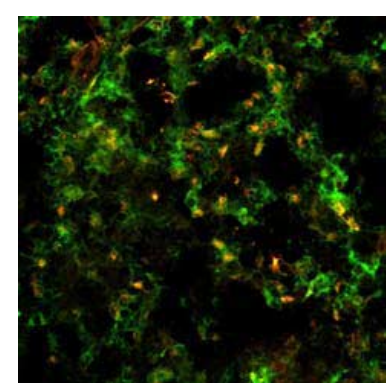

D Percentage of $\mathrm{CD}^{+} \mathrm{Foxp}^{+}$on $\mathrm{CD} 4^{+}$by immunofluorescence staining

\begin{tabular}{|c|c|c|c|c|c|}
\hline \multirow{2}{*}{\multicolumn{2}{|c|}{ days post transplant }} & \multirow{2}{*}{$\begin{array}{c}\text { rejecting } \\
8-10\end{array}$} & \multicolumn{3}{|c|}{ MSC-tolerized } \\
\hline & & & 10 & 21 & $>100$ \\
\hline $\mathrm{CD}^{+}{ }^{+}($cell/field $)$ & $0 \pm 0$ & $33.4 \pm 14.4$ & $16.4 \pm 11.4$ & $19.3 \pm 1.7$ & $22.3 \pm 4.62$ \\
\hline$\% \mathrm{CD}^{+}{ }^{+} \mathrm{Foxp}{ }^{+}$ & $0 \pm 0$ & $4.4 \pm 2$ & $30.0 \pm 3.7^{\mathrm{a}}$ & $30.1 \pm 8.8^{\mathrm{a}}$ & $35.2 \pm 7.0^{\mathrm{a}}$ \\
\hline
\end{tabular}

Cardiac grafts from naïve $(n=3)$, rejecting $(n=3)$ and MSC-tolerized mice (with a beating heart allograft) taken

at $7(n=3), 21(n=3)$ or $>100$ days $(n=4)$ after transplant were analyzed. ap $<0.05$ vs naïve and rejecting.

FIGURE 8. Treg accumulation and reduced IFN- $\gamma$ mRNA expression in the graft of MSC-tolerized mice. $A$, mRNA was extracted from cardiac allograft tissues from untreated B6 recipient mice ( $n=3$, 粼) or from B6 mice tolerized ( $>100$ days) by donor-derived B6C3 MSC $(n=3$, $\square)$ or by recipient-derived B6 MSC $(n=3, \mathbb{Q})$. mRNA was also extracted from native cardiac tissue of B6C3 mice (negative control). Foxp3 expression was evaluated by real-time PCR and expressed as AU. $\bigcirc, p<0.05$ vs rejecting. $B$ and $C$, Representative images of intragraft immunostaining of $\mathrm{CD} 4^{+}$cells (green) and $\mathrm{CD} 4{ }^{+} \mathrm{Foxp} 3^{+}$ cells (yellow/red) in cardiac grafts from untreated rejecting mice $(B)$ or from donor MSC-tolerized mice $>100$ days posttransplant $(C)$. Original magnification, $\times 400 . D$, Total $\mathrm{CD} 4^{+}$graft-infiltrating lymphocyte counts (cells per /high-power field) and percentages of $\mathrm{CD} 4{ }^{+}$Foxp $3^{+}$on total infiltrating $\mathrm{CD} 4{ }^{+}$cells from naive $(n=3)$, rejecting $(n=3)$ or donor MSC-tolerized mice (double portal/tail vein infusion) with a beating heart allograft taken at $7(n=3), 21(n=3)$, or $>100$ days $(n=4)$ after transplant. ${ }^{a} p<0.05$ vs naive and rejecting. $E$, mRNA was extracted from cardiac allograft tissues of recipient B6 mice tolerized by donor MSC ( $>100$ days posttransplant, $n=3$; $\square$ ) or from untreated rejecting mice $(n=4$; 圈). mRNA was also extracted from native cardiac tissue of $\mathrm{B} 6 \mathrm{C} 3$ mice (negative control). IFN- $\gamma$ expression was evaluated by real-time PCR and expressed as AU. ${ }^{\circ} p<0.05$ vs rejecting.

$n=7)$ and in rejecting untreated mice $(11.9 \pm 2.9$ spots $/ 250.000$ responders, $n=5$ ).

These data indicate that tolerance induced by MSC infusion is characterized by reduced Th1 effector cells without Th2 shift.

Consistently, we found less IFN- $\gamma$ mRNA expression in cardiac grafts from mice with long-term graft survival as compared with rejecting mice (Fig. $8 E$ ). The evaluation of graft IL-10 mRNA expression did not reveal any difference between long-term graft survival and rejecting mice (mice with long-term graft survival, $0.74 \pm 0.31$ arbitrary units (AU), $n=4$; rejecting, $1.10 \pm 0.23$ AU, $n=4, p=\mathrm{NS}$ ).

No IFN- $\gamma$, IL-10, and Foxp3 mRNA expression was found in cardiac tissues from naive $\mathrm{B} 6 \mathrm{C} 3$ mice.

Altogether these results indicate that tolerance induced by pretransplant donor MSC infusion is associated with the accumulation of $\mathrm{CD}^{+}{ }^{+} \mathrm{CD} 25^{+} \mathrm{Foxp}^{+}$Treg in lymphoid organs and in the graft and a reduction of anti-donor Th1 effector cells.

\section{Recipient-derived MSC prolong the survival of semiallogeneic cardiac allografts and induce the formation of Treg}

On the basis of in vitro data that MSC were capable of suppressing the proliferation of autologous $\mathrm{T}$ cells against alloantigens (Fig. $1 C$ ), we next evaluated whether infusion of recipient-derived MSC prolonged the survival of a semiallogeneic heart transplant. B6 mice were given $0.5 \times 10^{6} \mathrm{~B} 6 \mathrm{MSC}$ into the portal vein 7 days and a second dose into the tail vein 1 day before heart transplant from B6C3 mice (Table IV). The infusion of recipient-derived MSC induced tolerance to $\mathrm{B} 6 \mathrm{C} 3$ cardiac allografts in $50 \%$ of mice (Table IV). These results are very comparable to those obtained with donor-derived MSC infusion (Table I). 
Table IV. Effect of recipient-derived B6 MSC infusion on B6C3 cardiac allograft survival in B6 mice ${ }^{a}$

\begin{tabular}{|c|c|c|c|}
\hline Site and Timing & Injected Cells & Graft Survival (Days) & MST \\
\hline Portal vein, day -7 ; tail vein, day -1 & MSC & $10,10,12,25,>100 \times 4$ & $>62.5^{b}$ \\
\hline Portal vein, day -7 ; tail vein, day -1 & $\mathrm{MSC}+\mathrm{HSC}^{c}$ & $7,15,>40 \times 2$ & $>27.5^{b}$ \\
\hline Tail vein, day -7 ; tail vein, day -1 & MSC & $10,19,>100 \times 2$ & $>59.5^{b}$ \\
\hline Tail vein, day +1 & MSC & $9,9,12$ & 9 \\
\hline Portal vein, day 0 & MSC & $8,14,17,28,>100 \times 2$ & $22.5^{b}$ \\
\hline Untreated & & $9,9,9,10,12,12,13$ & 10 \\
\hline
\end{tabular}

To investigate whether HSC of recipient origin hamper the tolerogenic potential of MSC, an additional group of B6 mice re-

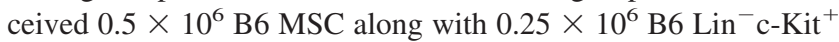
HSC (Table IV) 7 days (portal vein) and 1 day (tail vein) before a B6C3 heart transplantation. Two of four mice showed prolonged cardiac graft survival ( $>40$ days; Table IV), a percentage that was the same obtained with the sole injection of recipient-derived MSC, indicating that recipient-derived HSC did not antagonize the tolerogenic potential of MSC infusion, at variance with donor-derived HSC.

To verify whether in this setting tolerance was associated with the emergence of Treg, adoptive transfer experiments with splenocytes from B6 mice made tolerant to B6C3 heart by B6 MSC infusion were performed. Forty million splenocytes from tolerized animals had no effect on heart allograft survival (survival: 15 and 18 days; median survival time (MST), 16.5 days, $n=2$ ). However, infectious tolerance was obtained by increasing the amount of infused splenocytes to $70 \times 10^{6}$ (survival: 46,91 , and $>115$ days; MST, 91 days, $n=3$ ). In contrast, the same amount of splenocytes did not prolong the survival of BALB/c hearts to any extent (survival: 8,9 , and 9 days; MST, 9 days, $n=3$ ). FACS analysis of spleen cells from mice with long-term graft survival revealed a higher percentage of $\mathrm{CD} 4{ }^{+} \mathrm{CD} 25^{+} \mathrm{Foxp}^{+}$Treg than splenocytes from naive animals (Fig. $7 A ; p<0.05$ vs naive). Moreover, RTPCR analysis of heart allografts tolerized by recipient-derived MSC showed a well-detectable Foxp3 expression (Fig. 8A). However, both the percentage of Treg in the spleen and the level of Foxp3 expression in heart grafts from these animals were lower than those observed in $\mathrm{B} 6$ mice made tolerant to $\mathrm{B} 6 \mathrm{C} 3$ cardiac allografts by donor-derived MSC infusion (Figs. $7 A$ and $8 A$ ). These results indicate that recipient-derived MSC infusion induced the formation of Treg, although to a lesser extent than donor-derived MSC.

\section{Pretransplant infusion of recipient MSC is more effective than peritransplant infusion to prolong allograft survival}

With the perspective of clinical application of the tolerogenic procedure, experiments were also performed changing the MSC infusion protocol. We first tested the efficacy of a double tail vein dose of $0.5 \times 10^{6}$ recipient-derived MSC given to B6 mice 7 and 1 days before a $\mathrm{B} 6 \mathrm{C} 3$ heart transplant. The latter protocol had similar tolerogenic potential as the double intraportal/tail vein infusion (Table IV). To shorten the timing between MSC infusion and transplantation, $0.5 \times 10^{6} \mathrm{~B} 6 \mathrm{MSC}$ were infused in $\mathrm{B} 6$ mice, either into the portal vein during surgery (peritransplant) or into the tail vein 1 day after transplantation of $\mathrm{B} 6 \mathrm{C} 3$ heart grafts. As shown in Table IV, peritransplant infusion of recipient-derived MSC via the portal vein induced indefinite allograft survival in two of six mice, whereas tail vein infusion of B6 MSC 1 day after transplantation failed to prolong heart allograft survival to any extent (Table IV). Thus, peritransplant infusion of recipient-derived
MSC via the portal vein had a lower tolerogenic effect than pretransplant infusion, while a single tail vein MSC infusion 1 day after transplantation was ineffective.

\section{Recipient-derived MSC do not prolong fully allogeneic cardiac allograft survival}

We then investigated whether infusion of recipient-derived MSC was able to tolerize a fully MHC-mismatched cardiac allograft. To this purpose, a group of B6 mice $(n=4)$ was given a double infusion of $0.5 \times 10^{6}$ recipient-derived B6 MSC (day -7 in the portal vein and -1 in the tail vein) before receiving a $\mathrm{BALB} / \mathrm{c}$ allograft. MSC failed to prolong the survival of fully MHC-mismatched cardiac allografts (survival times: MSC-treated mice: 7, 7, 9, and 12 days; MST, 8 days; naive B6 mice: 8, 9, and 10 days; MST, 9 days).

\section{Discussion}

In the present study, we confirmed that MSC have immunosuppressive properties in vitro and in vivo and found that infusion of donor MSC is effective in prolonging the survival of semiallogeneic heart transplants in unconditioned recipient mice. This tolerogenic effect was not shared by total BM cells. Coinfusion of HSC abrogated the tolerogenic effect of MSC. More importantly, we found that MSC from the recipient strain are capable of prolonging a donor cardiac allograft survival as well. The tolerogenic potential of both donor-derived and recipient-derived MSC was associated with the expansion of $\mathrm{CD} 4{ }^{+} \mathrm{CD} 25^{+}$Foxp $3^{+}$Treg.

The in vitro immunosuppressive effect of murine MSC was dose dependent and not donor specific. Indeed, MSC inhibited the proliferative response of both autologous and allogeneic $\mathrm{CD} 4^{+} \mathrm{T}$ cells to either donor or third-party alloantigens in MLR, which is consistent with most published studies in human, baboon, and rodent $\operatorname{MSC}(13,14,18,21-26)$.

The role of either soluble factors or cell contact-dependent mechanisms in suppression of T cell response by MSC is still an unsolved issue. Immunosuppression by human MSC has been reported to be mediated by soluble factors such as hepatocyte growth factor (13) TGF- $\beta 1$ (13), PGE $_{2}$ (42), IDO-mediated tryptophan deletion (43), and NO (44). In contrast, T cell inhibition by murine MSC was either dependent on soluble factors $(23,24,43)$ or required cell contact $(14,23-25,43)$. In this study, we found that, in vitro, the conditioned medium of murine MSC-T cell cultures only partially affected $\mathrm{T}$ cell alloreactivity, which would suggest a role of cell contact in MSC-mediated T cell suppression. Discrepancies in different studies may be explained by the different experimental conditions used, such as the ratio between MSC and responder cells. Indeed, evidence is available that MSC-derived soluble factors played a role at high MSC:responders ratio (1:1) (23), whereas at lower ratios, as the one used in the present study $(1: 10)$, cell contact was required to inhibit immune cell response (25). In addition, most studies used total splenocytes as responders, which 
include disparate subsets of cells that may be potential MSC targets. In this regard, B lymphocytes were sensitive to the inhibitory action of MSC-released soluble factors, whereas the inhibition of $\mathrm{T}$ cell proliferation by MSC was cell contact dependent (24). The latter finding is consistent with a cell contact-dependent mechanism as suggested by our coculture experiments in which purified $\mathrm{CD} 4^{+} \mathrm{T}$ cells were used as targets.

Several studies in animal models and in humans have demonstrated that MSC are capable of long-term engraftment after i.v. injection, although only a small fraction of the infused cells underwent vascular emigration and tissue distribution in bone marrow, lungs, heart, kidneys, and lymphoid organs (29, 30, 45-48). By in vivo infusion experiments, we found that MSC tissue distribution was influenced by the site of injection but not by the donor-recipient match. After infusion, both allogeneic and syngeneic MSC rapidly but transiently localized in secondary lymphoid organs with a higher number of cells observed after tail vein than after portal vein injection. MSC were well detected in the recipient liver after portal vein injection, whereas after tail vein infusion MSC could be detected transiently in the liver and in lower numbers than when given via portal vein.

The different in vivo distribution of MSC following portal vein vs tail vein infusion influenced the MSC tolerogenic properties. Indeed, a single intraportal infusion of MSC caused reduction of T cell alloreactivity and prolonged the survival of semiallogeneic cardiac transplants, indicating that MSC when given via portal vein are capable to modulate immune cell response in vivo. By contrast, a single donor-derived MSC infusion into the tail vein was not enough to prolong allograft survival.

Altogether, these results are in line with previous studies indicating that the liver is an immune privileged organ for tolerance induction by donor cell infusion. Intraportal but not systemic i.v. infusions of donor splenocytes or bone marrow cells could extend the survival time of skin, islet, cardiac, and kidney transplants (37, 49-51). All of these models are consistent with the idea that the contact between donor-derived cells and the host immune system in the liver results in immune inactivation. The nature of this interaction is not clear, although it was hypothesized that either sinusoidal endothelial cells (52) or the liver's large population of sinusoidal macrophages, the Kupffer cells, may have a role (53).

Several studies in rodents $(3,6,7)$ have documented the possibility to achieve allogeneic chimerism and tolerance to solid organ allotransplantation by infusion of either BM cells or HSC, although different manipulations of the host immune system were required to achieve $\mathrm{BM}$ engraftment and tolerance $(6,7)$. In this study, we found that injection of total donor BM cells was not associated with any prolongation of allograft survival in an unconditioned host, whereas MSC were effective in this setting, which would support a more potent protolerogenic potential of MSC than total BM cells. More importantly, the protolerogenic effect of MSC was impaired when MSC were injected along with donor-derived but not recipient-derived HSC, suggesting that allogeneic HSC may have a negative impact on MSC immunomodulatory properties. The presence of allogeneic HSC in donor-derived MSC preparation could alter the delicate equilibrium of MSC and recipient T cell interaction by generating an allogeneic immune reaction.

Different mechanisms have been proposed to mediate the immunosuppressive properties of MSC, which include veto functions on effector T cells (14) and blunting effects on the maturation of professional APC $(42,54,55)$. MSC can also elicit T cell anergy, reversible by adding exogenous IL-2 (30). In an experimental model of myelin oligodendrocyte glycoprotein-induced experimental autoimmune encephalomyelitis in mice, MSC infusion caused $\mathrm{T}$ cell hyporesponsiveness to MOG-peptide, which was re- stored by IL-2 (30). In contrast, MSC inhibition of mouse T cell response against the male $\mathrm{HY}$ minor histocompatibility $\mathrm{Ag}$ was not overcome by IL-2 added to the cell culture (26). In line with the latter study, we found that the hyporesponsiveness of $\mathrm{T}$ cells from MSC-infused animals was not reverted by high-dose IL-2, excluding that recipient $\mathrm{T}$ cells were anergized by MSC infusion. Consistently, administration of IL-2 in donor-derived MSC-infused animals made tolerant to a semiallogeneic heart graft did not revert tolerance (data not shown).

There is increasing evidence that $\mathrm{T}$ cells with regulatory function play a central role in the control of both reactivity to self-Ags and alloimmune response (56). Namely, CD $4{ }^{+} \mathrm{CD} 25^{+} \mathrm{Foxp}^{+}$ Treg contribute to prevent allograft rejection in many animal models of tolerance induced by either donor cell infusion or costimulatory blockade (57-59).

The role of Treg in MSC-induced immunomodulation is controversial. Data exist that human MSC-mediated immune inhibition is not reversed by removing Treg from cocultured MLR (25). Others have reported that the $\mathrm{CD} 4{ }^{+} \mathrm{CD} 25^{+}$Treg population increased significantly in MLR when MSC were present $(20,42,60$, $61)$. In this study, we demonstrated that the induction and maintenance phases of tolerance after donor-derived MSC infusion in mice are associated with the emergence of functional Treg (Fig. 9), since splenocytes harvested either 7 days after MSC injection or at $>100$ days after transplantation from mice with long-term graft survival were capable of transferring tolerance to secondary naive recipients. Increased numbers of $\mathrm{CD} 4{ }^{+} \mathrm{CD} 25^{+} \mathrm{Foxp}^{+}$cells in lymphoid organs and in the graft of animals with long-term graft survival along with the ability of $\mathrm{CD} 4{ }^{+} \mathrm{CD} 25^{+}$cells to transfer tolerance to naive secondary hosts indicate that expansion of this specific cell subset played a role in MSC-induced tolerance. We hypothesize that, despite the rather low degree of MSC engraftment into lymphoid organs and in the liver, these cells are capable of initiating an active tolerogenic process that self-sustains by interacting with the resident $\mathrm{T}$ cell population and favoring the generation of $\mathrm{CD} 4{ }^{+} \mathrm{CD} 25^{+}$Treg. Regulation, once established, becomes the dominant mechanism that limits Th1 cell priming and prevents the rejection of subsequent semiallogeneic and fully allogeneic donor-specific allografts. MSC-induced tolerogenic mechanisms in vivo were donor specific, since mice adoptively transferred with splenocytes taken from donor-derived MSC-tolerized animals acutely rejected a third-party heart. In line with this interpretation are published data showing that Treg, isolated from ABM mice that spontaneously accepted bm12 heart allografts, suppressed rejection of alloantigen-specific bm12 but not of thirdparty skin allografts when coinfused with effector T cells into nude mice (62).

Of note, heart allografts taken at $>100$ days from MSC-infused mice showed signs of chronic allograft vasculopathy. Why MSCtreated mice were not protected from chronic allograft rejection despite an enhanced number of Treg in lymphoid organs and in the graft remains matter of speculation. One possibility is that the number of Treg did not reach the threshold level to properly suppress the complex pathways of effector T cells. Another possibility could be that MSC-induced Treg were specific for directly presented donor Ags but did not suppress the indirect pathway, which appears to play a main role in chronic rejection. In this regard, in a recent report in irradiated mice receiving donor bone marrow, infusion of Treg specific for directly presented donor Ags prevented acute but not chronic rejection of skin and heart allografts, whereas regulatory $\mathrm{T}$ cells specific for both directly and indirectly presented alloantigens prevented both acute and chronic rejection (63). 
donor-derived

$\operatorname{MSC}$ B6C3 (H-2 b,k)

FIGURE 9. Proposed mechanism for MSC induced tolerance. A) $\mathrm{B} 6 \mathrm{C} 3$ $\left(\mathrm{H} 2^{\mathrm{b}, \mathrm{k}}\right)$ MSC infused into $\mathrm{B} 6\left(\mathrm{H} 2^{\mathrm{b}}\right)$ recipients promote the emergence of $\mathrm{H} 2^{\mathrm{b}, \mathrm{k}}$ donor-specific Tregs that prevent graft disruption by effector $\mathrm{T}$ cells. B) B6 ( $\left.\mathrm{H}^{\mathrm{b}}\right)$ MSC infused into B6 recipients expand naturally occurring Tregs that, by recognition of $\mathrm{H} 2^{\mathrm{b}}$ Ags in the graft, prevents the activation of effector T cells by $\mathrm{H} 2^{\mathrm{k}} \mathrm{Ags}$ in B6C3 grafts through linked suppression. C) By contrast, naturally occurring Tregs, generated by infusion of B6 ( $\left.\mathrm{H} 2^{\mathrm{b}}\right)$ MSC into B6 recipients, do not recognize fully mismatched $\mathrm{H} 2^{\mathrm{d}}$ Ags on BALB/c transplant and graft rejection occurs.

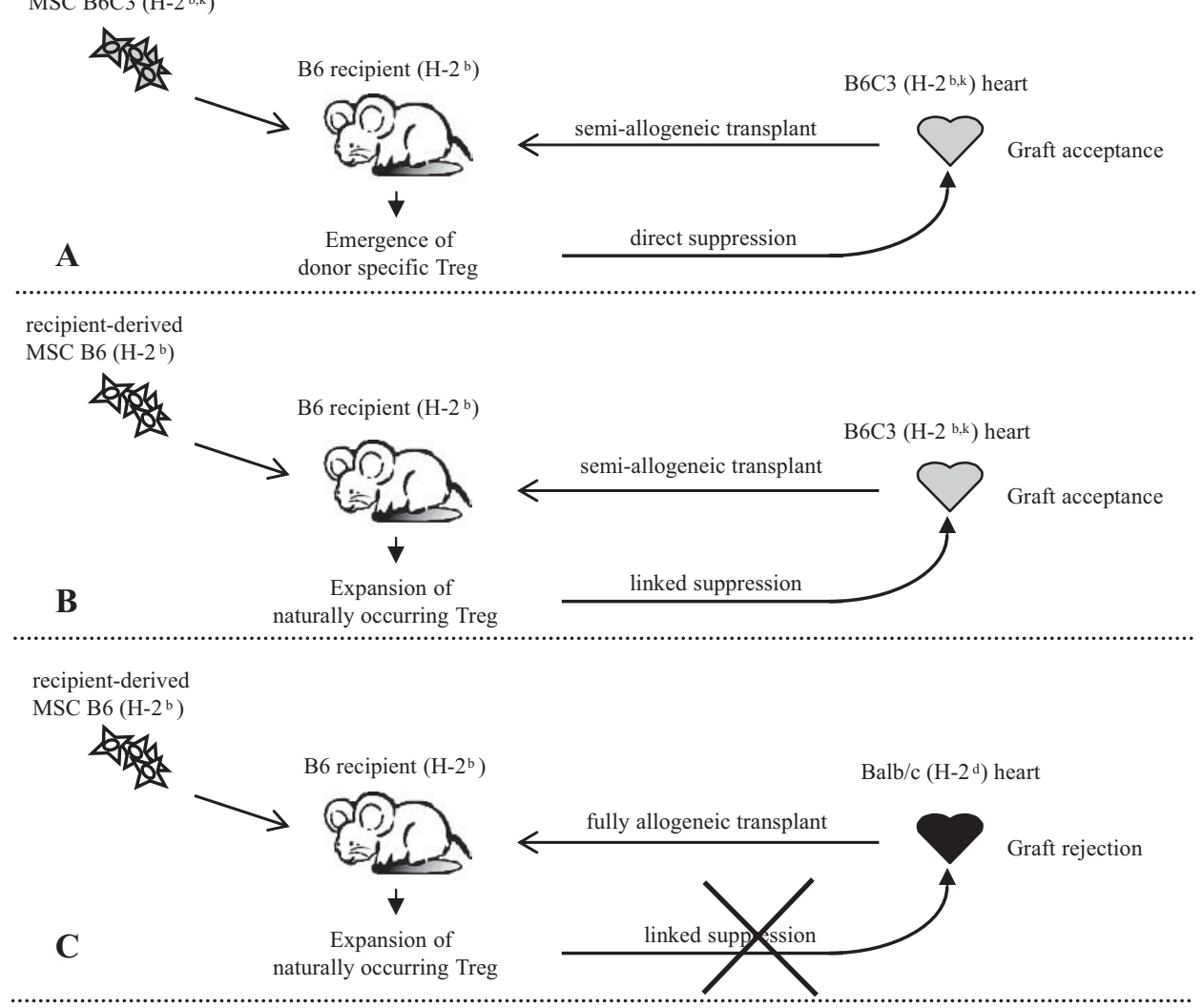

Another major finding of this study is that pretransplant infusion of B6 MSC of recipient origin was as effective in inducing longterm acceptance of semiallogeneic $\mathrm{B} 6 \mathrm{C} 3$ cardiac allografts as donor-derived MSC (Fig. 9). Of note, recipient-derived MSC did not prolong the survival of a fully MHC-mismatched BALB/c heart (Fig. 9). We hypothesize that in the semiallogeneic setting, B6 MHC molecules on MSC interacted with B6-restricted TCR of recipient $\mathrm{T}$ cells and caused expansion of naturally occurring Treg (Fig. 9). These cells recognized B6 Ags in the graft and prevented a host $\mathrm{T}$ cell response against C3 Ags as well, through linked suppression, but did not recognize fully mismatched BALB/c alloantigens. This interpretation is supported by findings of increased numbers of Treg in lymphoid organs and in the grafts of tolerant animals.

Of relevance, we found that a double pretransplant infusion of recipient MSC via tail vein had a similar tolerogenic effect as the combined intraportal/tail vein infusions, which would make this tolerogenic protocol less risky in a clinical setting. This result is at variance with lack of tolerogenic effect we observed with single tail vein infusion of donor-derived MSC. Whether the discrepancy depends on the double vs single tail vein infusions or whether allogeneic but not syngeneic MSC that engraft primarily in lymphoid organs following tail vein infusion could elicit an immune response remains to be established.

In contrast, a single recipient-derived MSC infusion given peritransplant was marginally effective, and a single MSC dose given 1 day after transplantation was not effective at all. These results indicate that MSC should have already activated protolerogenic mechanisms at the time the recipient immune system comes in contact with graft alloantigens to induce graft acceptance. Relevant to this interpretation are data that MHCII expression on MSC requires stimulation by low IFN- $\gamma$ levels, whereas in the presence of high IFN- $\gamma$ levels MSC lose their expression of MHCII (64). This may suggest that during an ongoing immune response, in the presence of high levels of IFN- $\gamma$ released by effector T cells, MSC lose their ability to interact with $\mathrm{CD} 4{ }^{+} \mathrm{T}$ cells and to induce Treg differentiation. This possibility is supported by published studies (20, 65) showing that administration of anti-MHCII-blocking Abs prevented MSC-mediated T cell inhibition in vitro (20) and tolerance induction in vivo (65). However, the possibility that treating the recipient with multiple MSC infusion posttransplant could have tolerogenic potential cannot be excluded on the basis of the present data.

In summary, we documented that MSC may act as a biological immunosuppressive agent in vivo through the induction of donorspecific $\mathrm{CD} 4{ }^{+} \mathrm{CD} 25^{+}$Foxp $3{ }^{+}$Treg. Recipient-derived MSC are equally effective as donor-derived MSC in prolonging allograft survival, which makes this strategy clinically applicable to cadaveric organ transplantation. However, the requirement of a partial MHC match between the donor and the recipient and of pretransplant infusion for MSC tolerogenic effects should be taken into account in designing clinical studies in the setting of solid organ allotransplantation.

\section{Acknowledgments}

We thank Dr. Sistiana Aiello and Dr. Linda Cassis for technical assistance in FACS experiments.

\section{Disclosures}

The authors have no financial conflict of interest.

\section{References}

1. Lechler, R. I., M. Sykes, A. W. Thomson, and L. A. Turka. 2005. Organ transplantation: how much of the promise has been realized? Nat. Med. 11: 605-613.

2. Salama, A. D., G. Remuzzi, W. E. Harmon, and M. H. Sayegh. 2001. Challenges to achieving clinical transplantation tolerance. J. Clin. Invest. 108: 943-948. 
3. Noris, M., N. Azzollini, M. Mister, A. Pezzotta, G. Piccinini, F. Casiraghi, D. Cugini, N. Perico, S. Orisio, and G. Remuzzi. 1999. Peripheral donor leukocytes prolong survival of rat renal allografts. Kidney Int. 56: 1101-1112.

4. Young, K. J., L. Yang, M. J. Phillips, and L. Zhang. 2002. Donor-lymphocyte infusion induces transplantation tolerance by activating systemic and graft-infiltrating double-negative regulatory T cells. Blood 100: 3408-3414.

5. Morita, H., K. Sugiura, M. Inaba, T. Jin, J. Ishikawa, Z. Lian, Y. Adachi, S. Sogo, K. Yamanishi, H. Taki, et al. 1998. A strategy for organ allografts without using immunosuppressants or irradiation. Proc. Natl. Acad. Sci. USA 95: 6947-6952.

6. Wekerle, T., J. Kurtz, H. Ito, J. V. Ronquillo, V. Dong, G. Zhao, J. Shaffer, M. H. Sayegh, and M. Sykes. 2000. Allogeneic bone marrow transplantation with costimulatory blockade induces macrochimerism and tolerance without cytoreductive host treatment. Nat. Med. 6: 464-469.

7. Seung, E., J. P. Mordes, A. A. Rossini, and D. L. Greiner. 2003. Hematopoietic chimerism and central tolerance created by peripheral-tolerance induction without myeloablative conditioning. J. Clin. Invest. 112: 795-808.

8. Devine, S. M., and R. Hoffman. 2000. Role of mesenchymal stem cells in hematopoietic stem cell transplantation. Curr. Opin. Hematol. 7: 358-363.

9. Muguruma, Y., T. Yahata, H. Miyatake, T. Sato, T. Uno, J. Itoh, S. Kato, M. Ito, T. Hotta, and K. Ando. 2006. Reconstitution of the functional human hematopoietic microenvironment derived from human mesenchymal stem cells in the murine bone marrow compartment. Blood 107: 1878-1887.

10. Chen, X., M. A. Armstrong, and G. Li. 2006. Mesenchymal stem cells in immunoregulation. Immunol. Cell Biol. 84: 413-421.

11. Stagg, J. 2006. Immune regulation by mesenchymal stem cells: two sides to the coin. Tissue Antigens 69: 1-9.

12. Le Blanc, K., C. Tammik, K. Rosendahl, E. Zetterberg, and O. Ringden. 2003. HLA expression and immunologic properties of differentiated and undifferentiated mesenchymal stem cells. Exp. Hematol. 31: 890-896.

13. Di Nicola, M., C. Carlo-Stella, M. Magni, M. Milanesi, P. D. Longoni, P. Matteucci, S. Grisanti, and A. M. Gianni. 2002. Human bone marrow stromal cells suppress T-lymphocyte proliferation induced by cellular or nonspecific mitogenic stimuli. Blood 99: 3838-3843.

14. Potian, J. A., H. Aviv, N. M. Ponzio, J. S. Harrison, and P. Rameshwar. 2003. Veto-like activity of mesenchymal stem cells: functional discrimination between cellular responses to alloantigens and recall antigens. J. Immunol. 171: 3426-3434.

15. Majumdar, M. K., M. Keane-Moore, D. Buyaner, W. B. Hardy, M. A. Moorman, and J. D. Mosca. 2003. Characterization and functionality of cell surface molecules on human mesenchymal stem cells. J. Biomed. Sci. 10: 228-241.

16. Tse, W., J. D. Pendleton, W. M. Beyer, M. C. Egalka, and E. C. Guinan. 2003 Suppression of allogeneic T-cell proliferation by human marrow stromal cells: implication in transplantation. Transplantation 75: 389-397.

17. Ryan, J. M., F. P. Barry, J. M. Murphy, and B. P. Mahon. 2005. Mesenchymal stem cells avoid allogeneic rejection. J. Inflamm. 2: 8.

18. Rasmusson, I., O. Ringden, B. Sundberg, and K. Le Blanc. 2005. Mesenchymal stem cells inhibit lymphocyte proliferation by mitogens and alloantigens by different mechanisms. Exp. Cell Res. 305: 33-41.

19. Le Blanc, K., L. Tammik, B. Sundberg, S. E. Haynesworth, and O. Ringden. 2003. Mesenchymal stem cells inhibit and stimulate mixed lymphocyte cultures and mitogenic responses independently of the major histocompatibility complex. Scand. J. Immunol. 57: 11-20.

20. Batten, P., P. Sarathchandra, J. W. Antoniw, S. S. Tay, M. W. Lowdell, P. M. Taylor, and M. H. Yacoub. 2006. Human mesenchymal stem cells induce $\mathrm{T}$ cell anergy and downregulate $\mathrm{T}$ cell alloresponses via the TH2 pathway: relevance to tissue engineering human heart valves. Tissue Eng. 12: 2263-2273.

21. Bartholomew, A., C. Sturgeon, M. Siatskas, K. Ferrer, K. McIntosh, S. Patil, W. Hardy, S. Devine, D. Ucker, R. Deans, et al. 2002. Mesenchymal stem cells suppress lymphocyte proliferation in vitro and prolong skin graft survival in vivo. Exp. Hematol. 30: 42-48.

22. Inoue, S., F. Popp, G. Koehl, P. Piso, H. Schlitt, E. Geissler, and M. Dahlke. 2006. Immunomodulatory effects of mesenchymal stem cells in a rat organ transplant model. Transplantation 81: 1589-1595.

23. Djouad, F., P. Plence, C. Bony, P. Tropel, F. Apparailly, J. Sany, D. Noel, and C. Jorgensen. 2003. Immunosuppressive effect of mesenchymal stem cells favors tumor growth in allogeneic animals. Blood 102: 3837-3844

24. Augello, A., R. Tasso, S. M. Negrini, A. Amateis, F. Indiveri, R. Cancedda, and G. Pennesi. 2005. Bone marrow mesenchymal progenitor cells inhibit lymphocyte proliferation by activation of the programmed death 1 pathway. Eur. J. Immunol. 35: 1482-1490.

25. Krampera, M., S. Glennie, J. Dyson, D. Scott, R. Laylor, E. Simpson, and F. Dazzi. 2003. Bone marrow mesenchymal stem cells inhibit the response of naive and memory antigen-specific T cells to their cognate peptide. Blood 101: 3722-3729.

26. Glennie, S., I. Soeiro, P. Dyson, E. Lam, and F. Dazzi. 2005. Bone marrow mesenchymal stem cells induce division arrest anergy of activated T cells. Blood 105: 2821-2827.

27. Li, H., Z. K. Guo, Z. K. Li, C. M. Hou, P. H. Tang, and N. Mao. 2007. Functional and phenotypic alteration of intrasplenic lymphocytes affected by mesenchymal stem cells in a murine allosplenocyte transfusion model. Cell Transplant. 16 $85-95$

28. Le Blanc, K., I. Rasmusson, B. Sundberg, C. Gotherstrom, M. Hassan, M. Uzunel, and O. Ringden. 2004. Treatment of severe acute graft-versus-host disease with third party haploidentical mesenchymal stem cells. Lancet 363: $1439-1441$.

29. Le Blanc, K., F. Frassoni, L. Ball, F. Locatelli, H. Roelofs, I. Lewis, E. Lanino, B. Sundberg, M. E. Bernardo, M. Remberger, et al. 2008. Mesenchymal stem cells for treatment of steroid-resistant, severe, acute graft-versus-host disease: a phase II study. Lancet 371: 1579-1586.

30. Zappia, E., S. Casazza, E. Pedemonte, F. Benvenuto, I. Bonanni, E. Gerdoni, D. Giunti, A. Ceravolo, F. Cazzanti, F. Frassoni, et al. 2005. Mesenchymal stem cells ameliorate experimental autoimmune encephalomyelitis inducing T-cell anergy. Blood 106: 1755-1761.

31. Zhou, H. P., D. H. Yi, S. Q. Yu, G. C. Sun, Q. Cui, H. L. Zhu, J. C. Liu, J. Z. Zhang, and T. J. Wu. 2006. Administration of donor-derived mesenchymal stem cells can prolong the survival of rat cardiac allograft. Transplant. Proc. 38: 3046-3051.

32. Chabannes, D., M. Hill, E. Merieau, J. Rossignol, R. Brion, J. P. Soulillou, I. Anegon, and M. C. Cuturi. 2007. A role for heme oxygenase-1 in the immunosuppressive effect of adult rat and human mesenchymal stem cells. Blood 110: 3691-3694.

33. Morigi, M., B. Imberti, C. Zoja, D. Corna, S. Tomasoni, M. Abbate, D. Rottoli, S. Angioletti, A. Benigni, N. Perico, et al. 2004. Mesenchymal stem cells are renotropic, helping to repair the kidney and improve function in acute renal failure. J. Am. Soc. Nephrol. 15: 1794-1804.

34. Corry, R., H. Winn, and P. Russell. 1973. Primarily vascularized allografts of hearts in mice. Transplantation 16: 343-350.

35. Fandrich, F., X. Lin, G. Chai, M. Schultze, D. Ganten, M. Bader, J. Holle, D. Huang, R. Parwaresch, N. Zavazava, and B. Binas. 2002. Preimplantationstage stem cells induce long-term allogeneic graft acceptance without supplementary host conditioning. Nat. Med. 8: 171-178.

36. Zhang, Y., R. Yasumizu, K. Sugiura, F. Hashimoto, Y. Amoh, Z. Lian, Cherry, N. Nishio, and S. Ikehara. 1994. Fate of allogeneic or syngeneic cells in intravenous or portal vein injection: possible explanation for the mechanism of tolerance induction by portal vein injection. Eur. J. Immunol. 24: 1558-1565.

37. Crispe, I., M. Giannandrea, I. Klein, B. John, B. Sampson, and S. Wuensch. 2006. Cellular and molecular mechanisms of liver tolerance. Immunol. Rev. 213: 101-108.

38. Phinney, D. G., G. Kopen, D. J. Isaacson, and D. J. Prockop. 1999. Plastic adherence stromal cells from the bone marrow of commonly used strains of inbred mice: variation in yield, growth, and differentiation. J. Cell Biochem. 72: $570-585$.

39. Tropel, P., D. Noel, N. Platet, P. Legrand, A. L. Benabid, and F. Berger. 2004. Isolation and characterization of mesenchymal stem cells from adult mouse bone marrow. Exp. Cell Res. 295: 395-406.

40. Qin, S., S. P. Cobbold, H. Pope, J. Elliott, D. Kioussis, J. Davies, and H. Waldmann. 1993. "Infectious" transplantation tolerance. Science 259: 974-977.

41. Walsh, P. T., D. K. Taylor, and L. A. Turka. 2004. Tregs and transplantation tolerance. J. Clin. Invest. 114: 1398-1403.

42. Aggarwal, S., and M. F. Pittenger. 2005. Human mesenchymal stem cells modulate allogeneic immune cell responses. Blood 105: 1815-1822.

43. Meisel, R., A. Zibert, M. Laryea, U. Gobel, W. Daubener, and D. Dilloo. 2004. Human bone marrow stromal cells inhibit allogeneic T-cell responses by indoleamine 2,3-dioxygenase-mediated tryptophan degradation. Blood 103: 4619-4621.

44. Sato, K., K. Ozaki, I. Oh, A. Meguro, K. Hatanaka, T. Nagai, K. Muroi, and K. Ozawa. 2007. Nitric oxide plays a critical role in suppression of T-cell proliferation by mesenchymal stem cells. Blood 109: 228-234.

45. Horwitz, E. M., P. L. Gordon, W. K. K. Koo, J. C. Marx, M. D. Neel, R. Y. McNall, L. Muul, and T. Hofmann. 2002. Isolated allogeneic bone marrowderived mesenchymal stem cells engraft and stimulate growth in children with osteogenesis imperfecta: Implication for cell therapy of bone. Proc. Natl. Acad. Sci. USA 99: 8932-8937.

46. Devine, S. M., C. Cobbs, M. Jennings, A. Bartholomew, and R. Hoffman. 2003. Mesenchymal stem cells distribute to a wide range of tissues following systemic infusion into nonhuman primate. Blood 101: 2999-3001.

47. Gao, J., J. E. Dennis, R. F. Muzic, M. Lundberg, and A. I. Caplan. 2001. The dynamic in vivo distribution of bone marrow-derived mesenchymal stem cells after infusion. Cells Tissues Organs 169: 12-20.

48. Barbash, I. M., J. Chouraqui, J. Baron, M. S. Feinberg, S. Etzion, A. Tessone, L. Miller, E. Guetta, D. Zipori, L. H. Kedes, et al. 2003. Systemic delivery of bone marrow-derived mesenchymal stem cells to the infarcted myocardium: feasibility, cell migration, and body distribution. Circulation 108: 863-868.

49. Gorczynski, R. M., and W. Holmes. 1991. Specific manipulation in vivo of immunity to skin grafts bearing multiple minor histocompatibility differences. Immunol. Lett. 27: 163-171.

50. Ikebukuro, K., Y. Adachi, Y. Yamada, S. Fujimoto, Y. Seino, H. Oyaizu, K. Hioki, and S. Ikehara. 2002. Treatment of streptozotocin-induced diabetes mellitus by transplantation of islet cells plus bone marrow cells via portal vein in rats. Transplantation 73: 512-518.

51. Goss, J. A., Y. Nakafusa, and M. W. Flye. 1992. Intrathymic injection of donor alloantigens induces donor-specific vascularized allograft tolerance without immunosuppression. Ann. Surg. 216: 409-416.

52. Tokita, D., H. Ohdan, T. Onoe, H. Hara, Y. Tanaka, and T. Asahara. 2005. Liver sinusoidal endothelial cells contribute to alloreactive T-cell tolerance induced by portal venous injection of donor splenocytes. Transpl. Int. 18: 237-245.

53. Kamei, T., M. P. Callery, and M. W. Flye. 1990. Kupffer cell blockade prevents induction of portal venous tolerance in rat cardiac allograft transplantation. J. Surg. Res. 48: 393-396.

54. Beyth, S., Z. Borovsky, D. Mevorach, M. Liebergall, Z. Gazit, H. Aslan, E. Galun, and J. Rachmilewitz. 2005. Human mesenchymal stem cells alter antigen-presenting cell maturation and induce T-cell unresponsiveness. Blood 105: 2214-2219. 
55. Nauta, A. J., A. B. Kruisselbrink, E. Lurvink, R. Willemze, and W. E. Fibbe. 2006. Mesenchymal stem cells inhibit generation and function of both CD34 ${ }^{+}$derived and monocyte-derived dendritic cells. J. Immunol. 177: 2080-2087.

56. Cassis, L., S. Aiello, and M. Noris. 2005. Natural versus adaptive regulatory T cells. Contrib. Nephrol. 146: 121-131.

57. Cavinato, R. A., F. Casiraghi, N. Azzollini, P. Cassis, D. Cugini, M. Mister, A. Pezzotta, S. Aiello, G. Remuzzi, and M. Noris. 2005. Pretransplant donor peripheral blood mononuclear cells infusion induces transplantation tolerance by generating regulatory T cells. Transplantation 79: 1034-1039.

58. Lechler, R. I., O. A. Garden, and L. A. Turka. 2003. The complementary roles of deletion and regulation in transplantation tolerance. Nat. Rev. Immunol. 3: $147-158$.

59. Kingsley, C. I., M. Karim, A. R. Bushell, and K. J. Wood. 2002. CD $25^{+}$CD $4^{+}$ regulatory $\mathrm{T}$ cells prevent graft rejection: CTLA-4- and IL-10-dependent immunoregulation of alloresponses. J. Immunol. 168: 1080-1086.

60. Maccario, R., M. Podesta, A. Moretta, A. Cometa, P. Comoli, D. Montagna, L. Daudt, A. Ibatici, G. Piaggio, S. Pozzi, et al. 2005. Interaction of human mesenchymal stem cells with cells involved in alloantigen-specific immune re- sponse favors the differentiation of $\mathrm{CD} 4^{+} \mathrm{T}$-cell subsets expressing a regulatory/ suppressive phenotype. Haematologica 90: 516-525.

61. Di Ianni, M., B. Del Papa, M. De Ioanni, L. Moretti, E. Bonifacio, D. Cecchini, P. Sportoletti, F. Falzetti, and A. Tabilio. 2008. Mesenchymal cells recruit and regulate T regulatory cells. Exp. Hematol. 36: 309-318.

62. Sanchez-Fueyo, A., S. Sandner, A. Habicht, C. Mariat, J. Kenny, N. Degauque, X. X. Zheng, T. B. Strom, L. A. Turka, and M. H. Sayegh. 2006. Specificity of $\mathrm{CD} 4{ }^{+} \mathrm{CD} 25^{+}$regulatory $\mathrm{T}$ cell function in alloimmunity. J. Immunol. 176: 329-334.

63. Joffre, O., T. Santolaria, D. Calise, T. Al Saati, D. Hudrisier, P. Romagnoli, and J. van Meerwijk. 2008. Prevention of acute and chronic allograft rejection with $\mathrm{CD} 4{ }^{+} \mathrm{CD} 25^{+}$Foxp $^{+}$regulatory T lymphocytes. Nat. Med. 14: 88-92.

64. Chan, J. L., K. C. Tang, A. P. Patel, L. M. Bonilla, N. Pierobon, N. M. Ponzio, and P. Rameshwar. 2006. Antigen-presenting property of mesenchymal stem cells occurs during a narrow window at low levels of interferon- $\gamma$. Blood 107: 4817-4824.

65. Umemura, A., A. P. Monaco, and T. Maki. 2000. Donor MHC class II antigen is essential for induction of transplantation tolerance by bone marrow cells. J. Immunol. 164: 4452-4457. 


\section{CHAPTER 3}

\section{Autologous Mesenchymal Stromal Cells and Kidney Transplantation:}

\section{A Pilot Study of Safety and Clinical Feasibility}

N. Perico, F. Casiraghi, M. Introna, E. Gotti, M. Todeschini, R.A. Cavinato, C. Capelli,

A. Rambaldi, P. Cassis, P. Rizzo, M. Cortinovis, M. Marasà, J Golay, M. Noris and G. Remuzzi

published in: Clinical Journal of American Society of Nephrology 2011; 6: 412-422 


\title{
Autologous Mesenchymal Stromal Cells and Kidney Transplantation: A Pilot Study of Safety and Clinical Feasibility
}

\author{
Norberto Perico, ${ }^{*+}$ Federica Casiraghi, ${ }^{*+}$ Martino Introna, ${ }^{* \neq}$ Eliana Gotti, ${ }^{+}$Marta Todeschini, ${ }^{*+}$ \\ Regiane Aparecida Cavinato, ${ }^{*+}$ Chiara Capelli, ${ }^{*}$ Alessandro Rambaldi, ${ }^{\text {S }}$ Paola Cassis, ${ }^{*+}$ Paola Rizzo, ${ }^{+}$ \\ Monica Cortinovis, ${ }^{*+}$ Maddalena Marasà, ${ }^{+}$Josee Golay, ${ }^{\neq}$Marina Noris, ${ }^{*+}$ and Giuseppe Remuzzi ${ }^{*+}$
}

\section{Summary}

Background and objectives Mesenchymal stromal cells (MSCs) abrogate alloimmune response in vitro, suggesting a novel cell-based approach in transplantation. Moving this concept toward clinical application in organ transplantation should be critically assessed.

Design, setting, participants \& measurements A safety and clinical feasibility study (ClinicalTrials.gov, NCT00752479) of autologous MSC infusion was conducted in two recipients of kidneys from living-related donors. Patients were given T cell-depleting induction therapy and maintenance immunosuppression with cyclosporine and mycophenolate mofetil. On day 7 posttransplant, MSCs were administered intravenously. Clinical and immunomonitoring of MSC-treated patients was performed up to day 360 postsurgery.

Results Serum creatinine levels increased 7 to 14 days after cell infusion in both MSC-treated patients. A graft biopsy in patient 2 excluded acute graft rejection, but showed a focal inflammatory infiltrate, mostly granulocytes. In patient 1 protocol biopsy at 1-year posttransplant showed a normal graft. Both MSCtreated patients are in good health with stable graft function. A progressive increase of the percentage of $\mathrm{CD}^{+}{ }^{+} \mathrm{CD} 25^{\text {high }} \mathrm{FoxP}^{+}{ }^{+} \mathrm{CD} 127^{-}$Treg and a marked inhibition of memory CD45RO ${ }^{+} \mathrm{RA}^{-} \mathrm{CD}^{+} \mathrm{T}$ cell expansion were observed posttransplant. Patient $\mathrm{T}$ cells showed a profound reduction of $\mathrm{CD} 8^{+} \mathrm{T}$ cell activity.

Conclusions Findings from this study in the two patients show that MSC infusion in kidney transplant recipients is feasible, allows enlargement of Treg in the peripheral blood, and controls memory CD8 ${ }^{+} \mathrm{T}$ cell function. Future clinical trials with MSCs to look with the greatest care for unwanted side effects is advised.

Clin J Am Soc Nephrol 6: 412-422, 2011. doi: 10.2215/CJN.04950610

\section{Introduction}

Transplant patients rely on life-long immunosuppressive drugs to prevent $\mathrm{T}$ cell activation and graft loss, but are exposed to drug-related complications (1). Induction of immune tolerance would overcome these shortcomings, possibly allowing indefinite graft survival (2). Attempts to translate successful strategies to induce tolerance in animal models to humans have been disappointing (3-5) and only anecdotal examples are available (6). Regulation of specific effector $\mathrm{T}$ cell function might be a suitable strategy to control alloimmune response (7). In this regard, induction protocols including $\mathrm{T}$ cell-depleting agents have been used with the aim of resetting the immune system to promote a tolerance-permissive environment $(4,5)$. The rational for this approach rests on the evidence that transient lymphopenia following $\mathrm{T}$ cell-depleting therapy would result in homeostatic expansion of a unique population of regulatory $\mathrm{T}$ cells (Treg) with potent in vitro and in vivo immunoregulatory effects (8). Nevertheless, in hu- man kidney transplantation T cell-depleting induction therapy with monoclonal anti-CD52 antibody alemtuzumab or polyclonal rabbit antithymocyte globulin (RATG) did not appreciably protect renal transplant recipients from chronic allograft injury and dysfunction (9), despite enhancing circulating Treg count and preserving their suppressive activity $(10,11)$. Recent advances in experimental transplantation have also demonstrated that memory $\mathrm{T}$ cells ultimately compromise the development of transplant tolerance, with the presence of donorspecific memory $\mathrm{T}$ cells often being associated with poor allograft outcome (12).

Bone marrow-derived mesenchymal stromal cells (MSCs) - unique for their immunologic characteristics, such as low immunogenicity and immunoregulatory properties (13) - in vitro increase the percentage of Treg at coculture with T lymphocytes (14) and inhibit the proliferative response of antigen-specific memory $T$ cells $(15,16)$, suggesting a novel cell-based approach for immunotherapy which
*Transplant Research Center "Chiara Cucchi de Alessandri e Gilberto Crespi" and ${ }^{\dagger}$ Department of Immunology and Transplantation, Ospedali Riuniti di Bergamo, "Mario Negri" Institute for Pharmacological Research, Bergamo, Italy; and " Laboratory of Cell Therapy G.

Lanzani and §Department of Haematology, Ospedali Riuniti di Bergamo, Bergamo, Italy

Correspondence: $\mathrm{Dr}$. Giuseppe Remuzzi, "Mario Negri" Institute for Pharmacological Research, Centro Anna Maria Astori, Parco Scientifico Tecnologico Kilometro Rosso, via Stezzano 87, 24126 Bergamo, Italy. Phone: +39035 42131; Fax: +39035 319331.

E-mail: gremuzzi@ marionegri.it 
also targets Treg and memory T cells. By infusing either autologous or donor-derived MSCs in unconditioned mice, we were able to induce tolerance to a semiallogeneic heart transplantation (17).

For clinical studies with MSCs in organ transplantation, however, unwanted side effects of cell infusion must be assessed with the greatest care before planning large efficacy trials for tolerance induction. This particularly for the concern of possible MSC maldifferentiation in vivo and their potential for facilitating the growth of pre-existing but occult tumors $(18,19)$. Although these side effects have been so far observed only in very few experimental animal models (20-22), the question of risk and benefit must be well assessed in pilot clinical studies, especially when MSCs meet additional immunosuppressive drugs. Also the question of whether patients should be treated with autologous, donor-derived, or third-party MSCs remains to be addressed. Applying recipient-unrelated MSCs in organ transplantation at this point in time may raise objections because they may cause recipient sensitization. To prevent activation of immune cells and sensitization of transplant recipients, the introduction of foreign antigen should be avoided and first pilot studies should thus begin with autologous MSCs, making safety the first objective. Moreover, experimental evidence indicates that autologous MSCs are equally capable of inhibiting the antidonor immune response as donor-derived MSCs (17).

Here we have extended our experimental work to define the safety and clinical feasibility of the autologous MSC approach in two human recipients of kidneys from living-related donors (ClinicalTrials. gov Identifier: NCT00752479).

\section{Materials and Methods \\ Patients}

A 22-year-old man (patient 1) on hemodialysis due to ESRD of unknown etiology received a renal transplant from his mother, mismatched for two HLA haplotypes (one mismatch on HLA-A and one on HLA-B whereas HLA-DR alleles were coincidental) (Figure 1A).

A second 34-year-old man (patient 2) on ESRD secondary to IgA nephropathy received a pre-emptive renal transplant from his father, mismatched for two HLA haplotypes (one mismatch on HLA-A and one on HLA-B while HLA-DR alleles were coincidental) (Figure 1A). Four months before transplantation both of them underwent sterna bone marrow aspiration under local anesthesia. MSCs were isolated and ex vivo expanded according to Good-ManufacturingPractice procedures (Cell-Therapy Laboratory "G. Lanzani", Ospedali Riuniti di Bergamo, authorization no. aM-189/2008 Agenzia Italiana del Farmaco, AIFA) $(23,24)$. On day 7 after kidney transplant, autologous MSCs were administered intravenously $\left(1.7 \times 10^{6}\right.$ cells and $2.0 \times 10^{6}$ cells per $\mathrm{kg}$ body weight, respectively) after premedication with chlorphenamine and acetaminophen. Three patients receiving a living-related kidney who were transplanted previ- ously to patients 1 and 2 were taken as the control group. They were given the same induction therapy, but not MSCs (Figure 1A). In all transplant recipients immunophenotyping of peripheral blood $\mathrm{T}$ cell populations and also monitoring of $\mathrm{T}$ lymphocyte function were performed before and up to day 360 postsurgery.

Written informed consent was obtained from all recipients and living donors. All treatment protocols were approved by the Istituto Superiore di Sanità (ISS, Rome, Italy, authorization no. 45253(06)-PRE.21882) and by the Institutional Review Board of the Ospedali Riuniti Bergamo (authorization no. 352, March 18, 2008).

All patients received induction regimen with basiliximab (20 mg intravenous pretransplant and on day 4 posttransplant) and low-dose rabbit antithymocyte globulin (RATG) infusion (thymoglobulin, $0.5 \mathrm{mg} /$ $\mathrm{kg}$, daily from day 0 to day 6 posttransplant) as per center practice (25). Maintenance immunosuppression was with cyclosporine A (CsA, target trough blood levels of 300 to $400 \mathrm{ng} / \mathrm{ml}$ up to day 7 postsurgery, and 100 to $150 \mathrm{ng} / \mathrm{ml}$ at month 5 posttransplantation), mycophenolate mofetil (plasma trough mycophenolic acid [MPA] levels of 0.5 to $1.5 \mu \mathrm{g} / \mathrm{ml}$ ) (26), and steroids. Five hundred milligrams of methylprednisolone were administered before the first RATG infusion to minimize the possible cytokine release reaction related to the antibodies, and continued for 2 more days posttransplant (250 and $125 \mathrm{mg}$, respectively). Subsequently, oral prednisone $(75 \mathrm{mg})$ was administered, which was progressively tapered and discontinued after day 7 postsurgery.

\section{MSC Isolation and Expansion}

MSCs were processed and cultured as previously reported $(23,24)$. In brief, bone marrow aspirates were collected and nucleated cells were plated at 500,000 cells per $\mathrm{cm}^{2}$ in minimum essential medium- $\alpha$ in the presence of $5 \%$ human platelet lysate. The use of human platelet lysate avoids the need of fetal calf serum, which is a source of xenogenic antigens that may induce an adverse immune response. Nonadherent cells were removed after 2 to 3 days and a 50\% medium change was performed twice weekly until $80 \%$ confluence. Then cells were recovered and subsequently replated at 200 cells per $\mathrm{cm}^{2}$ and cultured for an additional 12 days. The cells were classified as MSCs based on their ability to differentiate into bone, fat, and cartilage and by flow cytometric analysis (positive for CD44, CD29, CD73, HLA-ABC, CD90, and CD105, but negative for CD14, CD34, CD45, and HLA-DR) responding to defined criteria for MSCs recently stated by the International Society of Cell Therapy (ISCT) (27). The final product was characterized with respect to viability, purity, and therapeutic potential. Because a major concern with MSCs is the potential for malignant transformation, the MSC preparation underwent cytogenetic analysis, which showed a normal karyotype. Safety has been judged on the basis of negativity for all of the tested contam- 
A Patients' characteristics

\begin{tabular}{lccc}
\hline & Patient 1 & Patient 2 & Sim/RATG patients ${ }^{1}$ \\
\cline { 2 - 4 } Age & 22 & 34 & $30 \pm 18$ \\
Gender (M/F) & Male & Male & $1 / 2$ \\
HLA mismatches & & & \\
median (range) & 2 & 2 & $1(0-3)$ \\
Cross-match & negative & negative & $\begin{array}{l}\text { negative } \\
\text { Anti-donor Abs }\end{array}$ \\
\hline
\end{tabular}

1. Data are mean $\pm S D, n=3$

B

Patient \#1
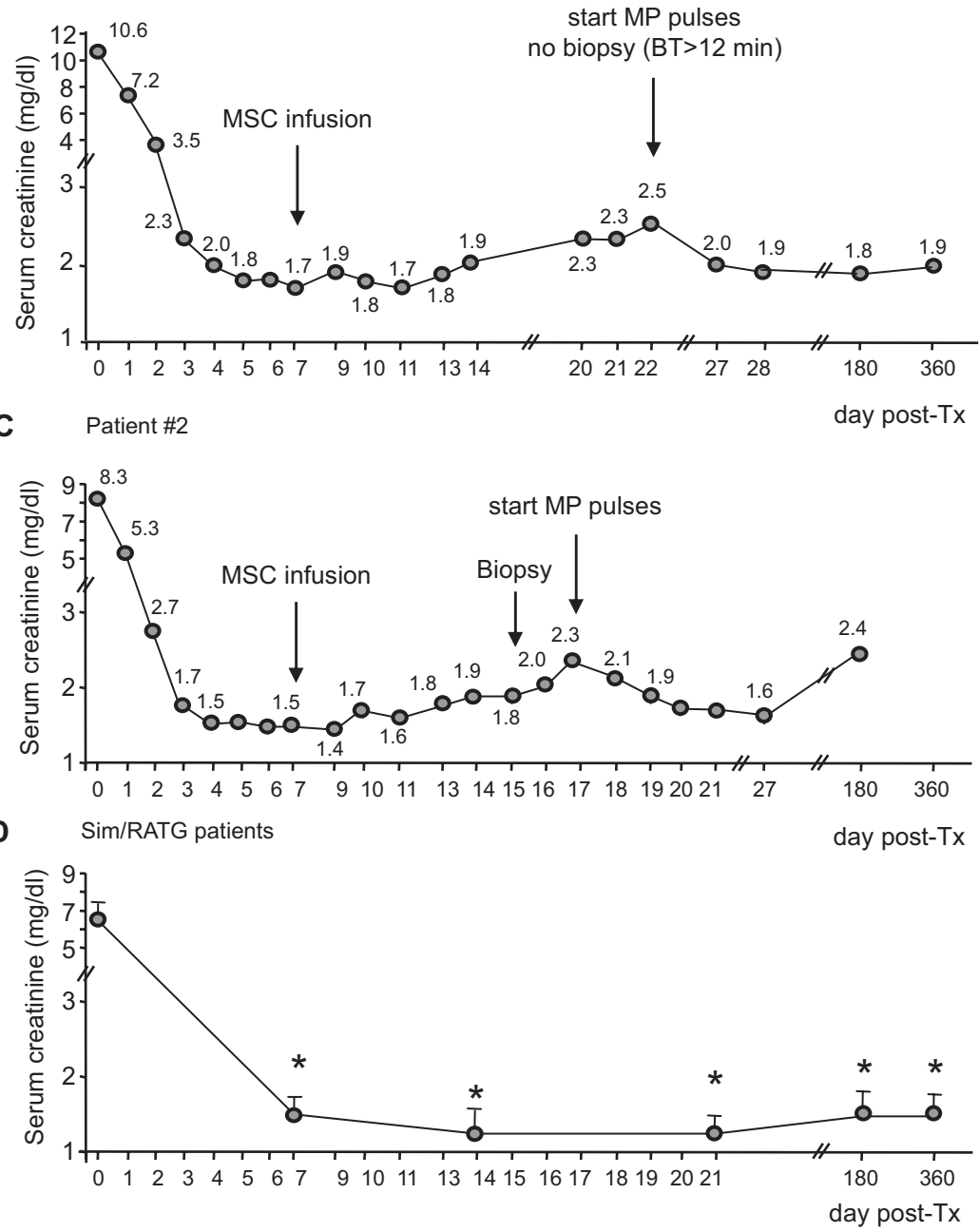

Figure 1. | Characteristics and posttransplant course of serum creatinine in patients given MSCs and in control patients: Patients' characteristics (A) and profile of serum creatinine levels before and after MSC infusion in patient 1 (B) and patient 2 (C) and profile of serum creatinine in Sim/RATG patients (D) during the first year after kidney transplantation are shown. Sim/RATG patients are control living donor-kidney transplant recipients given the same induction therapy but not MSCs. Data are means \pm SEM; $* P<0.05$ versus time 0 .

inants and lack of genetic lesions at cytogenetic analysis. Criteria for MSC batch release were the following: expression of CD105, CD73, and CD90 >70\%, expression of CD34, CD45, and CD14 $<10 \%$; negative for mycoplasma, Gram-positive, and Gram-negative bacteria and fungi; endotoxin below $5 \mathrm{EU} / \mathrm{kg}$; viability $>80 \%$. MSCs were frozen in liquid nitrogen until the day of the infusion into the kidney transplant recipient (see Supplemental Text).

\section{Phenotypic and Functional Immunological Assays}

To establish the ideal timing for MSC infusion, we first assessed in vitro whether RATG binds to MSC and affects their inhibitory properties on peripheral blood mononuclear cell (PBMC) proliferation. Immunophenotyping of peripheral blood T cell subpopulations was monitored by FACS analysis (10). Alloimmune response against donor and third-party antigens were assessed by ELISPOT for IFN- $\gamma$ (10) 
and for Granzyme-B and by cell-mediated lympholysis. Anti-HLA class I and II antibodies were sequentially monitored by means of flow-panel reactive antibody assay.

\section{Histology and Immunohistochemistry}

Paraffin-embedded sections of kidney tissue stained with Massons trichrome, hematoxylin and eosin, and periodic acid-Schiff were evaluated by an independent pathologist. Graft infiltrating cells, MSC localization, and complement deposition were assessed by immunofluorescence or immunoperoxidase technique (see Supplemental Text).

\section{Statistical Analyses}

Variations in serum creatinine concentration, peripheral blood $\mathrm{CD}^{+}$and $\mathrm{CD}^{+}{ }^{+} \mathrm{T}$ cell counts, percentages of $\mathrm{T}$ cell subpopulation, immunologic assay data from control living donor-kidney transplant recipients given the same induction therapy but not MSCs (Sim/RATG patients) were assessed by ANOVA for repeated measures. The statistical significance level was defined as $P<0.05$.

\section{Results \\ In Vitro Pretransplant Studies}

In culture medium RATG bound in a dose-dependent manner to human MSCs, with $85 \% \pm 13 \%$ and $10 \% \pm 8 \%$ binding at the antibody concentrations of 5 and $0.5 \mu \mathrm{g}$ per $10^{6}$ cells, respectively (Figure 2A). These concentrations are expected to be achieved in vivo in kidney recipients given $0.5 \mathrm{mg} / \mathrm{kg}$ RATG at day 0 (after the first RATG dose) and day 7 ( 24 hours after the last RATG dose) posttransplant, respectively. Conversely, $>95 \%$ of PBMCs bound RATG independently of the antibody concentration in the medium (Figure 2B). To confirm these findings, we exposed MSCs to serum from RATG-treated kidney transplant patients taken 7 and 14 days postsurgery. We found a very low percentage of RATG bound to MSCs compared with $>70 \%$ of RATG bound to PBMCs (Figure 2, C and D). After exposure to patients' serum, MSC viability ranged from $88 \%$ to $100 \%$ (by trypan blue dye exclusion). Moreover, the minimal RATG binding to MSCs after exposure to patients' serum drawn at day 7 posttransplant did not impair their ability to inhibit MLR T cell proliferation (Figure 2E). Incubation of MSCs with methylprednisolone (MP), CsA, or MPA did not significantly affect their capability to inhibit $\mathrm{T}$ cell proliferation in response to anti-CD3/ CD28 mAbs (Figure 2F). Of note, MPA at the highest concentration synergized with MSCs in further inhibiting $\mathrm{T}$ cell proliferation.

On the basis of these in vitro findings, MSC infusion was set at day 7 after kidney transplantation to minimize any possible depleting effect of RATG on MSCs in vivo.

\section{Clinical Course}

In patient 1 renal function rapidly improved posttransplantation (Figure 1B). On the morning of the autologous MSC infusion, serum creatinine was $1.7 \mathrm{mg} / \mathrm{dl}$, which fluctuated in the following days between 1.7 and $1.9 \mathrm{mg} / \mathrm{dl}$. From day 14 onward, a mild progressive increase in serum creatinine was observed (Figure 1B). Renal ultrasound showed a slightly increased resistivity index (0.79); blood CsA trough levels were in the therapeutic range. No anti-HLA alloantibodies were detected. Graft biopsy was not performed because of a substantially prolonged bleeding time, and MP pulses were started for the clinical suspect of graft rejection (Figure 1B). Corticosteroid was then tapered and continued at the maintenance dose $(8 \mathrm{mg} / \mathrm{d})$. Renal function slowly recovered. At day 180 posttransplantation allograft function remained stable (serum creatinine $1.8 \mathrm{mg} / \mathrm{dl}$ ). A protocol biopsy at 1 year posttransplantation showed no signs of acute rejection nor chronic allograft injury. Serum creatinine was $1.93 \mathrm{mg} / \mathrm{dl}$ and measured GFR (28) was $48.41 \mathrm{ml} / \mathrm{min}$ per $1.73 \mathrm{~m}^{2}$. CsA and MPA trough levels were within the anticipated ranges. Thereafter, the corticosteroid was gradually tapered and treatment discontinued. The patient is in good health with stable graft function.

In patient 2 the early postoperative course was characterized by rapid improvement of renal function (Figure 1C). Before autologous MSC infusion serum creatinine was $1.49 \mathrm{mg} / \mathrm{ml}$ and then graft function progressively deteriorated. On day 15 posttransplant a kidney biopsy was performed, which showed a slight aspecific inflammatory infiltrate not consistent with acute graft rejection. Because serum creatinine further increased up to 2.34 $\mathrm{mg} / \mathrm{dl}$, intravenous pulses of MP were started. After being tapered, corticosteroid was maintained at the dose of $8 \mathrm{mg} / \mathrm{d}$. Renal function transiently improved, thereafter stabilizing at serum creatinine levels of 2.0 to $2.3 \mathrm{mg} / \mathrm{dl}$. A routine abdomen ultrasonography 2 months posttransplantation disclosed two solid nodular images in the right native kidney of 1 and $2 \mathrm{~cm}$, respectively (of note, small cortical cysts bilaterally on native kidneys were reported pretransplant; see Supplemental Figure 1) subsequently confirmed by angio-computed tomography (CT) scan evaluation. On the basis of the anticipated neoplastic nature of the nodular hyperdense lesions at CT scan, the patient underwent bilateral nephrectomy of native kidneys. Histologic examination showed dual renal hemangiomas in the right native kidney. Hemangioma was histologically defined by the positivity for Factor VIII, CD34, and CD31 expression and negativity for CD10, CK CAM 5.2, and CK 7 expression. Proliferative index by Ki67 staining was $10 \%$ to $15 \%$. The surgery and the postoperative period were uneventful without worsening of kidney graft function. At 6 months posttransplantation the patient was in good health with stable graft function (serum creatinine $2.3 \mathrm{mg} / \mathrm{dl}$, GFR $38.9 \mathrm{ml} / \mathrm{min}$ per $\left.1.73 \mathrm{~m}^{2}\right)$. In control recipients of a living-related kidney $(n=3)$ given the same induction therapy 

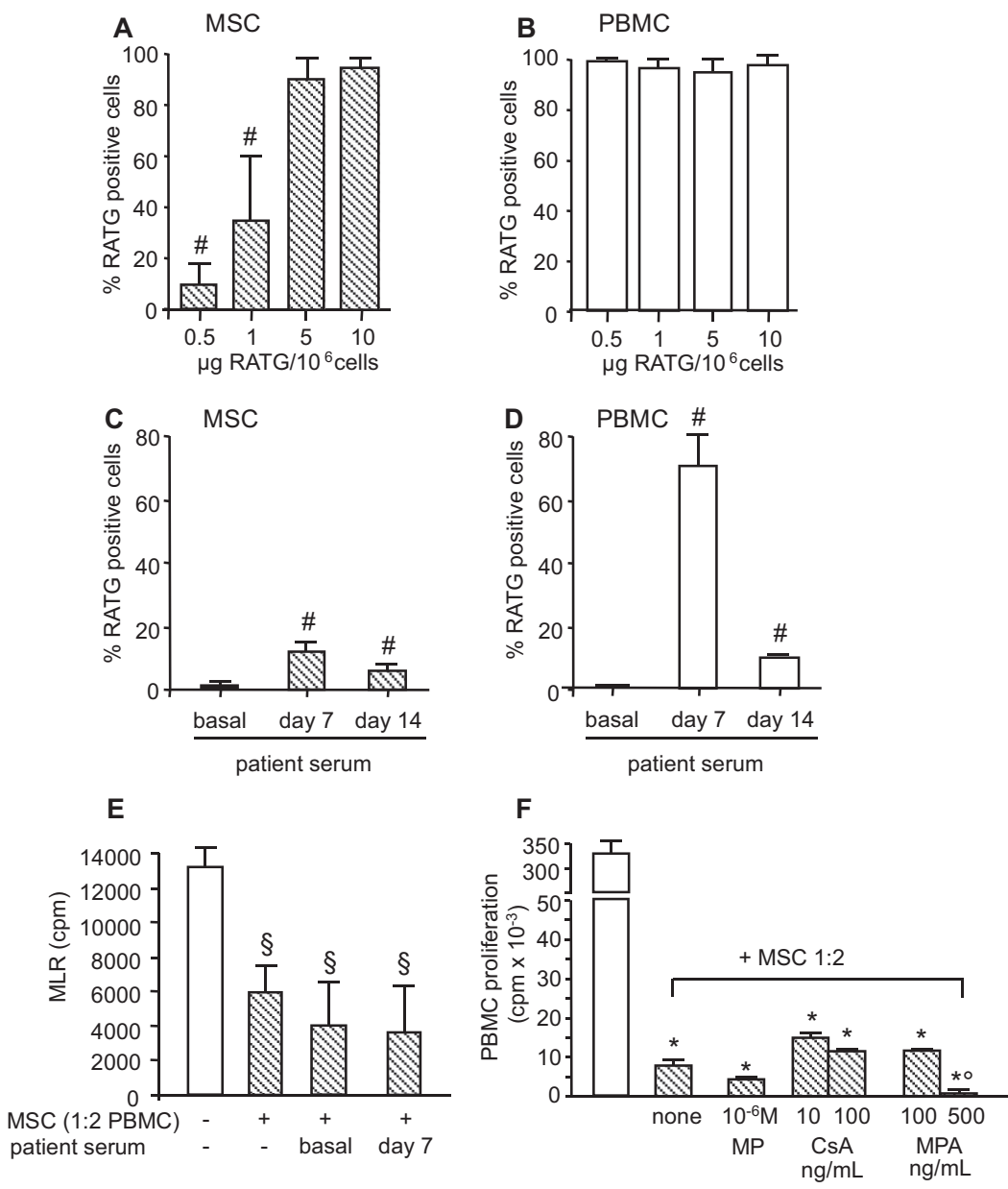

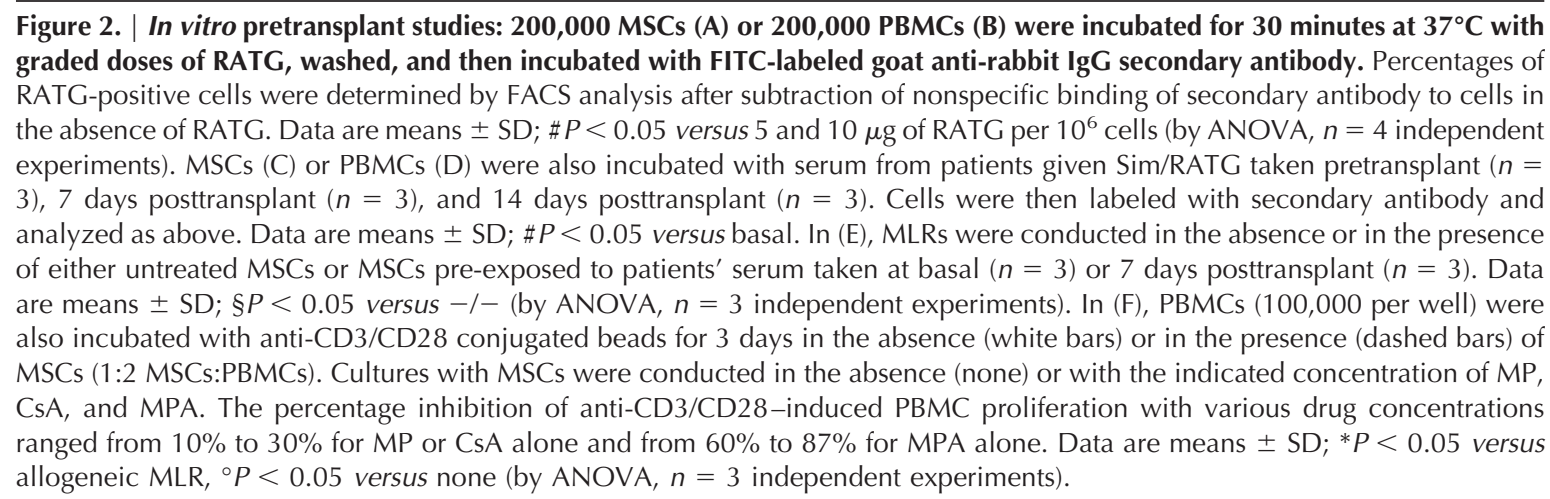

but not MSCs, serum creatinine levels at 180 and 360 days were $1.5 \pm 0.3$ and $1.6 \pm 0.2 \mathrm{mg} / \mathrm{dl}$, respectively (Figure 1D). No acute rejection episodes occurred in these control patients during the 1-year follow-up.

\section{Histology and Immunohistochemistry}

The protocol biopsy from patient 1 showed findings within normal limits, except for mild neutrophil infiltrate (Figure 3A). MSCs in the graft were negligible (Figure 3D).

Early biopsy of patient 2 showed focal inflammatory cell infiltrate. Intragraft $\mathrm{CD}^{+}, \mathrm{CD}^{+} \mathrm{T}$ cells,
$\mathrm{CD}_{14}{ }^{+}$monocytes, CD20 ${ }^{+} \mathrm{B}$ cells, and $\mathrm{CD} 68^{+}$macrophages were very low as compared with those in control kidney graft biopsies from patients given the same immunosuppression who experienced acute cellular rejection (Figure 3A). There were a high number of granulocytes in the peritubular inflammatory infiltrate of patient 2 (Figure 3, A through C). Granulocytes were negligible in the control graft biopsies with acute cellular rejection. Intragraft staining for C3 (mainly peritubular and interstitial localization) was higher in patient 2 than in grafts with early acute cellular rejection (Figure 3, A through C). MSCs were found in the graft 


\begin{tabular}{|c|c|c|c|c|c|c|c|}
\hline & $\begin{array}{l}\mathrm{CD}^{+} \\
\mathrm{T} \text { cells }\end{array}$ & $\begin{array}{l}\mathrm{CD}^{+} \\
\mathrm{T} \text { cells }\end{array}$ & $\begin{array}{c}\mathrm{CD}_{14}^{+} \\
\text {monocytes }\end{array}$ & $\begin{array}{l}\mathrm{CD} 20^{+} \\
\mathrm{B} \text { cells } \\
\text { (cells/field) }\end{array}$ & $\begin{array}{c}\mathrm{CD68}^{+} \\
\text {macrophages }\end{array}$ & $\begin{array}{l}\text { Granulo- } \\
\text { cytes }\end{array}$ & $\begin{array}{c}\text { C3 } \\
\text { (semiquantitative } \\
\text { score) }\end{array}$ \\
\hline $\begin{array}{l}\text { Pt\#2 } \\
\text { Pts with acute }\end{array}$ & & $9.8 \pm 8.1$ & $6.4 \pm 3.7$ & $1.2 \pm 2.2$ & $26 \pm 15$ & $31 \pm 17$ & $0.98 \pm 0.6$ \\
\hline rejections $(n=3)$ & $80 \pm 35$ & $103 \pm 35$ & $39 \pm 12$ & $20 \pm 16$ & $58 \pm 2$ & $5.5 \pm 1.2$ & $0.2 \pm 0.3$ \\
\hline $\begin{array}{l}\text { Pt\#1 } \\
\text { Ctrs: per-protocol } \\
\text { biopsies }(n=3)\end{array}$ & $\begin{array}{l}6.5 \pm 11.3 \\
95+5.6\end{array}$ & $\begin{array}{l}5.5 \pm 8.5 \\
14+7\end{array}$ & $\begin{array}{l}1.6 \pm 2.7 \\
1.7+0.6\end{array}$ & $0.3 \pm 0.7$ & $12.2 \pm 8.4$ & $\begin{array}{c}14 \pm 12 \\
5.8 \pm 4.2\end{array}$ & \\
\hline
\end{tabular}
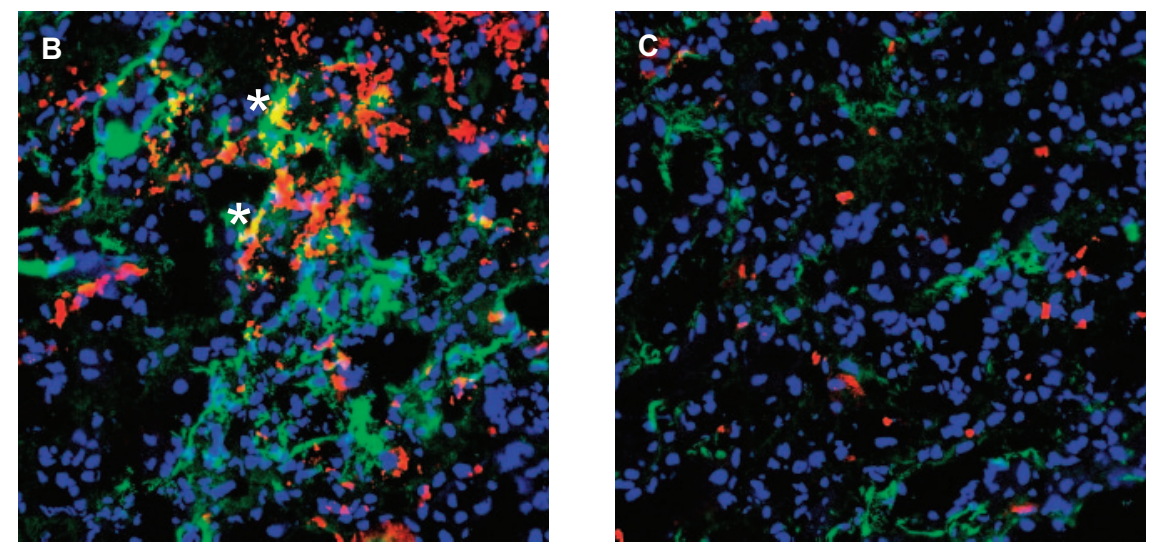

\begin{tabular}{|c|c|}
\hline $\begin{array}{r}\mathrm{CD}^{2} 105^{+} \\
\text {(cells }\end{array}$ & $\begin{array}{l}\text { D44 }{ }^{+} \text {MSCs } \\
\left.3 \mathrm{~mm}^{2}\right)\end{array}$ \\
\hline $\mathrm{Pt}$ 2 & 17 \\
\hline Pt. with acute rejection & 0 \\
\hline $\mathrm{Pt} \# 1$ & 1.33 \\
\hline Ctr: Per-protocol biopsy & 1.36 \\
\hline Ctr: Normal kidneys $(n=4)$ & $1.5+2.6$ \\
\hline
\end{tabular}

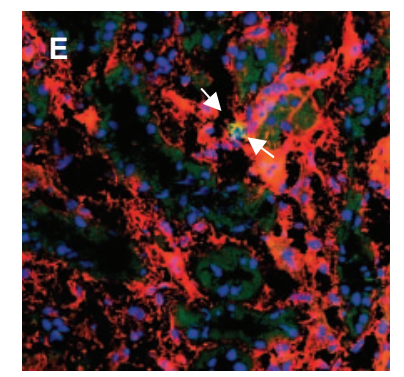

Figure 3. | Characterization of infiltrating cells, complement deposition, and MSCs in kidney grafts. Kidney graft biopsies were taken at day 15 posttransplant in patient 2 because of the suspicion of graft rejection and at day 360 in patient 1 (protocol biopsy). As controls, renal biopsies from patients with acute graft rejection $(n=3)$ within 15 to 100 days postoperative and from patients $(n=3)$ undergoing protocol biopsy at 1 year posttransplant were analyzed. (A) reports counts of intragraft cell infiltrates and score of C3 complement deposition. For both immunofluorescence and immunoperoxidase analyses the number of positive cells were counted in at least 20 to 30 high-power fields. Complement deposition, analyzed by immunofluorescence technique, was scored for intensity (absent, faint, moderate, intense: 0 to 3) in at least 20 to 30 high-power fields. Data for patients 1 and 2 are the mean \pm SD of cell counts in the 20 to 30 high-power fields. (B) and (C) are representative images of intragraft immunostaining for granulocytes (red) and C3 deposition (green) in patient 2 given MSCs and in a patient with acute graft rejection, respectively. In patient 2 granulocytes colocalized with C3 staining $(*)$. Original magnification, $\times 400$. (D) reports intragraft CD105 and CD44 double-positive cell counts in kidney graft biopsies from patients 2 and 1 . As controls, renal biopsies from a patient with acute graft rejection at day 15 postoperative, a patient undergoing protocol biopsy at 1 year posttransplant, and a section of normal renal tissue from patients undergoing nephrectomy for renal carcinoma were analyzed. The total number of double-positive cells counted in $3 \mathrm{~mm}^{2}$ (corresponding to the area of about 30 high-power fields) is reported. (E) is a representative image of intragraft double-positive MSCs for CD105 and CD44 (arrows) in patient 2. Original magnification, $\times 400$.

interstitium of patient 2 , but not in naïve untransplanted kidneys nor in a renal graft with acute cellular rejection (Figure 3, D and E).

\section{Immunophenotyping of Peripheral Blood T \\ Lymphocytes}

In patients 1 and 2, and in control living-related kidney transplant recipients given the same induction therapy (Simulect (Sim)/RATG patients), RATG induced profound $\mathrm{CD}^{+}$and $\mathrm{CD}^{+} \mathrm{T}$ cell depletion (Figure 4, A and B). At 180 and 360 days posttransplant, $\mathrm{CD}^{+} \mathrm{T}$ cells approached pretransplant levels, whereas the $\mathrm{CD}^{+} \mathrm{T}$ cell counts remained lower than pretransplant values both in patients given MSCs and in Sim/RATG patients (Figure 4, A and B).

In patient 1 the percentage of memory $\mathrm{CD} 45 \mathrm{RO}^{+}$ 

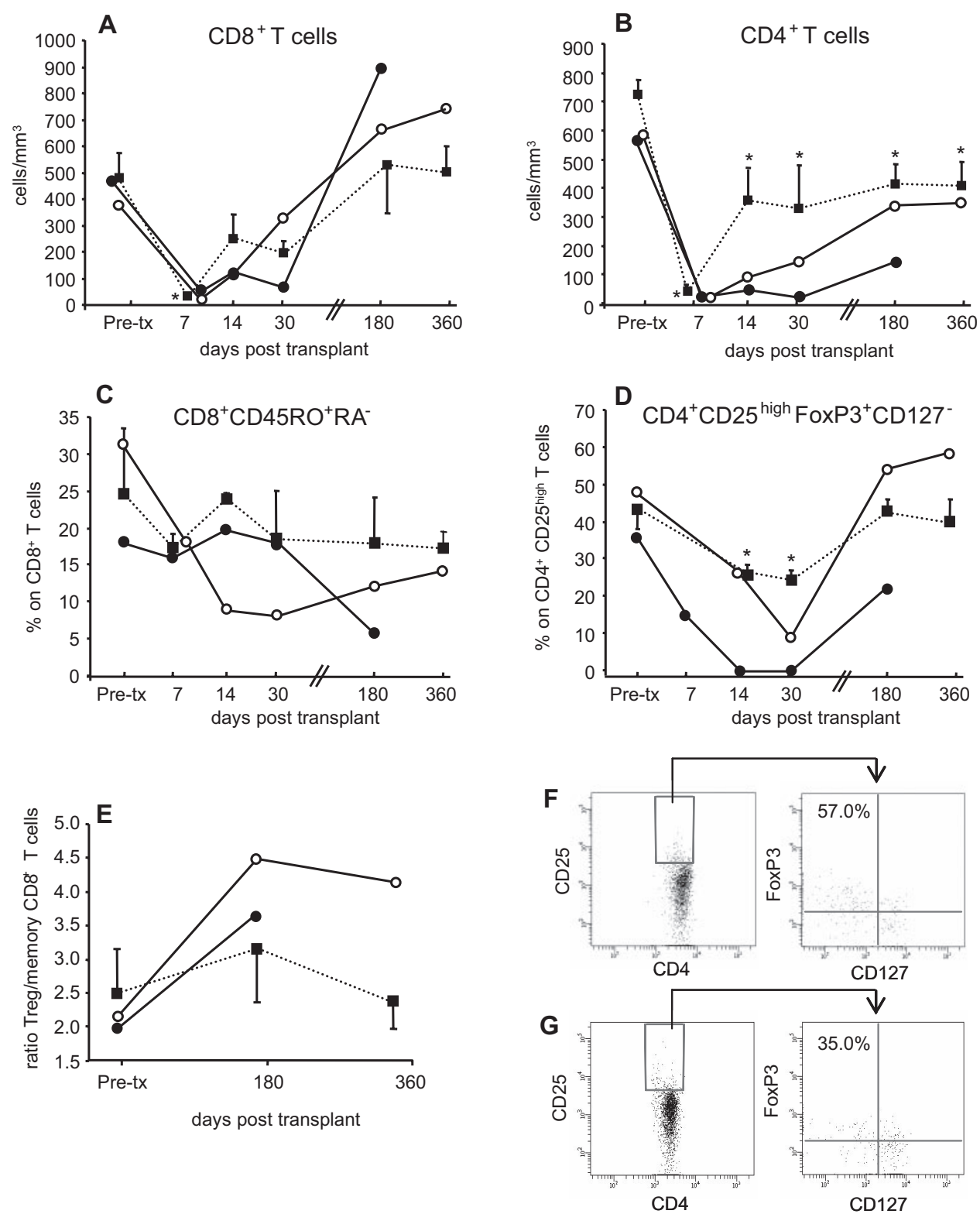

Figure 4. | Kinetics of repopulating $T$ cells in peripheral blood: (A) and (B) show the kinetics of absolute numbers of repopulating $\mathrm{CD8}^{+}$and $\mathrm{CD}^{+}{ }^{+}$cells, respectively, in the peripheral blood of patient $1(\bigcirc)$ and patient $2(\bullet)$ and Sim/RATG patients (living donor-kidney transplant recipients given the same induction therapy but not MSCs, as controls, $\square$ ) from baseline (pretransplant) to day 360 posttransplant. Data are means \pm SEM. ${ }^{*} P<0.05$ versus pretransplant. Percentages of memory $\mathrm{CD}_{5} \mathrm{RO}^{+} \mathrm{RA}^{-} \mathrm{T}$ cells within $\mathrm{CD} 8^{+} \mathrm{T}$ cells $(\mathrm{C})$ and of regulatory CD25 ${ }^{\text {high }} \mathrm{FoxP} 3^{+} \mathrm{CD} 127^{-}$cells within CD4 ${ }^{+} \mathrm{T}$ cells $[\mathrm{Treg}$, (D)] and the ratio of Treg/memory $\mathrm{CD}^{+}{ }^{+}$T cells $(\mathrm{E})$ from patient $1(\mathrm{O})$ and patient $2(\mathbf{O})$ and from Sim/RATG patients $(\mathbf{\square})$ from baseline (pretransplant) to day 360 posttransplant. Data are means \pm SEM. ${ }^{*} P<0.05$ versus pretransplant. Expression of FoxP3 and CD127 antigens (dot plots on the right) by gated $\mathrm{CD}^{+}$and $\mathrm{CD} 25^{\text {high }} \mathrm{T}$ cells (dot plots on the left) at day 360 posttransplant from patient 1 (F) and from a living donor-kidney transplant recipient given the same induction therapy but not MSCs (G) is shown. Numbers in outlined areas indicate percentage of FoxP $3^{+} \mathrm{CD} 127^{-} \mathrm{T}$ cells.

$\mathrm{RA}^{-} \mathrm{CD}^{+} \mathrm{T}$ cells within the total $\mathrm{CD}^{+} \mathrm{T}$ cell population progressively decreased up to day 30 posttransplant and remained lower than pretransplant values thereafter (Figure 4C). In patient 2 the percentage of memory $\mathrm{CD} 45 \mathrm{RO}^{+} \mathrm{RA}^{-} \mathrm{CD} 8^{+} \mathrm{T}$ cells remained comparable to pretransplant values during the first 30 days and then decreased to a very low level at day 180 when the total $\mathrm{CD} 8^{+} \mathrm{T}$ cell counts completely recovered. Conversely, in Sim/RATG patients the percentage of
CD45RO ${ }^{+} \mathrm{RA}^{-} \mathrm{CD} 8^{+} \mathrm{T}$ cells at 30,180 , and 360 days posttransplant was comparable to pretransplant values (Figure 4C).

The percentage of $\mathrm{CD} 4{ }^{+} \mathrm{CD} 25^{\text {high }} \mathrm{FoxP} 3^{+} \mathrm{CD} 127^{-}$regulatory $\mathrm{T}$ cells (Treg) within the total $\mathrm{CD} 4^{+} \mathrm{T}$ cell population markedly decreased during the first 30 days both in patients given MSCs and in Sim/RATG patients (Figure 4D). Thereafter, in patient 1 the percentage of Treg considerably increased, reaching pretransplant values at days 180 and 360 
(Figure 4, D and F). Similarly, in patient 2 a marked increase in the percentage of Treg was found from day 30 onward. In Sim/RATG recipients the percentage of Treg only marginally increased from 30 to 360 days follow-up (Figure 4, D and $\mathrm{G})$. Thus, the ratio of Treg/memory $\mathrm{CD}^{+} \mathrm{T}$ cells was higher in patients given MSCs than in Sim/RATG recipients (Figure $4 \mathrm{E})$.

\section{Ex Vivo Posttransplant Immunologic Assays}

At day 180 posttransplantation, the frequencies of antidonor IFN- $\gamma$-producing memory $\mathrm{T}$ cells (Figure 5A) and antidonor granzyme-B-producing memory $\mathrm{CD}^{+} \mathrm{T}$ cells (29) (Figure 5B) in MSC-treated patients 1 and 2 were comparably lower than pretransplant values. These memory responses were less affected in Sim/RATG controls (Figure 5, A and B). At the same time posttransplant, the cytolytic function of $\mathrm{CD}^{+} \mathrm{T}$ cells was completely abrogated in response to donor antigens and reduced against third-party antigens in patients 1 and 2 (Figure 5C). In Sim/RATG patients the $\mathrm{CD}^{+} \mathrm{T}$ cell cytolytic response toward both donor and third-party antigens did not significantly change as compared with pretransplant values (Figure 5C).
Both patient 1 and patient 2 did not develop anti-HLA class I and II antibodies during the entire follow-up.

\section{Discussion}

The main purpose of the study was to establish the safety and clinical feasibility of cell-based therapy with MSCs in the context of kidney transplantation.

Patients given autologous bone marrow-derived MSCs and kidney transplantation both developed renal insufficiency 7 to 14 days after cell infusion. In patient $1-$ who could not receive a kidney biopsynormal BP, lack of fever, preserved diuresis, no graft pain or tenderness in the presence of expected blood CsA trough levels, normal size and structure of the kidney graft, and no edema of renal pelvis at ultrasound with mild increase in renal resistivity index render a diagnosis of acute rejection extremely unlikely. In patient 2 graft kidney biopsy showed a focal inflammatory infiltrate of renal interstitium, mostly granulocytes with very few $T$ and B cells. These findings were taken to exclude a kidney graft rejection. Instead, CD44 and CD105 double-positive MSCs were found in the graft, bona

A $\quad($ spots $/ 300.000$ cells $)$

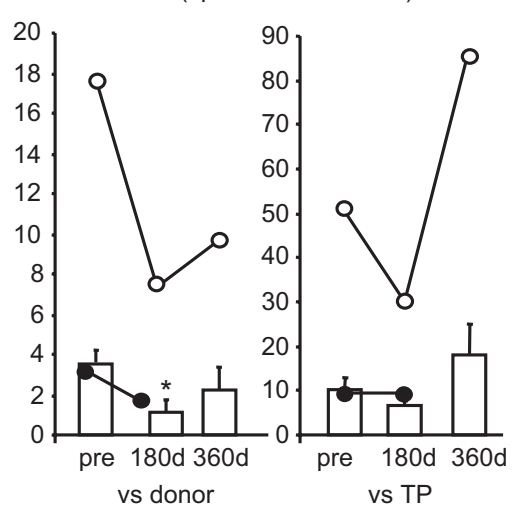

$\mathrm{GrB}$

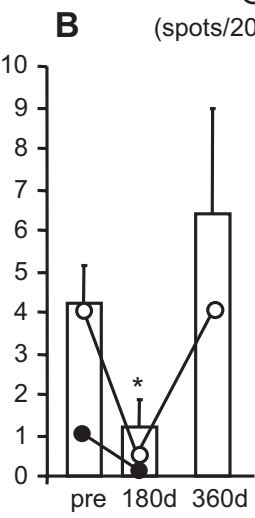

vs donor

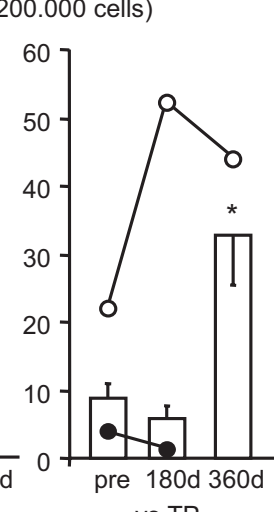

vs TP

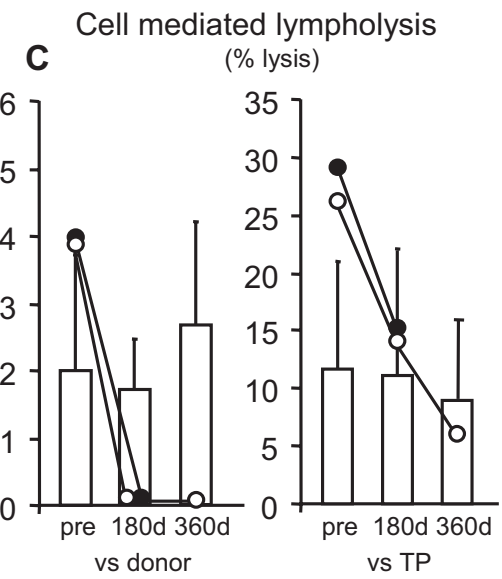

Figure 5. | Immunological assays of the memory T cell response were evaluated by ELISPOT for IFN- $\gamma$ (A) and Granzyme-B (B) and the $\mathrm{CDB}^{+} \mathrm{T}$ cell function by $\mathrm{T}$ cell-mediated lympholysis [percentage-specific lysis at 50:1 effector-target ratio, (C)] toward donor and third-party (TP) antigens on PBMCs taken pretransplant ("pre") and at day 180 and day 360 posttransplant from patient $1(\bigcirc)$ and day 180 from patient $2(\bullet)$, and from Sim/RATG patients (living donor-kidney transplant recipients given the same induction therapy but not MSCs, as controls, white bars). Data are means \pm SEM. ${ }^{*} P<0.05$ versus pretransplant. 
fide from the autologous cells previously infused in the transplant recipient, because no MSCs were documented in untransplanted kidneys or kidney from a patient with early acute graft rejection. Despite the well known anti-inflammatory properties of MSCs (30), the various soluble factors produced by MSCs also include proinflammatory mediators (31-33), which eventually may have contributed to the intragraft recruitment of granulocytes and slow progressive deterioration of renal function. Patients 1 and 2 are in good health with stable graft function after 360 and 180 days posttransplantation, respectively, and are still on follow-up.

In the first clinical trials assessing safety of MSC infusion and possible treatment strategies for graftversus-host disease, ischemic heart disease, spinal cord injury, and systemic lupus erythematosus, none of the patients have reported any significant adverse events associated with MSC transplantation (34-38) (Supplemental Text). Until now, however, there has been no report about the safety of MSC infusion in patients undergoing solid organ transplantation. Maldifferentiation, promotion of tumor growth, and malignant transformation have also been suggested as possible side effects after MSC injection $(18,19)$. Furthermore, some reports showed transformation of human MSCs in culture (39), although at least in two cases a tumor was formed or initiated because of contamination of MSCs with cancer cells $(40,41)$. This observation further underlines the need of careful phenotypic, functional, and genetic characterization of MSCs before cell administration (39). So far, however, tumor-promoting events of MSCs have never been observed in any of more than 500 patients who received this cell therapy (34-38) (Supplemental Text). The contribution of MSCs in the development of hemangiomas on native kidney in patient 2 remains ill defined. Paracrine mechanisms may favor endothelial proliferation, whereas MSC differentiation into adipocytes may contribute to adipogenesis during hemangioma involution (42). However, these lesions could also be accidental findings unrelated to MSC infusion.

In this study, we also wanted to gain initial insight into the in vivo effect of MSC infusion on homeostatic proliferation and function of $\mathrm{T}$ cells after peritransplant $\mathrm{T}$ cell depletion. We found that, in the two patients given MSCs, but not in the control transplant recipients, the percentage of memory $\mathrm{CD} 8^{+} \mathrm{T}$ cells within the overall $\mathrm{CD}^{+} \mathrm{T}$ cell population markedly decreased posttransplant despite the anticipated homeostatic proliferation of the remaining $\mathrm{T}$ cell subsets. The expansion of memory $\mathrm{T}$ cells that escape deletion after lymphoablation represents a major barrier to transplant tolerance. The mechanism responsible for the MSC-mediated suppression of memory $\mathrm{CD}^{+} \mathrm{T}$ cell proliferation remains under investigation. Because MSCs produce TGF- $\beta(14,43)$, which antagonizes the effect of IL-15-relevant to memory $\mathrm{CD}^{+} \mathrm{T}$ cell expansion (44) - the possibility exists that MSCinduced downregulation of homeostatic repopulation of memory $\mathrm{CD} 8^{+} \mathrm{T}$ cells could be a TGF- $\beta$-mediated event.

The change in the memory $\mathrm{CD}^{+} \mathrm{T}$ cell profile in the peripheral blood of the patients given MSCs was associated with a profound reduction in $\mathrm{CD}^{+} \mathrm{T}$ cell activity. These effects were less pronounced in control kidney transplant recipients given the same induction therapy but not MSCs. These findings can be interpreted as to indicate that MSCs have an additional effect beyond that of immunosuppressive drug therapy on the inhibition of memory $\mathrm{CD}^{+} \mathrm{T}$ cell expansion and function in the transplant setting.

Evidence from experimental models of solid organ transplantation suggests that the mechanisms of MSC-induced tolerance include regulatory $\mathrm{T}$ cells $(17,45,46)$. Despite the two patients given MSCs were receiving $\mathrm{CsA}$, known to prevent the development of Treg by the inhibition of IL-2 $(10,47)$, a progressive expansion of Treg was documented posttransplant. This skewed the Treg/memory $\mathrm{CD}^{+} \mathrm{T}$ cell ratio toward the regulatory cells, favoring a protolerogenic environment.

Our findings in the two patients show, for the first time, that MSC infusion in kidney transplant recipients is feasible and restricts memory $\mathrm{T}$ cell expansion while enlarging the Treg population. However, infusion of MSCs after kidney transplantation induced graft dysfunction. The safety concern of posttransplant MSCs anticipated the need to modify the study protocol moving cell infusion pretransplant, an approach being effective in experimental models of solid organ transplantation $(17,48)$. Moreover, we advise for future clinical trials with MSCs to look with the greatest care for the unexpected, especially concerning unwanted side effects.

\section{Acknowledgments}

This study has been partially supported by grants from Fondazione ART per la Ricerca sui Trapianti (Milan, Italy) and from AIRC (Associazione Italiana Ricerca sul Cancro), Piano Regionale Sangue-Lombardia, AIL Bergamo sez "Paolo Belli." Dr. Monica Cortinovis is a recipient of a fellowship from Fondazione Aiuti per la Ricerca sulle Malattie Rare (ARMR), Bergamo, Italy. We are grateful to Dr. Mario Bontempelli for the lymphocyte subset profiling in the peripheral blood and Dr. Aurelio Sonzogni and Mr. Franco Marchetti for histologic processing and analysis of biopsy specimens. The authors are members of the Mesenchymal Stem Cells in Solid Organ Transplantation (MISOT) study group, www.misot.de.

\section{Disclosures}

None.

\section{References}

1. Sayegh $\mathrm{MH}$, Carpenter CB: Transplantation 50 years later-progress, challenges, and promises. $N$ Engl J Med 351: 2761-2766, 2004

2. Sayegh MH, Remuzzi G: Clinical update: Immunosuppression minimisation. Lancet 369: 1676-1678, 2007

3. Millan MT, Shizuru JA, Hoffmann P, Dejbakhsh-Jones S, Scandling JD, Grumet FC, Tan JC, Salvatierra O, 
Hoppe RT, Strober S: Mixed chimerism and immunosuppressive drug withdrawal after HLA-mismatched kidney and hematopoietic progenitor transplantation. Transplantation 73: 1386-1391, 2002

4. Shapiro R, BasGray E, Kahn A, Randhawa P, Basu A, Tan H, Murase N, Zeevi A, Girnita A, Metes D, Ness R, Bass DC, Demetris AJ, Fung JJ, Marcos A, Starzl TE: Kidney transplantation under minimal immunosuppression after pretransplant lymphoid depletion with Thymoglobulin or Campath. J Am Coll Surg 200: 505-515, quiz A559-A561, 2005

5. Kirk AD, Mannon RB, Kleiner DE, Swanson JS, Kampen RL, Cendales LK, Elster EA, Wakefield T, Chamberlain C, Hoffmann SC, Hale DA: Results from a human renal allograft tolerance trial evaluating T-cell depletion with alemtuzumab combined with deoxyspergualin. Transplantation 80: 1051-1059, 2005

6. Kawai T, Cosimi AB, Spitzer TR, Tolkoff-Rubin N, Suthanthiran M, Saidman SL, Shaffer J, Preffer Fl, Ding R, Sharma V, Fishman JA, Dey B, Ko DS, Hertl M, Goes NB, Wong W, Williams WW Jr., Colvin RB, Sykes M, Sachs DH: HLA-mismatched renal transplantation without maintenance immunosuppression. N Engl J Med 358: 353-361, 2008

7. Wood KJ, Jones ND, Bushell AR, Morris PJ: Alloantigeninduced specific immunological unresponsiveness. Philos Trans R Soc Lond B Biol Sci 356: 665-680, 2001

8. Goldrath AW, Luckey CJ, Park R, Benoist C, Mathis D: The molecular program induced in T cells undergoing homeostatic proliferation. Proc Natl Acad Sci U S A 101: 16885-16890, 2004

9. Ruggenenti P, Perico N, Gotti E, Cravedi P, D'Agati V, Gagliardini E, Abbate M, Gaspari F, Cattaneo D, Noris M, Casiraghi F, Todeschini M, Cugini D, Conti S, Remuzzi G: Sirolimus versus cyclosporine therapy increases circulating regulatory $\mathrm{T}$ cells, but does not protect renal transplant patients given alemtuzumab induction from chronic allograft injury. Transplantation 84: 956-964, 2007

10. Noris $M$, Casiraghi $F$, Todeschini $M$, Cravedi $P$, Cugini D, Monteferrante G, Aiello S, Cassis L, Gotti E, Gaspari F, Cattaneo D, Perico N, Remuzzi G: Regulatory T cells and T cell depletion: Role of immunosuppressive drugs. J Am Soc Nephrol 18: 1007-1018, 2007

11. Sewgobind VD, Kho MM, van der Laan LI, Hendrikx TK, van Dam T, Tilanus HW, ljzermans JN, Weimar W, Baan CC: The effect of rabbit anti-thymocyte globulin induction therapy on regulatory $\mathrm{T}$ cells in kidney transplant patients. Nephrol Dial Transplant 24: 1635-1644, 2009

12. Valujskikh A, Li XC: Frontiers in nephrology: T cell memory as a barrier to transplant tolerance. J Am Soc Nephrol 18: 2252-2261, 2007

13. Crop M, Baan C, Weimar W, Hoogduijn M: Potential of mesenchymal stem cells as immune therapy in solidorgan transplantation. Transpl Int 22: 365-376, 2009

14. English K, Ryan JM, Tobin L, Murphy MJ, Barry FP, Mahon BP: Cell contact, prostaglandin E(2) and transforming growth factor beta 1 play non-redundant roles in human mesenchymal stem cell induction of CD4+CD25(High) forkhead box P3+ regulatory T cells. Clin Exp Immunol 156: 149-160, 2009

15. Krampera M, Glennie S, Dyson J, Scott D, Laylor R, Simpson E, Dazzi F: Bone marrow mesenchymal stem cells inhibit the response of naive and memory antigenspecific T cells to their cognate peptide. Blood 101: 3722-3729, 2003

16. Karlsson H, Samarasinghe S, Ball LM, Sundberg B, Lankester AC, Dazzi F, Uzunel M, Rao K, Veys P, Le Blanc K, Ringden O, Amrolia PJ: Mesenchymal stem cells exert differential effects on alloantigen and virusspecific T-cell responses. Blood 112: 532-541, 2008

17. Casiraghi F, Azzollini N, Cassis P, Imberti B, Morigi M, Cugini D, Cavinato RA, Todeschini M, Solini S, Sonzogni A, Perico N, Remuzzi G, Noris M: Pretransplant infusion of mesenchymal stem cells prolongs the sur- vival of a semiallogeneic heart transplant through the generation of regulatory T cells. J Immunol 181: 39333946, 2008

18. Feng B, Chen L: Review of mesenchymal stem cells and tumors: executioner or coconspirator? Cancer Biother Radiopharm 24: 717-721, 2009

19. Motaln H, Schichor C, Lah TT: Human mesenchymal stem cells and their use in cell-based therapies. Cancer 116: 2519-2530, 2010

20. Fiorina P, Jurewicz $M$, Augello A, Vergani A, Dada $S$, La Rosa S, Selig M, Godwin J, Law K, Placidi C, Smith RN, Capella C, Rodig S, Adra CN, Atkinson M, Sayegh $\mathrm{MH}$, Abdi R: Immunomodulatory function of bone marrow-derived mesenchymal stem cells in experimental autoimmune type 1 diabetes. J Immunol 183: 9931004,2009

21. Tolar J, Nauta AJ, Osborn MJ, Panoskaltsis Mortari A, McElmurry RT, Bell S, Xia L, Zhou N, Riddle M, Schroeder TM, Westendorf JJ, Mclvor RS, Hogendoorn PC, Szuhai K, Oseth L, Hirsch B, Yant SR, Kay MA, Peister A, Prockop DJ, Fibbe WE, Blazar BR: Sarcoma derived from cultured mesenchymal stem cells. Stem Cells 25: $371-379,2007$

22. Li H, Fan X, Kovi RC, Jo Y, Moquin B, Konz R, Stoicov C, Kurt-Jones E, Grossman SR, Lyle S, Rogers AB, Montrose $M$, Houghton J: Spontaneous expression of embryonic factors and p53 point mutations in aged mesenchymal stem cells: A model of age-related tumorigenesis in mice. Cancer Res 67: 10889-10898, 2007

23. Capelli C, Domenghini M, Borleri G, Bellavita P, Poma R, Carobbio A, Mico C, Rambaldi A, Golay J, Introna M: Human platelet lysate allows expansion and clinical grade production of mesenchymal stromal cells from small samples of bone marrow aspirates or marrow filter washouts. Bone Marrow Transplant 40: 785-791, 2007

24. Capelli C, Salvade A, Pedrini O, Barbui V, Gotti E, Borleri G, Cabiati B, Belotti D, Perseghin P, Bellavita P, Biondi A, Biagi E, Rambaldi, Golay J, Introna M: The washouts of discarded bone marrow collection bags and filters are a very abundant source of hMSCs. Cytotherapy 11: 403-413, 2009

25. Ruggenenti P, Codreanu I, Cravedi P, Perna A, Gotti E, Remuzzi G: Basiliximab combined with low-dose rabbit anti-human thymocyte globulin: a possible further step toward effective and minimally toxic T cell-targeted therapy in kidney transplantation. Clin J Am Soc Nephrol 1: 546-554, 2006

26. Baldelli S, Merlini S, Perico N, Nicastri A, Cortinovis M, Gotti E, Remuzzi G, Cattaneo D: C-440T/T-331C polymorphisms in the UGT1A9 gene affect the pharmacokinetics of mycophenolic acid in kidney transplantation. Pharmacogenomics 8: 1127-1141, 2007

27. Dominici M, Le Blanc K, Mueller I, Slaper-Cortenbach I, Marini F, Krause D, Deans R, Keating A, Prockop D, Horwitz E: Minimal criteria for defining multipotent mesenchymal stromal cells. The International Society for Cellular Therapy position statement. Cytotherapy 8: 315-317, 2006

28. Gaspari F, Perico N, Ruggenenti P, Mosconi L, Amuchastegui CS, Guerini E, Daina E, Remuzzi G: Plasma clearance of nonradioactive iohexol as a measure of glomerular filtration rate. J Am Soc Nephrol 6: 257263, 1995

29. Nowacki TM, Kuerten S, Zhang W, Shive CL, Kreher CR, Boehm BO, Lehmann PV, Tary-Lehmann M: Granzyme $B$ production distinguishes recently activated CD8(+) memory cells from resting memory cells. Cell Immunol 247: 36-48, 2007

30. Uccelli A, Moretta L, Pistoia V: Mesenchymal stem cells in health and disease. Nat Rev Immunol 8: 726 736, 2008

31. Bischoff DS, Zhu JH, Makhijani NS, Yamaguchi DT: Acidic $\mathrm{pH}$ stimulates the production of the angiogenic 
CXC chemokine, CXCL8 (interleukin-8), in human adult mesenchymal stem cells via the extracellular signalregulated kinase, p38 mitogen-activated protein kinase, and NF-kappaB pathways. J Cell Biochem 104: $1378-$ 1392, 2008

32. Dahl SR, Kleiveland CR, Kassem M, Lea T, Lundanes E, Greibrokk T: Determination of thromboxanes, leukotrienes and lipoxins using high-temperature capillary liquid chromatography-tandem mass spectrometry and on-line sample preparation. J Chromatogr A 1216: 4648-4654, 2009

33. Huang $\mathrm{H}$, Kim HJ, Chang EJ, Lee ZH, Hwang SJ, Kim HM, Lee Y, Kim HH: IL-17 stimulates the proliferation and differentiation of human mesenchymal stem cells: Implications for bone remodeling. Cell Death Differ 16: 1332-1343, 2009

34. Battiwalla M, Hematti P: Mesenchymal stem cells in hematopoietic stem cell transplantation. Cytotherapy 11: 503-515, 2009

35. Lucchini G, Introna M, Dander E, Rovelli A, Balduzzi A, Bonanomi S, Salvadè A, Capelli C, Belotti D, Gaipa G, Perseghin P, Vinci P, Lanino E, Chiusolo P, Rofino MG, Marktel S, Golay J, Rambaldi A, Biondi A, D'Amico G, Biagi E: Platelet-lysate-expanded mesenchymal stromal cells as a salvage therapy for severe resistant graft versus host disease in a pediatric population. Biol Blood Marrow Transplant 16: 1293-1301, 2010

36. Giordano A, Galderisi U, Marino IR: From the laboratory bench to the patient's bedside: An update on clinical trials with mesenchymal stem cells. J Cell Physiol 211: 27-35, 2007

37. Pal R, Venkataramana NK, Bansal A, Balaraju S, Jan M Chandra R, Dixit A, Rauthan A, Murgod U, Totey S: Ex vivo-expanded autologous bone marrow-derived mesenchymal stromal cells in human spinal cord injury/ paraplegia: A pilot clinical study. Cytotherapy 11: $897-$ 911, 2009

38. Sun L, Akiyama K, Zhang H, Yamaza T, Hou Y, Zhao S, Xu T, Le A, Shi S: Mesenchymal stem cell transplantation reverses multiorgan dysfunction in systemic lupus erythematosus mice and humans. Stem Cells 27: 14211432, 2009

39. Prockop DJ: Defining the probability that a cell therapy will produce a malignancy. Mol Ther 18: 1249-1250, 2010

40. Garcia S, Bernad A, Martin MC, Cigudosa JC, GarciaCastro J, de la Fuente R: Pitfalls in spontaneous in vitro transformation of human mesenchymal stem cells. Exp Cell Res 316: 1648-1650, 2010
41. Torsvik A, Rosland GV, Svendsen A, Molven A, Immervoll H, McCormack E, Lonning PE, Primon M, Sobala E, Tonn JC, Goldbrunner R, Schichor C, Mysliwietz J, Lah TT, Motaln H, Knappskog S, Bjerkvig R: Spontaneous malignant transformation of human mesenchymal stem cells reflects cross-contamination: Putting the research field on track - letter. Cancer Res 70: 6393-6396, 2010

42. Yu Y, Fuhr J, Boye E, Gyorffy S, Soker S, Atala A, Mulliken JB, Bischoff J: Mesenchymal stem cells and adipogenesis in hemangioma involution. Stem Cells 24: 1605-1612, 2006

43. Di Nicola M, Carlo-Stella C, Magni M, Milanesi M, Longoni PD, Matteucci P, Grisanti S, Gianni AM: Human bone marrow stromal cells suppress T-lymphocyte proliferation induced by cellular or nonspecific mitogenic stimuli. Blood 99: 3838-3843, 2002

44. Williams KM, Hakim FT, Gress RE: T cell immune reconstitution following lymphodepletion. Semin Immunol 19: 318-330, 2007

45. Ge W, Jiang J, Baroja ML, Arp J, Zassoko R, Liu W, Bartholomew A, Garcia B, Wang H: Infusion of mesenchymal stem cells and rapamycin synergize to attenuate alloimmune responses and promote cardiac allograft tolerance. Am J Transplant 9: 1760-1772, 2009

46. Wang Y, Zhang A, Ye Z, Xie H, Zheng S: Bone marrow-derived mesenchymal stem cells inhibit acute rejection of rat liver allografts in association with regulatory T-cell expansion. Transplant Proc 41: 4352-4356, 2009

47. Zeiser R, Nguyen VH, Beilhack A, Buess M, Schulz S, Baker J, Contag $\mathrm{CH}$, Negrin RS: Inhibition of $\mathrm{CD} 4+\mathrm{CD} 25+$ regulatory T-cell function by calcineurindependent interleukin-2 production. Blood 108: 390 399, 2006

48. Popp FC, Eggenhofer E, Renner P, Slowik P, Lang SA, Kaspar H, Geissler EK, Piso P, Schlitt HJ, Dahlke MH: Mesenchymal stem cells can induce long-term acceptance of solid organ allografts in synergy with low-dose mycophenolate. Transpl Immunol 20: 55-60, 2008

Received: June 4, 2010 Accepted: September 6, 2010

Published online ahead of print. Publication date available at www.cjasn.org.

N.P., F.C., and M.I. contributed equally to this work.

Supplemental information for this article is available online at www.cjasn.org. 
CHAPTER 4

Localization of mesenchymal stromal cells dictates their immune or proinflammatory effects in kidney transplantation

F. Casiraghi, N. Azzollini, M. Todeschini, R.A. Cavinato, P. Cassis, S. Solini, C. Rota, M. Morigi, M. Introna, R. Maranta, N. Perico, G. Remuzzi and M. Noris

published in: American Journal of Transplantation 2012; 12:2373-83 


\section{Localization of Mesenchymal Stromal Cells Dictates Their Immune or Proinflammatory Effects in Kidney Transplantation}

F. Casiraghi ${ }^{\mathrm{a}, \mathrm{b}, *}$, N. Azzollini $i^{\mathrm{a}, \mathrm{b}}$, M. Todeschini ${ }^{\mathrm{a}, \mathrm{b}}$, R. A. Cavinato ${ }^{a, b}$, P. Cassis ${ }^{a, b}$, S. Solini ${ }^{a, b}$, C. Rota ${ }^{c}$, M. Morigi ${ }^{c}$, M. Introna ${ }^{b, d}$, R. Maranta ${ }^{a, b}$, N. Perico ${ }^{a, b}$, G. Remuzzi ${ }^{a, b, c}$ and M. Noris ${ }^{a, b}$

a Transplant Research Center "Chiara Cucchi de Alessandri e Gilberto Crespi," Mario Negri Institute for

Pharmacological Research, Milan, Italy

${ }^{b}$ Department of Immunology and Transplantation,

Ospedali Riuniti-Mario Negri Institute for

Pharmacological Research, Milan, Italy

${ }^{c}$ Centro Anna Maria Astori, Mario Negri Institute for

Pharmacological Research, Milan, Italy

¿Laboratory of Cell Therapy G. Lanzani, Ospedali Riuniti,

Bergamo, Italy

* Corresponding author: Federica Casiraghi,

federica.casiraghi@marionegri.it

Multipotent mesenchymal stromal cells (MSC) have recently emerged as promising candidates for cell-based immunotherapy in solid-organ transplantation. However, optimal conditions and settings for fully harnessing MSC tolerogenic properties need to be defined. We recently reported that autologous MSC given posttransplant in kidney transplant patients was associated with transient renal insufficiency associated with intragraft recruitment of neutrophils and complement C3 deposition. Here, we moved back to a murine kidney transplant model with the aim to define the best timing of MSC infusion capable of promoting immune tolerance without negative effects on early graft function. We also investigated the mechanisms of the immunomodulatory and/or proinflammatory activities of MSC according to whether cells were given before or after transplant. Posttransplant MSC infusion in mice caused premature graft dysfunction and failed to prolong graft survival. In this setting, infused MSC localized mainly into the graft and associated with neutrophils and complement $\mathrm{C} 3$ deposition. By contrast, pretransplant MSC infusion induced a significant prolongation of kidney graft survival by a Treg-dependent mechanism. MSC-infused pretransplant localized into lymphoid organs where they promoted early expansion of Tregs. Thus, pretransplant MSC infusion may be a useful approach to fully exploit their immunomodulatory properties in kidney transplantation.
Key words: Graft inflammation, in vivo localization, kidney transplantation, mesenchymal stromal cells, mice, regulatory $T$ cells

Abbreviations: BM, bone marrow; BUN, blood urea nitrogen; ELISPOT, enzyme-linked immunosorbent spot assays; GFP, green fluorescence protein; MSC, multipotent mesenchymal stem cells.

Received 06 December 2011, revised 22 March 2012 and accepted for publication 07 April 2012

\section{Introduction}

Transplantation is regarded as the only therapeutic choice for end-stage organ failure; however the prolonged acceptance of transplanted organs requires long-term use of combined immunosuppressive drugs which carries serious risks for long-term side effects such as accelerated cardiovascular disease, metabolic complications, life-threatening infections and malignancies (1). Induction of immune tolerance would overcome these shortcoming, possibly allowing indefinite graft survival (2).

Multipotent mesenchymal stromal cells (MSC) (3) have recently emerged as a promising candidate for cell-based therapy in transplantation given their unique immunomodulatory properties. In vitro, MSC inhibit T cell proliferation by both cell-to-cell interaction and release of soluble factors $(4,5)$. MSC also promote the differentiation of $\mathrm{CD}^{+}{ }^{+} \mathrm{T}$ cells to specific subsets. Indeed, MSC skew T cell responses toward Foxp3 ${ }^{+}$regulatory $T$ cells (Tregs) and concurrently suppress Th1, Th2 or Th17 responses (68). MSC modulate dendritic cell (DC) maturation toward a tolerogenic population through downregulation of cell surface expression of $\mathrm{MHCll}$, the costimulatory molecules CD40, CD80 and CD86 and by preventing the cell homing to lymph node through lowering chemokine-receptor CCR7 expression (9-13). Moreover, we and others showed that infusion of MSC was effective in prolonging allograft survival in skin (14), heart (12,15-19), kidney (20), liver $(21)$ and pancreatic islet $(19,22)$ transplantation in rodents.

We recently extended our experimental work to clinical transplantation in two living-related donor kidney 


\section{Casiraghi et al.}

recipients who were given ex vivo expanded, autologous, bone marrow-derived MSC at day 7 posttransplant, after induction therapy with Basiliximab/low-dose thymoglobulin (23). MSC infusion did promote on long term a protolerogenic environment characterized by lower memory/effector $\mathrm{CD}^{+}{ }^{+} \mathrm{T}$ cells, expansion of CD4 ${ }^{+}$Tregs and reduction of donor-specific $\mathrm{CD}^{+} \mathrm{T}$ cell cytotoxicity, compared with control kidney transplant recipients given the same induction therapy but not MSC. However, few days after cell infusion, both MSC-treated patients developed acute renal insufficiency. Histologic and immunohistochemic analysis of graft infiltrating cells did exclude an acute cellular or humoral rejection, but intragraft recruitment of neutrophils together with MSC, as well as complement-C3 deposition were observed (23). The subclinical inflammatory environment of the graft in the few days postsurgery could have favored the intragraft recruitment and activation of the infused MSC. Such event could have promoted a proinflammatory milieu with complement activation, neutrophil recruitment and ultimately kidney dysfunction. Therefore, it was suggested that the unexpected acute deterioration of graft function following MSC infusion could be avoided by giving cells before kidney transplantation. To test this possibility, in this study we moved back to a clinically relevant murine kidney transplant model with the aim to define the best timing of autologous MSC infusion that allows to control donorspecific alloreactive $T$ cells and to promote immune tolerance without any negative effect on early graft function. We also aimed at exploring the mechanisms of the immunomodulatory and/or inflammatory activities of MSC according to whether cells were given before or after transplantation.

\section{Materials and Methods}

Detailed methods of murine kidney transplantation, enzyme-linked immunosorbent spot (ELISPOT) assays and flow-cytometry analysis and quantitative real-time RT-PCR may be found in the online version of this article.

\begin{abstract}
Mice
Eight- to 10-week-old C57BL/6 (C57) and Balb/c mice were from Charles

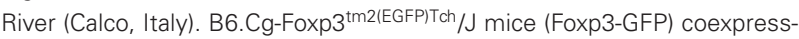
ing green fluorescence protein (GFP) and the transcription factor Foxp3 were from Jackson Laboratory (Bar Harbor, Maine, USA). All animal experiments were approved by the Institutional Animal Care and Committee and were conducted in conformity with the institutional guidelines and international law and policies.
\end{abstract}

\section{MSC isolation and characterization}

Bone marrow was flushed from the shaft of femurs and tibias of 2-monthold C57 mice with DMEM (Sigma-Aldrich) containing 5\% FCS (Invitrogen) and then filtered through a $100-\mu \mathrm{m}$ sterile filter to produce a single-cell suspension. Filtered BM cells were plated in DMEM/10\% FCS and allowed to adhere for $6 \mathrm{~h}$. Medium was then changed regularly every 3 days; after 2-3 weeks adherent cells were detached by trypsin-EDTA. Primary MSC cultures were collected and immunodepleted of $\mathrm{CD}_{4} 5^{+}$and $\mathrm{CD} 11 \mathrm{~b}^{+}$cells as previously described (12). CD45- CD11 b- MSC expressed low levels of
MHC class I and II, were positive for CD44 expression and negative for CD86 expression (12). MSC properties to differentiate toward osteoblasts, adipocytes and chondroblasts in vitro have been routinely assayed, as previously described (24). Independent MSC batches were used for transplant experiments.

\section{Detection of infused MSC in recipient organs}

MSC were labeled with the membrane dye PKH26 according to the manufacturer's protocol (Red Fluorescence Cell Linker kit; Sigma-Aldrich) prior to intravenous infusion. Labeling efficacy was found to be $>90 \%$ by FACS analysis. MSC localization into spleens and kidneys was performed as previously described (12). For each tissue, three nonconsecutive sections were analyzed and $\mathrm{PKH}_{26}{ }^{+}$cells in 50 randomly selected high-power fields (HPF) were counted. Results are expressed as number of $\mathrm{PKH}_{2} 6^{+}$cells per $\mathrm{mm}^{2}$

\section{Immunohistochemical analysis}

Intragraft $\mathrm{CD}^{+}{ }^{+}$Foxp3 $^{+}$cells in wild-type C57 mice were analyzed by the immunofluorescence technique on frozen tissue sections, as previously described (12). Numbers of total single- or double-positive cells were counted in at least eight randomly selected HPF. For each animal, percentages of $\mathrm{CD}^{+}{ }^{+} \mathrm{Foxp}^{+}$on $\mathrm{CD}^{+}$cells were calculated.

Foxp3-GFP ${ }^{+}$cells into the spleens of Foxp3-GFP mice were counted in at least $25 \mathrm{HPF}$ and expressed as number of Foxp3-GFP ${ }^{+}$cells $/ \mathrm{mm}^{2}$.

Intragraft neutrophils and C3 deposition were analyzed by the immunofluorescence technique on frozen tissue previously fixed in PFA $2 \%$. Airdried and fixed sections $(5 \mu \mathrm{m})$ were then incubated with either rat antimouse Gr1 followed by FITC-conjugated goat anti-rat IgG for neutrophils or with FITC-conjugated goat anti-mouse C3. Neutrophils were counted in at least 10-15 randomly selected HPF (X400) and expressed as number of cells $/ \mathrm{mm}^{2}$. C3 was scored $(0=$ absent; $1=$ faint staining; $2=$ moderate staining; 3 = intense staining) as previously described (25). Around 10 glomeruli and 10-15 randomly selected HPF (X400) with tubuli for each section were examined.

Negative controls were carried out by omitting the primary antibody or with isotype antibody, usually on a second section on the same slide.

\section{Statistical analysis}

Survival data were compared using the log-rank test. All other data were analyzed by ANOVA. Differences with a $p$ value $<0.05$ were considered significant.

\section{Results}

\section{Murine model of acute rejection to a kidney transplant for studying tolerogenic properties of MSC} The conventional transplantation of a fully $\mathrm{MHC}$ mismatched Balb/c kidney $\left(\mathrm{H}-2^{\mathrm{d}}\right)$ in $\mathrm{C} 57$ recipients $\left(\mathrm{H}-2^{\mathrm{b}}\right)$ resulted in variable graft survival times with some animals that acutely rejected the graft within 10 days posttransplant while one-third of them experienced graft survival of more than 60 days (Figure 1A), with moderately impaired but stable graft function (Figure 1B). To achieve a more reproducible and severe kidney transplant model, we sensitized $\mathrm{C} 57$ recipient mice toward donor antigens by the infusion of donor Balb/c splenocytes $\left(1 \times 10^{6}\right.$ i.v., 7 days before kidney transplantation). Recipient sensitization enhanced frequency of donor Balb/c-reactive IFN $\gamma$-producing 
A

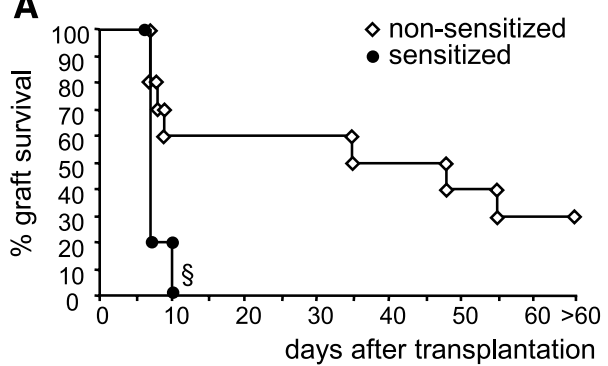

B

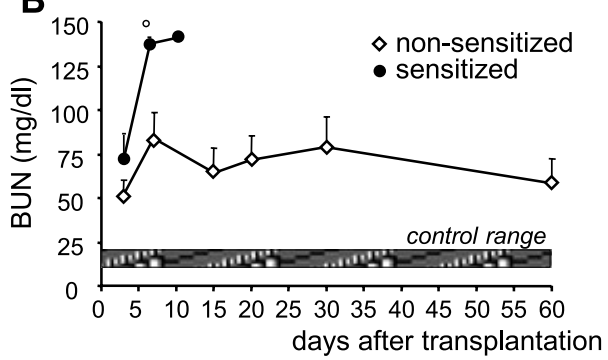

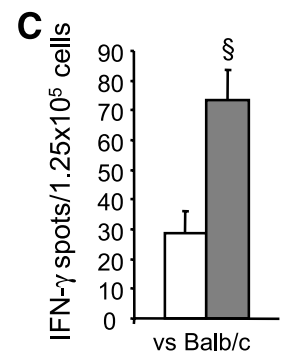

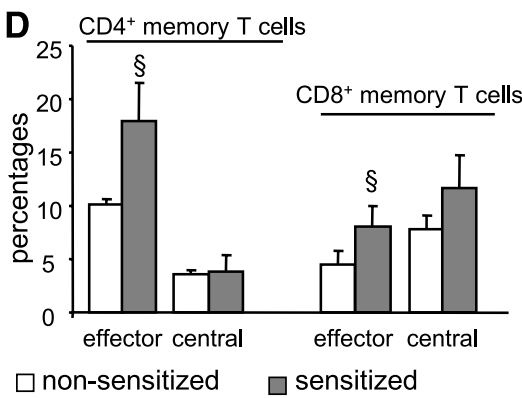

E Treg/effector memory T cells (ratio)

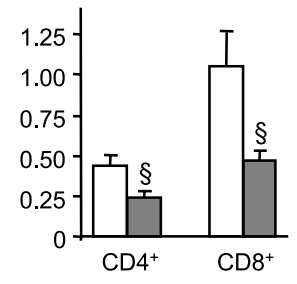

Figure 1: Donor sensitization resulted in a more severe kidney graft rejection. (A) C57 mice, sensitized by the infusion of Balb/c splenocytes $(n=5)$, acutely rejected Balb/c kidney allograft, at variance with nonsensitized mice that experienced long-term graft survival $(n=10) . \S p<0.05$ versus nonsensitized mice. (B) Kidney graft function, by the evaluation of BUN levels, rapidly deteriorated in sensitized mice whereas remain moderately impaired in nonsensitized mice during the 60 days follow-up (range of BUN from nontransplanted naïve mice is shown in horizontal dashed bars); ${ }^{\circ} p<0.05$ versus BUN at day 7 posttransplant in nonsensitized mice. (C) Frequency of donorreactive IFN $\gamma$-producing cells following ex vivo exposure of spleen cells from sensitized mice $(n=5)$ to Balb/c stimulators was significantly lower than those observed in nonsensitized mice $(n=5)$. (D) FACS analysis showed increased percentages of splenic $\mathrm{CD}^{2} 4^{\text {high }} \mathrm{CD} 62 \mathrm{~L}^{-}$ effector memory cells either on $\mathrm{CD}^{+}{ }^{+} \mathrm{CD} 4^{+} \mathrm{T}$ cells or on $\mathrm{CD}^{+}{ }^{+} \mathrm{CD} 8^{+} \mathrm{T}$ cells in sensitized mice compared with nonsensitized mice, whereas $\mathrm{CD}_{4} 4^{\text {high }} \mathrm{CD} 62 \mathrm{~L}^{+}$central memory $\mathrm{CD} 4^{+}$and $\mathrm{CD} 8^{+} \mathrm{T}$ cells were comparable between the two groups of mice. (E) The ratio between Treg and effector memory $\mathrm{CD}^{+}$and $\mathrm{CD} 8^{+} \mathrm{T}$ cells is reduced in sensitized mice compared with nonsensitized animals, $\$ p<0.05$ versus nonsensitized mice. Data are mean $\pm \mathrm{SE}$.

cells when tested 7 days after Balb/c splenocyte infusion (Figure 1C). Alloantigen sensitization also increased the percentage of splenic CD44 ${ }^{\text {high }}$ CD62 $\mathrm{L}^{-}$effector/memory $\left(\mathrm{T}_{\mathrm{EM}}\right) \mathrm{CD}^{+}$and $\mathrm{CD}^{+} \mathrm{T}$ cells compared with nonsensitized mice (Figure 1D) and, consequently, significantly reduced the ratios of Treg/CD4 ${ }^{+}$or $\mathrm{CD}^{+} \mathrm{T}_{\mathrm{EM}}$ (Figure 1E). Allosensitization was accompanied by donor-specific antibody development (Figure S1). Transplantation of Balb/c kidneys into sensitized mice ( $n=5$, Figure 2 ) resulted in a rapid increase in BUN levels (Figure 1B) and acute graft rejection (Figure $1 \mathrm{~A}$ ) within 10 days in all transplanted mice.

\section{Different timing of MSC infusion affects kidney graft function and survival in sensitized mice}

We assessed the effect of different timing of MSC infusion in prolonging kidney graft survival. To this purpose donorsensitized C57 recipient mice were given syngeneic MSC infusion $\left(0.5 \times 10^{6}\right.$, i.v. $)$ either post- or pretransplantation. A group of mice received a posttransplant MSC infusion (day $+2, n=5$ ). Three additional groups received pretransplant MSC infusion: 7 days $(n=5), 1$ day $(n=5)$ before transplant or the double pretransplant MSC infusions (at days -7 and $-1, n=5$, Figure 2). All mice received a Balb/c kidney transplant at day 0 . Mice given MSC 2 days after transplantation showed a significantly higher BUN levels 4 days posttransplant (i.e. 2 days after MSC infusion) compared to non-MSC infused transplanted mice (Figure 3A). This sudden increase was not observed in mice receiving either single or double infusion of MSC prior to transplantation (Figure $3 \mathrm{~A}$ ), indicating that posttransplant infusion of MSC did associate with premature graft dysfunction. Then in mice given MSC 2 days after transplantation, kidney graft function progressively and further deteriorated (Figure 3A) and all mice rejected the kidney allograft within 20 days (Figure 3B). By contrast, a single (either day -7 or day -1) and double (at day -7 and at day -1) pretransplant infusion of MSC significantly prolonged kidney graft survival compared with untreated transplanted mice (Figure 3B). The double MSC infusion showed a trend toward a better graft survival, albeit not to a statistically significant level.

At histologic analysis, kidneys from MSC-treated rejecting mice showed inflammatory infiltrates and tubular damage similar to those from non-MSC infused rejecting mice indicating an ongoing acute cellular rejection. At variance, MSC-tolerized kidney grafts showed minimal histologic changes (Figure S1). Similar IgG deposition was found 


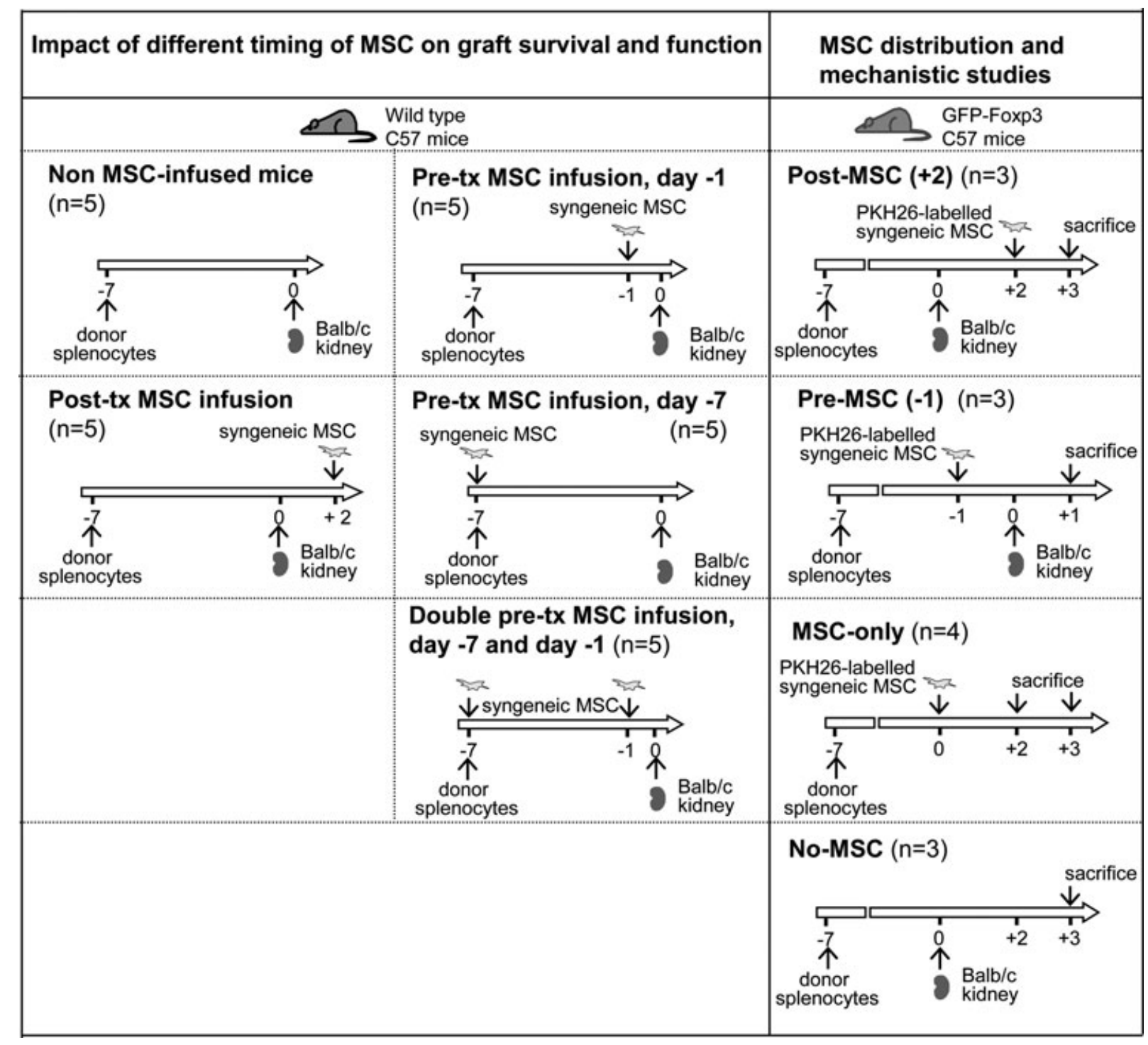

Figure 2: Experimental flow chart for in vivo study design. C57 mice, were given (or not) syngeneic MSC infusion at different time points respect to a Balb/c kidney transplant to assess the impact of different timing of MSC on graft survival and function. GFP-Foxp3 mice, received PKH26-MSC at different time points respect to a Balb/c kidney transplant and then killed 2-3 days after cell infusion to assess MSC distribution and for mechanistic studies.

in kidney grafts from mice given double pretransplant infusions of MSC and either had failing grafts during the 60 day follow-up or had long-term graft survival (Figure S1). These data would not support a humoral rejection as the leading cause of acute kidney graft failure in MSC-treated mice, at least during the first 60 days after transplant.

In mice receiving pretransplant MSC infusion and surviving more than 20 days posttransplant, kidney graft function was well preserved during the 60-day follow-up (Figure 3A).

Long-term surviving pretransplant MSC-infused mice were killed and ex vivo studies were performed to dissect mech- anism(s) leading to long-term graft acceptance. In MLR experiments, splenocytes from tolerant MSC-treated mice ( $n=5$ ) showed a lower frequency of antidonor IFN $\gamma$ producing cells toward Balb/c stimulators than in sensitized nontransplanted mice, whereas the response against third-party $\mathrm{C} 3 \mathrm{H}$ antigens was similar between groups (Figure 4A), indicating a donor-specific $T$ cell hyporesponsiveness in MSC-tolerized mice. To assess the role of Treg in MSC-induced tolerance, we stained splenocytes from tolerant and sensitized nontransplanted mice with antiCD4 and anti-Foxp3 antibodies for FACS analysis. In MSCtolerized mice the percentage of $\mathrm{CD}^{+}{ }^{+} \mathrm{Foxp}^{+}$Tregs over total $\mathrm{CD}^{+}{ }^{+} \mathrm{T}$ cells was higher and accordingly, the ratios 
A
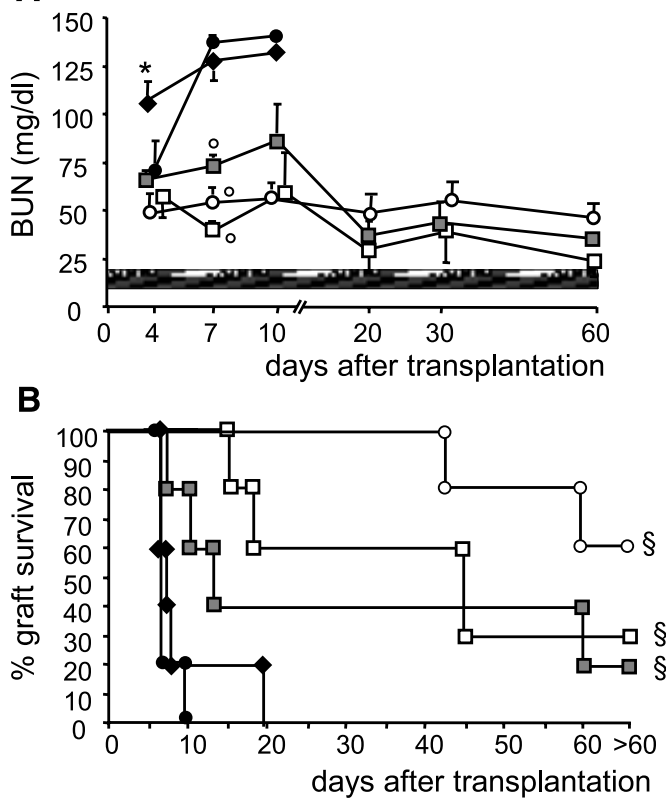

- non MSC-infused mice

- post-tx MSC infusion, day +2

$\square$ pre-tx MSC infusion, day -1

a pre-tx MSC infusion, day -7

o double pre-tx MSC infusions, day -7 and day -1

Figure 3: Impact of different timing of MSC infusion in prolonging kidney graft survival. (A) BUN levels at day 4 after transplantation are significantly higher in mice receiving MSC 2 days after transplant than those from non MSC-infused mice or mice given pretransplant MSC infusion either at day -7 or at day -1 or the double pretransplant MSC infusion. From day -7 onward, BUN levels are significantly lower in mice given pretransplant MSC infusions than those from untreated mice. Data are mean $\pm S D, * p<0.05$ versus all the other groups at day 4 posttransplant, ${ }^{\circ} \mathrm{p}<0.05$ versus $\mathrm{BUN}$ in mice receiving $\mathrm{MSC}$ at day +2 or non-MSC infused mice at day 7 posttransplant. (B) Sensitized mice receiving either single or double pretransplant intravenous infusion of syngeneic MSC $\left(0.5 \times 10^{6}\right)$ had prolonged kidney graft survival compared with mice receiving posttransplant (day +2 ) cell infusion or non-MSC infused mice. ${ }^{\S} p<0.05$ versus no cell infusion.

Treg/CD4 ${ }^{+}$or $\mathrm{CD}^{+} \mathrm{T}_{\mathrm{EM}}$ were significantly increased than in sensitized non-MSC infused untransplanted mice (Figure $4 \mathrm{~B}, \mathrm{C}$ ). Immunohistochemical analysis of kidney allografts showed that $27 \%$ of $\mathrm{CD} 4^{+} \mathrm{T}$ cells in grafts taken from MSC-treated tolerant mice expressed Foxp3 compared with $9 \%$ in rejected kidneys from non-MSC infused transplanted mice (Figures 4D and E).

Three additional mice receiving double pretransplant infusion of MSC (at 7 and 1 day before transplant) were given a depleting anti-CD25 antibody (clone PC61, $500 \mu$ g i.p. (26)) at days 1 and 3 posttransplant. A slight prolongation of kidney graft survival was observed compared to non-MSC infused mice but eventually all mice rejected the kidney graft within 20 days posttransplant (Figure 4F), confirming that $\mathrm{CD} 25^{+}$Treg have a role in MSC-induced prolongation of graft survival.

\section{Homing of MSC into the graft according to pre- and posttransplant cell infusion and MSC-induced graft inflammation}

Four groups of sensitized C57 mice were studied (Figure 2). Three mice were transplanted with a Balb/c kidney, were given $0.5 \times 10^{6}$ PKH26-MSC 2 days after surgery and 24 $\mathrm{h}$ later animals were killed (post-MSC (+2)). Three additional mice received $0.5 \times 10^{6} \mathrm{PKH} 26-\mathrm{MSC}$ the day before a Balb/c kidney transplant, and then killed $24 \mathrm{~h}$ posttransplant (pre-MSC (-1)). As controls, four mice received $0.5 \times 10^{6}$ PKH26-MSC and then were killed 24-48 h after cell infusion without being transplanted (MSC-only), while three other mice were transplanted with a Balb/c kidney, left untreated and killed 3 days later (no-MSC).

In post-MSC $(+2)$ animals, $\mathrm{PKH} 26^{+} \mathrm{MSC}$ were clearly detectable in the kidney graft the day after cell infusion and the numbers of intragraft $\mathrm{PKH} 26^{+} \mathrm{MSC}$ were significantly higher than those found in grafts from pre-MSC $(-1)$ mice, where MSC was negligible (Figure 5A). Very few MSC were also found in the kidney of nontransplanted mice (MSC-only), indicating that MSC infusion before kidney transplantation did not associate with their localization in the graft (Figures 5A-C).

To establish whether ischemia/reperfusion (I/R) injury could contribute to MSC recruitment into the graft, we performed syngeneic $\mathrm{C} 57$ kidney transplants into sensitized $\mathrm{C} 57$ recipients $(n=3)$. PKH26+ MSC were infused 2 days after transplant $\left(0.5 \times 10^{6}\right.$, i.v.) and mice killed $24 \mathrm{~h}$ later. A significantly higher number of MSC was found into syngeneic grafts compared with kidney from MSC-infused nontransplanted mice (Figure $5 \mathrm{~A}$ ), suggesting that $\mathrm{I} / \mathrm{R}$ injury plays a role in MSC recruitment into the transplanted grafts. However, the numbers of MSC in syngeneic kidney grafts was lower than those found in allografts from post-MSC (+2) mice (Figure 5A). This finding also suggests that the ongoing immune insult to the allograft contributed to MSC localization into the injured kidneys.

We then evaluated graft infiltrating neutrophils and complement deposition on allografts from mice of the post-MSC $(+2)$, pre-MSC $(-1)$ and no-MSC groups. Accordingly, we found a significant increased number of neutrophils (Figures 5D-G) and increased complement deposition both in peritubular capillaries and in glomeruli in allografts from post-MSC $(+2)$ mice compared with mice from pre-MSC $(-1)$ and no-MSC groups (Figures $5 \mathrm{H}-\mathrm{K}$ ).

To characterize MSC-induced graft inflammation we evaluated mRNA expression of IL-6, TNF $\alpha$, IFN $\gamma$, iNOS and TGF $\beta$ by real-time PCR in renal tissues from post-tx MSC 


\section{Casiraghi et al.}
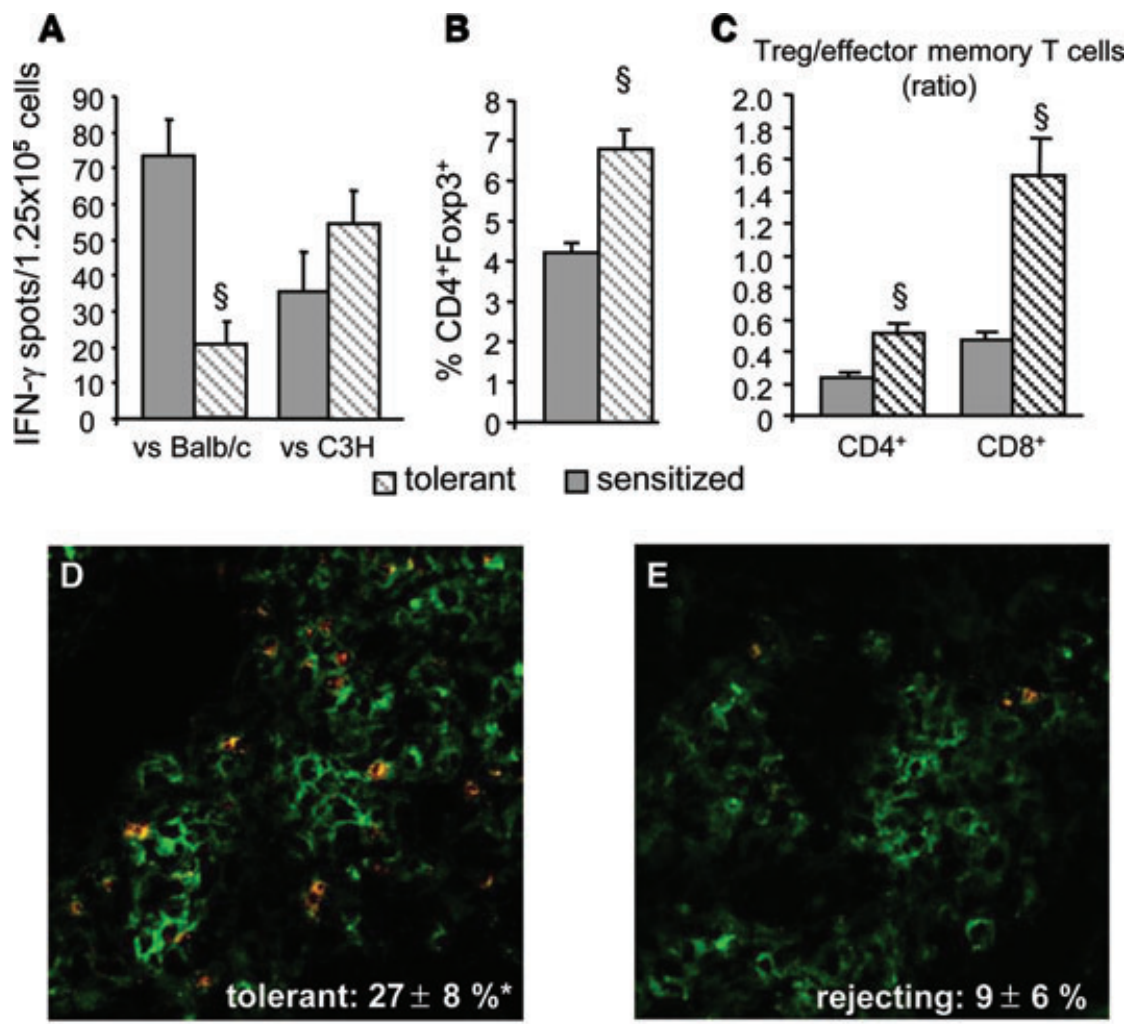

Figure 4: Treg expansion in longterm surviving MSC-treated mice. (A) Spleen cells isolated from MSCinfused long-term tolerant mice ( $\mathrm{n}=$ 5) showed lower frequency of antidonor Balb/c IFN $\gamma$-producing cells compared with sensitized nontransplanted mice. Frequencies of anti-C3H (used as third party antigens) IFN $\gamma$ producing cells were comparable between groups. Data are mean $\pm \mathrm{SE}$, $\S_{p}<0.05$ versus sensitized nontransplanted mice. (B) FACS analysis of Foxp3 ${ }^{+}$cells on splenic $\mathrm{CD}^{+} \mathrm{CD}^{+}$ $T$ cells from MSC-infused long-term tolerant mice revealed an increased percentage of Tregs compared with those found in spleen from sensitized nontransplanted mice. (C) The ratios of Treg/effector memory $\mathrm{CD}^{+}$and Treg/effector memory $\mathrm{CD}^{+} \mathrm{T}$ cells were increased in tolerant animals compared with sensitized mice. Data are mean $\pm S E, \delta p<0.05$ versus sensitized mice. (D,E) Representative images of intragraft immunostaining of $\mathrm{CD}^{+}$cells (green) and $\mathrm{CD}^{+}{ }^{+}$Foxp3 $^{+}$ cells (yellow/red) in kidney allografts from MSC-infused long-term tolerant mice ( $\mathrm{n}=5$ mice surviving $>60$ days after transplant) or from sensitized mice rejecting their graft $(n=3$ mice), respectively. Original magnification $\times 400$. Percentages (indicated in the respective image) of $\mathrm{CD}^{+}{ }^{+} \mathrm{Foxp}^{+}$ on total infiltrating $\mathrm{CD}^{+}$cells in MSCinfused long-term tolerant mice were significantly higher than those found in sensitized mice rejecting their kidney graft (mean $\pm S D, * p<0.05$ vs. rejecting). (F) Anti-CD25 mAb administration to mice given double pretransplant MSC infusions resulted in graft rejection within 20 days posttransplant. $\S p<0.05$ versus MSC at day -7 and at day -1 .

$(+2)$ and from no-MSC allogeneic and syngeneic groups, both taken 3 days after surgery.

A trend toward an increased mRNA expression of IL-6 and TNF $\alpha$ was found in kidney allografts from post-tx MSC (+2) mice versus no-MSC allografts. The difference reached statistical significance in syngeneic groups (Figures $5 \mathrm{~L}$ and M). mRNA levels for IFN $\gamma$, iNOS and TGF $\beta$ were similar between the MSC-treated and no-MSC groups (Figures $5 \mathrm{~L}$ and $\mathrm{M})$.

Altogether these data indicate that MSC infusion postbut not pre-kidney transplantation allows preferentially
MSC recruitment into the subclinical inflammatory environment of the graft created by $I / R$ injury and by immune insult, and once in this environment MSC contribute to upregulate inflammatory cytokine expression. Eventually MSC promotes complement activation and neutrophil recruitment.

\section{Localization of MSC into the recipient spleen dictates Treg expansion}

We investigated whether timing of MSC infusion affected their capability to localize into lymphoid organs and to induce Treg expansion. A high number of infused 
A PKH26+ MSC (cells $\left./ \mathrm{mm}^{2}\right)$

\begin{tabular}{rcl} 
& kidney & spleen \\
\hline post-MSC (+2) & $26.6 \pm 4.0^{\circ}$ & $58.9 \pm 20.9^{\circ}$ \\
pre-MSC (-1) & $4.7 \pm 0.14$ & $290 \pm 104$ \\
MSC only & $2.9 \pm 1.3$ & $204 \pm 10$ \\
$\begin{array}{r}\text { syngeneic grafts } \\
\text { (MSC }+2)\end{array}$ & $16.0 \pm 5.6^{*}$ & $129 \pm 45^{*}$ \\
\hline
\end{tabular}
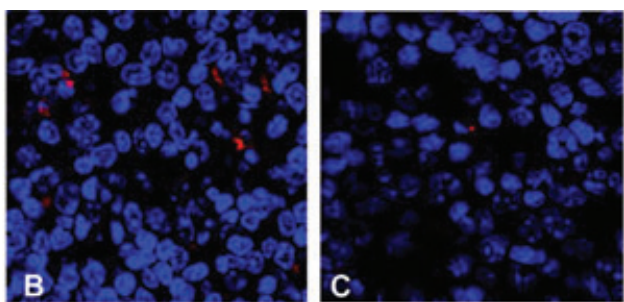
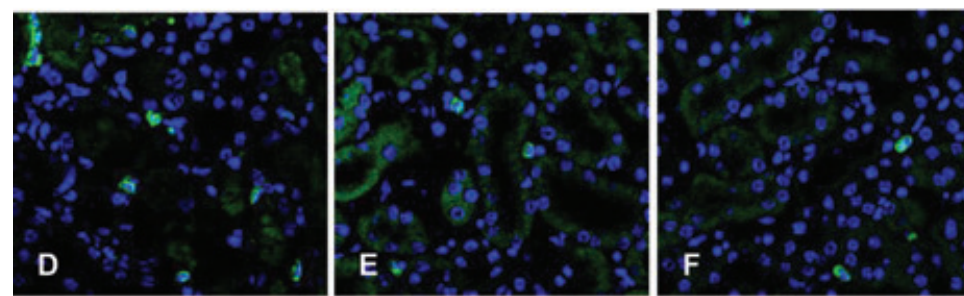

\begin{tabular}{lc}
\multicolumn{1}{c}{ G } & $\begin{array}{c}\text { neutrophils } \\
\left(\text { cells } / \mathrm{mm}^{2}\right)\end{array}$ \\
\hline post-MSC (+2) & $275 \pm 92^{*}$ \\
pre-MSC $(-1)$ & $129 \pm 70$ \\
no MSC infusion & $146 \pm 35$ \\
\hline
\end{tabular}
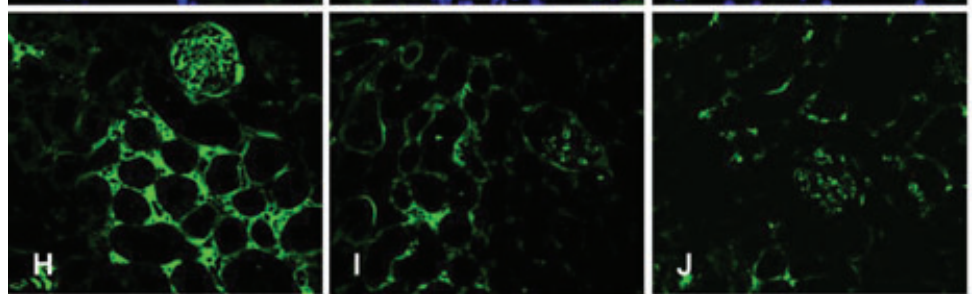

complement C3 (score)

\section{K}

PTC glomeruli

post-MSC (+2) $1.7 \pm 0.06^{*} \quad 1.1 \pm 0.1^{*}$

pre-MSC (-1) $\quad 0.9 \pm 0.01 \quad 0.7 \pm 0.2$

no MSC infusion $1.0 \pm 0.11 \quad 0.8 \pm 0.0$
L $\square$ kidney allografts from non-MSC infused mice $\square$ kidney allografts from post-tx MSC (+2) mice
M $\square$ syngeneic grafts from non-MSC infused mice $\square$ syngeneic grafts from post-tx MSC (+2) mice
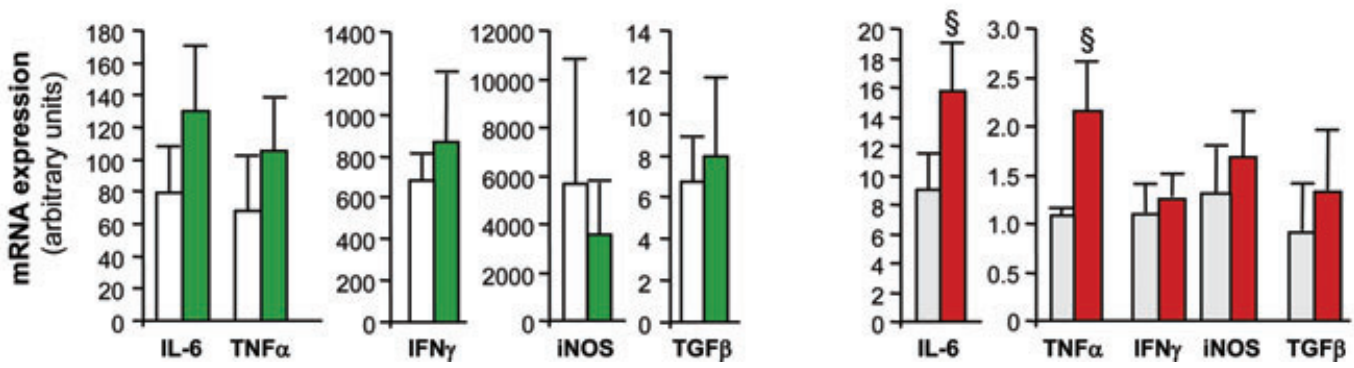

Figure 5: Homing of MSC according to pre- and posttransplant cell infusion in sensitized mice and MSC-induced graft inflammation. Panel A reported the number of $\mathrm{PKH}_{2} 6^{+} \mathrm{MSC}$ (as cells $/ \mathrm{mm}^{2}$ ) in kidney grafts and in spleen from mice receiving MSC 2 days after transplantation (post-MSC (+2)), mice receiving MSC 1 day before transplantation (pre-MSC $(-1)$ ), and from mice receiving the only MSC infusion (MSC-only). The number of $\mathrm{PKH}_{26}{ }^{+} \mathrm{MSC}$ in kidney grafts and in spleen from mice given MSC infusion 2 days after a syngeneic kidney grafts is also included. ${ }^{\circ} \mathrm{p}<0.05$ versus pre-MSC $(-1)$ and MSC-only, ${ }^{*} p<0.05$ versus MSC-only and post-MSC (+2). Either overestimation of MSC due to apoptotic vesicle or membrane fragment phagocytosis by macrophages or underestimation because of PKH26 dilution in MSC proliferating cells cannot be excluded. Representative images of $\mathrm{PHK}^{2} 6^{+} \mathrm{MSC}$ in spleen of mice receiving MSC infusion one day before transplantation and killed $48 \mathrm{~h}$ after cell infusion (pre-MSC $(-1), \mathrm{B})$ or from transplanted mice receiving MSC 2 days after the Balb/c kidney transplant and killed $24 \mathrm{~h}$ later (post-MSC (+2), C) are shown. Original magnification 400x. Panels D, $\mathrm{E}$ and $\mathrm{F}$ are representative images of immunohistochemical staining for neutrophils in kidney graft tissues from mice of post-MSC (+2), pre-MSC (-1) and no-MSC infused transplanted mice (no-MSC infusion) groups, respectively. In panel G are reported the counts (mean \pm $\mathrm{SD}$ ) of neutrophils as cell/ $/ \mathrm{mm}^{2}$ for each group of mice. Panels $\mathrm{H}$, I and $\mathrm{J}$ are representative images of immunohistochemical staining for complement C3 deposition in kidney graft tissues from mice of post-MSC (+2), pre-MSC (-1) and no-MSC infusion groups, respectively and the mean \pm SD score are reported in panel K. Original magnification $400 X$. $* p<0.05$ versus pre-MSC $(-1)$ no-MSC infusion groups. (L) Kidneys from post-MSC (+2) mice showed a trend toward increased mRNA expression of IL-6 and TNF $\alpha$ while expression of IFN $\gamma$, iNOS and TGF $\beta$ mRNAs were similar to non-MSC infused mice. (M) Syngeneic grafts from mice given MSC 2 days after surgery showed increased mRNA levels for IL-6 and TNF $\alpha$ compared to syngeneic grafts from non-MSC infused mice syngeneic grafts, $\$ p<0.05$ versus non-MSC infused mice. IFN $\gamma$, iNOS and TGF $\beta$ mRNAs were similar to non-MSC infused mice syngeneic grafts. 


\section{Casiraghi et al.}

PKH26+MSC localized into the spleen of mice receiving MSC pretransplant (pre-MSC (-1)) and of MSC-only mice, whereas a significantly lower number of cells was detected into the spleen of animals receiving MSC posttransplantation (post-MSC (+2), Figures 5A-C).

Foxp3-GFP + Tregs into the spleen of mice from post-MSC $(+2)$ and preMSC $(-1)$ groups were analyzed by FACS on spleen cell suspensions or by immunohistochemical analyses of spleen tissues. A significantly higher percentage of Tregs over total CD4 ${ }^{+}$T cells was found in splenocytes of mice from the pre-MSC (-1) group than in the post-MSC $(+2)$ group mice (Figures $6 A$ and B). Similarly, histochemical analysis of Foxp3-GFP ${ }^{+}$cells in spleen tissue showed a significantly higher number of Tregs in mice receiving MSC prior than in animals given MSC 2 days postkidney transplant (Figures 6C and D).

To confirm the capability of MSC to early expand functional Tregs in vivo, we performed adoptive transfer experiments. Splenocytes from nontransplanted mice given MSC infusion and killed 1-2 days after (MSC-only) or from control nontransplanted mice not given MSC (no-MSC) were transferred into C57 mice (previously sensitized by donor splenocyte infusion) the day before a Balb/c kidney transplantation. The transfer of $50 \times 10^{6}$ splenocytes from mice given MSC alone significantly prolonged the kidney allograft survival ( $n=4$, Figure 6E) compared to sensitized animals receiving cells from no-MSC animals ( $n=3$, Figure 6E)

\section{Discussion}

As part of a safety and clinical feasibility study on MSC infusion in kidney transplantation, we recently reported results of the first two living donor-kidney transplant recipients given autologous MSC infusion at day 7 posttransplant (23). The choice of administering MSC at day 7 posttransplant was dictated by two main reasons: (i) in vitro studies showed that thymoglobulin, which is part of the immunosuppressive induction regimen adopted in our center, bound in vitro to MSC (23), highlighting the possibility of in vivo MSC lysis should the cells be infused during the induction phase early posttransplant; (ii) the administration of MSC at the end of T cell depleting induction therapy could maximize the MSC effect on Treg expansion during homeostatic proliferation of residual $T$ cells, a condition previously shown to be favorable for expansion of Tregs (27). Although posttransplant infusion of MSC did result on the long-term in a donor-specific protolerogenic modulation of the host immune response, transient increase in serum creatinine level 7-14 days after cell infusion did occur, associated with hypocellular graft infiltration, mainly neutrophils, complement deposition and positive staining for MSC in the kidney biopsy. These clinical and histologic features were reminiscent to the ones reported during marrow recovery in recipients of combined bone marrow and
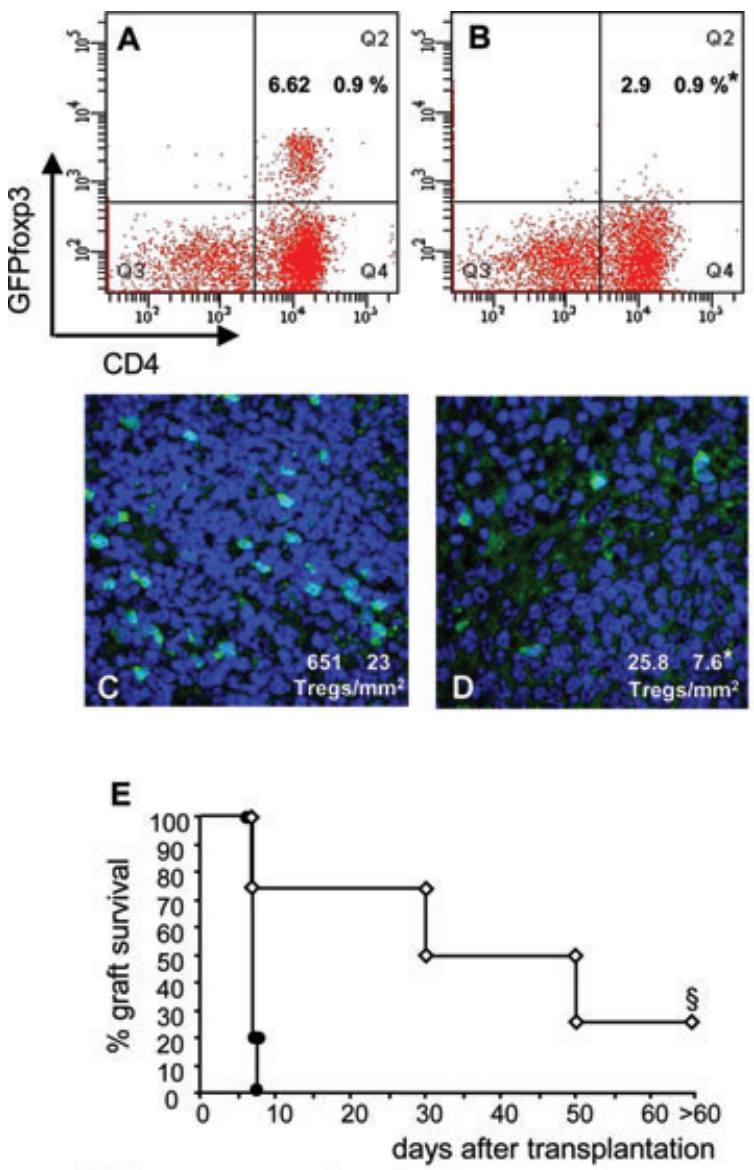

- AT from non transplanted mice

-AT from MSC-infused non transplanted mice (MSC-only)

Figure 6: Localization of MSC into the recipient spleen is associated with Treg expansion. Panels $A$ and $B$ are representative FACS dot plots of $\mathrm{CD}^{+}$Foxp3-GFP ${ }^{+}$cells on gated splenic $\mathrm{CD}^{+} \mathrm{T}$ cells from mice of pre-MSC $(-1)$ and post-MSC (+2) groups, respectively. The mean \pm SE of the percentage of splenic $\mathrm{CD}^{+} \mathrm{CD}^{+}{ }^{+}$Foxp3-GFP ${ }^{+}$are reported on the top of each dot plot. $* p<0.05$ versus pre-MSC $(-1)$. Representative images of Foxp3$\mathrm{GFP}^{+}$cells in spleen of mice from pre-MSC $(-1)$ group $(C)$ or from post-MSC (+2) groups (D) are shown. Original magnification $400 \times$. The mean \pm SE of the number of splenic Foxp3-GFP ${ }^{+} / \mathrm{mm}^{2}$ are reported on the respective figure. $* \mathrm{p}<0.05$ versus pre-MSC $(-1)$. (E) Sensitized C57 mice adoptively transferred with splenocytes from mice from MSC-only group experienced long-term Balb/c kidney graft survival. $\$ p<0.05$ versus adoptive transfer (AT) of splenocytes from non-MSC infused non transplanted mice.

kidney allografts (28), referred as engraftment syndrome (29).

To gain insight into the clinical observation in our kidney transplant recipients given MSC early posttransplant, here we moved back to a murine transplant model to address two main issues: (1) the impact of timing of MSC infusion (post vs. pretransplant) on kidney graft outcome; (2) the in vivo distribution of post- and pretransplant infused MSC 
and the consequent effects on MSC-induced immunomodulation.

This model is a fully allogeneic Balb/c kidney transplant in C57 recipient mice presensitized by donor cell infusion, which leads to generation of high frequency of donorreactive memory $T$ cells and eventually accelerates kidney graft rejection. It resembles the human transplant setting in which donor-specific memory T cells, present in higher frequency than in conventional experimental animals (30), are associated with poor allograft outcome $(31,32)$. In this murine model, we now documented that the time of syngeneic MSC infusion in respect to kidney transplantation dictates the possibility to develop early graft dysfunction as consequence of the engraftment syndrome. Indeed, as in humans, renal dysfunction did occur few days after posttransplant infusion of MSC, but not when cells were given before kidney transplantation. This effect was the result of a differential MSC distribution into the recipients according to the timing of cell infusion. Posttransplant MSC infusion resulted in preferential homing of cells into the graft, as in humans. At variance, MSC mainly localized into the spleen when infused before kidney transplantation. Subclinical graft injury induced by I/R could, at least in part, contributed to the preferential migration of MSC infused posttransplant toward the transplanted organ. This possibility is supported by the finding on intragraft MSC recruitment in syngeneic kidneys transplanted after cold ischemia. Consistently, previously published data documented preferential MSC homing to site of tissue damage in experimental models of stroked brains (33), tumors (34), ischemic myocardium (35) and acute renal failure (36). Evidence is available that in a mouse model of glycerol-induced acute renal failure the migration of infused MSC into the injured kidney was promoted by the expression of CD44 molecule on the MSC surface which binds to its ligand hyaluronic acid (HA) into the organ (36). Since increased HA production has been shown in rats with renal ischemia-reperfusion injury (37), we anticipate that CD44-HA signaling could be one of the mechanisms driving MSC recruitment into the kidney graft.

As previously found in kidney biopsies of transplant patients receiving MSC posttransplantation (23), MSC into the murine graft were associated with a significant neutrophil infiltration and complement-C3 deposition. MSC recruitment was followed by increased expression of IL-6, and TNF $\alpha$, suggesting that MSC promoted a proinflammatory environment. Despite the well-known antiinflammatory properties of MSC (5), in an inflammatory environment MSC can also shift toward a proinflammatory phenotype. In vitro activation of MSC with TLR3 and TLR4 ligands has been shown to induce the production of inflammatory mediators such as IL-1, IL6 and IL-8, further increased by IFN $\alpha$ and IFN $\gamma$ priming, an event associated in vivo with attraction of neutrophils into matrigel-embedded MSC implants (38-42). In addition, exposure of MSC to complement-active human serum/blood caused the deposition of activated complement products on the MSC cell surface and the generation of soluble anaphylatoxins (43). This process led to a complement-mediated activation of neutrophils and monocytes via the engagement of complement receptor type 3 (CD11b/CD18) on these cells (43). Together these findings suggest that in our kidney transplant model TLRs signaling and/or complement activation, both elicited in response to ischemia/reperfusion injury (44-47), would promote the activation of MSC recruited into the graft, with release into the microenvironment of neutrophil-chemotactic factors and inflammatory cytokines, and further amplification of complement activation, leading to premature acute graft dysfunction.

We then explored whether preferential localization into the spleen of MSC infused pretransplant translated into better kidney graft outcome than when cells were given after transplantation. Infusion of syngeneic MSC either at day -1 , or at day -7 or their combination, but not at day 2 posttransplantation, significantly prolonged kidney graft survival compared to transplanted animals not given MSC, all groups without any additional immunosuppressive therapy. Moreover, all animals surviving more than 20 days posttransplant had stable graft function up to the end of 60 days follow-up with minimal graft histology changes. These findings are in line with previous observation that the interaction of MSC with immune cells in lymphoid tissues is critical to achieve immunomodulation in models of autoimmune encephalomyelitis and enteropathy in mice $(48,49)$. Thus, to fully exert immunomodulatory activities in kidney transplantation setting MSC need to interact with immune cells at sites of initial effector $\mathrm{T}$ cell priming as in the spleen or lymph nodes. This supports our observation that preferential migration into the spleen of pretransplant but not posttransplant infused MSC was associated with better outcome of kidney graft.

MSC act as a pleiotropic immune regulator and suppress an ongoing immune process through various pathways (5). In particular MSC inhibit the activity of effector T cells in response to alloantigens (5). Consistently with this observation, we found reduced frequency of antidonor IFN $\gamma$ producing $T$ cells among splenocytes of MSC-tolerized mice. In addition, MSC have the unique capability to promote Treg expansion and this process has been shown to be the main mechanism of MSC-mediated tolerance induction in experimental models of solid-organ transplantation $(12,19,21,22)$. Accordingly, we also found increased number of Tregs into the spleen and kidney grafts from mice made tolerant by pretransplant MSC infusion and Treg depletion by an anti-CD25 antibody abrogated MSC-induced tolerance. Moreover, adoptive transfer of spleen Treg from MSC-infused animals into naive mice induced tolerance to a kidney allograft. These findings underline a key role of Treg in promoting MSC-induced prolongation of graft survival in our model. 


\section{Casiraghi et al.}

In summary, we documented that in a sensitized mouse model of kidney allograft, pretransplant but not posttransplant administration of syngeneic MSC avoided engraftment syndrome and promoted immunomodulation of host immune response. Through the expansion of donorspecific Treg into lymphoid organs, MSC prolonged allograft survival and eventually allowed the development of tolerance. Thus, the requirement of pretransplant infusion for safely achieving the MSC immunomodulatory effects should be taken into account in designing future clinical studies in the setting of kidney transplantation.

\section{Acknowledgments}

This study has been partially supported by grants from Fondazione ART per la Ricerca sui Trapianti (Milan, Italy). R.M. is a fellowship from Fondazione ARMR through the generosity of Delegazione ARMR Lugano Canton Ticino. We are grateful to Dr. Alessandro Rambaldi for useful discussion and criticism. The Authors are member of the Mesenchymal Stem Cells in Solid Organ Transplantation (MISOT) study group, www.misot.de.

\section{Disclosure}

The authors of this manuscript have no conflict of interest to disclose as described by the American Journal of Transplantation.

\section{References}

1. Sayegh MH Carpenter CB. Transplantation 50 years laterprogress, challenges, and promises. N Engl J Med 2004; 351: 2761-2766.

2. Sayegh MH, and Remuzzi G. Clinical update: Immunosuppression minimisation. Lancet 2007; 369: 1676-1678.

3. Dominici M, Le Blanc K, Mueller I, et al. Minimal criteria for defining multipotent mesenchymal stromal cells. The International Society for Cellular Therapy position statement. Cytotherapy 2006; 8: 315-317.

4. Nauta AJ Fibbe WE. Immunomodulatory properties of mesenchymal stromal cells. Blood 2007; 110: 3499-3506.

5. Uccelli A, Moretta L, Pistoia V. Mesenchymal stem cells in health and disease. Nat Rev Immunol 2008; 8: 726-736.

6. Rafei M, Campeau PM, Aguilar-Mahecha A, et al. Mesenchymal stromal cells ameliorate experimental autoimmune encephalomyelitis by inhibiting CD4 Th17 T cells in a CC chemokine ligand 2-dependent manner. J Immunol 2009; 182: 5994-6002.

7. Ghannam S, Pene J, Torcy-Moquet G, Jorgensen C, Yssel H. Mesenchymal stem cells inhibit human Th17 cell differentiation and function and induce a $\mathrm{T}$ regulatory cell phenotype. $\mathrm{J}$ Immunol 2010; 185: 302-312.

8. Carrion F, Nova E, Luz P, Apablaza F, Figueroa F. Opposing effect of mesenchymal stem cells on Th1 and Th17 cell polarization according to the state of CD4+ T cell activation. Immunol Lett 2011; 135: 10-16.

9. Nauta AJ, Kruisselbrink AB, Lurvink E, Willemze R, Fibbe WE. Mesenchymal stem cells inhibit generation and function of both CD34+-derived and monocyte-derived dendritic cells. J Immunol 2006; 177: 2080-2087.
10. Djouad F, Charbonnier LM, Bouffi C, et al. Mesenchymal stem cells inhibit the differentiation of dendritic cells through an interleukin-6-dependent mechanism. Stem Cells 2007; 25: 20252032.

11. English K, Barry FP, Mahon B P. Murine mesenchymal stem cells suppress dendritic cell migration, maturation and antigen presentation. Immunol Lett 2008; 115: 50-58.

12. Casiraghi F, Azzollini N, Cassis $P$, et al. Pretransplant infusion of mesenchymal stem cells prolongs the survival of a semiallogeneic heart transplant through the generation of regulatory $T$ cells. $J$ Immunol 2008; 181:3933-3946.

13. Wang Y, Zhang A, Ye Z, Xie H, Zheng S. Bone marrow-derived mesenchymal stem cells inhibit acute rejection of rat liver allografts in association with regulatory $T$ cell expansion. Transplant Proc 2009; 41: 4352-4356.

14. Bartholomew A, Sturgeon C, Siatskas M, et al. Mesenchymal stem cells suppress lymphocyte proliferation in vitro and prolong skin graft survival in vivo. Exp Hematol 2002; 30: 42-48.

15. Chabannes D, Hill M, Merieau E, et al. A role for heme oxygenase1 in the immunosuppressive effect of adult rat and human mesenchymal stem cells. Blood 2007; 110: 3691-36941.

16. Inoue S, Popp FC, Koehl GE, Piso P, Schlitt HJ, Geissler EK, Dahlke $\mathrm{MH}$. Immunomodulatory effects of mesenchymal stem cells in a rat organ transplant model. Transplantation 2006; 81: 1589-1595.

17. Popp FC, Eggenhofer E, Renner $P$, et al. Mesenchymal stem cells can induce long-term acceptance of solid organ allografts in synergy with low-dose mycophenolate. Transpl Immunol 2008; 20: 55-60.

18. Zhou HP, Yi DH, Yu SQ, et al. Administration of donor-derived mesenchymal stem cells can prolong the survival of rat cardiac allograft. Transplant Proc 2006; 38: 3046-3051.

19. Ding $Y, X u D$, Feng G, Bushell A, Muschel RJ, Wood KJ. Mesenchymal stem cells prevent the rejection of fully allogenic islet grafts by the immunosuppressive activity of matrix metalloproteinase-2 and -9. Diabetes 2009; 58: 1797-1806.

20. Ge W, Jiang J, Arp J, Liu W, Garcia B, Wang H. Regulatory T-cell generation and kidney allograft tolerance induced by mesenchymal stem cells associated with indoleamine 2,3-dioxygenase expression. Transplantation 2010; 90:1312-1320.

21. Ge W, Jiang J, Baroja ML, et al. Infusion of mesenchymal stem cells and rapamycin synergize to attenuate alloimmune responses and promote cardiac allograft tolerance. Am J Transplant 2009; 9: 1760-1772.

22. Berman DM, Willman MA, Han D, et al. Mesenchymal stem cells enhance allogeneic islet engraftment in nonhuman primates. Diabetes 2010; 59: 2558-2568.

23. Perico N, Casiraghi F, Introna M, et al. Autologous mesenchymal stromal cells and kidney transplantation: A pilot study of safety and clinical feasibility. Clin J Am Soc Nephrol 2011; 6: 412-422.

24. Morigi M, Imberti B, Zoja $C$, et al. Mesenchymal stem cells are renotropic, helping to repair the kidney and improve function in acute renal failure. J Am Soc Nephrol 2004; 15: 1794-1804.

25. Noris $M$, Todeschini $M$, Cassis $P$, et al. L-arginine depletion in preeclampsia orients nitric oxide synthase toward oxidant species. Hypertension 2004; 43: 614-622.

26. Noris $M$, Cassis $P$, Azzollini $N$, et al. The Toll-IL-1R member Tir8/SIGIRR negatively regulates adaptive immunity against kidney grafts. J Immunol 2009; 183: 4249-4260.

27. Zhang $H$, Chua KS, Guimond $M$, et al. Lymphopenia and interleukin-2 therapy alter homeostasis of CD4+CD25 +regulatory T cells. Nat Med 2005; 11: 1238-1243.

28. Farris $A B$, Taheri $D$, Kawai $T$, et al. Acute renal endothelial injury during marrow recovery in a cohort of combined kidney and bone marrow allografts. Am J Transplant 2011; 11: 1464-1477. 
29. Kawai T, Cosimi AB, Spitzer TR, et al. HLA-mismatched renal transplantation without maintenance immunosuppression. N Engl J Med 2008; 358: 353-361.

30. Valujskikh A, Li XC. Frontiers in nephrology: T cell memory as a barrier to transplant tolerance. J Am Soc Nephrol 2007; 18: 2252 2261.

31. Heeger PS, Greenspan NS, Kuhlenschmidt S, et al. Pretransplant frequency of donor-specific, IFN-gamma-producing lymphocytes is a manifestation of immunologic memory and correlates with the risk of posttransplant rejection episodes. J Immunol 1999; 163: 2267-2275.

32. Najafian N, Salama AD, Fedoseyeva EV, Benichou G, Sayegh MH. Enzyme-linked immunosorbent spot assay analysis of peripheral blood lymphocyte reactivity to donor HLA-DR peptides: Potential novel assay for prediction of outcomes for renal transplant recipients. J Am Soc Nephrol 2002; 13: 252-259.

33. Li Y, Chen J, Wang L, Zhang L, Lu M, Chopp M. Intracerebral transplantation of bone marrow stromal cells in a 1-methyl-4-phenyl1,2,3,6-tetrahydropyridine mouse model of Parkinson's disease. Neurosci Lett 2001; 316: 67-70.

34. Spaeth E, Klopp A, Dembinski J, Andreeff M, Marini F. Inflammation and tumor microenvironments: Defining the migratory itinerary of mesenchymal stem cells. Gene Ther 2008; 15: 730738.

35. Kawada H, Fujita J, Kinjo K, et al. Nonhematopoietic mesenchymal stem cells can be mobilized and differentiate into cardiomyocytes after myocardial infarction. Blood 2004; 104: 3581-3587.

36. Herrera MB, Bussolati B, Bruno S, et al. Exogenous mesenchymal stem cells localize to the kidney by means of CD44 following acute tubular injury. Kidney Int 2007; 72: 430-441.

37. Goransson V, Johnsson C, Jacobson A, Heldin P, Hallgren R, Hansell $P$. Renal hyaluronan accumulation and hyaluronan synthase expression after ischaemia-reperfusion injury in the rat. Nephrol Dial Transplant 2004; 19: 823-830.

38. Romieu-Mourez R, Francois M, Boivin MN, Bouchentouf M Spaner DE, Galipeau J. Cytokine modulation of TLR expression and activation in mesenchymal stromal cells leads to a proinflammatory phenotype. J Immunol 2009; 182: 7963-7973.

39. Raicevic G, Rouas R, Najar M, et al. Inflammation modifies the pattern and the function of Toll-like receptors expressed by human mesenchymal stromal cells. Hum Immunol 2010; 71: 235-244.

40. Waterman RS, Tomchuck SL, Henkle SL, Betancourt AM. A new mesenchymal stem cell (MSC) paradigm: Polarization into a proinflammatory MSC1 or an Immunosuppressive MSC2 phenotype. PLoS One 2010; 5: e10088.
41. Liotta F, Angeli R, Cosmi L, et al. Toll-like receptors 3 and 4 are expressed by human bone marrow-derived mesenchymal stem cells and can inhibit their T-cell modulatory activity by impairing Notch signaling. Stem Cells 2008; 26: 279-289.

42. Tomchuck SL, Zwezdaryk KJ, Coffelt SB, Waterman RS, Danka ES, Scandurro AB. Toll-like receptors on human mesenchymal stem cells drive their migration and immunomodulating responses. Stem Cells 2008; 26: 99-107.

43. Moll G, Jitschin R, von Bahr L, et al. Mesenchymal stromal cells engage complement and complement receptor bearing innate effector cells to modulate immune responses. PLoS One 2011; 6: e21703.

44. Kaczorowski DJ, Nakao A, Mollen KP, et al. Toll-like receptor 4 mediates the early inflammatory response after cold ischemia/reperfusion. Transplantation 2007; 84: 1279-1287.

45. Leemans JC, Stokman G, Claessen N, et al. Renal-associated TLR2 mediates ischemia/reperfusion injury in the kidney. J Clin Invest 2005; 115: 2894-2903.

46. Wu H, Chen G, Wyburn KR, et al. TLR4 activation mediates kidney ischemia/reperfusion injury. J Clin Invest 2007; 117: 2847-2859.

47. Damman J, Schuurs TA, Ploeg RJ, Seelen MA. Complement and renal transplantation: From donor to recipient. Transplantation 2008; 85: 923-927

48. Zappia E, Casazza S, Pedemonte E, et al. Mesenchymal stem cells ameliorate experimental autoimmune encephalomyelitis inducing T-cell anergy. Blood 2005; 106: 1755-1761.

49. Parekkadan B, Tilles AW, Yarmush ML. Bone marrow-derived mesenchymal stem cells ameliorate autoimmune enteropathy independently of regulatory T cells. Stem Cells 2008; 26: 1913-1919.

\section{Supporting Information}

The following additional supporting information may be found in the online version of this article:

Figure S1: Donor sensitization induced donor-specific antibody development.

Please note: Wiley-Blackwell is not responsible for the content or functionality of any supporting materials supplied by the authors. Any queries (other than missing material) should be directed to the corresponding author for the article. 


\section{CHAPTER 5}

Mesenchymal stromal cells and kidney transplantation: pretransplant infusion protects from graft dysfunction while fostering immunoregulation

N. Perico, F. Casiraghi, M. Introna, E. Gotti, M. Todeschini, R.A. Cavinato, C. Capelli,

A. Rambaldi, P. Cassis, P. Rizzo, M. Cortinovis, M. Marasà, J Golay, M. Noris and G. Remuzzi

published in: Transplant International 2013; 26:867-78 


\title{
Mesenchymal stromal cells and kidney transplantation: pretransplant infusion protects from graft dysfunction while fostering immunoregulation
}

\author{
Norberto Perico, ${ }^{1,2 *}$ Federica Casiraghi, ${ }^{1,2 *}$ Eliana Gotti, ${ }^{1 *}$ Martino Introna, ${ }^{3}$ Marta Todeschini, ${ }^{1,2}$ \\ Regiane Aparecida Cavinato, ${ }^{1,2}$ Chiara Capelli, ${ }^{3}$ Alessandro Rambaldi, ${ }^{4}$ Paola Cassis, ${ }^{1,2}$ Paola Rizzo, ${ }^{1}$ \\ Monica Cortinovis, ${ }^{1,2}$ Marina Noris ${ }^{1,2}$ and Giuseppe Remuzzi ${ }^{1,2}$ \\ 1 Department of Immunology and Transplantation, Azienda Ospedaliera - IRCCS - Istituto di Ricerche Farmacologiche "Mario Negri", Bergamo, Italy \\ 2 Transplant Research Center, "Chiara Cucchi de Alessandri e Gilberto Crespi" Ranica, Bergamo, Italy \\ 3 Laboratory of Cell Therapy "G. Lanzani", Papa Giovanni XXIII, Bergamo, Italy \\ 4 Department of Hematology, Papa Giovanni XXIII, Bergamo, Italy
}

\author{
Keywords \\ immunomodulation, living-related kidney \\ transplantation, mesenchymal stromal cells, \\ pretransplant cell infusion. \\ Correspondence \\ Giuseppe Remuzzi MD, FRCP, IRCCS - Istituto \\ di Ricerche Farmacologiche "Mario Negri", \\ Centro Anna Maria Astori, Science and \\ Technology Park, Kilometro Rosso, Via \\ Stezzano 87, 24126 Bergamo, Italy. \\ Tel.: +39 0354213404; \\ fax: +39035319331 ; \\ e-mail: giuseppe.remuzzi@marionegri.it
}

Conflicts of interest

There is no conflict of interest for any of the authors of the manuscript.

*These authors contributed equally to this study.

Received: 17 December 2012

Revision requested: 28 January 2013

Accepted: 13 May 2013

doi:10.1111/tri.12132

\section{Introduction}

Notwithstanding promising preclinical [1-11] and early clinical [12] results with bone marrow-derived mesenchymal stromal cells (MSC), moving the concept of MSCbased therapy forward towards clinical application in solid organ transplantation should be critically assessed. There are few protocols of MSC-based therapy in organ transplantation [13-18]. Our clinical MSC protocol in renal

\begin{abstract}
Summary
Bone marrow-derived mesenchymal stromal cells (MSC) have emerged as useful cell population for immunomodulation therapy in transplantation. Moving this concept towards clinical application, however, should be critically assessed by a tailor-made step-wise approach. Here, we report results of the second step of the multistep MSC-based clinical protocol in kidney transplantation. We examined in two living-related kidney transplant recipients whether: (i) pre-transplant (DAY-1) infusion of autologous MSC protected from the development of acute graft dysfunction previously reported in patients given MSC post-transplant, (ii) avoiding basiliximab in the induction regimen improved the MSC-induced Treg expansion previously reported with therapy including this anti-CD25-antibody. In patient 3, MSC treatment was uneventful and graft function remained normal during 1 year follow-up. In patient 4 , acute cellular rejection occurred 2 weeks post-transplant. Both patients had excellent graft function at the last observation. Circulating memory $\mathrm{CD}^{+} \mathrm{T}$ cells and donor-specific $\mathrm{CD}^{+}{ }^{+} \mathrm{T}$-cell cytolytic response were reduced in MSC-treated patients, not in transplant controls not given MSC. $\mathrm{CD}^{+}{ }^{+} \mathrm{FoxP}^{+}$Treg expansion was comparable in MSC-treated patients with or without basiliximab induction. Thus, pre-transplant MSC no longer negatively affect kidney graft at least to the point of impairing graft function, and maintained MSC-immunomodulatory properties. Induction therapy without basiliximab does not offer any advantage on $\mathrm{CD} 4^{+} \mathrm{FoxP}^{+}{ }^{+}$Treg expansion (ClinicalTrials.gov number: NCT 00752479).
\end{abstract}

transplant recipients was conceived as a tailor-made stepwise approach every few patients to look for the unexpected and ultimately identify a definite protocol that allows to create favourable conditions for tolerance while avoiding unwanted effects. This strategy has been adopted because MSC-therapy in organ transplantation is a very innovative potentially useful approach to transplant tolerance, but still in its infancy. Indeed, while initial results appear promising, there remain many open questions as to how these cells 
have to be administered and how they may function to modulate host immune response in vivo in clinical transplant setting. Along this line, our protocol was focussed to characterize the safety and tolerability of peri-transplant MSC infusion and define the biological/mechanistic effects of this cell therapy. Similar to the approach to the pathophysiology of a rare condition in few patients that may contribute to the understanding of other more common disorders, intensively studying few transplant patients given MSC would possibly enlighten the path to elucidate safety issues and mechanistic immunomodulatory pathways rather than jumping altogether on large trials before fundamental questions have been addressed. Admittedly, this reflects the opinion of the authors. Still we believe that playing with cells and potent biological agents for which there is uncertainty about safety and efficacy and that may have unexpected side effects justify cautiousness. Thus, we initially started with two living-related donor kidney recipients who were given ex vivo expanded, autologous, bone marrow-derived MSC at day 7 post-transplant, after induction therapy with basiliximab/low-dose thymoglobulin [15]. MSC infusion did promote on long-term a pro-tolerogenic environment characterized by lower memory/effector $\mathrm{CD}^{+} \mathrm{T}$ cells, expansion of $\mathrm{CD}^{+}$Tregs and reduction in donor-specific $\mathrm{CD}^{+}$T-cell cytotoxicity, compared with control kidney transplant recipients given the same induction therapy but not MSC. However, few days after cell infusion, both MSC-treated patients developed acute renal insufficiency. Histological and immunohistochemical analysis of graft infiltrating cells did exclude an acute cellular or humoral rejection, but intragraft recruitment of neutrophils together with MSC, as well as complement-C3 deposition were observed [15]. It was hypothesized that the subclinical inflammatory environment of the graft in the few days of postsurgery could have favoured the prevalent intragraft recruitment and activation of the infused MSC promoting a pro-inflammatory milieu with eventual acute renal dysfunction (engraftment syndrome), as reported by others with combined kidney and bone marrow transplantation [19]. Therefore, to gain insight into the clinical observation in these two patients given MSC post-transplantation, we moved back to a clinically relevant murine kidney transplant model, and found that a single administration of cells before (DAY-1) but not after renal transplantation avoided the acute deterioration of graft function, while maintaining the immunomodulatory effects associated with MSC treatment, including a marked Treg expansion [8].

These experimental findings did represent a gain of knowledge to further implement our clinical protocol with the aim to create favourable conditions for MSC-promoting immunomodulation and Treg expansion, avoiding the unwanted effect of acute deterioration of graft function associated with the prevalent intragraft localization of MSC when given at day 7 post-transplantation.

Moreover, our first two MSC-treated transplant recipients were given induction therapy which included the antiIL-2-receptor (CD25) monoclonal antibody basiliximab [15]. Recent evidence in kidney transplant patients showed that basiliximab may cause a transient loss of CD $25^{+}$FoxP3 ${ }^{+}$Treg cells in the circulation [20]. Together these findings led us to eliminate basiliximab from the induction regimen used in previous step 1 with the aim to possibly maximize the expansion of $\mathrm{CD} 25^{+}$FoxP $3^{+}$Treg cells.

Therefore, in this study (step 2) in two additional livingrelated kidney transplant recipients, we sought to: (i) look for unwanted and unexpected events when autologous bone marrow-derived MSC are administered at DAY-1 pretransplantation, (ii) evaluate the induction therapy that would maximize the MSC-induced Treg expansion and immunomodulation in the setting of pretransplant cell infusion, (iii) get insights on the mechanisms underlying the promotion in vivo of a pro-tolerogenic environment, if any, by MSC-based therapy.

\section{Patients and methods}

\section{Patients}

A 37-year-old man (patient 3) on peritoneal dialysis caused by end-stage renal disease (ESRD) secondary to IgA nephropathy received a renal transplant from his father, mismatched for two HLA haplotypes (one mismatch on HLA-A and one on HLA-DR) (Table 1).

A consecutive 34-year-old man (patient 4) on ESRD secondary to medullary sponge disease received a pre-

Table 1. Baseline patients' characteristics.

\begin{tabular}{|c|c|c|c|c|}
\hline & Patient 3 & Patient 4 & $\begin{array}{l}\text { Control group 1* } \\
\text { RATG alone }\end{array}$ & $\begin{array}{l}\text { Control } \\
\text { group 2* } \\
\text { Bas/RATG }\end{array}$ \\
\hline Age & 37 & 34 & $56 \pm 9$ & $42 \pm 15$ \\
\hline Gender (M/F) & M & M & $5 / 1$ & $4 / 2$ \\
\hline $\begin{array}{l}\text { HLA mismatches } \\
\text { median (range) }\end{array}$ & 2 & 3 & $4(3-5)$ & $2(0-4)$ \\
\hline Cross-match & Negative & Negative & Negative & Negative \\
\hline $\begin{array}{l}\text { Anti-donor } \\
\text { HLA Abs }\end{array}$ & Negative & Negative & Negative & Negative \\
\hline
\end{tabular}

*Control group 1: kidney transplant recipients given induction therapy with RATG alone and not given MSC $(n=6)$. Control group 2: kidney transplant recipients given Bas/RATG induction therapy but not MSC $(n=6)$.

Data are mean $\pm S D$. HLA mismatches range was 0-3 for living-donors $(n=3)$ and 3-4 for deceased donor $(n=3)$.

RATG, rabbit anti-thymocyte globulin; Bas, basiliximab. 
emptive renal transplant from his mother, mismatched for three HLA haplotypes (one on HLA-A, HLA-B and HLA$\mathrm{DR}$, respectively) (Table 1). Although negative for antidonor HLA-antibodies, he was positive for nondonor-specific anti-HLA DR4 antibodies.

Four to six months before transplantation both of them underwent right posterior superior iliac crest aspiration under local anaesthesia. MSC were isolated and ex vivo expanded according to Good-Manufacturing-Practice procedures (Cell Therapy Laboratory "G Lanzani”, Ospedali Riuniti di Bergamo, authorization no. aM-189/2008 Agenzia Italiana del Farmaco, AIFA [21,22]). The day before kidney transplantation (DAY-1), autologous MSC were administered intravenously $\left(2.0 \times 10^{6}\right.$ cells $/ \mathrm{kg}$ body weight) after premedication with chlorphenamine and hydrocortisone. Immunophenotyping of peripheral blood T-cell subsets and monitoring of T-lymphocyte function were performed before and up to day 360 and 180 posttransplant, in patients 3 and 4, respectively. Written informed consent was obtained from recipients and living donors. All treatment protocols were approved by the Istituto Superiore di Sanità (ISS, Rome, Italy, authorization no. 45253(06)-PRE.21-882) and by the Institutional Review Board of the Ospedali Riuniti di Bergamo (authorization no. 352, March 18, 2008).

The patients received induction therapy with low-dose rabbit anti-thymocyte globulin (RATG) infusion (thymoglobulin, $0.5 \mathrm{mg} / \mathrm{kg}$ daily starting immediately pretransplantation up to day 6 post-transplant). Maintenance immunosuppression was with cyclosporine A (CsA, target trough blood levels of $300-400 \mathrm{ng} / \mathrm{ml}$ up to day 7 postsurgery, and $100-150 \mathrm{ng} / \mathrm{ml}$ at month 5 post-transplantation), mycophenolate mofetil (plasma trough mycophenolic acid levels [23] of $0.5-1.5 \mu \mathrm{g} / \mathrm{ml})$, and steroids. Five hundred milligrams of methylprednisolone were administered before the first RATG infusion and continued for 2 more days post-transplantation (250 and $125 \mathrm{mg}$, respectively). Thereafter, oral prednisone (75 mg) was administered, which was progressively tapered and discontinued after day 7 postsurgery. As controls, historical kidney transplant recipients with a deceased donor $(n=6$, Table 1$)$ given induction therapy with low-dose RATG and the same maintenance immunosuppression were also considered. From these patients, PBMC samples taken before and at days 180 and 360 post-transplant were available. Donor cells for functional studies were, however, available only from one patient. Thus, as additional controls, six patients receiving a living-related $(n=3)$ or deceased kidney $(n=3)$ with comparable HLA mismatches (Table 1), but not MSC from whom donor cells were available were studied. They were given basiliximab and low-dose RATG and the same maintenance immunosuppressive regimen of MSC-treated patients.
This induction therapy has been introduced in our clinical practice in kidney transplantation since 2005 to minimize side effects associated with the standard dose of RATG [24]. Moreover, to avoid the risk of insufficient anti-rejection activity, we integrated this regimen of very low dose of RATG (approximately half the currently recommended doses for induction and one-third to onefourth of doses administered in the large majority of previous reports [25-27]) with basiliximab (20 mg day i.v. at day 0 and day 4 post-transplantation) with the rationale of inhibiting those lymphocytes eventually surviving low-dose RATG exposure. The dual induction regimen allows to achieve rapid and effective lymphocyte depletion while simultaneously allowing safe minimization of maintenance immunosuppression, especially when low dose RATG is started before patient referral to the surgical room [28]. With this perioperative minimal induction therapy, the rate of acute graft rejection was very low (4\%) [28]. This is in line with recent findings with a similar regimen of dual antibody induction therapy with ATG and daclizumab [29].

\section{MSC isolation and expansion}

Mesenchymal stromal cells were processed and cultured as previously reported [21,22]. Cells were classified as MSC based on their ability to differentiate into bone, fat and cartilage, and by flow cytometric analysis (positive for CD44, CD29, CD73, HLA-ABC, CD90, and CD105, but negative for CD14, CD34, CD45 and HLA-DR) responding to defined criteria for MSC stated by the International Society of Cell Therapy [30]. The final product was characterized with respect to viability, purity and therapeutic potential. Detailed methods for MSC isolation and expansion and characterization are given in Data S1.

\section{Immunophenotyping of peripheral blood lymphocytes}

Blood mononuclear cells were stained with fluorochrome conjugated monoclonal antibodies against CD3, CD4, CD8, CD45RO, CD45RA, CD25 (clone MA251, which binds to a CD25 epitope different from that recognized by basiliximab), CD127 and FoxP3. Multicolour flow cytometry was used to identify T-cell subsets with standard techniques and equipment (FACSAria - BD Bioscience) [31].

\section{Ex vivo functional immunological assays}

Transplant patients were monitored before and every 6 months post-transplantation for alloimmune response against donor and third-party antigens by cell-mediated lympholysis [15]. 


\section{Histology and immunohistochemistry}

Detailed methods for histological and immunohistochemical analysis are given in Data S1.

\section{Statistical analyses}

Variations in peripheral blood $\mathrm{CD}^{+}$and $\mathrm{CD} 8^{+}$T-cell counts, percentage and counts of T-cell subpopulations and $\mathrm{CD}^{+}{ }^{+} \mathrm{T}$-cell-mediated lysis from control kidney transplant recipients not given MSC as well as variation in peripheral T-cell counts and percentages between the two control groups were assessed by AnOva. The statistical significance level was defined as $P<0.05$.

\section{Results}

\section{Clinical course}

In patient 3, pretransplant infusion of MSC was uneventful. After kidney transplantation, renal function rapidly improved and normalized within 3 days (Fig. 1a). Thereafter, the graft function remained stable up to day 360 posttransplantation. At this time point, a 'protocol' biopsy showed no signs of acute rejection (Fig. 1b). The patient is in good health with stable graft function at the last available evaluation (day 540 post-Tx: serum creatinine $1.0 \mathrm{mg} / \mathrm{dl}$; proteinuria $0.14 \mathrm{~g} / 24 \mathrm{~h}$ ).

Patient 4 also received pretransplant MSC infusion with no side effects. Renal function rapidly improved and normalized on day 3 post-transplant (serum creatinine $1.3 \mathrm{mg} / \mathrm{dl}$ ). From day 14 onwards, a rapid progressive increase in serum creatinine was observed up to $2.3 \mathrm{mg} / \mathrm{dl}$ (Fig. 1c). Renal ultrasound showed normal structure and resistivity index (IR: 0.58). CsA trough levels were in the therapeutic range. A moderate increase in temperature $\left(38{ }^{\circ} \mathrm{C}\right)$ was documented. Thoracic X-ray, viral blood tests and urine culture were negative. On day 17 post-transplant, a kidney biopsy was performed which showed moderatesevere acute cellular rejection (Fig. 1d). Intravenous pulses of methylprednisolone were started. After tapering, the corticosteroid was maintained at the daily dose of $8 \mathrm{mg}$. Renal function progressively improved and serum creatinine returned to normal value within 10 days (serum creatinine $1.3 \mathrm{mg} / \mathrm{dl}$ ). At 12 months post-transplant, the patient was in good health with stable graft function (serum creatinine $1.25 \mathrm{mg} / \mathrm{dl}$; proteinuria $0.11 \mathrm{~g} / 24 \mathrm{~h}$ ).

In the control groups not receiving MSC, at 180 posttransplantation serum creatinine levels were $1.58 \pm 0.28$ and $1.47 \pm 0.40 \mathrm{mg} / \mathrm{dl}$ and proteinuria values were $0.27 \pm 0.12$ and $0.26 \pm 0.16 \mathrm{~g} / 24 \mathrm{~h}$ in patients given lowdose RATG or the combination of Bas/low-dose RATG, respectively. At 360 post-transplantation, serum creatinine levels were $1.45 \pm 0.31$ and $1.54 \pm 0.34 \mathrm{mg} / \mathrm{dl}$ and proteinuria values were $0.26 \pm 0.17$ and $0.18 \pm 0.19 \mathrm{~g} /$ $24 \mathrm{~h}$, respectively. No acute rejection episodes occurred in these control patients during the 1-year follow-up.

\section{Histology and immunohistochemistry}

The 1-year protocol biopsy from patient 3 showed very mild signs of CsA chronic nephrotoxicity including interstitial fibrosis, thickness of vessel wall as well as focal atrophic lesions of the tubular epithelium (Fig. 1b). Graft infiltrating CD44/CD105-double positive cells, considered as bona-fide MSC [15] were negligible (Fig. 1e). Early posttransplant biopsy of patient 4 showed moderate-interstitial fibroedema and severe lymphocyte infiltrate of perivascular interstitium and tubular epithelium, consistent with acute cellular rejection (Fig. 1d). Staining for C4d was negative. Intragraft $\mathrm{CD}^{+}, \mathrm{CD}^{+} \mathrm{T}$ cells and $\mathrm{CD} 20^{+} \mathrm{B}$ cells were lower than in a control group of patients with acute cellular rejection, but higher than in transplant recipients without graft rejection (Fig. 1f). The number of granulocytes in the graft was negligible and comparable to control graft biopsies with acute cellular rejection (Fig. 1f). MSC were negligible in the graft of patient 4 (Fig. 1e).

\section{Immunophenotyping of peripheral blood lymphocytes}

In patients 3 and 4 , and in control kidney transplant recipients, RATG induced profound $\mathrm{CD}^{+}$and $\mathrm{CD}^{+}$T-cell depletion in the peripheral blood (Fig. 2).

In patient 3, percentage and counts of memory/effector $\mathrm{CD}^{+} \mathrm{CD} 45 \mathrm{RO}^{+} \mathrm{RA}^{-} \mathrm{T}$ cells markedly decreased within day 7 post-transplant and remained lower than pretransplant values thereafter (Fig. 3a and b). In patient 4 , the percentage of $\mathrm{CD}^{+} \mathrm{CD} 45 \mathrm{RO}^{+} \mathrm{RA}^{-} \mathrm{T}$ cells was reduced at day 7 post-transplant as compared with pretransplant values, remained stable thereafter up to day 180 with the exception of a transient increase at day 14 and further decreased at day 360 (Fig. 3a). CD8 ${ }^{+} \mathrm{CD} 45 \mathrm{RO}^{+} \mathrm{RA}^{-}$T-cell counts during the whole post-transplant period were lower than pretransplant values (Fig. 3b). Conversely, in control patients given induction therapy with low-dose RATG alone, percentages and counts of $\mathrm{CD}{ }^{+} \mathrm{CD} 45 \mathrm{RO}^{+} \mathrm{RA}^{-} \mathrm{T}$ cells significantly increased at days 180 and 360 post-transplant as compared with pretransplant values (Fig. $3 \mathrm{a}$ and b). In control patients given Bas/low-dose RATG, the percentages and counts of $\mathrm{CD} 8{ }^{+} \mathrm{CD} 45 \mathrm{RO}^{+} \mathrm{RA}^{-} \mathrm{T}$ cells up to day 360 post-transplant was comparable with pretransplant values (Fig. 3a and b).

The percentage of $\mathrm{CD} 4{ }^{+} \mathrm{CD} 25^{\text {high }} \mathrm{FoxP} 3^{+} \mathrm{CD} 127^{-}$regulatory $\mathrm{T}$ cells (Treg) was mildly reduced in patient 3 , remained unchanged in patient 4 till 180 days post-transplant and decrease at day 360 as compared with pretransplant value during the respective observation period 
(a)

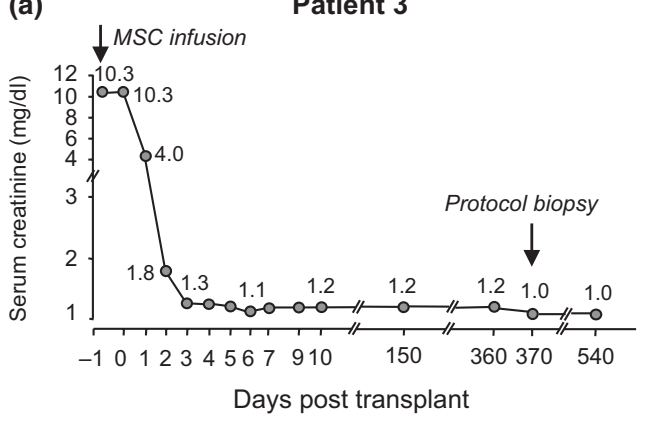

(c)

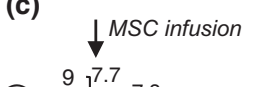

Patient 4

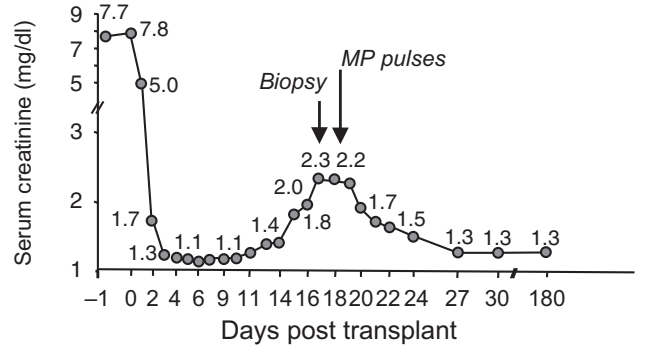

(d)

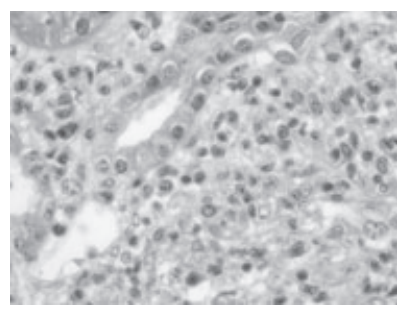

(b)

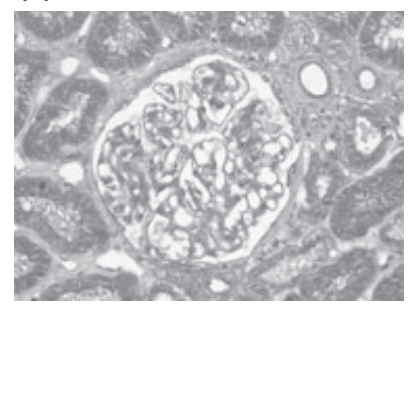

\begin{tabular}{lcc}
\hline (e) & $\begin{array}{c}\text { CD105 }{ }^{+} \mathrm{CD44} \\
\left(\mathrm{cells} / 3 \mathrm{~mm}^{2}\right)\end{array}$ \\
& $\mathbf{M S C s}$ \\
Pt 3 & 1.36 \\
Ctr: Per-protocol biopsy & 1.4 \\
Ctr: Normal kidneys $(\mathrm{n}=4)$ & $1.5 \pm 2.6$ \\
& \\
Pt 4 & $\mathbf{5 . 5}$ \\
Pt. with acute rejection & 0 \\
\hline
\end{tabular}

\begin{tabular}{|c|c|c|c|c|c|c|}
\hline (f) & $\begin{array}{l}\mathrm{CD}^{+} \\
\mathrm{T} \text { cells }\end{array}$ & $\begin{array}{l}\mathrm{CD}^{+} \\
\mathrm{T} \text { cells }\end{array}$ & $\begin{array}{l}\mathrm{CD}^{+} 0^{+} \\
\mathrm{B} \text { cells } \\
\quad \text { (cell. }\end{array}$ & $\begin{array}{c}\mathrm{CD68}^{+} \\
\text {macrophages } \\
\text { /field) }\end{array}$ & Granulocytes & $\begin{array}{c}\text { C3 } \\
\text { (semiquantitative } \\
\text { score) }\end{array}$ \\
\hline $\mathrm{Pt} 3$ & 14.6 & 16.7 & 6.2 & 30.6 & 7.7 & \\
\hline $\begin{array}{l}\text { Ctrs: per-protocol } \\
\text { biopsies }(n=3)\end{array}$ & $9.5 \pm 5.6$ & $14 \pm 7$ & $3 \pm 2.4$ & $25 \pm 8$ & $5.8 \pm 4.2$ & \\
\hline $\begin{array}{l}\text { Pt } 4 \\
\text { Pts with acute } \\
\text { rejections }(n=3)\end{array}$ & $\begin{array}{c}45.0 \\
80 \pm 35\end{array}$ & $\begin{array}{c}\mathbf{2 8 . 2} \\
103 \pm 35\end{array}$ & $\begin{array}{c}8.6 \\
20 \pm 16\end{array}$ & $\begin{array}{c}37.3 \\
58 \pm 2\end{array}$ & $\begin{array}{c}\mathbf{8 . 6} \\
5.5 \pm 1.2\end{array}$ & $\begin{array}{c}\mathbf{0 . 6} \\
0.2 \pm 0.3\end{array}$ \\
\hline
\end{tabular}

Figure 1 Post-transplant course of graft function and histologic and immunohistochemic analysis of kidney graft biopsies from patients given pretransplant MSC infusion. (a) Profile of serum creatinine levels during the 1 year follow-up and (b) a representative image of Gomori's trichrome staining on protocol kidney graft biopsy (original magnification 200x) of patient 3 are shown. (c) Profile of serum creatinine levels during the 6 months follow-up and (d) a representative image of H\&E staining on kidney graft biopsy taken at day 17 post-transplant (original magnification $200 \times$ ) of patient 4 are shown. Measured GFR was $62.5 \mathrm{ml} / \mathrm{min} / 1.73 \mathrm{~m}^{2}$ at day 540 post-transplant in patient 3 and $51.06 \mathrm{ml} / \mathrm{min} / 1.73 \mathrm{~m}{ }^{2}$ at $6 \mathrm{months}$ posttransplant in patient 4. Panel (e) reports intragraft CD105 and CD44 double positive cell counts in patients 3 and 4 and in sections of normal renal tissue from patients undergoing nephrectomy for renal carcinoma. The total number of double-positive cells counted in $3 \mathrm{~mm}^{2}$ (corresponding to the area of about 30 high-power fields) is reported. Panel (f) reports counts of intragraft cell infiltrate and score of C3 complement deposition in patients 3 and 4. As controls, renal biopsies from patients with acute graft rejection $(n=3)$ within 15-100 days postoperatively, and patients $(n=3)$ undergoing per-protocol biopsy at 1 year post-transplant were analyzed in parallel (means \pm SD). For both immunofluorescence and immunoperoxidase analyses the number of positive cells were counted in at least 20-30 high power fields. Complement deposition was scored for intensity (absent, faint, moderate, intense: 0-3) in at least 20-30 high power fields. MSC, mesenchymal stromal cells. 

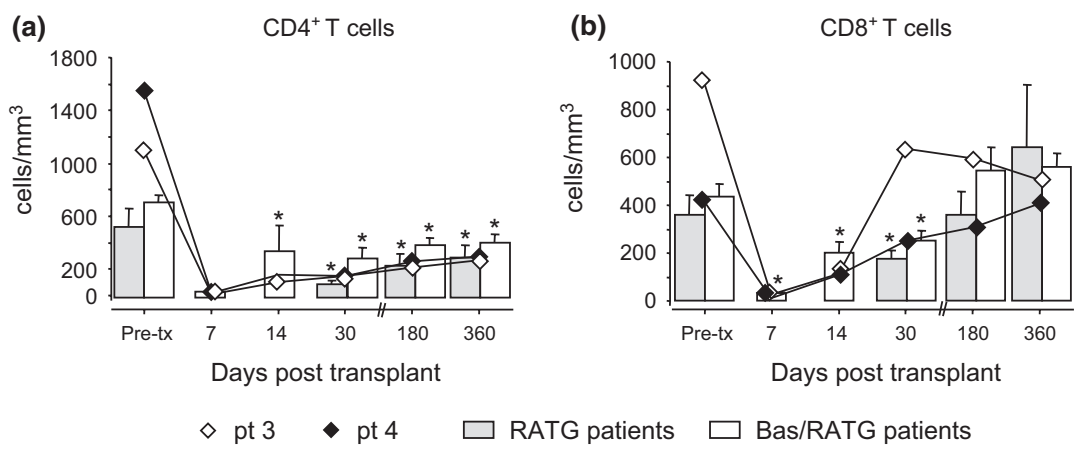

Figure 2 Profile of repopulating $C D 4^{+}$and $C D 8^{+}$T-cell counts. Absolute number of $C D 4^{+}(a)$ and $C D 8^{+}(b) T$ cells in peripheral blood of patient 3 (open diamonds), patient 3 (black diamonds) and control patients given RATG alone (grey histograms) or Bas/RATG (white histograms) not given MSC from baseline to 360 days post-transplant. Data are mean \pm SE. $* P<0.05$ versus pretransplant. At days 180 and 360 post-transplant, CD4 ${ }^{+} T_{-}$-cell counts remained lower than post-transplant values, whereas $C D 8^{+} \mathrm{T}$ cells approached pretransplant values both in patients given MSC and in the control groups not receiving the cell therapy.

(Fig. 3c). In both patients, Treg counts in the post-transplant period were lower than pretransplant except a marked increase in patient 4 at day 14 (Fig. 3d). In control patients given low-dose RATG alone, the percentage of Tregs at days 180 and 360 post-transplantation was comparable with pre-transplant value (Fig. 3c), whereas Treg cell numbers were significantly reduced (Fig. 3d). In the additional control group given Bas/low-dose RATG, a transient decrease in the percentage and counts of Treg up to day 30 post-transplant was documented, with complete recovery to pretransplant value thereafter (Fig. $3 \mathrm{c}$ and $\mathrm{d}$ ). Thus, the ratio of percentage of Treg/memory-effector $\mathrm{CD}^{+} \mathrm{T}$ cells was higher in patient 3, but not in patient 4 given MSC than in control recipients (Fig. 3e), whereas higher ratio of cell number of Treg/memory-effector $\mathrm{CD}^{+} \mathrm{T}$ cells was found in both patients (Fig. 3f).

\section{Effect of current induction regimen without basiliximab on FoxP3 ${ }^{+}$T-cell profile}

We compared the peripheral blood profile of $\mathrm{CD} 4{ }^{+} \mathrm{CD} 25^{\text {high }} \mathrm{FoxP}^{+} \mathrm{CD} 127^{-}$Treg in patients 3 and 4 given MSC and the induction therapy that avoids basiliximab with that in our previous MSC-treated patients 1 and 2 who received both basiliximab and low-dose RATG as induction regimen [15]. Patient 3 but not 4 showed an initial decline in $\mathrm{CD}^{+} \mathrm{CD} 25^{\text {high }} \mathrm{FoxP} 3^{+} \mathrm{CD} 127^{-}$Treg, less marked then that found in patients 1 and 2 (Fig. 4a). However, in all patients the Treg count recovered to pretransplant values between days 30 and 180 after transplantation and remained unchanged thereafter.

As basiliximab has been shown to down-regulate the expression of CD25 on Treg in vivo in renal transplant patients [32], we also evaluated percentages of total FoxP3expressing $\mathrm{CD}^{+} \mathrm{T}$ cells in MSC-treated patients. Total
FoxP3 expressing $\mathrm{CD}^{+}{ }^{+} \mathrm{T}$ cells underwent a significant expansion during the first 30 days post-transplant in all MSC patients but one (patient 1). At days 180 and 360, the level of $\mathrm{CD}^{+}{ }^{+} \mathrm{Foxp}^{+}$Treg was similar among MSC-treated and control patient group (Fig. 4b).

\section{Ex vivo immunologic functional assay}

In patient 3 , the cytolytic function of $\mathrm{CD}^{+} \mathrm{T}$ cells was completely abrogated in response to donor antigens and reduced against third-party antigens (Fig. 5). In patient 4, the $\mathrm{CD}^{+}{ }^{+} \mathrm{T}$-cell-mediated lympholysis against donor and third-party cells was completely abrogated at day 180 posttransplant. At day 360, the anti-donor $\mathrm{CD}^{+}$T-cell-mediated lympholysis still remained undetectable whereas antithird party response recovered to pretransplant values. In the patient given induction therapy with low-dose RATG alone, the anti-donor and anti-third party cytolytic response at days 180 and 360 post-transplant were similar to pretransplant levels, with a marked increase in the antithird party response at day 180 (Fig. 5). In the control group of patients given Bas/low-dose RATG, the $\mathrm{CD} 8^{+} \mathrm{T}$ cell cytolytic response toward donor antigens was transiently reduced at day 180 post-transplant as compared to pretransplant values and did not significantly change in response to third-party antigens (Fig. 5).

\section{Discussion}

The main purposes of the study were to: (i) establish whether DAY-1 pretransplant infusion of autologous bone marrow-derived MSC as compared to our previous protocol of MSC treatment at day 7 post-transplant in the context of kidney transplantation protects from cell-induced impairment of graft function and (ii) evaluate the effect on 

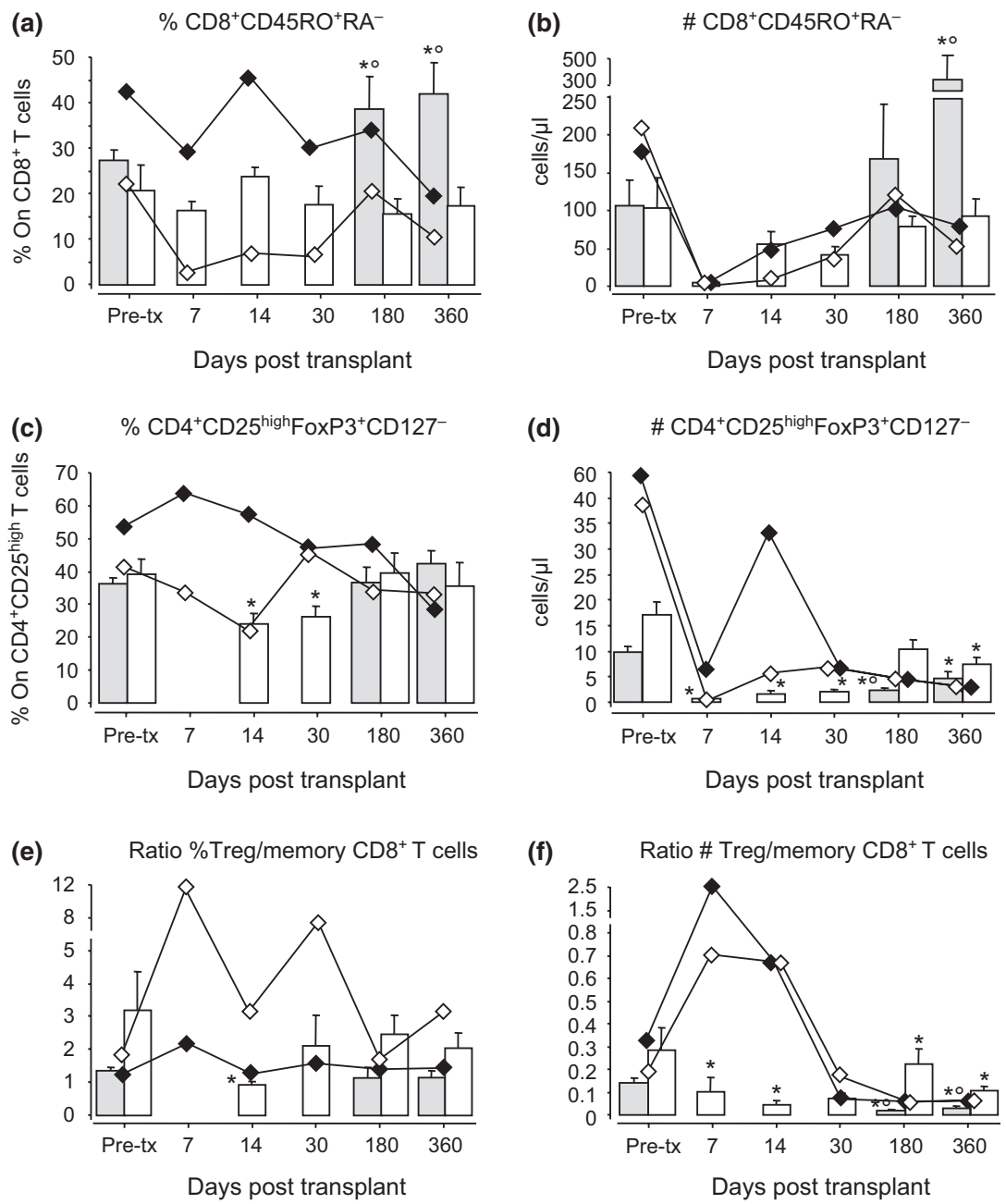

$\diamond$ pt $3 \diamond$ pt $4 \square$ RATG patients $\square$ Bas/RATG patients

Figure 3 Profile of memory and regulatory T cells in the peripheral blood. Percentages (within total CD8 ${ }^{+} \mathrm{T}$ cells) (a) and cell numbers (b) of memory CD45RO ${ }^{+} R A^{-} T$ cells and percentages (within $C D 4^{+} C D 25^{\text {high }} \mathrm{T}$ cells) (c) and cell number (d) of regulatory FoxP $3^{+} \mathrm{CD} 127^{-}$cells from patient 3 (open diamonds) and 4 (black diamonds) and from control patients given RATG alone (grey histograms) or Bas/RATG (white histograms) not given MSC from baseline to 360 days post-transplant. Panels (e) and (f) represent ratios of either percentages or cell number of $C D 4^{+} \mathrm{CD} 25^{\text {high }}$ FoxP3 ${ }^{+} \mathrm{CD} 127^{-} \mathrm{T}$ cells/ memory CD45RO ${ }^{+} A^{-} C D 8^{+} T$ cells from patient 3 (open diamonds) and 4 (black diamonds) and from control patients given RATG alone (grey histograms) or Bas/RATG (white histograms) not given MSC from baseline to 360 days post-transplant. Data are means \pm SEM. $* P<0.05$ versus pre-tx; ${ }^{\circ} P<0.05$ versus Bas/RATG patients.

circulating Treg of the induction regimen without basiliximab as compared with our previous induction therapy including this anti-CD25 antibody in MSC-treated patients.

\section{Pre-transplant MSC infusion protects from post- transplant cell-induced graft dysfunction}

None of the two patients developed cell-mediated impairment of graft function after pretransplant MSC infusion. In the first patient (3) the cell treatment was uneventful and graft function remained normal during the 1 year follow-up post-transplantation. These findings translated to clinics a recent observation in a murine model of kidney transplantation that the time of MSC infusion in respect to the allograft dictates the possibility to develop early graft dysfunction as a consequence of preferential intragraft localization of infused cells [8]. Thus, in mice given MSC the day before kidney transplantation, the cells mainly localized into the spleen. None of the animals developed kidney graft dysfunction. At variance, post-transplant MSC infusion resulted in preferential homing of cells into the grafts, associated with graft dysfunction. This observation is consistent with previously published data of preferential MSC homing to the site of 
(a)

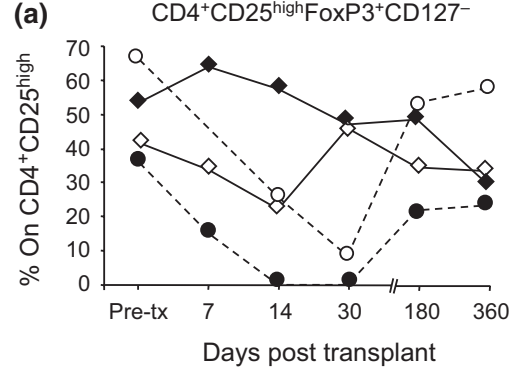

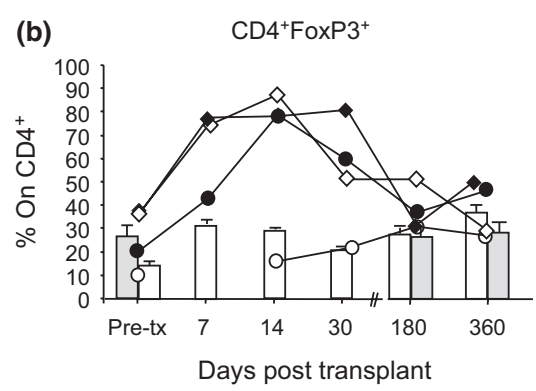

RATG patients $\square$ Bas/RATG patients

Figure 4 Profile of $\mathrm{CD} 4^{+} \mathrm{CD} 25^{\text {high }} \mathrm{Foxp3}^{+} \mathrm{CD} 127^{-}$Tregs and of total FoxP3-expressing $\mathrm{CD} 4^{+} \mathrm{T}$ cells in the peripheral blood of MSC-treated patients. Percentage of regulatory FoxP3 ${ }^{+} \mathrm{CD} 127^{-}$cells within $\mathrm{CD} 4^{+} \mathrm{CD} 25^{\text {high }} \mathrm{T}$ cells (a) and of FoxP3 ${ }^{+}$cells within $\mathrm{CD} 4^{+} \mathrm{T}$ cells (b) from patient 3 (open diamonds) and patient 3 (black diamonds) given MSC and induction therapy with low-RATG alone compared with that of our previous MSC-treated kidney transplant patients 1 and 2 who received basiliximab/low-RATG as induction therapy. Grey and white histograms are percentages of $C D 4^{+}$Foxp3 ${ }^{+}$ T cells from control patients given RATG alone or combined Bas/RATG, respectively. Follow-up is from baseline (pre-tx) to day 360 post-transplantation.

\section{Cell mediated lympholysis}

(\% lysis)

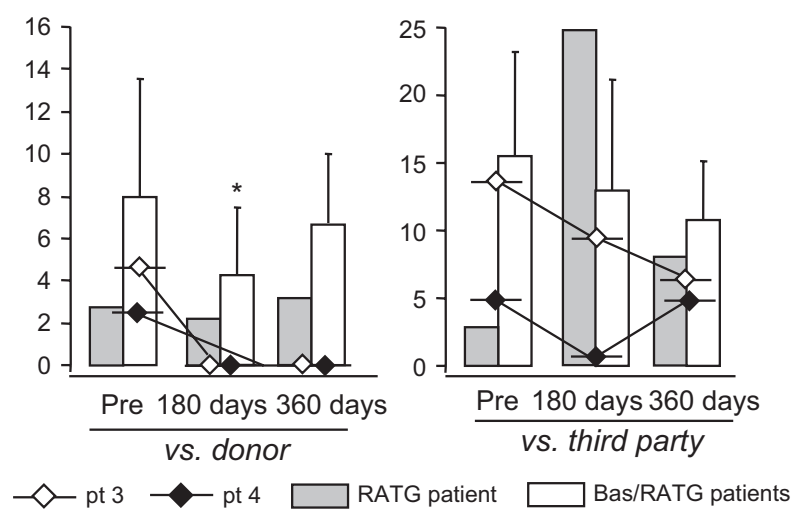

Figure $5 \mathrm{CD}^{+}$T-cell function by T-cell-mediated lympholysis assay. Cell-mediated lympholysis as percentage of specific lysis at 50:1 effector-target ratio against donor and third party antigens in patient 3 (open diamonds) and 4 (black diamonds) in a control patient given RATG alone (grey histograms) or patients given combined Bas/RATG (white histograms) on PBMC taken pre-transplant (pre) and at days 180 and 360 post-transplantation. Data are means \pm SEM. $* P<0.05$ versus pre.

tissue damage in experimental models of stroked brains [33], tumours [34], ischemic myocardium [35], and acute renal failure [36]. Experimental evidence in rodent models of acute renal injury has shown increased production in the kidney of hyaluronic acid (HA), the ligand for CD44 molecule expressed on MSC cell surface [36,37]. Therefore, we would like to suggest that in patients 3 and 4 , the infusion of MSC pretransplantation in an environment not yet hosting a kidney graft with subclinical inflammatory tissue injury, as it occurs few days post-surgery, might lead to preferential cell recruitment into lymphoid organs, because of lack of the intragraft HA chemotactic signal.
The second patient (4), given MSC the day before kidney transplantation, had acute renal dysfunction 14-17 days postsurgery, and the graft biopsy showed evidence of acute cellular rejection. Higher HLA haplotype mismatches in patient 4 than in 3 can possibly explain the occurrence of rejection in the former. Although based on findings in a single MSC-treated patient, there is also the possibility that autologous MSC may have low capacity to control host immune response in the context of high alloreactive environment. Of note, recent evidence in a large-cohort of living-related kidney transplants has shown that the use of autologous MSC alone compared with anti-IL-2-receptor antibody induction therapy resulted in lower incidence of acute rejection at 6 month post-transplant [17]. Similarly to our patient 3 , but at variance to patient 4 , in this largecohort of transplant recipients given MSC alone, HLA mismatching was on average lower than 3 [17]. Thus, with high HLA haplotype mismatches, adequate induction therapy including basiliximab could be of value to help the development of immunomodulatory function of MSC in the early post-transplant period, limiting the risk of acute graft rejection.

\section{Impact on Treg profile of basiliximab-free induction therapy}

The $\alpha$-chain of the IL-2 receptor, known as CD25, is not solely expressed on activated/effector $\mathrm{T}$ cells, but also on Treg constitutively expressing the $\mathrm{CD} 4^{+} \mathrm{CD} 25^{\text {high }}$ phenotype [38]. Specific cell markers for Tregs also include the transcription factor forkhead-box-P3 (FoxP3) [39] and more recently the down-regulation of the IL-7 receptor (CD127) [39-41]. Thus, the question was raised whether avoiding the anti-CD25 antibody basiliximab in the current induction regimen would better favour the emergence of 
Treg in the circulation after cell-therapy than with induction therapy including basiliximab as we adopted in our previous two MSC-treated kidney transplant patients [15]. Here we found no major difference in the profile of circulating $\mathrm{CD} 4^{+} \mathrm{CD} 25^{\text {high }} \mathrm{FoxP}^{+} \mathrm{CD} 127^{-}$or $\mathrm{CD} 4^{+} \mathrm{FoxP}^{+} \mathrm{T}$ cells in the present two patients given pretransplant MSC under the induction therapy that avoids basiliximab compared to the previous two patients receiving post-transplant MSC in the setting of combined basiliximab/low-RATG induction regimen [15]. This is in line with recent observation in liver transplant recipients that in vivo CD25 blockade with basiliximab did not lead to Treg changes as the proportion of FoxP $^{+}$cells among $\mathrm{CD}^{+}{ }^{+} \mathrm{T}$ cells and the level of FoxP3 expression were unaffected [42]. Moreover, others have shown in vitro that in the presence of basiliximab, $\mathrm{CD} 4{ }^{+} \mathrm{CD} 25^{\text {high }} \mathrm{FoxP}^{+}$cells were reduced because of the down-regulation of CD25 expression but the suppressive function of $\mathrm{CD}^{+} \mathrm{CD} 25^{-} \mathrm{FoxP}^{+} \mathrm{T}$ cells was maintained [43]. Together these findings indicate that CD25 molecule is not essential for in vivo maintenance of human Treg in the peripheral blood, and that basiliximab is unlikely to negatively influence strategies involving Treg to promote tolerance after organ transplantation as the MSC-based therapy.

In this study, we also wanted to gain insight into the in vivo effect of pretransplant MSC infusion on T-cell subsets and function after peritransplant $\mathrm{T}$-cell depletion with low-dose RATG induction therapy that avoids basiliximab. We found that in both patient 3 and (albeit less markedly) in patient 4 , but not in transplant recipients given lowRATG alone or combined with basiliximab and not MSC, the percentage of memory/effector $\mathrm{CD}^{+} \mathrm{T}$ cells within the overall $\mathrm{CD}^{+}$T-cell population in peripheral blood decreased post-transplantation. At the 1 year follow-up of the two patients, memory/effector $\mathrm{CD}^{+} \mathrm{T}$ cells remained lower than pretransplant values. These findings are reminiscent of changes in memory/effector $\mathrm{CD}^{+} \mathrm{T}$-cell profile in the initial two kidney transplant recipients given MSC at day 7 post-transplantation in the context of step 1 protocol [15]. The expansion of memory $\mathrm{T}$ cells that escape deletion after lymphoablation represents a major barrier to transplant tolerance [44]. With the limitation of few patients studied, overall our findings indicate that, at variance with current T-cell depleting induction therapy with RATG or Alemtuzumab, autologous MSC enable to control memory/ effector $\mathrm{CD}^{+}$T-cell proliferation long-lasting independently of whether a pre- or post-transplant cell infusion protocol is adopted. The mechanism(s) responsible for the MSC-mediated suppression of memory $\mathrm{CD}^{+} \mathrm{T}$-cell proliferation remains ill defined. A possible role of MSCproduced TGF- $\beta[45,46]$, which antagonizes the effect of IL-15 - a cytokine relevant to memory $\mathrm{CD}^{+} \mathrm{T}$-cell expansion [47] - is proposed.
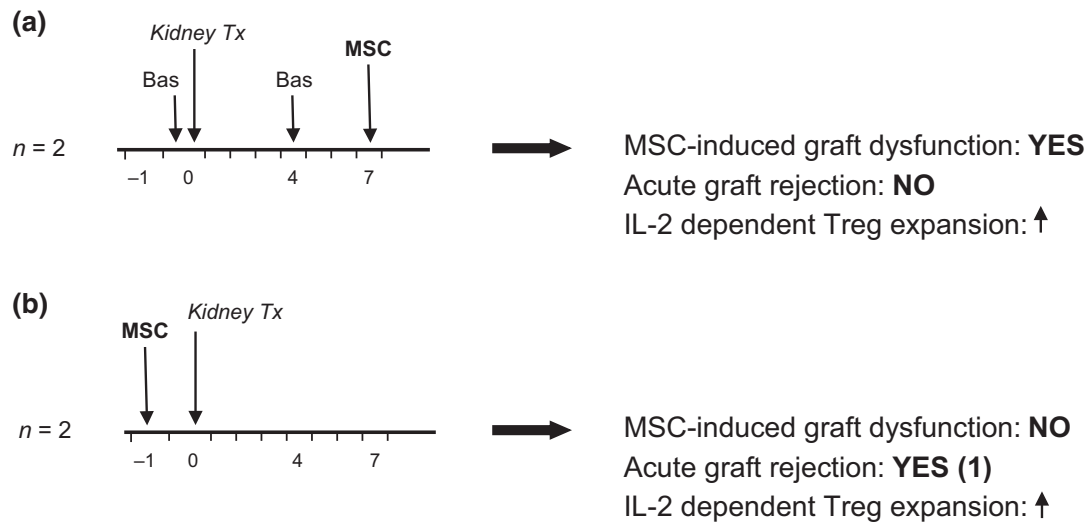

(c) Next protocol

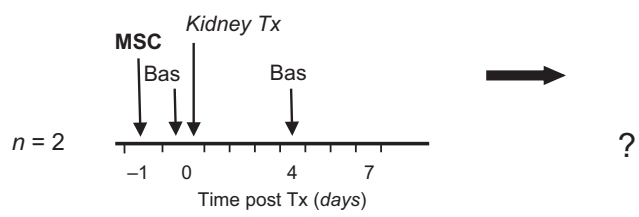

Figure 6 Clinical protocol of MSC-treated kidney transplant recipients implemented at our centre. The clinical MSC-based protocol on living-related kidney transplant recipients was conceived as a tailored-made step-wise gain of knowledge every two patients to eventually identify a definite protocol that allows to create favourable conditions for tolerance avoiding unwanted effects. Here are depicted the initial protocol (a) of post-transplant MSC infusion in patients 1 and 2 with induction therapy of basiliximab and low-RATG, the protocol (b) adopted thereafter in patient CM and DA of pretransplant MSC infusion with induction therapy of low-RATG alone. The study protocols are shown with major clinical and immunologic outcomes. The next up-dated protocol (c) to be tested in additional two patients is also reported. Bas, basiliximab. 
Evidence from experimental models of solid organ transplantation suggests that the mechanisms of MSC-induced tolerance also include Tregs $[4,6,8,9]$. Here we found that the number of $\mathrm{CD} 4{ }^{+} \mathrm{CD} 25^{\text {high }} \mathrm{Foxp} 3^{+} \mathrm{CD} 127^{-}$Treg in the peripheral blood of MSC-treated patients slowly expanded after a marked reduction because of the depleting action of the induction therapy, although the effect was only marginally higher than in control groups. Given the inconsistent effect on Treg count in the two patients receiving MSC, and the very small difference in the Treg profile as compared to controls, we advice caution to conclude for a robust impact of MSC treatment on Treg expansion, at least in peripheral blood of kidney transplant recipients. Nevertheless, MSC therapy did result in a clear increase in the ratio of Treg/memory $\mathrm{CD}^{+} \mathrm{T}$-cell count, suggesting a unique skewing toward regulation of host immune response. Indeed, as previously documented in patients undergoing post-transplant MSC infusion [15], the change in the memory/effector $\mathrm{CD}^{+} \mathrm{T}$-cell profile was associated with a profound and persistent reduction in donor-specific $\mathrm{CD}^{+}$T-cell cytolytic activity. These effects were not seen in kidney transplant recipients given low-RATG alone or combined with basiliximab induction therapy without MSC. Thus, MSC may have an additional effect beyond classical immunosuppressants of promoting inhibition of memory $\mathrm{CD}^{+} \mathrm{T}$-cell function that persists with time.

We acknowledge the many limitations of this preliminary work in few patients, that however has helped to get more insights on some of the open questions dealing with therapeutic administration of MSC on kidney transplant patients. Our findings also highlights that the time is probably not yet ripe for large clinical trials with MSC on organ transplantation.

In summary, in the second step of the multi-step clinical protocol under consideration here we documented that: (i) pretransplant (DAY-1) infusion of MSC provides a safety advantage over the protocol of post-transplant (day 7) cell administration, in that no longer associates with cellinduced impaired graft function, while maintains MSC immunomodulatory properties; (ii) induction therapy without basiliximab does not further expand $\mathrm{CD} 4^{+} \mathrm{FoxP}^{+}$ Treg pool as compared to the induction therapy with basiliximab, while exposing patients to the possibility of acute rejection early post-transplant [48]. Therefore, as further implementation of knowledge, we plan as next step a clinical protocol of pretransplant infusion of autologous bone marrow-derived MSC with basiliximab/low-RATG exactly as in step 1 (Fig. 6) where no patients had acute rejection.

\section{Authorship}

NP, FC and GR: participated in all stages of the study, made interpretation of the study findings, prepared the first draft of the report and the final manuscript. FC, MT, RAC and MC: performed immunophenotyping and functional immunological assays. MN: participated in research design and data interpretation. MI and CC: performed MSC isolation and characterization. EG, AR and GR: were in charge of patient care and monitoring. PC and PR: performed immunohistochemic analysis. GR: supervised all the study.

\section{Funding}

This study has been partially supported by grants from Fondazione ART per la Ricerca sui Trapianti (Milan, Italy) and from "Associazione Italiana Ricerca sul Cancro (AIRC) 5 per mille" to the AGIMM group (AIRC-Gruppo Italiano Malattie Mieloproliferative), "Associazione Italiana contro le Leucemie, Linfomi e Mieloma (AIL), Bergamo-Sezione Paolo Belli”, and Piano Regionale Sangue-Lombardia.

\section{Acknowledgements}

We are grateful to Dr Mario Bontempelli for the lymphocyte subset profiling in the peripheral blood and Dr Aurelio Sonzogni and Mr Franco Marchetti for histologic processing and analysis of biopsy specimens. We deeply thank Dr Giuseppe Locatelli and Dr Giovanni Rota for performing kidney transplantation, as well as Drs Piero Ruggenenti, Maddalena Marasà and Valentina Portalupi who monitored patients before and after kidney transplantation. The authors are members of the Mesenchymal Stem Cells in Solid Organ Transplantation (MISOT) study group, www. misot.de. Regiane Aparecida Cavinato is a recipient of a fellowship from Fondazione ART. Paola Rizzo is a recipient of a fellowship from Fondazione Aiuti per la Ricerca sulle Malattie Rare (ARMR).

\section{Supporting information}

Additional Supporting Information may be found in the online version of this article:

Data S1. Materials and methods.

\section{References}

1. Bartholomew A, Sturgeon C, Siatskas M, et al. Mesenchymal stem cells suppress lymphocyte proliferation in vitro and prolong skin graft survival in vivo. Exp Hematol 2002; 30: 42 .

2. Inoue S, Popp FC, Koehl GE, et al. Immunomodulatory effects of mesenchymal stem cells in a rat organ transplant model. Transplantation 2006; 81: 1589.

3. Zhou HP, Yi DH, Yu SQ, et al. Administration of donorderived mesenchymal stem cells can prolong the survival of rat cardiac allograft. Transplant Proc 2006; 38: 3046. 
4. Casiraghi F, Azzollini N, Cassis P, et al. Pretransplant infusion of mesenchymal stem cells prolongs the survival of a semiallogeneic heart transplant through the generation of regulatory T cells. J Immunol 2008; 181: 3933.

5. Popp FC, Eggenhofer E, Renner P, et al. Mesenchymal stem cells can induce long-term acceptance of solid organ allografts in synergy with low-dose mycophenolate. Transpl Immunol 2008; 20: 55.

6. Ge W, Jiang J, Baroja ML, et al. Infusion of mesenchymal stem cells and rapamycin synergize to attenuate alloimmune responses and promote cardiac allograft tolerance. Am J Transplant 2009; 9: 1760.

7. Ge W, Jiang J, Arp J, Liu W, Garcia B, Wang H. Regulatory $\mathrm{T}$-cell generation and kidney allograft tolerance induced by mesenchymal stem cells associated with indoleamine 2,3dioxygenase expression. Transplantation 2010; 90: 1312.

8. Casiraghi F, Azzollini N, Todeschini M, et al. Localization of mesenchymal stromal cells dictates their immune or proinflammatory effects in kidney transplantation. Am J Transplant 2012; 12: 2373.

9. Wang Y, Zhang A, Ye Z, Xie H, Zheng S. Bone marrowderived mesenchymal stem cells inhibit acute rejection of rat liver allografts in association with regulatory T-cell expansion. Transplant Proc 2009; 41: 4352.

10. Ding Y, Xu D, Feng G, Bushell A, Muschel RJ, Wood KJ. Mesenchymal stem cells prevent the rejection of fully allogenic islet grafts by the immunosuppressive activity of matrix metalloproteinase-2 and -9. Diabetes 2009; 58: 1797.

11. Berman DM, Willman MA, Han D, et al. Mesenchymal stem cells enhance allogeneic islet engraftment in nonhuman primates. Diabetes 2010; 59: 2558.

12. Le Blanc K, Frassoni F, Ball L, et al. Mesenchymal stem cells for treatment of steroid-resistant, severe, acute graft-versushost disease: a phase II study. Lancet 2008; 371: 1579.

13. ClinicalTrials.gov NCT 00734396.

14. ClinicalTrials.gov NCT 01429038.

15. Perico N, Casiraghi F, Introna M, et al. Autologous mesenchymal stromal cells and kidney transplantation: a pilot study of safety and clinical feasibility. Clin J Am Soc Nephrol 2011; 6: 412.

16. Popp FC, Fillenberg B, Eggenhofer E, et al. Safety and feasibility of third-party multipotent adult progenitor cells for immunomodulation therapy after liver transplantation - a phase I study (MISOT-I). J Transl Med 2011; 9: 124.

17. Tan J, Wu W, Xu X, et al. Induction therapy with autologous mesenchymal stem cells in living-related kidney transplants: a randomized controlled trial. JAMA 2012; 307: 1169.

18. Peng Y, Ke M, Xu L, et al. Donor-derived mesenchymal stem cells combined with low-dose tacrolimus prevent acute rejection after renal transplantation: a clinical pilot study. Transplantation 2013; 95: 161.

19. Farris AB, Taheri D, Kawai T, et al. Acute renal endothelial injury during marrow recovery in a cohort of combined kidney and bone marrow allografts. Am J Transplant 2011; 11: 1464.
20. Bluestone JA, Liu W, Yabu JM, et al. The effect of costimulatory and interleukin 2 receptor blockade on regulatory $\mathrm{T}$ cells in renal transplantation. Am J Transplant 2008; 8: 2086.

21. Capelli C, Domenghini M, Borleri G, et al. Human platelet lysate allows expansion and clinical grade production of mesenchymal stromal cells from small samples of bone marrow aspirates or marrow filter washouts. Bone Marrow Transplant 2007; 40: 785.

22. Capelli C, Salvade A, Pedrini O, et al. The washouts of discarded bone marrow collection bags and filters are a very abundant source of hMSCs. Cytotherapy 2009; 11: 403.

23. Baldelli S, Merlini S, Perico N, et al. C-440T/T-331C polymorphisms in the UGT1A9 gene affect the pharmacokinetics of mycophenolic acid in kidney transplantation. Pharmacogenomics 2007; 8: 1127.

24. Ruggenenti P, Codreanu I, Cravedi P, Perna A, Gotti E, Remuzzi G. Basiliximab combined with low-dose rabbit antihuman thymocyte globulin: a possible further step toward effective and minimally toxic T cell-targeted therapy in kidney transplantation. Clin J Am Soc Nephrol 2006; 1: 546.

25. Brennan DC, Daller JA, Lake KD, Cibrik D, Del Castillo D. Rabbir antithymocyte globulin versus basiliximab in renal transplantation. New Engl J Med 2006; 335: 1967.

26. Gaber AO, First MR, Tesi RJ, et al. Results of the doubleblind, randomized, multicenter, phase III clinical trial of thymoglobulin versus Atgam in the treatment of acute graft rejection episodes after renal transplantation. Transplantation 1998; 66: 29.

27. Brennan DC, Flavin K, Lowell JA, et al. A randomized, double-blind comparison of thymoglobulin versus Atgam for induction immunosuppressive therapy in adult renal transplant recipients. Transplantation 1999; 67: 1011.

28. Gennarini A, Cravedi P, Marasa M, et al. Perioperative minimal induction therapy: a further step toward more effective immunosuppression in transplantation. J Transplant 2012; 2012: 426042.

29. Ciancio G, Gaynor JJ, Sageshima J, et al. Randomized trial of dual antibody induction therapy with steroid avoidance in renal transplantation. Transplantation 2011; 92: 1348.

30. Dominici M, Le Blanc K, Mueller I, et al. Minimal criteria for defining multipotent mesenchymal stromal cells. The International Society for Cellular Therapy position statement. Cytotherapy 2006; 8: 315.

31. Noris M, Casiraghi F, Todeschini M, et al. Regulatory T cells and $\mathrm{T}$ cell depletion: role of immunosuppressive drugs. J Am Soc Nephrol 2007; 18: 1007.

32. Wang Z, Shi BY, Qian YY, Cai M, Wang Q. Short-term antiCD25 monoclonal antibody administration down-regulated CD25 expression without eliminating the neogenetic functional regulatory $\mathrm{T}$ cells in kidney transplantation. Clin Exp Immunol 2009; 155: 496.

33. Li Y, Chen J, Wang L, Zhang L, Lu M, Chopp M. Intracerebral transplantation of bone marrow stromal cells in a 1-methyl-4-phenyl-1,2,3,6-tetrahydropyridine mouse model of Parkinson's disease. Neurosci Lett 2001; 316: 67. 
34. Spaeth E, Klopp A, Dembinski J, Andreeff M, Marini F. Inflammation and tumor microenvironments: defining the migratory itinerary of mesenchymal stem cells. Gene Ther 2008; 15: 730.

35. Kawada H, Fujita J, Kinjo K, et al. Nonhematopoietic mesenchymal stem cells can be mobilized and differentiate into cardiomyocytes after myocardial infarction. Blood 2004; 104: 3581.

36. Herrera MB, Bussolati B, Bruno S, et al. Exogenous mesenchymal stem cells localize to the kidney by means of CD44 following acute tubular injury. Kidney Int 2007; 72: 430.

37. Goransson V, Johnsson C, Jacobson A, Heldin P, Hallgren R, Hansell P. Renal hyaluronan accumulation and hyaluronan synthase expression after ischaemia-reperfusion injury in the rat. Nephrol Dial Transplant 2004; 19: 823.

38. Baecher-Allan C, Brown JA, Freeman GJ, Hafler DA. CD4+CD25 high regulatory cells in human peripheral blood. J Immunol 2001; 167: 1245.

39. Fontenot JD, Gavin MA, Rudensky AY. Foxp3 programs the development and function of CD4+CD25+ regulatory $\mathrm{T}$ cells. Nat Immunol 2003; 4: 330.

40. Liu W, Putnam AL, Xu-Yu Z, et al. CD127 expression inversely correlates with FoxP3 and suppressive function of human CD4+ T reg cells. J Exp Med 2006; 203: 1701.

41. Seddiki N, Santner-Nanan B, Martinson J, et al. Expression of interleukin (IL)-2 and IL-7 receptors discriminates between human regulatory and activated T cells. J Exp Med 2006; 203: 1693.
42. de Goer de Herve MG, Gonzales E, Hendel-Chavez H, et al. CD25 appears non essential for human peripheral T(reg) maintenance in vivo. PLoS ONE2010; 5: e11784.

43. Vondran FW, Timrott K, Tross J, et al. Impact of basiliximab on regulatory $\mathrm{T}$-cells early after kidney transplantation: down-regulation of CD25 by receptor modulation. Transpl Int 2010; 23: 514.

44. Valujskikh A, Li XC. Frontiers in nephrology: T cell memory as a barrier to transplant tolerance. J Am Soc Nephrol 2007; 18: 2252.

45. English K, Ryan JM, Tobin L, Murphy MJ, Barry FP, Mahon BP. Cell contact, prostaglandin E(2) and transforming growth factor beta 1 play non-redundant roles in human mesenchymal stem cell induction of CD4+CD25(High) forkhead box P3+ regulatory T cells. Clin Exp Immunol 2009; 156: 149.

46. Di Nicola M, Carlo-Stella C, Magni M, et al. Human bone marrow stromal cells suppress T-lymphocyte proliferation induced by cellular or nonspecific mitogenic stimuli. Blood 2002; 99: 3838.

47. Williams KM, Hakim FT, Gress RE. T cell immune reconstitution following lymphodepletion. Semin Immunol 2007; 19: 318.

48. Vincenti F, de Andres A, Becker T, et al. Interleukin-2 receptor antagonist induction in modern immunosuppression regimens for renal transplant recipients. Transpl Int 2006; 19: 446. 
CHAPTER 6

Immunomodulatory effects of mesenchymal stromal cells in solid organ transplantation

F. Casiraghi, N. Perico and G. Remuzzi

published in: Current Opinion in Organ Transplantation 2010, 15: 731-737. 


\section{Immunomodulatory effects of mesenchymal stromal cells in solid organ transplantation Federica Casiraghi, Marina Noris and Giuseppe Remuzzi}

Transplant Research Center 'Chiara Cucchi de Alessandri e Gilberto Crespi', Department of Immunology and Organ Transplantation, Ospedali Riuniti-Mario Negri Institute for Pharmacological Research, Bergamo, Italy

Correspondence to Giuseppe Remuzzi, MD, FRCP, Mario Negri Institute for Pharmacological Research, Via Gavazzeni 11, 24125 Bergamo, Italy

Tel: +39035 319888; fax: +30 035 319331;

e-mail: gremuzzi@marionegri.it

Current Opinion in Organ Transplantation 2010 15:731-737

\begin{abstract}
Purpose of review
Multipotent mesenchymal stromal cells (MSCs) possess powerful immunomodulatory activity highlighting the potential for their clinical translation in solid organ transplantation. In this review, we summarize recent advances in understanding MSC immunomodulatory effect in vitro and in experimental transplant models and discuss topics of crucial importance for the future clinical use of MSCs as immunotherapy in solid organ transplantation.
\end{abstract}

\section{Recent findings}

MSCs strongly inhibited T-cell activity in vitro and exerted similar inhibitory effects on other cells of the immune system. MSC-mediated immune suppression has been attributed mainly to the secretion of soluble factors; however, cell-contact mechanisms cannot be excluded. Available studies in animal transplant models raised variable results, but overall indicate that MSCs could be useful to modulate recipient immune cells. The timing of cell application and the origin of MSCs (autologous or allogeneic) seem to be the most crucial factors impacting the in-vivo efficacy of MSCs.

\section{Summary}

A better understanding of the mechanisms underlying the immunomodulatory effects of MSCs in vitro and in vivo is needed to define the optimal condition for the use of MSCs as immunotherapy in solid organ transplantation.

\section{Keywords}

immunomodulation, mesenchymal stromal cells, solid organ transplantation, T cells

Curr Opin Organ Transplant 15:731-737

(C) 2010 Wolters Kluwer Health | Lippincott Williams \& Wilkins 1087-2418

\section{Introduction}

Mesenchymal stem cells (MSCs) were discovered about 40 years ago as an adherent, fibroblast-like population in the adult bone marrow capable of regenerating rudiments of bone in vitro [1] and differentiating into other cells of mesenchymal lineage such as fat and cartilage [2]. Despite extensive research, no single specific cell surface marker for MSC direct isolation from the bone marrow cell suspension has been identified and, so far, MSCs have been selected indirectly by plastic adherence in vitro. Although MSCs in culture appear as a homogeneous population, they probably constitute a heterogeneous group of progenitor cells, which do not fulfill strict criteria for a stem-cell entity at a single cell level (self-renewal and multilineage differentiation capacity). As such these cells have recently been reclassified as multipotent mesenchymal stromal cells (with the same acronym MSCs) by the International Society for Cellular Therapy [3], which also provided the minimum criteria for defining human MSCs: plastic adherence under standard culture conditions; expression of CD105, CD73, and CD90 and absent expression of CD45, CD34, CD14 or
CD11b, CD79a or CD19, and human leukocyte antigenDR (HLA-DR); and differentiation into osteoblasts, adipocytes, and chondroblasts in vitro.

MSCs with similar phenotype and differentiation potential as bone marrow-derived MSCs have been also identified in other human adult tissues, including adipose tissue, and in fetal tissues such as lung, liver, and spleen [4-7]. Rich sources of MSCs are also amniotic fluid, placenta, umbilical cord blood, and wall [8-13].

The MSC capacity of extensive expansion with stable phenotype and function over many passages in vitro, their ability to differentiate into multiple different cell lineages, and to produce growth factors that facilitate repair of damaged tissue have stimulated research into their use for tissue regeneration.

MSCs can also strongly inhibit T-cell proliferation in vitro and in vivo and exert similar inhibitory effects on B cells, dendritic cells, natural killer (NK) cells, and on cells of innate immunity. These immunoregulatory properties have highlighted the potential for clinical translation of 
these cells to treat inflammatory and immune diseases as well as to prevent allograft rejection in solid organ transplantation. Here we will review recent advances in understanding the immunomodulatory effect of MSCs with focus on mechanisms and strategies that could be exploited in solid organ transplantation.

\section{Immunomodulatory properties of mesenchymal stromal cells in vitro}

MSCs have been considered as naturally immune privileged cells due to low expression of major histocompatibility complex (MHC) molecules in unstimulated conditions and absence of costimulatory molecules [3,1417]. As such, MSCs did not stimulate allogeneic T-cell response [14,16] and induced T-cell anergy [18-20]. However, more recent studies suggested that MSCs are not intrinsically immune privileged. In a narrow window of interferon- $\gamma$ (IFN- $\gamma$ ) concentration, MSCs express MHC molecules and can present both MHC class II [20-22] and class I-restricted antigens [23,24]. When infused into immunocompetent allogeneic mice, MSCs elicited both primary and memory T-cell responses $\left[25,26,27^{\circ}\right]$.

On the other hand, accumulating evidence is available that MSCs possess potent immunomodulatory effects when cocultured with T cells. Human [14-16,20,28,29], baboon [30], rat [31], and murine [32,33] MSCs have been shown to prevent $\mathrm{T}$-cell response to cellular and to nonspecific mitogenic stimuli $[15,16,28,34,35]$, targeting both naive and memory $\mathrm{CD}^{+}{ }^{+}$and $\mathrm{CD} 8^{+} \mathrm{T}$ cells [15,36-38]. MSCinduced T-cell suppression in MLR occurs independently of MHC matching with either stimulatory antigen-presenting cells (APCs) or responder lymphocytes $[16,28,30,32]$. However, the effect of MSCs on T-cell function is dose-dependent. At low MSC/T-cell ratios, MSCs enhanced proliferation of T cells, whereas at high ratios, they exerted powerful inhibitory effects [39].

The mechanism(s) of MSC-mediated T-cell suppression remains ill defined; soluble factors $[15,34,40,41]$ as well as cell-contact-dependent pathways have been suggested $[33,37,40,42,43]$. Hepatocyte growth factor (HGF) [15], transforming growth factor- $\beta$ (TGF- $\beta$ ) $[15,44]$, interleukin-10 (IL-10) [44], prostaglandin- $\mathrm{E}_{2}\left(\mathrm{PGE}_{2}\right) \quad[28,34]$, indoleamine 2,3-dioxygenase (IDO)-mediated tryptophan deletion [40], nitric oxide [41,45,46], HLA-G5, a soluble form of nonclassical HLA class I [47,48], and galectin-3 [49] have been reported to mediate MSCinduced immunosuppression. Failure to identify key soluble factor(s) may reflect different experimental settings and cell sources employed [50 $0^{\bullet}$. Immunosuppression by human-derived or monkey-derived MSCs is mediated by IDO, whereas under the same culture conditions, mouse MSCs utilize nitric oxide, indicating that mechanisms of MSC-mediated immunosuppression vary among species $\left[50^{\circ}\right]$.

In addition to soluble factors, the engagement of the inhibitory molecule programmed death-1 (PD-1) to its ligands PD-L1 and PD-L2 has been demonstrated to inhibit T-cell proliferation via direct contact of MSCs with target cells [33].

It has also been documented that MSCs induce changes in T-cell phenotype and promote the emergence of regulatory $\mathrm{T}$ cells (Tregs). Human MSCs generated $\mathrm{CD} 4{ }^{+} \mathrm{CD} 25^{\text {high }} \mathrm{FoxP}^{+}$Tregs when cultured with human peripheral blood mononuclear cells (PBMCs) [34,51], a mechanism partially mediated by the interaction of MSCderived $\mathrm{C}-\mathrm{C}$ chemokine-ligand-1 (CCL1) with its receptor on T cells $\mathrm{C}-\mathrm{C}$ chemokine-receptor-8 (CCR8) [20]. Others have shown that MSC-induced Treg generation requires cell-contact, $\mathrm{PGE}_{2}$ and TGF- $\beta-1$ [52 $]$ or HLAG5 released by MSCs in culture [48].

Recent observations support the hypothesis that an appropriate inflammatory environment licenses MSCs to exert their immunosuppressive actions. Thus, MSCs inhibited the proliferation of $\mathrm{T}$ cells activated by high concentration of mitogens and proinflammatory cytokines, whereas MSCs failed to suppress $\mathrm{T}$ cells preexposed to low concentration of mitogens or to antiinflammatory cytokines like IL-10 [53]. Proinflammatory cytokines, in particular IFN- $\gamma$, lead to upregulated expression of IDO [35,54,55], B7-H1 [56], cyclooxygenase-2 (COX-2) [54,55], and inducible nitric oxide synthase (iNOS) [45,57] and increased secretion of HGF and TGF- $\beta$ and chemokines [54], triggering MSC immunosuppressive function. In-vivo studies on knockout mice also demonstrated that IFN- $\gamma$ and iNOS are required for the immunomodulatory effects of MSCs to prevent delayed-type hypersensitivity and graft-versus-host disease (GVHD) [45]. Moreover, in an inflammatory milieu, MSCs and T cells upregulate adhesion molecules $[58,59]$ that enable their physical interaction and keep activated $\mathrm{T}$ cells in close proximity to MSCs, thus potentiating the inhibitory effect [60].

MSCs have multiple targets in the immune system. They control the differentiation and maturation of both monocyte-derived and $\mathrm{CD} 34^{+}$-derived dendritic cells [61-64] promoting the release of anti-inflammatory cytokines [61], a process partially mediated by the Notch pathway [64]. MSCs can also influence mature dendritic cells [65], converting them into a regulatory dendritic cell population capable of inhibiting lymphocyte proliferation via Jagged 2-dependent mechanisms [66 ${ }^{\circ}$ and of generating alloantigen-specific Tregs [67]. MSCs also inhibit B-cell proliferation, differentiation to plasma cells, and antibody production in vitro [68-70], although 
recently other studies have challenged these observations [71,72]. MSCs suppress IL-2 and IL-15-driven NK-cell proliferation and IFN- $\gamma$ production [34,73-75]. On the other hand, MSCs secrete soluble factors such as monocyte chemoattractant protein-1, macrophageinflammatory protein, IFN-inducible protein 10 , and IL-8, all of which may attract other immune cells such as monocytes, macrophages, and neutrophils $[42,76,77]$. However, the relevance of MSC production of these factors to the function of monocytes, macrophages, and neutrophils in an inflammatory environment is unknown.

In summary, current data suggest a complex interaction of MSCs with immune cells and no one mechanism can be identified as being solely responsible for MSCinduced immunomodulation. Even though results obtained in simplified in-vitro setting are not directly transferable to actual physiologic or pathologic conditions in vivo, a better understanding of the mechanisms underlying the immunomodulatory effects of MSC in vitro may help in defining the optimal conditions for their use in vivo as immunotherapeutics.

\section{Mesenchymal stromal cells in solid organ transplantation}

The immunomodulatory potential of MSCs in solid organ transplantation was first shown in a model of skin graft in nonhuman primates [30]. A single peritransplant infusion of donor MSCs significantly prolonged the survival of either donor-specific or third-party skin allograft from 7 to 14 days, an effect comparable with that achieved in the same model by potent immunosuppressants used in clinics in solid organ transplantation [30]. Thereafter, the in-vivo effect of MSC was tested mainly in models of heart transplantation in rodents. Either donor-derived or recipient-derived MSCs failed to prolong the survival of a fully allogeneic Lewis heart graft in untreated ACI rat recipients when infused at the time of transplantation. In the same setting, when MSCs were applied together with low-dose cyclosporine A (CsA), graft rejection was even accelerated [31]. In the same rat transplant model also pretransplant (at day 4) infusion of donor MSCs resulted in accelerated graft rejection. However, the association with a short course of low-dose mycophenolate mofetil (MMF) was capable of inducing long-term allograft acceptance [78]. In this study, donorderived MSCs were more effective for tolerance induction than recipient-derived MSCs, whereas third-party MSCs were ineffective [78]. MSC-induced tolerance was mediated, at least partially, by the expression of IDO and by the emergence of tolerogenic dendritic cells [78]. At variance, in a model of fully MHC-mismatched Wistar cardiac graft in Fisher 344 rat recipients, repeated infusions of donor-derived MSCs before and after heart transplantation significantly delayed graft rejection from 6 to 12 days without concomitant administration of immunosuppressive drugs [79]. Similarly, others have documented in a transplant model of LEW.1A rat recipients of a MHC-mismatched LEW.1W heart that the double infusion of high doses of donor-derived MSCs (7 days before and at the time of transplant) significantly prolonged allograft survival, an effect mediated by heme oxygenase-1 [46]. In a C57BL/6 to BALB/c murine heart allograft model, the intravenous infusion of donor MSCs $24 \mathrm{~h}$ after heart transplantation significantly abated rejection and doubled graft survival. Combination therapy of donor MSCs with low-dose rapamycin achieved donorspecific tolerance. Long-term surviving recipients exhibited high frequency of tolerogenic dendritic cells and $\mathrm{CD}^{+}{ }^{+} \mathrm{CD} 25^{+} \mathrm{FoxP}^{+}$Tregs $\left[80^{\circ}\right]$. The same tolerogenic properties of donor MSCs were shared by syngeneic and third-party MSCs [80 ${ }^{\circ}$. In our model of semi-allogeneic heart transplant in mice (B6C3F 1 heart in $\mathrm{B} 6$ recipients), we found that pretransplant infusions of donor-derived MSCs in unconditioned mice significantly prolonged graft survival with $30 \%$ of MSC-treated animals experiencing indefinite graft survival. The same tolerogenic potential was shared by recipient-derived MSCs when given pretransplant. In contrast, recipient-derived MSC infusion given peritransplant was less effective and infusion 1 day after transplantation did not prolong heart allograft survival at any extent [81]. The tolerogenic effect of both donor-derived and recipient-derived MSCs was mediated by the generation of donor-specific Tregs. Indeed, adoptive transfer of splenocytes from tolerant mice prevented the rejection of fully MHCmismatched donor-specific secondary allografts but not of third-party grafts [81].

Recently, MSCs were also tested in models of liver and islet transplantation. Rats given repeated doses of MSCs after liver transplantation survived longer that those without MSCs. These effects occurred regardless of whether the MSCs were autologous, donor or thirdparty-derived and were associated with expansion of $\mathrm{CD} 4^{+} \mathrm{CD} 25^{+} \mathrm{FoxP}^{+}{ }^{+}$Tregs [82]. Similarly, in a model of allogeneic pancreatic islet transplantation in streptozotocin-treated immunodeficient mice reconstituted with effector $\mathrm{CD} 4^{+} \mathrm{T}$ cells, administration of syngeneic MSCs prevented graft rejection and led to long-term normoglycemia. [83]. The efficacy of MSC treatment was related to local production of immunosuppressive matrix metalloproteinase-2 and metalloproteinase-9 [83].

Thus, these early results provide the evidence that MSCs could be effective immunomodulators in solid organ transplantation, but further studies on animal models are required to establish the best dosing and time of MSC administration in respect to transplantation for more consistent results. 


\section{Interaction with immunosuppressive drugs}

To the clinical perspective of MSC-based cell therapy in organ transplantation, it would be relevant to know whether immunosuppressive agents currently used in the transplantation settings may negatively affect MSCinduced immunomodulation. This has been mainly assessed in in-vitro studies. Evidence is available that at low ratios of MSC/responder $\mathrm{T}$ cells in MLR, the inhibitory effect of human MSCs was potentiated in the presence of CsA, tacrolimus, rapamycin, mycophenolic acid (MPA), or dexamethasone. At high MSC/responder cell ratio (1:5), calcineurin inhibitors and rapamycin antagonized the inhibitory effect of MSCs, whereas MPA promoted it and dexamethasone had no effect [84]. However, other in-vitro MLR studies using phytohemagglutinin (PHA)-activated lymphocytes [85] or activated alloantigen-specific cytotoxic lymphocytes as responders [86] documented a synergistic immunosuppressive effect of calcineurin inhibitors and MSGs. On the other hand, human heart tissue-derived MSCs antagonized the immunosuppressive properties of tacrolimus and rapamycin on alloactivated PBMCs in vitro, whereas MSCs and MPA exerted cumulative inhibitory effects $\left[87^{\circ}\right]$. These in-vitro findings have not been consistently translated into in-vivo experiments. At variance with the in-vitro antagonism on MSC-induced immunosuppression, in-vivo rapamycin exerted a synergistic effect with MSCs in promoting long-term cardiac graft survival $\left[80^{\bullet}\right]$. Additionally, CsA antagonized the MSC-mediated immunomodulation in kidney transplant model in rodents [88]. This observation is, however, challenged by the findings that in the setting of experimental and human bone marrow transplantation, MSCs showed their immunomodulatory activity also in the presence of immunosuppressive regimens, including CsA [89-92]. Taken together, this evidence highlights the need to choose a proper immunosuppressive drug combination for future clinical trial to support but not surpass the immunomodulatory effect of MSCs in organ transplantation (ClinicalTrials.gov, NC'T00752479).

\section{Conclusion}

The potential of MSC-based therapy in solid organ transplantation is certainly relevant, but further mechanistic experimental studies are urgently needed to define the optimal conditions and setting for achieving consistent clinical results. Several issues should be clarified. The timing of MSC application and the source of these cells are crucial factors affecting the in-vivo immunomodulatory activities of MSCs in solid organ transplantation. MSCs are more effective when given before or during transplant procedure [78,81], indicating that both the migration pattern of MSC and/or the degree of T-cell activation at the time of MSC infusion could influence their in-vivo effect. MSCs have to interact with immune cells in lymphoid tissues to promote immunomodulation $[19,93]$. Due to their peculiar tropism for injured tissues [94], it is anticipated that when given after transplantation, MSCs could be eventually recruited into the graft, preventing them to reach lymphoid organs. The better efficacy of MSCs in inducing long-term graft survival when given together with low-dose immunosuppressive drugs suggests that MSGs alone could not be sufficient to control the intense stimulation of recipient $\mathrm{T}$ cells by alloantigens $\left[78,80^{\circ}\right]$. Because it is unlikely that MSCs would be exploited in clinical transplantation as standalone therapy, the efforts of future research should be focused to identify the ideal immunosuppressive drug regimen that in vivo synergizes or, at least, does not antagonize the immunomodulatory properties of MSCs.

Recipient-derived and donor-derived MSCs have shown better immunomodulatory therapeutic potential $\left[46,78,79,80^{\circ}, 82\right]$ than third-party MSCs in experimental organ transplantation. Donor-derived MSCs, however, could be quickly cleared from the recipient because of the host allogeneic response, causing recipient sensitization $\left[25,26,27^{\bullet}\right]$. Even syngeneic MSCs rapidly disappear few days after infusion and do not permanently engraft in recipient lymphoid organs [80 $0^{\circ}$, suggesting that MSCs cannot be able to lastingly alter the immune response in vivo, but they should activate regulatory pathways early after transplantation $\left[78,80^{\bullet}, 81,82\right.$, 95,96], which in turn sustain immunoregulation in the long-term.

Nevertheless, these events could be also function of the number of MSCs applied peritransplantation. However, not much is conclusively known about the ideal cell dose. Animal data on solid organ transplantation have been obtained with doses of MSCs of 2-10 million/kg, corresponding to the maximum intravenous dose, which did not cause fatal lung embolism. In human setting, a recent clinical trial on GVHD showed that doses ranging from 0.5 to 9 million cells $/ \mathrm{kg}$ did not lead to adverse side effects and, interestingly, the immunomodulatory effects appeared to be independent of the dose [92]. Alongside the effects of MSCs on host immune response, possible side effects after MSC injection must be assessed with the greatest priority, an issue only marginally addressed so far $\left[97^{\bullet \bullet}\right]$.

MSCs are currently evaluated in clinical phase I and II studies for GVHD and inflammatory diseases and their introduction into solid organ transplantation is still eagerly awaited. Many questions regarding the clinical use of MSCs remain to be answered, including those related to their potential toxicity. Thus, monitoring of patients must be extensive and trials performed solely with well characterized cell population. 


\section{Acknowledgements}

The present study has been partially supported by grants from Fondazione ART (Fondazione per la Ricerca sui Trapianti, Milan, Italy).

The authors thank Dr. Norberto Perico for critically reading the article.

The authors have no conflicts of interest to declare.

\section{References and recommended reading}

Papers of particular interest, published within the annual period of review, have been highlighted as:

- of special interest

-• of outstanding interest

Additional references related to this topic can also be found in the Current

World Literature section in this issue (pp. 785-786)

1 Friedenstein AJ, Petrakova KV, Kurolesova Al, Frolova GP. Heterotopic of bone marrow. Analysis of precursor cells for osteogenic and hematopoietic tissues. Transplantation 1968; 6:230-247.

2 Friedenstein AJ, Chailakhjan RK, Lalykina KS. The development of fibroblast colonies in monolayer cultures of guinea-pig bone marrow and spleen cells. Cell Tissue Kinet 1970; 3:393-403.

3 Dominici M, Le Blanc K, Mueller I, et al. Minimal criteria for defining multipotent mesenchymal stromal cells. The International Society for Cellular Therapy position statement. Cytotherapy 2006; 8:315-317.

4 Campagnoli C, Roberts IA, Kumar S, et al. Identification of mesenchymal stem/progenitor cells in human first-trimester fetal blood, liver, and bone marrow. Blood 2001; 98:2396-2402.

5 De Ugarte DA, Morizono K, Elbarbary A, et al. Comparison of multi-lineage cells from human adipose tissue and bone marrow. Cells Tissues Organs 2003; 174:101-109.

6 Hoogduijn MJ, Crop MJ, Peeters AM, et al. Human heart, spleen, and perirenal fat-derived mesenchymal stem cells have immunomodulatory capacities. Stem Cells Dev 2007; 16:597-604.

7 Arai $\mathrm{F}$, Ohneda $\mathrm{O}$, Miyamoto $\mathrm{T}$, et al. Mesenchymal stem cells in perichondrium express activated leukocyte cell adhesion molecule and participate in bone marrow formation. J Exp Med 2002; 195:1549-1563.

8 Erices $\mathrm{A}$, Conget $\mathrm{P}$, Minguell JJ. Mesenchymal progenitor cells in human umbilical cord blood. Br J Haematol 2000; 109:235-242.

9 In 't Anker PS, Scherjon SA, Kleijburg-van der Keur C, et al. Isolation of mesenchymal stem cells of fetal or maternal origin from human placenta. Stem Cells 2004; 22:1338-1345.

10 In 't Anker PS, Scherjon SA, Kleijburg-van der Keur C, et al. Amniotic fluid as a novel source of mesenchymal stem cells for therapeutic transplantation. Blood 2003; 102:1548-1549.

11 Bieback K, Kern S, Kluter H, Eichler H. Critical parameters for the isolation of mesenchymal stem cells from umbilical cord blood. Stem Cells 2004; 22:625-634.

12 Weiss LM, Anderson C, Medicetty S, et al. Immune properties of human umbilical cord Wharton's jelly-derived cells. Stem Cells 2008; 26:2865-2874.

13 Li CD, Zhang WY, Li HL, et al. Mesenchymal stem cells derived from human placenta suppress allogeneic umbilical cord blood lymphocyte proliferation. Cell Res 2005; 15:539-547.

14 Le Blanc K, Tammik C, Rosendahl K, et al. HLA expression and immunologic properties of differentiated and undifferentiated mesenchymal stem cells. Exp Hematol 2003; 31:890-896.

15 Di Nicola M, Carlo-Stella C, Magni M, et al. Human bone marrow stromal cells suppress T-lymphocyte proliferation induced by cellular or nonspecific mitogenic stimuli. Blood 2002; 99:3838-3843.

16 Tse WT, Pendleton JD, Beyer WM, et al. Suppression of allogeneic T-cell proliferation by human marrow stromal cells: implications in transplantation. Transplantation 2003; 75:389-397.

17 Pittenger MF, Mackay AM, Beck SC, et al. Multilineage potential of adult human mesenchymal stem cells. Science 1999; 284:143-147.

18 Glennie S, Soeiro I, Dyson PJ, et al. Bone marrow mesenchymal stem cells induce division arrest anergy of activated T cells. Blood 2005; 105:28212827.

19 Zappia E, Casazza S, Pedemonte E, et al. Mesenchymal stem cells ameliorate experimental autoimmune encephalomyelitis inducing T-cell anergy. Blood $2005 ; 106: 1755-1761$
20 Batten P, Sarathchandra P, Antoniw JW, et al. Human mesenchymal stem cells induce T cell anergy and downregulate T cell allo-responses via the TH2 pathway: relevance to tissue engineering human heart valves. Tissue Eng 2006; $12: 2263-2273$.

21 Stagg J, Pommey S, Eliopoulos N, Galipeau J. Interferon-gamma-stimulated marrow stromal cells: a new type of nonhematopoietic antigen-presenting cell. Blood 2006; 107:2570-2577.

22 Romieu-Mourez R, Francois M, Boivin MN, et al. Regulation of MHC class II expression and antigen processing in murine and human mesenchymal stromal cells by IFN-gamma, TGF-beta, and cell density. J Immunol 2007; 179:1549-1558.

23 Morandi F, Raffaghello L, Bianchi G, et al. Immunogenicity of human mesenchymal stem cells in HLA-class I-restricted T-cell responses against viral or tumor-associated antigens. Stem Cells 2008; 26:1275-1287.

24 Francois M, Romieu-Mourez R, Stock-Martineau S, et al. Mesenchymal stromal cells cross-present soluble exogenous antigens as part of their antigen-presenting cell properties. Blood 2009; 114:2632-2638.

25 Nauta AJ, Westerhuis G, Kruisselbrink AB, et al. Donor-derived mesenchymal stem cells are immunogenic in an allogeneic host and stimulate donor graft rejection in a nonmyeloablative setting. Blood 2006; 108:2114-2120.

26 Eliopoulos N, Stagg J, Lejeune L, et al. Allogeneic marrow stromal cells are immune rejected by MHC class I- and class II-mismatched recipient mice. Blood 2005; 106:4057-4065.

27 Zangi L, Margalit R, Reich-Zeliger S, et al. Direct imaging of immune rejection

- and memory induction by allogeneic mesenchymal stromal cells. Stem Cells $2009 ; 27: 2865-2874$.

This study demonstrates definitely that allogeneic MSC induces a memory CD4 and CD8 T-cell response in vivo.

28 Rasmusson I, Ringden O, Sundberg B, Le Blanc K. Mesenchymal stem cells inhibit lymphocyte proliferation by mitogens and alloantigens by different mechanisms. Exp Cell Res 2005; 305:33-41.

29 Le Blanc K, Tammik L, Sundberg B, et al. Mesenchymal stem cells inhibit and stimulate mixed lymphocyte cultures and mitogenic responses independently of the major histocompatibility complex. Scand J Immunol 2003; 57:11-20.

30 Bartholomew A, Sturgeon C, Siatskas M, et al. Mesenchymal stem cells suppress lymphocyte proliferation in vitro and prolong skin graft survival in vivo. Exp Hematol 2002; 30:42-48.

31 Inoue S, Popp FC, Koehl GE, et al. Immunomodulatory effects of mesenchymal stem cells in a rat organ transplant model. Transplantation 2006; 81:1589-1595

32 Djouad F, Plence P, Bony C, et al. Immunosuppressive effect of mesenchymal stem cells favors tumor growth in allogeneic animals. Blood 2003; 102:38373844.

33 Augello A, Tasso R, Negrini SM, et al. Bone marrow mesenchymal progenitor cells inhibit lymphocyte proliferation by activation of the programmed death 1 pathway. Eur J Immunol 2005; 35:1482-1490.

34 Aggarwal S, Pittenger MF. Human mesenchymal stem cells modulate allogeneic immune cell responses. Blood 2005; 105:1815-1822.

35 Krampera $\mathrm{M}$, Cosmi $\mathrm{L}$, Angeli $\mathrm{R}$, et al. Role for interferon-gamma in the immunomodulatory activity of human bone marrow mesenchymal stem cells. Stem Cells 2006; 24:386-398.

36 Rasmusson I, Ringden O, Sundberg B, Le Blanc K. Mesenchymal stem cells inhibit the formation of cytotoxic T lymphocytes, but not activated cytotoxic $T$ lymphocytes or natural killer cells. Transplantation 2003; 76:1208-1213.

37 Krampera M, Glennie S, Dyson J, et al. Bone marrow mesenchymal stem cells inhibit the response of naive and memory antigen-specific $T$ cells to their cognate peptide. Blood 2003; 101:3722-3729.

38 Karlsson H, Samarasinghe S, Ball LM, et al. Mesenchymal stem cells exert differential effects on alloantigen and virus-specific T-cell responses. Blood 2008; 112:532-541.

39 Liu XJ, Zhang JF, Sun B, et al. Reciprocal effect of mesenchymal stem cell on experimental autoimmune encephalomyelitis is mediated by transforming growth factor-beta and interleukin-6. Clin Exp Immunol 2009; 158:37-44.

40 Meisel R, Zibert A, Laryea M, et al. Human bone marrow stromal cells inhibit allogeneic T-cell responses by indoleamine 2,3-dioxygenase-mediated tryptophan degradation. Blood 2004; 103:4619-4621.

41 Sato K, Ozaki K, Oh I, et al. Nitric oxide plays a critical role in suppression of Tcell proliferation by mesenchymal stem cells. Blood 2007; 109:228-234.

42 Potian JA, Aviv H, Ponzio NM, et al. Veto-like activity of mesenchymal stem cells: functional discrimination between cellular responses to alloantigens and recall antigens. J Immunol 2003; 171:3426-3434.

43 Beyth S, Borovsky Z, Mevorach D, et al. Human mesenchymal stem cells alter antigen-presenting cell maturation and induce T-cell unresponsiveness. Blood 2005; 105:2214-2219. 
44 Nasef A, Chapel A, Mazurier C, et al. Identification of IL-10 and TGF-beta transcripts involved in the inhibition of T-lymphocyte proliferation during cel contact with human mesenchymal stem cells. Gene Exp 2007; 13:217-226.

45 Ren G, Zhang L, Zhao X, et al. Mesenchymal stem cell-mediated immunosuppression occurs via concerted action of chemokines and nitric oxide. Cell Stem Cell 2008; 2:141-150.

46 Chabannes D, Hill M, Merieau E, et al. A role for heme oxygenase-1 in the immunosuppressive effect of adult rat and human mesenchymal stem cells. Blood 2007; 110:3691-3694.

47 Nasef A, Mathieu N, Chapel A, et al. Immunosuppressive effects of mesenchymal stem cells: involvement of HLA-G. Transplantation 2007; 84:231-237.

48 Selmani Z, Naji A, Zidi l, et al. Human leukocyte antigen-G5 secretion by human mesenchymal stem cells is required to suppress $T$ lymphocyte and natural killer function and to induce CD4+CD25highFOXP3 + regulatory $T$ cells. Stem Cells 2008; 26:212-222.

49 Sioud M, Mobergslien A, Boudabous A, Floisand Y. Evidence for the involvement of galectin-3 in mesenchymal stem cell suppression of allogeneic T-cell proliferation. Scand J Immunol 2010; 71:267-274.

50 Ren G, Su J, Zhang L, et al. Species variation in the mechanisms of

- mesenchymal stem cell-mediated immunosuppression. Stem Cells 2009; 27:1954-1962

This study shows that human MSCs mediate immunosuppression through IDO, whereas mouse MSCs utilize nitric oxide in the same culture condition. The species-associated difference helps to explain discrepancies in the identification of key soluble factors in MSC-mediated immunosuppression.

51 Maccario R, Podesta M, Moretta A, et al. Interaction of human mesenchymal stem cells with cells involved in alloantigen-specific immune response favors the differentiation of CD4+ T-cell subsets expressing a regulatory/suppressive phenotype. Haematologica 2005; 90:516-525.

52 English K, Ryan JM, Tobin L, et al. Cell contact, prostaglandin $\mathrm{E}(2)$ and

- transforming growth factor beta 1 play non-redundant roles in human mesenchymal stem cell induction of CD4+CD25(High) forkhead box P3+ regulatory T cells. Clin Exp Immunol 2009; 156:149-160.

This study described the mechanism of regulatory T-cell induction by MSCs and identified cell-contact, $\mathrm{PGE}_{2}$, and TGF- $\beta$ as crucial factors.

53 Renner $\mathrm{P}$, Eggenhofer $\mathrm{E}$, Rosenauer $\mathrm{A}$, et al. Mesenchymal stem cells require a sufficient, ongoing immune response to exert their immunosuppressive function. Transplant Proc 2009; 41:2607-2611.

54 Ryan JM, Barry F, Murphy JM, Mahon BP. Interferon-gamma does not break, but promotes the immunosuppressive capacity of adult human mesenchyma stem cells. Clin Exp Immunol 2007; 149:353-363.

55 English K, Barry FP, Field-Corbett CP, Mahon BP. IFN-gamma and TNF-alpha differentially regulate immunomodulation by murine mesenchymal stem cells. Immunol Lett 2007; 110:91-100.

56 Sheng $\mathrm{H}$, Wang $\mathrm{Y}$, Jin $\mathrm{Y}$, et al. A critical role of IFNgamma in priming MSCmediated suppression of $\mathrm{T}$ cell proliferation through up-regulation of $\mathrm{B} 7-\mathrm{H} 1$. Cell Res 2008; 18:846-857.

57 Oh I, Ozaki K, Sato K, et al. Interferon-gamma and NF-kappaB mediate nitric oxide production by mesenchymal stromal cells. Biochem Biophys Res Commun 2007; 355:956-962.

58 Majumdar MK, Keane-Moore M, Buyaner D, et al. Characterization and functionality of cell surface molecules on human mesenchymal stem cells. J Biomed Sci 2003; 10:228-241.

59 Suva D, Passweg J, Arnaudeau S, et al. In vitro activated human T lymphocytes very efficiently attach to allogenic multipotent mesenchymal stromal cells and transmigrate under them. J Cell Physiol 2008; 214:588-594.

60 Quaedackers ME, Baan CC, Weimar W, Hoogduijn MJ. Cell contact interaction between adipose-derived stromal cells and allo-activated T lymphocytes. Eur J Immunol 2009; 39:3436-3446.

61 Jiang XX, Zhang $Y$, Liu B, et al. Human mesenchymal stem cells inhibit differentiation and function of monocyte-derived dendritic cells. Blood 2005; 105:4120-4126.

62 Djouad F, Charbonnier LM, Bouffi C, et al. Mesenchymal stem cells inhibit the differentiation of dendritic cells through an interleukin-6-dependent mechanism. Stem Cells 2007; 25:2025-2032.

63 Nauta AJ, Kruisselbrink AB, Lurvink E, et al. Mesenchymal stem cells inhibit generation and function of both CD34+-derived and monocyte-derived dendritic cells. J Immunol 2006; 177:2080-2087.

64 Li YP, Paczesny S, Lauret E, et al. Human mesenchymal stem cells license adult CD34+ hemopoietic progenitor cells to differentiate into regulatory dendritic cells through activation of the Notch pathway. J Immunol 2008 180:1598-1608

65 Zhang W, Ge W, Li C, et al. Effects of mesenchymal stem cells on differentiation, maturation, and function of human monocyte-derived dendritic cells. Stem Cells Dev 2004; 13:263-271.
66 Zhang B, Liu R, Shi D, et al. Mesenchymal stem cells induce mature dendritic

- cells into a novel Jagged-2-dependent regulatory dendritic cell population. Blood 2009; 113:46-57.

This study describes the induction of potent immunoregulatory function in mature dendritic cells exposed to MSCs in vitro and identifies Jagged-2 as crucial mediator.

67 Wang Q, Sun B, Wang D, et al. Murine bone marrow mesenchymal stem cells cause mature dendritic cells to promote T-cell tolerance. Scand J Immunol 2008; 68:607-615.

68 Corcione A, Benvenuto F, Ferretti E, et al. Human mesenchymal stem cells modulate B-cell functions. Blood 2006; 107:367-372.

69 Comoli P, Ginevri F, Maccario R, et al. Human mesenchymal stem cells inhibit antibody production induced in vitro by allostimulation. Nephrol Dial Transplant 2008; 23:1196-1202.

70 Tabera S, Perez-Simon JA, Diez-Campelo M, et al. The effect of mesenchymal stem cells on the viability, proliferation and differentiation of B-lymphocytes. Haematologica 2008; 93:1301-1309.

71 Rasmusson I, Le Blanc K, Sundberg B, Ringden O. Mesenchymal stem cells stimulate antibody secretion in human B cells. Scand J Immunol 2007; 65:336-343.

72 Traggiai E, Volpi S, Schena F, et al. Bone marrow-derived mesenchymal stem cells induce both polyclonal expansion and differentiation of B cells isolated from healthy donors and systemic lupus erythematosus patients. Stem Cells 2008; 26:562-569.

73 Spaggiari GM, Capobianco A, Becchetti S, et al. Mesenchymal stem cellnatural killer cell interactions: evidence that activated NK cells are capable of killing MSCs, whereas MSCs can inhibit IL-2-induced NK-cell proliferation. Blood 2006; 107:1484-1490.

74 Sotiropoulou PA, Perez SA, Gritzapis AD, et al. Interactions between human mesenchymal stem cells and natural killer cells. Stem Cells 2006; 24:74-85.

75 Spaggiari GM, Capobianco A, Abdelrazik H, et al. Mesenchymal stem cells inhibit natural killer-cell proliferation, cytotoxicity, and cytokine production: role of indoleamine 2,3-dioxygenase and prostaglandin E2. Blood 2008 111:1327-1333.

76 Bischoff DS, Zhu JH, Makhijani NS, Yamaguchi DT. Acidic $\mathrm{pH}$ stimulates the production of the angiogenic CXC chemokine, CXCL8 (interleukin-8), in human adult mesenchymal stem cells via the extracellular signal-regulated kinase, p38 mitogen-activated protein kinase, and NF-kappaB pathways. J Cell Biochem 2008; 104:1378-1392.

77 Croitoru-Lamoury J, Lamoury FM, Zaunders JJ, et al. Human mesenchymal stem cells constitutively express chemokines and chemokine receptors that can be upregulated by cytokines, IFN-beta, and Copaxone. J Interferon Cytokine Res 2007; 27:53-64.

78 Popp FC, Eggenhofer E, Renner P, et al. Mesenchymal stem cells can induce long-term acceptance of solid organ allografts in synergy with low-dose mycophenolate. Transpl Immunol 2008; 20:55-60.

79 Zhou HP, Yi DH, Yu SQ, et al. Administration of donor-derived mesenchymal stem cells can prolong the survival of rat cardiac allograft. Transplant Proc 2006; 38:3046-3051.

80 Ge W, Jiang J, Baroja ML, et al. Infusion of mesenchymal stem cells and - rapamycin synergize to attenuate alloimmune responses and promote cardiac allograft tolerance. Am J Transplant 2009; 9:1760-1772.

In an experimental model of heart transplantation, the study shows that MSC infusion in combination with rapamycin promotes cardiac allograft tolerance.

81 Casiraghi F, Azzollini N, Cassis P, et al. Pretransplant infusion of mesenchymal stem cells prolongs the survival of a semiallogeneic heart transplant through the generation of regulatory T cells. J Immunol 2008; 181:3933-3946.

82 Wang $Y$, Zhang A, Ye Z, et al. Bone marrow-derived mesenchymal stem cells inhibit acute rejection of rat liver allografts in association with regulatory $\mathrm{T}$-cell expansion. Transplant Proc 2009; 41:4352-4356.

83 Ding $Y, X u$ D, Feng G, et al. Mesenchymal stem cells prevent the rejection of fully allogenic islet grafts by the immunosuppressive activity of matrix metalloproteinase-2 and -9. Diabetes 2009; 58:1797-1806.

84 Buron $\mathrm{F}$, Perrin $\mathrm{H}$, Malcus $\mathrm{C}$, et al. Human mesenchymal stem cells and immunosuppressive drug interactions in allogeneic responses: an in vitro study using human cells. Transplant Proc 2009; 41:3347-3352.

85 Le Blanc K, Rasmusson I, Gotherstrom C, et al. Mesenchymal stem cells inhibit the expression of CD25 (interleukin-2 receptor) and CD38 on phytohaemagglutinin-activated lymphocytes. Scand J Immunol 2004; 60:307315.

86 Maccario R, Moretta A, Cometa A, et al. Human mesenchymal stem cells and cyclosporin $A$ exert a synergistic suppressive effect on in vitro activation of alloantigen-specific cytotoxic lymphocytes. Biol Blood Marrow Transplant 2005; 11:1031-1032. 
87 Hoogduijn MJ, Crop MJ, Korevaar SS, et al. Susceptibility of human me- senchymal stem cells to tacrolimus, mycophenolic acid, and rapamycin. Transplantation 2008; 86:1283-1291.

The studies mentioned in Refs. [84] and [ $87^{\circ}$ ] are first reports assessing the interaction of MSCs and immunosuppressive drugs in the inhibition of T-cell proliferation in vitro.

88 Zhang W, Qin C, Zhou ZM. Mesenchymal stem cells modulate immune responses combined with cyclosporine in a rat renal transplantation model. Transplant Proc 2007; 39:3404-3408.

89 Sbano P, Cuccia A, Mazzanti B, et al. Use of donor bone marrow mesenchymal stem cells for treatment of skin allograft rejection in a preclinical rat model. Arch Dermatol Res 2008; 300:115-124.

90 Kuo YR, Goto S, Shih HS, et al. Mesenchymal stem cells prolong composite tissue allotransplant survival in a swine model. Transplantation 2009; 87:1769-1777.

91 Le Blanc K, Rasmusson I, Sundberg B, et al. Treatment of severe acute graftversus-host disease with third party haploidentical mesenchymal stem cells. Lancet 2004; 363:1439-1441.

92 Le Blanc K, Frassoni F, Ball L, et al. Mesenchymal stem cells for treatment of steroid-resistant, severe, acute graft-versus-host disease: a phase II study. Lancet 2008; 371:1579-1586.
93 Parekkadan B, Tilles AW, Yarmush ML. Bone marrow-derived mesenchymal stem cells ameliorate autoimmune enteropathy independently of regulatory $T$ cells. Stem Cells 2008; 26:1913-1919.

94 Chamberlain G, Fox J, Ashton B, Middleton J. Concise review: mesenchymal stem cells - their phenotype, differentiation capacity, immunological features, and potential for homing. Stem Cells 2007; 25:27392749.

95 Gonzalez MA, Gonzalez-Rey E, Rico L, et al. Treatment of experimental arthritis by inducing immune tolerance with human adipose-derived mesenchymal stem cells. Arthritis Rheum 2009; 60:1006-1019.

96 Nemeth K, Keane-Myers A, Brown JM, et al. Bone marrow stromal cells use TGF-beta to suppress allergic responses in a mouse model of ragweed-induced asthma. Proc Natl Acad Sci U S A 2010; 107:56525657.

97 Dahlke $\mathrm{MH}$, Hoogduijn M, Eggenhofer E, et al. Toward MSC in solid organ -• transplantation: 2008 position paper of the MISOT study group. Transplantation 2009; 88:614-619.

This is the position paper summarizing the recommendations for early clinical trials and ongoing basic research in the field of MSC-induced solid organ graft acceptance - agreed upon on the first meeting of the Mesenchymal Stem Cells In Solid Organ Transplantation (MISOT) study group in 2008. 
CHAPTER 7

Mesenchymal stromal cells to promote solid organ transplantation tolerance

F. Casiraghi, N. Perico and G. Remuzzi

published in: Current Opinion in Organ Transplantation 2013, 18:51-58. 


\title{
Mesenchymal stromal cells to promote solid organ transplantation tolerance
}

\author{
Federica Casiraghi, Norberto Perico, and Giuseppe Remuzzi
}

\begin{abstract}
Purpose of review
Mesenchymal stromal cells (MSCs) possess unique immunomodulatory features. MSCs dampen effector T-cell response while promoting the emergence of regulatory T cells. By skewing this balance, MSC could represent the ideal strategy for tolerance induction in organ transplantation. Here we review recent evidence on the efficacy of MSC-based therapy in experimental models of solid organ transplantation as well as the early clinical experiences in kidney transplantation.
\end{abstract}

\section{Recent findings}

MSC infusion in experimental models of solid organ transplantation resulted in a Treg-mediated tolerance. MSC also synergized with low-dose or transient pharmacological immunosuppression in inducing long-term graft survival indicating that these cells could allow safe minimization of maintenance drug therapy. Early results from clinical studies in kidney transplant recipients reported encouraging results on the immunoregulatory effect of MSC, although posttransplant MSC infusion could associate with acute graft dysfunction (engraftment syndrome).

\section{Summary}

Immunoregulatory functions of MSC are not fixed but rather the result of microenvironment they encounter in vivo. Further studies are needed to establish how and wherein these cells have to be administered and how they may function to safely modulate host immune response in vivo in clinical transplant setting.

\section{Keywords}

effector T cells, kidney transplantation, mesenchymal stromal cells, regulatory $T$ cells, solid organ transplantation

\section{INTRODUCTION}

Since the first successful renal transplantation in Boston in 1954 [1], organ transplantation has made dramatic strides, evolving from an experimental procedure to standard of care in the treatment of patients with end-stage organ disease. Although powerful immunosuppressive drugs are undoubtedly the cornerstone of transplant success by preventing acute cellular rejection [2], they affect the function of all responding $\mathrm{T}$ cells irrespective of their antigen-specificity, rendering transplant recipients susceptible to life-threatening infections and malignancy $[3,4]$. In addition, life-long use of broad-spectrum pharmacological immunosuppression is associated with unwanted side effects, including accelerated cardiovascular disease, metabolic complications and with a direct toxic effect to transplanted tissues $[3,4]$, eventually contributing to long-term graft loss, a common event in renal transplantation. Ideally, the induction of donorspecific tolerance would overcome these shortcomings, possibly allowing indefinite graft survival [5].
The immune system has evolved multiple mechanisms for controlling the effector adaptive immune response [6]. Transplantation of a major histocompatibility complex-incompatible graft triggers the activation of graft destructive effector $\mathrm{T}$ cells as well as protective regulatory T cells (Tregs); it is the balance of such opposing subsets that ultimately determines the fate of the allotransplant [5]. The most extensively studied populations of Tregs are the so-called naturally occurring $\mathrm{CD} 4^{+} \mathrm{CD} 25^{+}$Foxp3 $^{+}$Treg that develop in the thymus $[7,8]$ and the adaptive Tregs

\footnotetext{
Department of Immunology and Transplantation, Transplant Research Center 'Chiara Cucchi de Alessandri e Gilberto Crespi', Mario Negri Institute for Pharmacological Research, Ospedali Riuniti - 'Mario Negri' Institute for Pharmacological Research, Bergamo, Italy

Correspondence to Federica Casiraghi, Transplant Research Center, 'Chiara Cucchi de Alessandri e Gilberto Crespi', Mario Negri Institute for Pharmacological Research, Via Camozzi 3, 24020 Ranica (Bergamo), Italy. Tel: +39035 4535361; fax: +39035 4535377; e-mail: federica. casiraghi@marionegri.it
}

Curr Opin Organ Transplant 2013, 18:51-58

DOI:10.1097/MOT.0b013e32835c5016 


\section{KEY POINTS}

- MSC possess the ability to skew the balance between effector T cells and regulatory T cells toward emergence of Tregs. This unique feature proposed MSC as the ideal tolerance-inducing tool in organ transplantation.

- Depending on the experimental settings, MSC induced a Treg-dependent tolerance when infused alone or when given together with low-dose transient immunosuppressive drugs in animals undergoing tissue or solid organ transplantation. However, immunoregulatory functions of MSC are not fixed but rather the result of microenvironment they encounter in vivo. Results from early clinical studies are now coming out.

- There remain many open questions both on the risk and the real benefit of these cells. Further studies are needed to establish how and where these cells have to be administered and how they may function to safely modulate host immune response in vivo in clinical transplant setting. Tailor made step-wise clinical approaches are recommended before embarking in large clinical trails.

that are induced in the periphery in response to antigen stimulation under tolerogenic conditions [9]. Together, Tregs maintain tolerance to self-antigens and control excessive immune response to foreign antigens and may contribute to the induction and maintenance of tolerance to allografts $[10,11]$.

Bone marrow-derived multipotent mesenchymal stromal cells (MSC) have emerged as a promising cell population for immunomodulatory therapy in transplantation given their unique immunoregulatory properties on both the adaptive [12] and innate [13"'] immune cells. MSC are capable of suppressing $\mathrm{T}$ effector cells [14] including memory $\mathrm{T}$ cells $[15,16]$, skewing $\mathrm{T}$ cells toward Foxp $3^{+}$ Tregs with concurrent suppression of Th1, Th2 or Th17 responses [14]. The findings that MSC target effector/memory $\mathrm{T}$ cells and promote the development of Tregs have led to propose MSC as a novel, potentially suitable cell-based approach for tolerance induction in organ transplantation.

Here, we have reviewed recent evidence on the capability of MSC to skew the balance between $\mathrm{T}$ effector cells and Tregs as well as the safety and efficacy of MSC-based therapy in experimental models of solid organ transplantation and in early clinical experience.

\section{MESENCHYMAL STROMAL CELLS AND REGULATORY T CELL GENERATION}

MSC are a heterogeneous population of adult, fibroblast-like multipotent cells characterized by their ability to differentiate into tissues of mesodermal lineages, including adipocytes, chondrocytes and osteocytes [17]. First identified and isolated from the bone marrow as plastic adherent cells [18], MSC are now isolated from a number of other sources including umbilical cord blood, adipose tissue and muscle $[19,20]$. The isolation of MSC by in-vitro expansion of plastic-adherent cells yields a heterogeneous cell population evidenced by the different morphology and functional potential. In order to create a consensus and more uniformly characterize these cells the International Society of Cellular Therapy proposed a standard set to define the identity of MSC [21]: adherence to plastic surfaces; potential to differentiate into osteocytes, adipocytes and chondrocytes under standard invitro differentiating conditions; and expression of CD105, CD73 and CD90 and must lack expression of CD45, CD34, CD14, CD11b, CD79a and HLA-DR.

Several in-vitro and in-vivo studies have documented the remarkable ability of MSC to polarize $\mathrm{T}$ cells toward a regulatory phenotype. In-vitro coincubation of human MSC with peripheral blood mononuclear cells or with purified $\mathrm{CD} 4^{+} \mathrm{T}$ cells induced the differentiation of $\mathrm{CD}^{+} \mathrm{T}$ cells into Foxp3-expressing Tregs [22-25], a process involving direct MSC contact with $\mathrm{T}$ cells followed by prostaglandin $\mathrm{E}_{2}$ and transforming growth factor $\beta-1$ (TGF $\beta-1$ ) expression [22,24]. Expanded Tregs potently suppressed the alloantigen-specific proliferative response in mixed-lymphocyte reaction (MLR) assay $[23,24]$. MSC induced a Treg phenotype $\left(\mathrm{CD} 25^{\text {bright }} \mathrm{Foxp}^{+} \mathrm{CD} 127^{\text {low }}\right)$ both in naive $\mathrm{CD}^{+}$ $\mathrm{CD} 45 \mathrm{RA}^{+}$and in memory $\mathrm{CD}^{+} \mathrm{CD}^{+} 5 \mathrm{RO}^{+} \mathrm{T}$ cells [26]. Other potential mechanisms of MSC-induced Treg generation include the release of soluble HLA-G5, a nonclassical HLA class I molecule [27] or of microvescicles [28]. MSC are also able to reprogram fully differentiated Th17 cells into Foxp3-expressing Tregs [29]. However, both the activation state of $\mathrm{CD}^{+}{ }^{+} \mathrm{T}$ cells and the cytokine milieu that MSC encounter dictate the ultimate cell outcome. Whereas the early addition of MSC to $\mathrm{T}$ cells cultured under Th1 and Th17 polarizing conditions exerted an extensive suppressive effect on all $\mathrm{CD}^{+}{ }^{+} \mathrm{T}$-cell lineages, MSC added to already differentiated Th1/Th17 cells decreased IFN $\gamma$ production by Th1 cells, but paradoxically increased proinflammatory interleukin 17 (IL-17) [30"]. Moreover, MSC cultured in the presence of inflammatory cytokines secreted significant levels of IL-6, which, in addition to a spontaneous production of TGF $\beta$ supported retinoic acid-related orphan receptor $\gamma \mathrm{t}$ expression and development of Th17 [31"].

By exerting inhibitory effects on antigen presenting cells (APC), MSC can generate regulatory 
APC with own Treg promoting activity. Dendritic cells cultured in the presence of MSC or conditioned medium expressed lower level of costimulatory molecules, hardly stimulated T-cell proliferation and efficiently generated Tregs through the release of TGF $\beta[32,33]$. Tregs could also be expanded by macrophages polarized by MSC toward the M2 anti-inflammatory phenotype [34"]. In the in-vitro setting of anti-CD3/anti-CD28 antibody T-cell stimulation, MSC promoted the differentiation of the monocyte fraction of peripheral blood mononuclear cells into IL-10- secreting M2 immunosuppressive macrophages via the induction of indoleamine 2,3-dioxygenase expression [35"]. These macrophages were in turn implicated in the generation of Tregs [35"].

The role of macrophages in MSC-induced Tregs has been recently confirmed in vivo in mouse models of fibrillin-mutated systemic sclerosis and experimental colitis [36"']. Indeed, systemic infusion of either syngeneic or allogeneic murine bone marrow MSC in these mice-induced transient T-cell apoptosis via the FasL-Fas pathway, which triggered macrophages to produce high levels of TGF $\beta$ in the peripheral blood, eventually enhancing $\mathrm{CD} 4^{+}$ $\mathrm{CD} 25^{+} \mathrm{Foxp}^{+}$Treg generation. This effect translated into the amelioration of the disease phenotypes [36"'].

The polarization of $\mathrm{T}$ cells toward a Treg phenotype with a concomitant decrease in Th1/Th17 development has been also shown to be associated with MSC immunomodulatory effect in other experimental models of autoimmune and inflammatory diseases such as systemic lupus erythematosus [37], collagen-induced arthritis [38-40], diabetes [41-44], colitis [45] and autoimmune myasthenia gravis $[46,47]$.

Together these in-vitro and in-vivo studies indicate the ability of MSC to modulate the immune response to antigens mainly by promoting the generation of $\mathrm{T}$ cells with regulatory phenotype and possibly lowering the availability of Th1/Th17 effector cells.

\section{MESENCHYMAL STROMAL CELLS IN EXPERIMENTAL MODELS OF SOLID ORGAN TRANSPLANTATION}

Almost a decade has elapsed since the first study reporting the capability of MSC to prolong survival of skin graft in nonhuman primates [48]. Subsequent studies in rodent models of heart [49-55], liver [56] islet [57-59,60",61"], kidney [62,63"] and composite tissue $\left[64^{\prime}, 65^{\prime}\right]$ allotransplantation confirmed the immunomodulatory potential of MSC in transplantation (Table $1\left[48-59,60^{*}, 61^{*}, 62,63^{-}-\right.$ $\left.\left.65^{*}, 66\right]\right)$. Of note, long-term graft acceptance achieved after MSC infusion alone or in association with low-dose immunosuppressive drugs was found to be related to the expansion of Tregs $[52,53,56$, $\left.60^{\prime}, 61^{\prime}, 62,63^{*}-65^{\prime}\right]$ or tolerogenic dendritic cells $[51,53]$.

There is also evidence that Treg depletion abrogated the MSC effect of inducing longterm graft acceptance $\left[62,63^{-}\right]$, highlighting that MSC-mediated tolerance is maintained by Tregs. Regulatory T-cells isolated from long-term survival mice were antigen-specific [52].

We recently demonstrated that the timing of MSC infusion in respect to solid organ transplantation is one of the main factors affecting MSC capability to expand Tregs and prolong graft survival [63"]. Murine MSC given to mice pretransplantation localized preferentially into lymphoid organs where allowed early expansion of Tregs, eventually leading to immune tolerance to subsequent kidney allografts. At variance, MSC infused posttransplant localized preferentially into the kidney graft with very low expansion of Tregs [63"]. Intragraft MSC localization associated with acute graft dysfunction, intragraft neutrophil recruitment and C3 deposition and poor graft survival [63"]. Similarly, the migration of MSC into recipient lymphoid tissues have been shown to be critical for MSC immunomodulatory effects in autoimmune encephalomyelitis [67], autoimmune enteropathy [68], diabetes [69"] and graft-versus-host disease [70], supporting the concept that MSC need to interact with immune cells in sites of initial effector T-cell priming in order to effectively exert immunomodulation.

Most of the experimental studies with MSC in organ transplantation have been performed without any additional pharmacological immunosuppressive therapy. However, in the perspective of translating cell-based MSC therapy to clinical transplant programs, it is critical to evaluate the possible negative impact of currently used antirejection drugs on MSC-induced Treg generation and function and eventually graft survival.

Data on the effect of cyclosporine (CsA) on MSC-induced immunoregulation are controversial $[55,66]$ (Table 1). There is experimental and clinical evidence that calcineurin inhibitors (CNI), by blocking IL-2 expression in T cells, prevent both Treg development and homeostasis [71], although at low-dose these drugs may expand Tregs in both the periphery and the allografts [72].

In a mouse model of in-vivo MLR, CsA inhibited the MSC-mediated suppression of $\mathrm{CD}^{+}$T-cell proliferation [54]. At variance, other in-vitro studies have documented the CsA did not interfere with MSC-mediated Treg generation [23] and that MSC 
Table 1. Effect of bone marrow-derived mesenchymal stromal cells on graft survival in experimental models of solid organ transplantation

\begin{tabular}{|c|c|c|c|c|c|c|c|c|c|}
\hline \multirow[b]{2}{*}{ Model } & \multirow[b]{2}{*}{ MSC source } & \multirow[b]{2}{*}{ Dose } & \multirow{2}{*}{$\begin{array}{l}\text { Timing } \\
(\text { tx = day } 0)\end{array}$} & \multirow{2}{*}{$\begin{array}{l}\text { Immunosuppression } \\
\mathrm{tx}=\text { day } 0\end{array}$} & \multicolumn{3}{|c|}{ Graft survival (days) } & \multirow{2}{*}{$\begin{array}{c}\text { Treg } \\
\text { expansion }\end{array}$} & \multirow[b]{2}{*}{ Reference } \\
\hline & & & & & None & MSC & $M S C+I S$ & & \\
\hline Skin tx in baboons & Third party & $1-2 \times 107$ & Days 0 and +3 & None & 1 & 11 & & nd & [48] \\
\hline Heart tx in rats & Donor & $12 \times 106$ & Days -7 and 0 & None & 6 & 23 & & nd & [50] \\
\hline Heart tx in rats & Donor & $2 \times 106$ & Days $-7,0,+1,+2,+3$ & None & 6 & 12 & & nd & [49] \\
\hline \multirow[t]{2}{*}{ Heart tx in mice } & Donor & $0.5 \times 106$ & Days -7 and -1 & None & 10 & 40 & & YES & {$[52]$} \\
\hline & Syngeneic & & & None & 10 & $>60$ & & & \\
\hline Islet tx in mice & Syngeneic & $4 \times 106$ & Day 0 & None & 30 & $>90$ & & nd & [57] \\
\hline Islet tx in mice & Syngeneic & $3 \times 106$ & Day0 & None & 16 & 38 & & YES & [61"] \\
\hline Islet tx in mice & Donor & $1 \times 106$ & Days $-3,-2$ and 0 & None & 16 & $>28$ & & nd & [59] \\
\hline \multirow[t]{3}{*}{ Liver tx in rats } & Syngeneic & $2 \times 106$ & Days $0,+1,+2,+3$ & None & 21 & 45 & & YES & [56] \\
\hline & Donor & & $+8,+12,+16$ & None & 21 & 47 & & & \\
\hline & Third-party & & & None & 21 & 57 & & & \\
\hline Kidney $t x$ in mice & Donor & $1 \times 106$ & Day+1 & None & 31 & $>100$ & & YES & [62] \\
\hline Kidney $t x$ in mice & Syngeneic & $0.5 \times 106$ & Days -7 and -1 & None & 10 & $>60$ & & YES & [63"'] \\
\hline \multirow[t]{3}{*}{ Heart tx in rats } & Donor & $2 \times 106$ & Day-4 & $\begin{array}{l}\text { MMF }\left(20 \mathrm{mg} / \mathrm{kg}^{-1} \text { day }\right. \\
\text { from day } 0 \text { to }+7)\end{array}$ & 8 & 6 & $>100$ & NO & [51] \\
\hline & Third party & & & & & & 20 & & \\
\hline & Syngeneic & & & & & & 20 & & \\
\hline Heart tx in mice & Donor & $0.5 \times 106$ & Day-4 & $\begin{array}{l}\text { MMF }\left(160 \mathrm{mg} / \mathrm{kg}^{-1} \text { day }\right. \\
\text { from day } 0 \text { to }+7)\end{array}$ & 8 & 7 & 32 & nd & [54] \\
\hline Heart tx in mice & Donor & $1 \times 106$ & Day+1 & $\begin{array}{l}\text { Rapamycin }\left(2 \mathrm{mg} / \mathrm{kg}^{-1} \text { day }\right. \\
\text { from day } 0 \text { to }+13)\end{array}$ & 7.5 & 14 & $>100$ & YES & [53] \\
\hline \multirow[t]{2}{*}{ Heart tx in rats } & Donor & $5 \times 106$ & Days 0 and +3 & $\begin{array}{l}\text { CsA }\left(0.5 \mathrm{mg} / \mathrm{kg}^{-1} \text { day }\right. \\
\text { from day }+5 \text { to }+9)\end{array}$ & 9 & 8.8 & 10 & nd & [55] \\
\hline & Syngeneic & & & & & 8.6 & 10.4 & & \\
\hline \multirow[t]{2}{*}{ Islet tx in rats } & Syngeneic & $3 \times 106$ & Day0 & $\begin{array}{l}\mathrm{CsA}\left(10 \mathrm{mg} / \mathrm{kg}^{-1} \text { day }\right. \\
\text { from day } 0 \text { to }+20)\end{array}$ & 7 & & $>51$ & NO & [58] \\
\hline & Donor & & & & 7 & & 11 & & \\
\hline \multirow[t]{2}{*}{ Islet tx in rats } & Syngeneic & $2 \times 106$ & Day0 & $\begin{array}{l}\text { CsA }\left(5 \mathrm{mg} / \mathrm{kg}^{-1} \text { day }\right. \\
\text { from day } 0 \text { to }+14)\end{array}$ & 5 & 7.8 & 89 & YES & [60"] \\
\hline & Third-party & & & & 5 & 3.7 & 13.7 & & \\
\hline Heart-lung $t x$ in rats & Donor & $5 \times 106$ & DayO & CsA $(0.5 \mathrm{mg} / \mathrm{kgat}$ day -1$)$ & 3 & 14.5 & 18 & nd & [66] \\
\hline Hind-limb tx in swine & Third-party & $10 \times 107$ & Days $+1,+7,+14,+21$ & $\begin{array}{l}\text { Irradiation }+ \text { CsA }(10 \mathrm{mg} / \mathrm{kg} \\
\text { per day from day } 0 \text { to }+14 \\
5 \mathrm{mg} / \mathrm{kg} \text { per day from } \\
\text { day }+14 \text { to }+28)\end{array}$ & 10 & 25 & $>120$ & YES & [64"] \\
\hline Hemi-facial tx in swine & Third-party & $2.5 \times 107$ & $\begin{array}{l}\text { Days }-1,+1,+3,+7 \\
\quad+14,+21\end{array}$ & $\begin{array}{l}\mathrm{CsA}(10 \mathrm{mg} / \mathrm{kg} / \text { day from } \\
\text { day } 0 \text { to }+14 ; 5 \mathrm{mg} / \mathrm{kg} \\
\text { per day from day }+14 \text { to }+28)\end{array}$ & 9 & 34 & 70 & YES & [65"] \\
\hline
\end{tabular}

CsA, cyclosporin A; IS, immunosuppression; MMF, mycophenolate mofetil; MSC, mesenchymal stromal cells; nd, not evaluated; tx, transplant. 
synergized with CsA in inhibiting $\mathrm{T}$ lymphocyte activity [73]. The combination of MSC and subtherapeutic doses of CsA exerted a synergistic immunosuppressive effect, which translated into long-term graft acceptance of islet allografts [58,60"]. In rat islet allograft models MSC and low-dose CsA induced early expansion of IL-10 producing CD11b cells, which mediated T-cell hyporesponsiveness and allowed long-term Foxp3 Tregs expansion in lymph nodes and in the graft $\left[60^{*}\right]$. Moreover, in swine the combination of multiple infusions of allogeneic MSC with shortterm CsA immunosuppression achieved indefinite graft survival of hind-limb transplants [64"] and prolonged the survival of a hemi-facial transplant [65"]. In both studies long-term surviving animals showed increased levels of Foxp3 Tregs in the periphery and in the graft $\left[64^{\prime}, 65^{\prime}\right]$.

On the contrary, mammalian target-ofrapamycin inhibitors have been consistently shown to sustain Treg expansion in vitro and in vivo in animal models and kidney transplant recipients [74]. In an experimental model of heart transplantation in mice rapamycin synergized with MSC in inducing Treg-mediated tolerance [53]. Similarly, in the same model in rats, mycophenolate combined with donor MSC induced long-term graft acceptance $[51,54]$.

Altogether these results indicate that in experimental models MSC infusion synergized with low-dose or transient immunosuppressive drug treatment in inducing long-term graft acceptance, indicating that these cells allow safe minimization of maintenance pharmacological antirejection therapy.

\section{MESENCHYMAL STROMAL CELLS IN KIDNEY TRANSPLANTATION IN HUMANS}

There are few protocols of MSC-based therapy in organ transplantation (www.clinicaltrials.gov). Actually, clinical trials on the use of MSC in kidney and liver transplantation are being performed in our center in Bergamo, Italy (NCT00752479), in Leiden, The Netherlands (NCT00734396), in Liege, Belgium (NCT01429038) and in China (NCT00659620). So far only results from the Italian and Chinese experiences with MSC in living-donor kidney transplant recipients have been published. Our protocol is aimed at characterizing the safety and tolerability of peritransplant MSC infusion and to verify whether MSC, by skewing Treg/Teff balance allow creating a protolerogenic environment. We initially started with two living-related donor kidney recipients who were given ex-vivo expanded, autologous, bone marrow-derived MSC at day 7 posttransplant, after induction therapy with basiliximab/low-dose thymoglobulin [75"]. MSC infusion did promote on long-term a protolerogenic environment characterized by lower memory/effector $\mathrm{CD}^{+} \mathrm{T}$ cells, expansion of $\mathrm{CD}^{+}{ }^{+}$Tregs and reduction of donorspecific $\mathrm{CD}^{+}{ }^{+}$T-cell cytotoxicity, compared with control kidney transplant recipients given the same induction therapy but not MSC. However, few days after cell infusion, both MSC-treated patients developed acute renal insufficiency. Histological and immunohistochemical analysis of graft infiltrating cells did exclude an acute cellular or humoral rejection, but intragraft recruitment of neutrophils together with MSC, as well as complement-C3 deposition were observed [75"].

It was hypothesized that the subclinical inflammatory environment of the graft in the few days postsurgery could have favoured the prevalent intragraft recruitment and activation of the infused MSC promoting a proinflammatory milieu with eventual acute renal dysfunction (engraftment syndrome), as reported by others with combined kidney and bone marrow transplantation [76]. This hypothesis has been confirmed back into a murine kidney transplant model showing that MSC administration before (day-1) but not few days after kidney transplantation avoided the acute deterioration of graft function, while maintaining the immunomodulatory effect of MSC [63"].

The Chinese group performed a single-site prospective, randomized study aimed at comparing the risk-benefit profile of bone marrow-derived autologous MSC infusion (at kidney reperfusion and 2 weeks later) versus induction therapy with the anti-IL-2 receptor antibody basiliximab in living-related donor kidney transplants [77"]. MSC treatment resulted in lower incidence of acute rejection at 6 months posttransplant, decreased risk of opportunistic infection and better estimated renal function. The investigators concluded that MSC may replace basiliximab induction therapy, allowing the use of lower than conventional CNI maintenance doses without compromising patient safety and graft outcome. However, lower acute rejection rate and better renal function documented at 6 months after transplantation were transient and not confirmed at 1 year. The study has been criticized in a recent letter [78]. Unfortunately, this study did not report any attempt to in-depth assess the in-vivo effects of MSC on host immune system, especially on Treg and effector T-cell function by any immunological tests, which are mandatory for an innovative cell therapy still in its infancy before 
moving it to routine clinical application for transplant programs.

\section{CONCLUSION}

Cell therapy with MSC in solid organ transplantation has undoubtedly a great potential. However, although initial preclinical and early clinical results appear promising, moving the concept of MSCbased therapy forward toward clinical application should be critically assessed. We have to be aware that, so far, our knowledge about MSC is too scarce for embarking in large clinical trials and there remain many open questions both on the risk and the real benefit of these cells. Further studies are needed to establish how and where these cells have to be administered and how they may function to modulate host immune response in vivo in clinical transplant setting.

Rather than studying thousands of patients without enough attempt to safety issues and mechanistic/immunomodulatory pathways it seems preferable in our opinion in this kind of studies to proceed in few patients, however, very intensively investigated. Issues like source, dose, timing of administration, in-vivo localization, interaction with immunosuppressive drugs, whether these cells have to be used for prevention of acute rejection or for tolerance induction have not been addressed in this field and more explorative studies are required before embarking in formal clinical trials.

\section{Acknowledgements}

The Authors are member of the Mesenchymal Stem Cells in Solid Organ Transplantation (MISOT) study group, www.misot.de.

\section{Conflicts of interest}

This study has been partially supported by grants from Fondazione ART per la Ricerca sui Trapianti (Milan, Italy).

Grant support was received from Superpig Program, project co-financed by Lombardy Region through the 'Fund for promoting institutional agreements'

The authors of this manuscript have no conflict of interest to disclose.

\section{REFERENCES AND RECOMMENDED}

\section{READING}

Papers of particular interest, published within the annual period of review, have been highlighted as:

- of special interest

-1 of outstanding interest

Additional references related to this topic can also be found in the Current

World Literature section in this issue (p. 116).

1. Murray JE, Merrill JP, Harrison JH. Kidney transplantation between seven pairs of identical twins. Ann Surg 1958; 148:343-359.
2. U.S. Department of Health and Human Services 2008 Annual report of the U.S. Organ Procurement and Transplantation Network and the Scientific Registry of Transplant Recipients: Transplant Data. U.S. Department of Health and Human Services, Health Resources and Services Administration, Healthcare System Bureau, division of Transplantation, Rockville, MD; 1998-2007. www.str.org/annual_Reports.aspx

3. Lodhi SA, Lamb KE, Meier-Kriesche HU. Solid organ allograft survival improvement in the United States: the long-term does not mirror the dramatic short-term success. Am J Transplant 2011; 11:1226-1235.

4. Meier-Kriesche HU, Schold JD, Srinivas TR, Kaplan B. Lack of improvement in renal allograft survival despite a marked decrease in acute rejection rates over the most recent era. Am J Transplant 2004; 4:378-383.

5. Sayegh $\mathrm{MH}$, Remuzzi $\mathrm{G}$. Clinical update: immunosuppression minimisation. Lancet 2007; 369:1676-1678.

6. Ingulli E. Mechanism of cellular rejection in transplantation. Pediatr Nephrol 2010; 25:61-74.

7. Sakaguchi S. Naturally arising Foxp3-expressing CD25+CD4+ regulatory $\mathrm{T}$ cells in immunological tolerance to self and nonself. Nat Immunol 2005; $6: 345-352$.

8. Fontenot JD, Rudensky AY. A well adapted regulatory contrivance: regulatory $\mathrm{T}$ cell development and the forkhead family transcription factor Foxp3. Nat Immunol 2005; 6:331-337.

9. Curotto de Lafaille MA, Lafaille JJ. Natural and adaptive foxp $3+$ regulatory $T$ cells: more of the same or a division of labor? Immunity 2009; 30:626-635.

10. Wood KJ, Sakaguchi S. Regulatory $T$ cells in transplantation tolerance. Nat Rev Immunol 2003; 3:199-210.

11. $\mathrm{Li} X C$, Turka $L A$. An update on regulatory $T$ cells in transplant tolerance and rejection. Nat Rev Nephrol 2010; 6:577-583.

12. Griffin MD, Ritter $T$, Mahon BP. Immunological aspects of allogeneic mesenchymal stem cell therapies. Hum Gene Ther 2010; 21:1641-1655.

13. Le Blanc $K$, Mougiakakos D. Multipotent mesenchymal stromal cells and the

-1. innate immune system. Nat Rev Immunol 2012; 12:383-396.

An outstanding review of current knowledge regarding the effects of MSCs on the various components of the innate immune system and vice versa.

14. Duffy MM, Ritter T, Ceredig R, Griffin MD. Mesenchymal stem cell effects on T-cell effector pathways. Stem Cell Res Ther 2011; 2:34.

15. Krampera $M$, Glennie $S$, Dyson J, et al. Bone marrow mesenchymal stem cells inhibit the response of naive and memory antigen-specific $\mathrm{T}$ cells to their cognate peptide. Blood 2003; 101:3722-3729.

16. Karlsson H, Samarasinghe S, Ball LM, et al. Mesenchymal stem cells exert differential effects on alloantigen and virus-specific T-cell responses. Blood 2008; 112:532-541.

17. Caplan Al. Mesenchymal stem cells. J Orthop Res 1991; 9:641-650.

18. Friedenstein AJ, Chailakhyan RK, Latsinik NV, et al. Stromal cells responsible for transferring the microenvironment of the hemopoietic tissues. Cloning in vitro and retransplantation in vivo. Transplantation $1974 ; 17: 331-340$.

19. da Silva Meirelles $L$, Chagastelles PC, Nardi NB. Mesenchymal stem cells reside in virtually all postnatal organs and tissues. J Cell Sci 2006; 119:2204-2213.

20. Kern S, Eichler H, Stoeve J, et al. Comparative analysis of mesenchymal stem cells from bone marrow, umbilical cord blood, or adipose tissue. Stem Cells 2006; 24:1294-1301.

21. Dominici $M$, Le Blanc $K$, Mueller I, et al. Minimal criteria for defining multipotent mesenchymal stromal cells. The International Society for Cellular Therapy position statement. Cytotherapy 2006; 8:315-317.

22. Aggarwal $S$, Pittenger MF. Human mesenchymal stem cells modulate allogeneic immune cell responses. Blood 2005; 105:1815-1822.

23. Prevosto $C$, Zancolli $M$, Canevali $P$, et al. Generation of CD4+ or CD8+ regulatory $\mathrm{T}$ cells upon mesenchymal stem cell-lymphocyte interaction. Haematologica 2007; 92:881-888.

24. English K, Ryan JM, Tobin $L$, et al. Cell contact, prostaglandin $E(2)$ and transforming growth factor beta 1 play nonredundant roles in human mesenchymal stem cell induction of CD4+CD25(High) forkhead box P3+ regulatory T cells. Clin Exp Immunol 2009; 156:149-160.

25. Maccario R, Podesta $M$, Moretta $A$, et al. Interaction of human mesenchymal stem cells with cells involved in alloantigen-specific immune response favors the differentiation of CD4+ T-cell subsets expressing a regulatory/ suppressive phenotype. Haematologica 2005; 90:516-525.

26. Di lanni $M$, Del Papa $B$, De loanni $M$, et al. Mesenchymal cells recruit and regulate T regulatory cells. Exp Hematol 2008; 36:309-318.

27. Selmani Z, Naji A, Zidi I, et al. Human leukocyte antigen-G5 secretion by human mesenchymal stem cells is required to suppress $T$ lymphocyte and natural killer function and to induce CD4+CD25highFOXP3 + regulatory T cells. Stem Cells 2008; 26:212-222.

28. Mokarizadeh A, Delirezh N, Morshedi A, et al. Microvesicles derived from mesenchymal stem cells: Potent organelles for induction of tolerogenic signaling. Immunol Lett 2012; 147:47-54.

29. Ghannam S, Pene J, Torcy-Moquet G, et al. Mesenchymal stem cells inhibit human Th17 cell differentiation and function and induce a $\mathrm{T}$ regulatory cell phenotype. J Immunol 2010; 185:302-312.

30. Carrion F, Nova E, Luz P, et al. Opposing effect of mesenchymal stem cells on

- Th1 and Th17 cell polarization according to the state of CD4+ T cell activation. Immunol Lett $2011 ; 135: 10-16$.

The study showed how the activation status of T cells as well as the cytokine milieu that MSC encounter dictate the effect of MSC on Th17 cells. 
31. Svobodova E, Krulova M, Zajicova A, et al. The role of mouse mesenchymal

- stem cells in differentiation of naive T-cells into anti-inflammatory regulatory T-cell or proinflammatory helper T-cell 17 population. Stem Cells Dev 2012; $21: 901-910$

These studies showed how the activation status of T cells as well as the cytokine milieu that MSC encounter dictate the effect of MSC on Th17 cells.

32. Zhang B, Liu R, Shi D, et al. Mesenchymal stem cells induce mature dendritic cells into a novel Jagged-2-dependent regulatory dendritic cell population. Blood 2009; 113:46-57

33. Zhao ZG, Xu W, Sun $L$, et al. Immunomodulatory function of regulatory dendritic cells induced by mesenchymal stem cells. Immunol Invest 2012; 41:183-198.

34. Ylostalo JH, Bartosh TJ, Coble K, Prockop DJ. Human mesenchymal stem/

- stromal cells (hMSCs) cultured as spheroids are self-activated to produce prostaglandin E2 (PGE2) that directs stimulated macrophages into an antiinflammatory phenotype. 2012. Stem Cells 2012; 30:2283-2296.

The study describes how MSC induce macrophages to differentiate toward an anti-inflammatory M2 phenotype.

35. Francois M, Romieu-Mourez R, Li M, Galipeau J. Human MSC suppression - correlates with cytokine induction of indoleamine 2,3-dioxygenase and bystander M2 macrophage differentiation. Mol Ther 2012; 20:187-195.

These studies describe how MSC induce macrophages to differentiate toward an anti-inflammatory M2 phenotype.

36. Akiyama $K$, Chen $C$, Wang $D, X u X$, et al. Mesenchymal-stem-cell-induced

- immunoregulation involves FAS-ligand-/FAS-mediated T cell apoptosis. Cell Stem Cell 2012; 10:544-555.

This study uncovers a previously unrecognized MSC-mediated therapeutic mechanism by which MSC use FAS to regulate MCP-1 secretion for T-cell recruitment and subsequent use FAS to induce T-cell apoptosis. Macrophages subsequently take the apoptotic debris to release TGF $\beta$, leading to upregulation of Tregs and, ultimately, immune tolerance.

37. Sun L, Akiyama $\mathrm{K}$, Zhang $\mathrm{H}$, et al. Mesenchymal stem cell transplantation reverses multiorgan dysfunction in systemic lupus erythematosus mice and humans. Stem Cells 2009; 27:1421-1432.

38. Bouffi $C$, Bony $C$, Courties $G$, et al. IL-6-dependent PGE2 secretion by mesenchymal stem cells inhibits local inflammation in experimental arthritis. PLoS One 2010; 5:e14247.

39. Park MJ, Park HS, Cho ML, et al. Transforming growth factor beta-transduced mesenchymal stem cells ameliorate experimental autoimmune arthritis through reciprocal regulation of Treg/Th17 cells and osteoclastogenesis. Arthritis Rheum 2011; 63:1668-1680.

40. Zhou B, Yuan J, Zhou $Y$, et al. Administering human adipose-derived mesenchymal stem cells to prevent and treat experimental arthritis. Clin Immunol 2011; 141:328-337.

41. Abdi R, Fiorina $P$, Adra $C N$, et al. Immunomodulation by mesenchymal stem cells: a potential therapeutic strategy for type 1 diabetes. Diabetes 2008; 57:1759-1767.

42. Zhao $W$, Wang $Y$, Wang $D$, et al. TGF-beta expression by allogeneic bone marrow stromal cells ameliorates diabetes in NOD mice through modulating the distribution of CD4+ T cell subsets. Cell Immunol 2008; 253:23-30.

43. Madec AM, Mallone $\mathrm{R}$, Afonso $\mathrm{G}$, et al. Mesenchymal stem cells protect NOD mice from diabetes by inducing regulatory T cells. Diabetologia 2009; 52:1391-1399.

44. Bassi EJ, Mallone PM, Moreira Sa CS, et al. Immune regulatory properties of allogeneic adipose-derived mesenchymal stem cells in the treatment of experimental autoimmune diabetes. Diabetes 2012; 61:2534-2545.

45. Gonzalez MA, Gonzalez-Rey E, Rico L, et al. Adipose-derived mesenchymal stem cells alleviate experimental colitis by inhibiting inflammatory and autoimmune responses. Gastroenterology 2009; 136:978-989.

46. Kong QF, Sun B, Bai SS, et al. Administration of bone marrow stromal cells ameliorates experimental autoimmune myasthenia gravis by altering the balance of Th1/Th2/Th17/Treg cell subsets through the secretion of TGF-beta. J Neuroimmunol 2009; 207:83-91.

47. Kong QF, Sun B, Wang GY, et al. BM stromal cells ameliorate experimental autoimmune myasthenia gravis by altering the balance of Th cells through the secretion of IDO. Eur J Immunol 2009; 39:800-809.

48. Bartholomew A, Sturgeon C, Siatskas M, et al. Mesenchymal stem cells suppress lymphocyte proliferation in vitro and prolong skin graft survival in vivo. Exp Hematol 2002; 30:42-48.

49. Zhou HP, Yi DH, Yu SQ, et al. Administration of donor-derived mesenchymal stem cells can prolong the survival of rat cardiac allograft. Transplant Proc 2006; 38:3046-3051.

50. Chabannes D, Hill M, Merieau E, et al. A role for heme oxygenase-1 in the immunosuppressive effect of adult rat and human mesenchymal stem cells. Blood 2007; 110:3691-3694.

51. Popp FC, Eggenhofer E, Renner $P$, et al. Mesenchymal stem cells can induce long-term acceptance of solid organ allografts in synergy with low-dose mycophenolate. Transpl Immunol 2008; 20:55-60.

52. Casiraghi F, Azzollini N, Cassis $P$, et al. Pretransplant infusion of mesenchymal stem cells prolongs the survival of a semiallogeneic heart transplant through the generation of regulatory T cells. J Immunol 2008; 181:3933-3946.

53. Ge W, Jiang J, Baroja ML, et al. Infusion of mesenchymal stem cells and rapamycin synergize to attenuate alloimmune responses and promote cardiac allograft tolerance. Am J Transplant 2009; 9:1760-1772.
54. Eggenhofer $E$, Renner $P$, Soeder $Y$, et al. Features of synergism between mesenchymal stem cells and immunosuppressive drugs in a murine heart transplantation model. Transpl Immunol 2011; 25:141-147.

55. Inoue S, Popp FC, Koehl GE, et al. Immunomodulatory effects of mesenchymal stem cells in a rat organ transplant model. Transplantation 2006; 81:1589-1595.

56. Wang $Y$, Zhang A, Ye Z, et al. Bone marrow-derived mesenchymal stem cells inhibit acute rejection of rat liver allografts in association with regulatory T-cell expansion. Transplant Proc 2009; 41:4352-4356.

57. Ding $Y, X u D$, Feng $G$, et al. Mesenchymal stem cells prevent the rejection of fully allogeneic islet grafts by the immunosuppressive activity of matrix metalloproteinase-2 and -9. Diabetes 2009; 58:17971806.

58. Solari MG, Srinivasan S, Boumaza I, et al. Marginal mass islet transplantation with autologous mesenchymal stem cells promotes long-term islet allograft survival and sustained normoglycemia. J Autoimmun 2009; 32:116124.

59. Li FR, Wang XG, Deng CY, et al. Immune modulation of co-transplantation mesenchymal stem cells with islet on T and dendritic cells. Clin Exp Immunol 2010; 161:357-363.

60. Kim YH, Wee YM, Choi MY, et al. Interleukin (IL)-10 induced by CD11b(+)

- cells and IL-10-activated regulatory T cells play a role in immune modulation of mesenchymal stem cells in rat islet allografts. Mol Med 2011; 17:697708.

This study, together with [61"], described how MSC administration delays rejection of allogeneic islets in rodents by inducing Foxp3-expressing Tregs in lymph nodes and grafts.

61. Xu DM, Yu XF, Zhang D, et al. Mesenchymal stem cells differentially mediate regulatory $T$ cells and conventional effector $T$ cells to protect fully allogeneic islet grafts in mice. Diabetologia 2012; 55:1091-1102.

This study, together with [60"] described how MSC administration delays rejection of allogeneic islets in rodents by inducing Foxp3-expressing Tregs in lymph nodes and grafts.

62. Ge W, Jiang J, Arp J, et al. Regulatory T-cell generation and kidney allograft tolerance induced by mesenchymal stem cells associated with indoleamine 2,3-dioxygenase expression. Transplantation 2010; 90:1312-1320.

63. Casiraghi F, Azzollini N, Todeschini M, et al. Localization of mesenchymal

- stromal cells dictates their immune or proinflammatory effects in kidney transplantation. Am J Transplant 2012; 12:2373-2383.

This study shows that in a murine kidney transplant model, posttransplant MSC infusion causes premature graft dysfunction and fails to prolong graft survival, whereas pretransplant MSC infusion induces a significant prolongation of kidney graft survival by a regulatory $\mathrm{T}$-cell dependent mechanism.

64. Kuo YR, Chen CC, Shih HS, et al. Prolongation of composite tissue

allotransplant survival by treatment with bone marrow mesenchymal stem cells is correlated with T-cell regulation in a swine hind-limb model. Plast Reconstr Surg 2011; 127:569-579.

In composite tissue allotransplantation models in large animals the combination of allogeneic MSC with short-term immunosuppression prolonged graft survival and was associated with increased levels of Foxp3 Tregs in the periphery and in the graft.

65. Kuo YR, Chen CC, Goto S, et al. Immunomodulatory effects of bone marrow- derived mesenchymal stem cells in a swine hemi-facial allotransplantation model. PLoS One 2012; 7:e35459.

In composite tissue allotransplantation models in large animals the combination of allogeneic MSC with short-term immunosuppression prolonged graft survival and was associated with increased levels of Foxp3 Tregs in the periphery and in the graft.

66. Longoni B, Szilàgyi E, Puviani L, et al. Mesenchymal stem cell-based immunomodulation in allogeneic heterotopic heart-lung transplantation. J Transplant Technol Res 2012; 2:107.

67. Zappia E, Casazza S, Pedemonte E, et al. Mesenchymal stem cells ameliorate experimental autoimmune encephalomyelitis inducing T-cell anergy. Blood 2005; 106:1755-1761.

68. Parekkadan B, Tilles AW, Yarmush ML. Bone marrow-derived mesenchymal stem cells ameliorate autoimmune enteropathy independently of regulatory T cells. Stem Cells 2008; 26:1913-1919.

69. Ezquer F, Ezquer M, Contador D, et al. The antidiabetic effect of mesenchymal

- stem cells is unrelated to their transdifferentiation potential but to their capability to restore $\mathrm{TH} 1 / \mathrm{TH} 2$ balance and to modify the pancreatic microenvironment. Stem Cells 2012; 30:1664-1674.

This study documents that the antidiabetic effect of MSC was correlated to their engraftment into secondary lymphoid organs associated with reduction of autoreactive $T$ cells together with an increase in Treg cells.

70. Highfill SL, Kelly RM, O'Shaughnessy MJ, et al. Multipotent adult progenitor cells can suppress graft-versus-host disease via prostaglandin E2 synthesis and only if localized to sites of allopriming. Blood 2009; 114:693-701.

71. Zeiser R, Nguyen VH, Beilhack A, et al. Inhibition of CD4+CD25+ regulatory $\mathrm{T}$-cell function by calcineurin-dependent interleukin-2 production. Blood 2006; 108:390-399.

72. Wang $\mathrm{Z}$, Shi $\mathrm{B}$, Jin $\mathrm{H}$, et al. Low-dose of tacrolimus favors the induction of functional $\mathrm{CD}^{+} \mathrm{CD} 25^{+} \mathrm{FoxP} 3^{+}$regulatory T cells in solid-organ transplantation. Int Immunopharmacol 2009; 9:564-569. 
73. Shi D, Liao L, Zhang B, et al. Human adipose tissue-derived mesenchymal stem cells facilitate the immunosuppressive effect of cyclosporin $A$ on T lymphocytes through Jagged-1-mediated inhibition of NF-kappaB signaling. Exp Hematol 2011; 39:214-224; e211.

74. Battaglia $M$, Stabilini $A$, Roncarolo $M G$. Rapamycin selectively expands CD4+CD25+FoxP3+ regulatory T cells. Blood 2005; 105:4743-4748.

75. Perico N, Casiraghi F, Introna M, et al. Autologous mesenchymal stromal cells

- and kidney transplantation: a pilot study of safety and clinical feasibility. Clin J Am Soc Nephrol 2011; 6:412-422.

This is the first report on the immunomodulatory effect of MSC in living-related kidney transplant recipients documenting that peritransplant infusion induced acute kidney graft dysfunction.
76. Farris $A B$, Taheri $D$, Kawai $T$, et al. Acute renal endothelial injury during marrow recovery in a cohort of combined kidney and bone marrow allografts. Am J Transplant 2011; 11:1464-1477.

77. Tan J, Wu W, Xu X, et al. Induction therapy with autologous mesenchymal - stem cells in living-related kidney transplants: a randomized controlled trial. JAMA 2012; 307:1169-1177.

This study reports results of a perspective, randomized study with autologous mesenchymal stem cells versus induction therapy with the anti IL-2 receptor antibody in living-related kidney transplants.

78. Riella LV, Chandraker A. Stem cell therapy in kidney transplantation. JAMA 2012; 308:130. 
CHAPTER 8

\section{GENERAL DISCUSSION AND CONCLUSIONS}




\section{GENERAL DISCUSSION}

Autologous vs allogeneic MSC

MSC are considered naturally immunoprivileged cells due to low expression of MHC molecules in unstimulated conditions and absence of costimulatory molecules (91). As such MSC did not stimulate allogeneic $\mathrm{T}$ cell response and induced $\mathrm{T}$ cell anergy. In in-vitro studies described in chapter 2, we confirmed that murine bone marrow-derived MSC expressed low level of MHCI and MHCII and were negative for CD86 expression. Consequently, they failed to induce allogeneic $\mathrm{CD}^{+} \mathrm{T}$ cell proliferation when used as stimulator cells. These results suggest that MSC escape the immune system and therefore could be infused into allogeneic hosts without being rejected, avoiding the need of conditioning regimen. More importantly, studies with human $(55,58,60)$, baboon (56), rat (92) and murine $(57,61)$ MSC have shown that they potently inhibited in-vitro T cell response to cellular or non-specific stimuli. Accordingly, we showed in chapter 2 that MSC inhibited the proliferation of murine $\mathrm{CD}^{+} \mathrm{T}$ cells in response to allogeneic stimulator cells. The effect was dose-dependent and MHC-independent. Indeed MSC inhibited the proliferative response of both syngeneic and allogeneic $\mathrm{CD}^{+} \mathrm{T}$ cells to either donor or third-party alloantigens in MLR, suggesting that in the setting of solid organ transplantation MSC from autologous or allogeneic sources (donor-derived or third-party) could be used. To test this hypothesis, in in-vivo studies of chapter 2 we evaluated the potential of either donor- or recipient-derived MSC in prolonging the survival of semi-allogeneic heart transplant mice. We documented that donor-derived MSC infused via portal vein (but not via tail vein) caused reduction of $\mathrm{T}$ cell alloreactivity and prolonged the survival of a semi allogeneic heart transplant, indicating that donor-MSC were capable to modulate immune cell response in-vivo when given intraportally. These results are in line with previous studies indicating that the liver is an immunoprivileged organ for transplant tolerance induction by donor cell infusion; in the liver the contact between donor-derived cells and the host immune system results in immune inactivation (93, 94). Conversely, allogeneic donor-derived MSC delivered in the circulation via tail vein could have elicited an immune response and eventually been rejected. Available studies support this hypothesis. It has been documented in mice that MSC, when infused into allogeneic hosts, elicited both primary and memory $\mathrm{T}$ cell responses (95-97), eventually leading to recipient sensitization toward donor alloantigens.

To avoid the concern of immune cell activation, the introduction of foreign antigens has been avoided and the first pilot studies (Chapters 3 and 5) thus began with autologous MSC, making safety the first objective. In clinical studies of Chapters 3 and 5, autologous bone-marrow derived MSC were isolated and expanded under strict Good Manufacturing Practice (GMP) compliance in an authorized cell factory. The cells were classified as MSC based on their ability to differentiate 
into osteocytes, adipocytes and chondrocytes, and at flow-cytometry (FACS) analysis positive for CD73, CD90 and CD105 and negative for CD14, CD34, CD45 and HLA-DR (according to criteria defined by ISCT (54)).

\section{Timing of BM-MSC infusion}

The first aim we addressed was to establish the timing of MSC infusion in respect to immunosuppressive therapy. The maintenance immunosuppressive drugs methylprednisolone, Cyclosporine A (CsA) and Mycophenolate mofetil (MMF) added in-vitro at the same doses achieved in-vivo in kidney transplant patients did not change the capability of MSC to inhibit T cell proliferation in response to anti-CD3 and anti-CD28 mAbs. By contrast, we found that RATG bound in a dose dependent manner human MSC in-vitro, highlighting the possibility of in-vivo MSC lysis should the cells be infused concomitantly with induction therapy post-transplant. On the basis of these results described in Chapter 3 the timing of MSC infusion was set at day 7 posttransplant, 24 hours after the last infusion of MSC. This timing also coincided with the start of lymphopenia-induced homeostatic proliferation, a condition previously shown to be favourable for expansion of Tregs. Thus MSC administration could foster Treg expansion. Concomitantly, based on evidence that MSC-mediated immunosuppression also target memory T cells, giving MSC at this timing could result in the inhibition of lymphopenia-induced proliferation of memory $\mathrm{T}$ cells. However, results from the first two patients of Chapter 3, subsequently confirmed in experimental animals in Chapter 4, but already partially obtained in Chapter 2 clearly show that the posttransplant period is not the ideal timing for infusing MSC.

In both patients of Chapter 3 given MSC at day 7 post-transplant, a transient impairment of kidney graft function was observed, characterized by intragraft recruitment of neutrophils, as well as complement C3 deposition were observed. CD44 and CD105 double positive cells, taken as bonafide MSC, were also found in the early kidney graft biopsy. Thus, we hypothesized that the subclinical inflammatory environment in the few days post surgery could have favoured the intragraft recruitment and activation of the infused MSC promoting a proinflammatory environment with eventual acute renal dysfunction.

To gain insight into this clinical observation, we moved back to a murine kidney transplant model. We documented in Chapter 4 that syngeneic MSC given 2 days post-transplant in pre-sensitized mice caused premature graft dysfunction and failed to prolong graft survival. In this setting, infused MSC preferentially localized in the allograft in response to post-surgery inflammatory milieu of the renal tissue. Subclinical graft injury induced by ischemia reperfusion injury could, at least in part, have contributed to the preferential migration of MSC infused post-transplant toward the 
transplanted organ. This possibility is supported by the finding on intragraft MSC recruitment in syngeneic kidneys transplanted after cold ischemia (Chapter 4). Consistently, previous published data documented the capability of MSC to home to the tissue injury sites in experimental models of stroked brains (98), tumors (99), ischemic myocardium (100), as well as acute renal failure ((101). MSC recruitment into the graft was followed by increased expression of IL-6 and Tumor necrosis factor- $\alpha$ (TNF- $\alpha$ ) mRNA (Chapter 4), amplifying the graft inflammation. Increasing evidence suggest that, in certain conditions, MSC can take on a pro-inflammatory phenotype and could actually worsen the graft outcome. Ligands binding the toll-like receptor (TLR)-3 and -4 induced MSC to release proinflammatory cytokines (102) an event associated in-vivo with attraction of neutrophils into matrigel-embedded MSC implants (103). Similarly, MSC caused in-vitro complement activation eventually leading to the generation of anaphylatoxins and neutrophil activation (104). In a rat model of kidney transplantation MSC administration at the time of transplant led to granulocyte accumulation and disseminated intravascular coagulopathy (105), confirming our data.

In Chapter 4 we also documented that in contrast to post-transplant infusion, MSC administered pre-transplantation localized into lymphoid organs and did not reach the transplanted organ, thus avoiding negative effect on kidney graft function. The homing of MSC toward lymphoid organ in naïve mice was also previously documented in tissue distribution studies of Chapter 2 . Localization of MSC in lymphoid organ resulted in Treg generation and induction of tolerance (Chapter 4). These findings are in line with previous observations that the interaction of MSC with immune cells in lymphoid tissues is critical to achieve immunomodulation in models of autoimmune encephalomyelitis and enteropathy in mice $(79,106)$, also discussed in Chapter 6.

The experimental findings of Chapter $\mathbf{4}$ did represent a gain of knowledge to further implement our clinical protocol. Thus two subsequent living-related kidney transplant recipients received pretransplant (day-1) intravenous infusion of bone-marrow derived autologous MSC before T celldepleting induction therapy and maintenance immunosuppression with CsA and MMF (Chapter 5). None of the two patients developed cell-mediated impairment of graft function, suggesting that the infusion of MSC pre-transplantation in an environment not yet hosting a kidney graft might avoid preferential cell recruitment into inflamed graft tissue.

\section{Immunomodulatory effects of MSC on T cells in allograft recipients}

Different mechanisms of MSC-mediated immunomodulation have been suggested and it emerges a complex interaction of MSC with both innate and adaptive immune cells (Chapter 6). The ability 
of MSC to induce regulatory APC and T cell population has been proposed at the main mechanisms of long term graft acceptance in experimental model of solid organ transplantation (Chapter 7).

Experimental studies in Chapter $\mathbf{2}$ and Chapter $\mathbf{4}$ clearly documented that both the induction and maintenance phases of MSC-induced tolerance in experimental models of solid organ transplantation relied on generation of Treg. MSC-induced tolerance were associated with expansion of $\mathrm{CD}^{+} \mathrm{FOXP}^{+}$Treg in lymphoid organs and into the grafts. By adoptive transfer experiments we documented that regulatory $\mathrm{T}$ cells able to transfer tolerance are rapidly expanded early post MSC infusion (Chapter 2 and 4) and Treg depletion abrogated the MSC effect in inducing long-term graft tolerance (Chapter 4). We also demonstrated that MSC-induced Tregs were antigen specific in the long-term (Chapter 2). This unique capability to promote the emergence of regulatory cells has been demonstrated in several studies in experimental models of solid organ transplantation, summarized in Chapter 7.

Treg expansion in mice with long term kidney graft survival of Chapter $\mathbf{4}$ was associated with increased Treg/effector memory $\mathrm{CD}^{+}$and $\mathrm{CD}^{+} \mathrm{T}$ cell ratios and with $\mathrm{T}$ cell hyporesponsiveness toward donor antigens in ex-vivo mixed lymphocyte reaction (also documented in Chapter 2).

The effect of MSC infusion on T cell homeostatic proliferation and function was also evaluated in kidney transplant patients given MSC in Chapter 3 and 5. In Chapter 3 we found that, in the two patients given MSC but not in the living donor kidney transplant recipients given the same induction and maintenance immunosuppressive therapy but not MSC (controls) the percentage of memory $\mathrm{CD}^{2} 5 \mathrm{RO}^{+} \mathrm{RA}^{-} \mathrm{CD}^{+} \mathrm{T}$ cell population decreased post-transplant. The change in the memory $\mathrm{CD}^{+} \mathrm{T}$ cell profile in the peripheral blood of the patients given MSC was associated with a profound reduction in anti-donor $\mathrm{CD}^{+} \mathrm{T}$ cell cytotoxic activity. In patients given MSC, an increase in the ratio Treg/memory $\mathrm{CD}^{+} \mathrm{T}$ cell toward regulatory cells was documented, suggesting a pro-tolerogenic environment.

\section{Impact of anti-CD25 antibody as part of induction therapy}

Regarding patients given pre-transplant MSC infusion (Chapter 5), a particular concern about induction therapy with the anti-CD25 antibody arose, since evidence was available that basiliximab (the anti-CD25 antibody) may cause a transient loss of $\mathrm{CD}_{2} 5^{+} \mathrm{FOX} 3^{+}$Tregs when given as induction therapy to kidney transplant patients (107). These findings led us to eliminate basiliximab from the induction regimen with the aim to possibly maximize the expansion of $\mathrm{CD} 25^{+} \mathrm{FOXP} 3^{+}$ Treg cells. However, the second patient given MSC the day before kidney transplantation, had acute renal dysfunction 14 to 17 days post-surgery, and the graft biopsy showed evidence of acute cellular rejection. Higher HLA mismatches in patient 4 than in 3 can possibly explain the occurrence of 
rejection in the former. Although based on findings in a single MSC-treated patient, we speculated that MSC may have low capacity to control host immune response in the context of high alloreactive environment. This observation bring us back to the initial findings in heart transplant model of Chapter 2. Recipient-derived MSC infusion was effective in inducing long term graft survival when applied in semi-allogeneic but not in fully allogeneic mice combination. These findings could be taken to suggest that MSC alone could not be sufficient to control an intense stimulation of recipient $\mathrm{T}$ cells by alloantigens early post-transplant, as in the case of fully allogeneic heart transplant combination in animal models (Chapter 2) and higher HLA mismatches in clinical kidney transplant setting (Chapter 5).

Nevertheless, MSC therapy did result in a clear increase in the ratio Treg/memory $\mathrm{CD}^{+} \mathrm{T}$ cell counts post-transplant and in a profound and persistent reduction in donor-specific $\mathrm{CD}^{+} \mathrm{T}$ cell cytolytic activity 6 and 12 months post-transplant, as previously documented in patients undergoing post-transplant MSC infusion of Chapter 3. These findings suggest that MSC immunomodulation could require a period of time to appear and create a pro-tolerogenic environment. By comparing the two patients given pre-transplant MSC under the induction therapy that avoids basiliximab to the previous two patients receiving post-transplant MSC in the setting of combined basiliximab/low-RATG induction regimen we found no major difference in the profile of circulating $\mathrm{CD} 4^{+} \mathrm{CD} 25^{\text {high }} \mathrm{FOXP} 3^{+} \mathrm{CD} 127^{-}$or $\mathrm{CD} 4^{+} \mathrm{FOXP} 3^{+} \mathrm{T}$ cells at FACS analysis (Chapter 5), suggesting that induction therapy without basiliximab does not further expand Tregs while exposing patients to the possibility of acute rejection. Therefore as further implementation of knowledge the next clinical protocol will be with pre-transplant MSC infusion and induction therapy with basiliximab/low-RATG.

\section{The risk-benefit profile of MSC infusion}

The four kidney transplant recipients given MSC described in Chapter $\mathbf{3}$ and $\mathbf{5}$ are all in good health with stable graft function and none experienced infectious complication during the follow-up (more than 2 year the latest to more than 5 years the first patient).

Recently, the risk-benefit profile of bone marrow-derived autologous MSC infusion versus induction therapy with basiliximab has been evaluated in a large cohort of living-related kidney transplants. MSC treatment resulted in lower incidence of acute rejection and better estimated renal function at 6 months post-transplant (108). The investigators concluded that MSC may replace basiliximab induction therapy, allowing the use of lower than conventional CNI maintenance doses without compromising patient safety and graft outcome. However, lower acute rejection rate and better renal function documented at 6 months after transplantation were transient and not confirmed 
at 1 year. Unfortunately, this study did not report any attempt to in-depth assess the in-vivo effects of MSC on host immune system, especially on Treg and effector T-cell function by any immunological tests. The large Tan's study has also shown that during the 1-year follow up, MSCtreated patients had significantly lower risk of opportunistic infections than those not receiving the cell infusion, suggesting the safety of MSC-based therapy as for the risk of promoting infections (108). This conclusion is challenged by the Leiden's safety and feasibility study in six kidney transplant recipients who were given two i.v. infusions of autologous BM-MSCs when a protocol renal biopsy showed signs of subclinical rejection and/or an increase in interstitial fibrosis/tubular atrophy (109). In two recipients with subclinical cellular rejection, MSC treatment allowed the resolution of tubulitis without interstitial fibrosis/tubular atrophy in both patients. Five out of the six patients displayed a donor-specific downregulation of ex-vivo PBMC proliferation assay. However, three patients developed an opportunistic viral infection suggesting that MSC could induce overimmunosuppression (109). This study suggests a careful monitoring of unwanted side-effects of MSC therapy especially in chronically immunosuppressed transplant recipients who are already at an increased risk of infection and malignancies.

\section{The next step: third-party BM-MSC in liver transplant recipients}

To make MSC-based therapy a routine practice in transplantation, this strategy should be applied to all solid organ transplant recipients from a deceased-donor, implying re-consideration of source of MSC and timing of cell infusion.

Autologous cells are clearly the safest option for clinical cell therapy in terms of relative risk of their possible rejection by the recipient. However, there are circumstances, e.g. liver transplantation, in which healthy autologous MSCs will not be available. First, individually tailored autologous MSC are expensive to produce and storage might exceed the capability of a clinical center. Second, regulation requires that MSCs have to be generated in a controlled and documented process under good manufacturing practice to obtain a safe product of high quality and not all clinical centers can perform and afford the production process. Third, the transplant surgery takes place few hours after a donor organ is available and the production of a sufficient amount of MSC requires at least several weeks. Thus, an "off-the-shelf" therapy consisting of healthy third-party allogeneic bonemarrow MSC would provide an immediate source ready for clinical use, bypassing the need for the difficult cost and time-consuming production process of personalized MSCs.

Regarding the issue of possible cell rejection and the consequent recipient sensitization after allogeneic MSC infusion it could be relevant to consider that MSC will be introduced in combination with immunosuppressive drugs/biological agents, making it possible to exploit the 
potential of MSCs without the risk of sensitization. Actually, third-party allogeneic MSC have been already used in patients with bone marrow transplantation to treat GVHD. Moreover, clinical studies currently ongoing or nearing initiation in liver transplant recipients (Clinicaltrials.gov Identifier: NCT01429038; Clinicaltrials.gov Identifier: NCT01841632) focus on the use of thirdparty allogeneic MSCs.

The setting of liver transplantation gives also the opportunity to further study MSC immunomodulation under the cover of induction therapy not including the anti-CD25 antibody, basiliximab. Indeed the liver is less immunogenic than the kidney and the induction therapy with RATG alone does not expose patients to the risk of acute rejection, thus offering a solution to the need to protect recipients while allowing to definitely establish whether basiliximab treatment can hinder the function of regulatory $\mathrm{T}$ cells.

With these concepts in mind we designed a phase I clinical study of the administration of thirdparty bone marrow-derived MSCs to patients undergoing liver transplantation from a deceased donor. Patients will be treated in Bergamo and Bologna, Italy. Five patients per center are randomized to receive a single infusion of third-party derived MSC ( $2 \times 10^{6} / \mathrm{Kg}$ body weight) few hours before liver transplantation and 5 patients per center will be randomized to no cell infusion. Both groups of patients will receive induction therapy with low dose RATG and maintenance immunosuppression with Tacrolimus and MMF.

The proposed study will be developed in two phases:

\section{A pilot explorative safety/biologic-mechanistic clinical study}

This is a pilot, explorative, randomized study to define the safety and biologic/mechanistic effects of the systemic intravenous infusion of third-party ex-vivo expanded MSC in liver transplant recipients under low-dose RATG induction therapy and maintenance immunosuppressive drugs with the ultimate objective to test the feasibility of safely achieving graft tolerance in a subsequent efficacy pilot study. Indeed, to complement the research with a clinical portion that documents operational tolerance, a pilot efficacy study of safely achieving liver graft tolerance after complete withdrawal of maintenance immunosuppressive therapy will follow pending on the fact that the results of biologic/mechanistic tests will document that MSC infusion allows the development of an immune microenvironment permissive to graft tolerance. Primary objective is to establish the feasibility and the safety of the systemic infusion of thirdparty ex-vivo expanded MSCs in liver transplant recipients. Secondary objectives are to assess whether in liver transplant recipients, third-party MSC infusion promotes a pro-tolerogenic immune environment by a series of biologic/mechanistic studies that include 
immunophenotyping of circulating cells, lymphocyte functional assays and liver tissue messenger RNA expression for genes involved in iron homeostasis found to be selectively increased in operationally tolerant liver transplant recipients (110).

2 A pilot efficacy clinical study

At 12 months post-liver transplantation, should the biologic/mechanistic ex-vivo studies document that MSC infusion allows the development of an immune microenvironment permissive to graft tolerance, a prospective pilot efficacy study to achieve operational tolerance after complete withdrawal of maintenance immunosuppressive therapy will follow.

Primary objective is to define the efficacy of peri-transplant third-party MSC infusion in liver transplant recipients to induce operational tolerance as documented by lack of acute graft rejection episodes during a 6 month follow-up after discontinuation of maintenance immunosuppression with low-dose TAC and low-dose MMF, starting 12 months posttransplantation.

Secondary objectives are to compare the patients receiving MSC infusion and on drug withdrawal with control patients not receiving cell therapy and with historical liver transplant recipients on long-term maintenance immunosuppression as far as:

a. Rate of decline of graft function as a surrogate index of chronic allograft injury

b. Graft and patient survival 


\section{CONCLUSIONS}

The potential of MSC-based therapy in solid organ transplantation is undoubtedly relevant. However, the field is still in its infancy and nobody so far has attempted to or provided evidence that this cell therapy is capable to promote operational tolerance. We do not have enough knowledge of safety, pharmacokinetics and quantitative assays for in-vivo immune responses. Small studies with a few patients intensively studied will hopefully allow us to determine when and where MSCs should be administered and how they function to regulate host immunity. These considerations may be particularly imperative for new biological agents such as MSCs for which, despite encouraging initial results, uncertainty about safety and efficacy still exists. 
CHAPTER 9

SUMMARY 
Successful solid organ transplantation would be a realistic therapeutic option only whether donorspecific immunologic tolerance could be reliably and safely induced.

Encouraging results have emerged from many tolerance induction strategies in experimental models, but translating these protocols across species from rodents to the clinic is providing a formidable task and so far we are still unable to induce tolerance in a routine intention-to-treat protocol. Mesenchymal Stromal Cells (MSC) have recently emerged as one of the most promising candidates for cell-based immunotherapy because they modulate the immune response via an array of direct and indirect interaction with a broad range of cell types in various ways. In particular, MSC drive $\mathrm{T}$ cells toward a regulatory phenotype and have the unique capability to control proliferation and activation of memory $\mathrm{T}$ cells which represent a major barrier to tolerance induction in transplant patients.

A number of studies either in experimental models of solid organ transplantation or in kidney transplant recipients were designed and performed in this thesis with the aim to establish the tolerogenic potential of MSC, their mechanisms of action as well as to find out the best infusion protocol to be applied in clinical transplantation.

The tolerogenic potential of MSC has been first evaluated in a murine model of semi-allogeneic heart (B6C3 heart in B6 recipient mice) transplantation (Chapter 2). Results showed that donorderived MSC were effective in prolonging heart graft survival when infused into the portal vein 7 days before surgery. The same tolerogenic potential was shared by recipient-derived MSCs when given pretransplant via tail vein. Both donor-derived and recipient-derived MSCs mediated in vivo expansion of regulatory $\mathrm{T}$ cells (Tregs). These results provided the basis for the design of a safety and clinical feasibility pilot clinical studies of autologous bone marrow derived MSC in kidney transplant recipients with a living donor. Results of the first two patients, reported in Chapter 3, indicated that post-transplant MSC infusion induced a transient renal insufficiency characterized at histological analysis by an inflammatory infiltrate of neutrophils and C3 deposition but no evidence of graft rejection. It was hypothesized that the subclinical inflammatory environment of the graft in the few days post-surgery could have favoured the prevalent intragraft recruitment and activation of the infused MSC promoting a proinflammatory environment with eventual acute renal dysfunction. This hypothesis has been confirmed back into a murine kidney transplant model (Chapter 4) showing that a single administration of syngeneic MSC before (one day before surgery) but not after renal transplantation avoided the acute deterioration of graft function, while maintaining the immunomodulatory effects associated with MSC treatment, including a marked Treg expansion.

These experimental findings did represent a gain of knowledge to further implement our clinical protocol, aimed at creating favourable conditions for MSC-promoting immunomodulation avoiding 
any possible side-effects associated with cell infusion. Thus two subsequent patients living-related kidney transplant recipients received pre-transplant (day-1) intravenous infusion of bone-marrow derived autologous MSC before T cell-depleting induction therapy. In the fist patient studied, MSC treatment was uneventful and graft function remained normal during 1 year follow-up. In the second patient, acute cellular rejection occurred 2 weeks post-transplant. Both patients had excellent graft function at the last observation. Circulating memory $\mathrm{CD}^{+} \mathrm{T}$ cells and donor-specific $\mathrm{CD}^{+} \mathrm{T}$ cell cytolytic response were reduced in MSC-treated patients. Thus, pre-transplant MSCs no longer negatively affect kidney graft and maintained MSC-immunomodulatory properties (Chapter 5).

Finally, chapters 6 and 7 are review chapters aimed at making the focus on the more recent acquaintance on MSC immunomodulatory effects in vivo in experimental transplant models as well as in early clinical experiences in kidney transplantation, and discuss topics of crucial importance for the future clinical use of MSC as immunotherapy in solid organ transplantation. 
CHAPTER 10

VALORISATION OF THE RESEARCH 


\section{Improvement of current treatment outcome in transplant recipients of solid organs}

Outcomes for solid organ transplantation have improved significantly during the last two decades. Improved immunosuppressive regimens have drastically reduced acute rejection rate. Among the renal transplants performed in Europe since 2000, overall patient and graft survival were $96 \%$ and $89 \%$ at 1 year, respectively. However, reduced acute rejection rate has not been automatically followed by better long term graft survival. In the United States on a total of 252,910 patients receiving a single organ kidney transplant between 1989 and 2009, graft half-life for deceaseddonor transplant was 6.6 years in 1989 and increased to 8.8 by 2005. In low-risk populations like living-donor-recipients half life did not change, with 11.4 years in 1989 and 11.9 years in 2005. Thus, long term graft survival had in fact changed very little despite dramatic short term improvement. Especially now, when first year survival rates are most close to perfect, it becomes clear that further improvements in long term survival are the goals on which transplant community has to shift its attention. Chronic rejection and complications of immunosuppressive therapy significantly affected long term graft survival, keeping long term graft loss a constant phenomenon. The very same medications that have allowed for short term survival improvement have specific side effects while additively contributing to an overall state of immunosuppression and to the increased risk of cardiovascular disease. Most immunosuppressive regimens are currently based on the combination of calcineurin inhibitor with anti-proliferative agents and steroids and associated with new-onset diabetes mellitus, hypertension, hyperlipidemia and polyoma virus-associated nephropathy, and for calcineurin inhibitors also nephrotoxicity. Cardiovascular disease mainly accounts for deaths with functioning graft and is responsible for deaths in kidney transplant recipients beyond the first post-transplant year. Infections are responsible for $11.7 \%$ of deaths and there is abundant evidence that cancer is increased in kidney transplant recipients because of immunosuppressive agents. Compared with the general population, mortality in transplant recipients is 4 times higher after the first year post-transplant. Nevertheless, in relation to acceptance of the allograft, immunosuppressants are indispensable in the clinical setting, as withdrawal of immunosuppressive therapy typically results in rejection of the transplanted organ.

Ideally, the induction of donor-specific tolerance would overcome these shortcomings, possibly allowing indefinite graft survival. Cellular therapy with immunological active cells is an intriguing new idea that has recently emerged to induce specific graft acceptance, and MSC are considered one of the most promising candidates. MSC may promote a pro-tolerogenic immune environment in transplant patients which could allow minimization or even discontinuation of immunosuppressive drugs in the long term, limiting the high risk of morbidity and mortality currently seen in solid organ transplant recipients related to drug-induced infections, malignancies and cardiovascular 
diseases. Maintaining the health of transplanted organs not only protects the recipients of transplants from death, re-transplantation, or other trauma; it also protects the scarce availability of organs.

\section{Impact on clinical management and transplant patients well being}

Chronic immunosuppressive treatments have been linked to physical complications that, although not life-threatening, greatly impact on post-transplant quality of life. Immunosuppression-related physical effects that can alter appearance - including hirsutism, gingival hyperplasia, weight gain, cushingoid faces, hand tremors, alopecia and skin disorders - are among the most bothersome to patients and may have serious psychosocial implications, including sexual dysfunction. The myriad of side effects associated with immunosuppression include also osteoporosis, mood disorders, headaches, insomnia, paresthesias, gastrointestinal disorders (dyspepsia, gastritis, peptic ulcer disease and diarrhoea, constipation, nausea, vomiting, and anorexia) and skin disorders (skin thinning, purpura, acne, condyloma acumination and skin cancer). Pregnancy in transplanted women is considered high risk. These women also may have other co-morbidities, such as hypertension and diabetes mellitus which put them in an even higher risk category. These include high risk for spontaneous abortions, intrauterine growth retardation, preeclampsia and worsening of pre-existing hypertension, premature delivery, less-than-normal gestational weight and acute kidney graft rejection. All these side effects greatly impact on quality of life and have serious psychosocial implications. Moreover, on the long term these side effects could lead patients to non-compliance to immunosuppressive therapy. Indeed, in recent years, non-adherence to medication regimens has emerged as a major risk factor for acute rejection and graft loss. Despite these serious consequences non compliance is frequent among transplant recipients. Transplant recipients are required to manage a strict regimen of multiple medications changes in dosage schedules and medication physical side effects and it is estimated that up to $67 \%$ of patients do not take immunosuppressive medications as prescribed.

Therefore, MSC-based cellular therapy in solid organ transplantation, able to reduce or even eliminate the need of chronic administration of immunosuppressive drugs is likely to allow better clinical management of transplanted patients and eventually have a major impact on their quality of life.

\section{Impact on health economy}

The cost of maintenance immunosuppressive drugs is very high and is estimated around 15,000 Euro per year/patient. Moreover, because immunosuppressive therapy is complex, patients must be 
monitored for both drug effectiveness and side effects by an experienced physician. Informal estimates suggest that the ambulatory visits and laboratory work solely to monitor immunosuppressive drugs could cost each patient roughly 1500 Euro per year. Further costs derive from additional outpatient medications such as antihypertensive agents and antibiotics for infections. Management of immunosuppressive drug side effects often requires additional medications and additional costs. Reducing the requirement of immunosuppressive drugs by using the MSC product to dampen immunological response to kidney and liver transplantation would result in reduction of overall costs for drug supply and management of solid organ transplant patients. 


\section{REFERENCES}

1. Meier-Kriesche, H. U., S. Li, R. W. Gruessner, J. J. Fung, R. T. Bustami, M. L. Barr, and A. B. Leichtman. 2006. Immunosuppression: evolution in practice and trends, 1994-2004. Am J Transplant 6:1111.

2. Meier-Kriesche, H. U., J. D. Schold, T. R. Srinivas, and B. Kaplan. 2004. Lack of improvement in renal allograft survival despite a marked decrease in acute rejection rates over the most recent era. Am J Transplant 4:378.

3. Meier-Kriesche, H. U., J. D. Schold, and B. Kaplan. 2004. Long-term renal allograft survival: have we made significant progress or is it time to rethink our analytic and therapeutic strategies? Am J Transplant 4:1289.

4. Libby, P., and J. S. Pober. 2001. Chronic rejection. Immunity 14:387.

5. Lamb, K. E., S. Lodhi, and H. U. Meier-Kriesche. 2011. Long-term renal allograft survival in the United States: a critical reappraisal. Am J Transplant 11:450.

6. Lodhi, S. A., K. E. Lamb, and H. U. Meier-Kriesche. 2011. Solid organ allograft survival improvement in the United States: the long-term does not mirror the dramatic short-term success. Am J Transplant 11:1226.

7. Lechler, R. I., M. Sykes, A. W. Thomson, and L. A. Turka. 2005. Organ transplantation-how much of the promise has been realized? Nat Med 11:605.

8. Salama, A. D., G. Remuzzi, W. E. Harmon, and M. H. Sayegh. 2001. Challenges to achieving clinical transplantation tolerance. J Clin Invest 108:943.

9. Eltzschig, H. K., and T. Eckle. 2011. Ischemia and reperfusion--from mechanism to translation. Nat Med 17:1391.

10. Takeuchi, O., and S. Akira. 2010. Pattern recognition receptors and inflammation. Cell 140:805.

11. Lo, D. J., T. A. Weaver, D. E. Kleiner, R. B. Mannon, L. M. Jacobson, B. N. Becker, S. J. Swanson, D. A. Hale, and A. D. Kirk. 2011. Chemokines and their receptors in human renal allotransplantation. Transplantation 91:70.

12. Larsen, C. P., P. J. Morris, and J. M. Austyn. 1990. Migration of dendritic leukocytes from cardiac allografts into host spleens. A novel pathway for initiation of rejection. $J$ Exp Med 171:307.

13. van Kooten, C., G. Lombardi, K. A. Gelderman, P. Sagoo, M. Buckland, R. Lechler, and M. C. Cuturi. 2011. Dendritic cells as a tool to induce transplantation tolerance: obstacles and opportunities. Transplantation 91:2.

14. Moreau, A., E. Varey, I. Anegon, and M. C. Cuturi. 2013. Effector mechanisms of rejection. Cold Spring Harb Perspect Med 3.

15. Afzali, B., G. Lombardi, and R. I. Lechler. 2008. Pathways of major histocompatibility complex allorecognition. Curr Opin Organ Transplant 13:438.

16. Ochando, J. C., N. R. Krieger, and J. S. Bromberg. 2006. Direct versus indirect allorecognition: Visualization of dendritic cell distribution and interactions during rejection and tolerization. Am J Transplant 6:2488.

17. Herrera, O. B., D. Golshayan, R. Tibbott, F. Salcido Ochoa, M. J. James, F. M. MarelliBerg, and R. I. Lechler. 2004. A novel pathway of alloantigen presentation by dendritic cells. J Immunol 173:4828.

18. Wood, K. J., and R. Goto. 2012. Mechanisms of rejection: current perspectives. Transplantation 93:1.

19. Li, X. C., D. M. Rothstein, and M. H. Sayegh. 2009. Costimulatory pathways in transplantation: challenges and new developments. Immunol Rev 229:271.

20. Liu, Z., H. Fan, and S. Jiang. 2013. CD4(+) T-cell subsets in transplantation. Immunol Rev 252:183. 
21. Sallusto, F., A. Lanzavecchia, K. Araki, and R. Ahmed. 2010. From vaccines to memory and back. Immunity 33:451.

22. Valujskikh, A., and X. C. Li. 2007. Frontiers in nephrology: T cell memory as a barrier to transplant tolerance. J Am Soc Nephrol 18:2252.

23. Ford, M. L., and C. P. Larsen. 2011. Transplantation tolerance: memories that haunt us. Sci Transl Med 3:86ps22.

24. Selin, L. K., and M. A. Brehm. 2007. Frontiers in nephrology: heterologous immunity, T cell cross-reactivity, and alloreactivity. J Am Soc Nephrol 18:2268.

25. Williams, K. M., F. T. Hakim, and R. E. Gress. 2007. T cell immune reconstitution following lymphodepletion. Semin Immunol 19:318.

26. Tchao, N. K., and L. A. Turka. 2012. Lymphodepletion and homeostatic proliferation: implications for transplantation. Am J Transplant 12:1079.

27. Chalasani, G., Z. Dai, B. T. Konieczny, F. K. Baddoura, and F. G. Lakkis. 2002. Recall and propagation of allospecific memory $\mathrm{T}$ cells independent of secondary lymphoid organs. Proc Natl Acad Sci U S A 99:6175.

28. Lakkis, F. G., and M. H. Sayegh. 2003. Memory T cells: a hurdle to immunologic tolerance. J Am Soc Nephrol 14:2402.

29. Valujskikh, A. 2006. The challenge of inhibiting alloreactive T-cell memory. Am $J$ Transplant 6:647.

30. Page, A. J., M. L. Ford, and A. D. Kirk. 2009. Memory T-cell-specific therapeutics in organ transplantation. Curr Opin Organ Transplant 14:643.

31. Krummey, S. M., and M. L. Ford. 2012. Heterogeneity within T Cell Memory: Implications for Transplant Tolerance. Front Immunol 3:36.

32. Lechler, R. I., O. A. Garden, and L. A. Turka. 2003. The complementary roles of deletion and regulation in transplantation tolerance. Nat Rev Immunol 3:147.

33. Wekerle, T., P. Blaha, Z. Koporc, S. Bigenzahn, M. Pusch, and F. Muehlbacher. 2003. Mechanisms of tolerance induction through the transplantation of donor hematopoietic stem cells: central versus peripheral tolerance. Transplantation 75:21S.

34. Ciancio, G., J. Miller, R. O. Garcia-Morales, M. Carreno, G. W. Burke, 3rd, D. Roth, W. Kupin, A. G. Tzakis, C. Ricordi, A. Rosen, L. Fuller, and V. Esquenazi. 2001. Six-year clinical effect of donor bone marrow infusions in renal transplant patients. Transplantation 71:827.

35. Fudaba, Y., T. R. Spitzer, J. Shaffer, T. Kawai, T. Fehr, F. Delmonico, F. Preffer, N. Tolkoff-Rubin, B. R. Dey, S. L. Saidman, A. Kraus, T. Bonnefoix, S. McAfee, K. Power, K. Kattleman, R. B. Colvin, D. H. Sachs, A. B. Cosimi, and M. Sykes. 2006. Myeloma responses and tolerance following combined kidney and nonmyeloablative marrow transplantation: in vivo and in vitro analyses. Am J Transplant 6:2121.

36. Kawai, T., A. B. Cosimi, T. R. Spitzer, N. Tolkoff-Rubin, M. Suthanthiran, S. L. Saidman, J. Shaffer, F. I. Preffer, R. Ding, V. Sharma, J. A. Fishman, B. Dey, D. S. Ko, M. Hertl, N. B. Goes, W. Wong, W. W. Williams, Jr., R. B. Colvin, M. Sykes, and D. H. Sachs. 2008. HLA-mismatched renal transplantation without maintenance immunosuppression. $N$ Engl J Med 358:353.

37. Kawai, T., D. H. Sachs, M. Sykes, and A. B. Cosimi. 2013. HLA-mismatched renal transplantation without maintenance immunosuppression. N Engl J Med 368:1850.

38. Scandling, J. D., S. Busque, J. A. Shizuru, E. G. Engleman, and S. Strober. 2011. Induced immune tolerance for kidney transplantation. N Engl J Med 365:1359.

39. Leventhal, J., M. Abecassis, J. Miller, L. Gallon, K. Ravindra, D. J. Tollerud, B. King, M. J. Elliott, G. Herzig, R. Herzig, and S. T. Ildstad. 2012. Chimerism and tolerance without GVHD or engraftment syndrome in HLA-mismatched combined kidney and hematopoietic stem cell transplantation. Sci Transl Med 4:124ra28. 
40. Salama, A. D., K. L. Womer, and M. H. Sayegh. 2007. Clinical transplantation tolerance: many rivers to cross. J Immunol 178:5419.

41. Sakaguchi, S. 2005. Naturally arising Foxp3-expressing CD25+CD4+ regulatory T cells in immunological tolerance to self and non-self. Nat Immunol 6:345.

42. Curotto de Lafaille, M. A., and J. J. Lafaille. 2009. Natural and adaptive foxp3+ regulatory T cells: more of the same or a division of labor? Immunity 30:626.

43. Wieckiewicz, J., R. Goto, and K. J. Wood. 2010. T regulatory cells and the control of alloimmunity: from characterisation to clinical application. Curr Opin Immunol 22:662.

44. Cobbold, S. P., and H. Waldmann. 2013. Regulatory cells and transplantation tolerance. Cold Spring Harb Perspect Med 3.

45. Tang, Q., and J. A. Bluestone. 2008. The Foxp3+ regulatory T cell: a jack of all trades, master of regulation. Nat Immunol 9:239.

46. Cobbold, S. P., S. Qin, L. Y. Leong, G. Martin, and H. Waldmann. 1992. Reprogramming the immune system for peripheral tolerance with CD4 and CD8 monoclonal antibodies. Immunol Rev 129:165.

47. Qin, S. X., M. Wise, S. P. Cobbold, L. Leong, Y. C. Kong, J. R. Parnes, and H. Waldmann. 1990. Induction of tolerance in peripheral $\mathrm{T}$ cells with monoclonal antibodies. Eur $J$ Immunol 20:2737.

48. Wood, K. J., and S. Sakaguchi. 2003. Regulatory T cells in transplantation tolerance. Nat Rev Immunol 3:199.

49. Li, X. C., and L. A. Turka. 2010. An update on regulatory T cells in transplant tolerance and rejection. Nat Rev Nephrol 6:577.

50. Friedenstein, A. J., R. K. Chailakhjan, and K. S. Lalykina. 1970. The development of fibroblast colonies in monolayer cultures of guinea-pig bone marrow and spleen cells. Cell Tissue Kinet 3:393.

51. Friedenstein, A. J., R. K. Chailakhyan, N. V. Latsinik, A. F. Panasyuk, and I. V. KeilissBorok. 1974. Stromal cells responsible for transferring the microenvironment of the hemopoietic tissues. Cloning in vitro and retransplantation in vivo. Transplantation 17:331.

52. Bianco, P., P. G. Robey, and P. J. Simmons. 2008. Mesenchymal stem cells: revisiting history, concepts, and assays. Cell Stem Cell 2:313.

53. Caplan, A. I. 1991. Mesenchymal stem cells. J Orthop Res 9:641.

54. Dominici, M., K. Le Blanc, I. Mueller, I. Slaper-Cortenbach, F. Marini, D. Krause, R. Deans, A. Keating, D. Prockop, and E. Horwitz. 2006. Minimal criteria for defining multipotent mesenchymal stromal cells. The International Society for Cellular Therapy position statement. Cytotherapy 8:315.

55. Di Nicola, M., C. Carlo-Stella, M. Magni, M. Milanesi, P. D. Longoni, P. Matteucci, S. Grisanti, and A. M. Gianni. 2002. Human bone marrow stromal cells suppress Tlymphocyte proliferation induced by cellular or nonspecific mitogenic stimuli. Blood 99:3838.

56. Bartholomew, A., C. Sturgeon, M. Siatskas, K. Ferrer, K. McIntosh, S. Patil, W. Hardy, S. Devine, D. Ucker, R. Deans, A. Moseley, and R. Hoffman. 2002. Mesenchymal stem cells suppress lymphocyte proliferation in vitro and prolong skin graft survival in vivo. Exp Hematol 30:42.

57. Glennie, S., I. Soeiro, P. J. Dyson, E. W. Lam, and F. Dazzi. 2005. Bone marrow mesenchymal stem cells induce division arrest anergy of activated T cells. Blood 105:2821.

58. Rasmusson, I., O. Ringden, B. Sundberg, and K. Le Blanc. 2003. Mesenchymal stem cells inhibit the formation of cytotoxic $\mathrm{T}$ lymphocytes, but not activated cytotoxic $\mathrm{T}$ lymphocytes or natural killer cells. Transplantation 76:1208.

59. Nauta, A. J., and W. E. Fibbe. 2007. Immunomodulatory properties of mesenchymal stromal cells. Blood 110:3499. 
60. Le Blanc, K., L. Tammik, B. Sundberg, S. E. Haynesworth, and O. Ringden. 2003. Mesenchymal stem cells inhibit and stimulate mixed lymphocyte cultures and mitogenic responses independently of the major histocompatibility complex. Scand J Immunol 57:11.

61. Krampera, M., S. Glennie, J. Dyson, D. Scott, R. Laylor, E. Simpson, and F. Dazzi. 2003. Bone marrow mesenchymal stem cells inhibit the response of naive and memory antigenspecific T cells to their cognate peptide. Blood 101:3722.

62. Duffy, M. M., T. Ritter, R. Ceredig, and M. D. Griffin. 2011. Mesenchymal stem cell effects on T-cell effector pathways. Stem Cell Res Ther 2:34.

63. Reading, J. L., S. Sabbah, S. Busch, and T. I. Tree. 2013. Mesenchymal stromal cells as a means of controlling pathological T-cell responses in allogeneic islet transplantation. Curr Opin Organ Transplant 18:59.

64. Aggarwal, S., and M. F. Pittenger. 2005. Human mesenchymal stem cells modulate allogeneic immune cell responses. Blood 105:1815.

65. English, K., J. M. Ryan, L. Tobin, M. J. Murphy, F. P. Barry, and B. P. Mahon. 2009. Cell contact, prostaglandin $\mathrm{E}(2)$ and transforming growth factor beta 1 play non-redundant roles in human mesenchymal stem cell induction of CD4+CD25(High) forkhead box P3+ regulatory T cells. Clin Exp Immunol 156:149.

66. Ghannam, S., J. Pene, G. Moquet-Torcy, C. Jorgensen, and H. Yssel. 2010. Mesenchymal stem cells inhibit human Th17 cell differentiation and function and induce a T regulatory cell phenotype. J Immunol 185:302.

67. Jiang, X. X., Y. Zhang, B. Liu, S. X. Zhang, Y. Wu, X. D. Yu, and N. Mao. 2005. Human mesenchymal stem cells inhibit differentiation and function of monocyte-derived dendritic cells. Blood 105:4120.

68. Djouad, F., L. M. Charbonnier, C. Bouffi, P. Louis-Plence, C. Bony, F. Apparailly, C. Cantos, C. Jorgensen, and D. Noel. 2007. Mesenchymal stem cells inhibit the differentiation of dendritic cells through an interleukin-6-dependent mechanism. Stem Cells 25:2025.

69. Nauta, A. J., A. B. Kruisselbrink, E. Lurvink, R. Willemze, and W. E. Fibbe. 2006. Mesenchymal stem cells inhibit generation and function of both CD34+-derived and monocyte-derived dendritic cells. J Immunol 177:2080.

70. Zhang, B., R. Liu, D. Shi, X. Liu, Y. Chen, X. Dou, X. Zhu, C. Lu, W. Liang, L. Liao, M. Zenke, and R. C. Zhao. 2009. Mesenchymal stem cells induce mature dendritic cells into a novel Jagged-2-dependent regulatory dendritic cell population. Blood 113:46.

71. Zhao, Z. G., W. Xu, L. Sun, Y. You, F. Li, Q. B. Li, and P. Zou. 2012. Immunomodulatory function of regulatory dendritic cells induced by mesenchymal stem cells. Immunol Invest 41:183.

72. Ylostalo, J. H., T. J. Bartosh, K. Coble, and D. J. Prockop. 2012. Human mesenchymal stem/stromal cells cultured as spheroids are self-activated to produce prostaglandin E2 that directs stimulated macrophages into an anti-inflammatory phenotype. Stem Cells 30:2283.

73. Francois, M., R. Romieu-Mourez, M. Li, and J. Galipeau. 2012. Human MSC suppression correlates with cytokine induction of indoleamine 2,3-dioxygenase and bystander M2 macrophage differentiation. Mol Ther 20:187.

74. Akiyama, K., C. Chen, D. Wang, X. Xu, C. Qu, T. Yamaza, T. Cai, W. Chen, L. Sun, and S. Shi. 2012. Mesenchymal-stem-cell-induced immunoregulation involves FAS-ligand-/FASmediated T cell apoptosis. Cell Stem Cell 10:544.

75. English, K. 2013. Mechanisms of mesenchymal stromal cell immunomodulation. Immunol Cell Biol 91:19.

76. Lee, R. H., A. A. Pulin, M. J. Seo, D. J. Kota, J. Ylostalo, B. L. Larson, L. Semprun-Prieto, P. Delafontaine, and D. J. Prockop. 2009. Intravenous hMSCs improve myocardial infarction in mice because cells embolized in lung are activated to secrete the antiinflammatory protein TSG-6. Cell Stem Cell 5:54. 
77. Oh, J. Y., R. H. Lee, J. M. Yu, J. H. Ko, H. J. Lee, A. Y. Ko, G. W. Roddy, and D. J. Prockop. 2012. Intravenous mesenchymal stem cells prevented rejection of allogeneic corneal transplants by aborting the early inflammatory response. Mol Ther 20:2143.

78. Polchert, D., J. Sobinsky, G. Douglas, M. Kidd, A. Moadsiri, E. Reina, K. Genrich, S. Mehrotra, S. Setty, B. Smith, and A. Bartholomew. 2008. IFN-gamma activation of mesenchymal stem cells for treatment and prevention of graft versus host disease. Eur $J$ Immunol 38:1745.

79. Zappia, E., S. Casazza, E. Pedemonte, F. Benvenuto, I. Bonanni, E. Gerdoni, D. Giunti, A. Ceravolo, F. Cazzanti, F. Frassoni, G. Mancardi, and A. Uccelli. 2005. Mesenchymal stem cells ameliorate experimental autoimmune encephalomyelitis inducing T-cell anergy. Blood 106:1755.

80. Rafei, M., E. Birman, K. Forner, and J. Galipeau. 2009. Allogeneic mesenchymal stem cells for treatment of experimental autoimmune encephalomyelitis. Mol Ther 17:1799.

81. Gonzalez, M. A., E. Gonzalez-Rey, L. Rico, D. Buscher, and M. Delgado. 2009. Treatment of experimental arthritis by inducing immune tolerance with human adipose-derived mesenchymal stem cells. Arthritis Rheum 60:1006.

82. Fiorina, P., M. Jurewicz, A. Augello, A. Vergani, S. Dada, S. La Rosa, M. Selig, J. Godwin, K. Law, C. Placidi, R. N. Smith, C. Capella, S. Rodig, C. N. Adra, M. Atkinson, M. H. Sayegh, and R. Abdi. 2009. Immunomodulatory function of bone marrow-derived mesenchymal stem cells in experimental autoimmune type 1 diabetes. J Immunol 183:993.

83. Sun, L., K. Akiyama, H. Zhang, T. Yamaza, Y. Hou, S. Zhao, T. Xu, A. Le, and S. Shi. 2009. Mesenchymal stem cell transplantation reverses multiorgan dysfunction in systemic lupus erythematosus mice and humans. Stem Cells 27:1421.

84. Kebriaei, P., L. Isola, E. Bahceci, K. Holland, S. Rowley, J. McGuirk, M. Devetten, J. Jansen, R. Herzig, M. Schuster, R. Monroy, and J. Uberti. 2009. Adult human mesenchymal stem cells added to corticosteroid therapy for the treatment of acute graft-versus-host disease. Biol Blood Marrow Transplant 15:804.

85. Wu, K. H., C. K. Chan, C. Tsai, Y. H. Chang, M. Sieber, T. H. Chiu, M. Ho, C. T. Peng, H. $\mathrm{P}$. $\mathrm{Wu}$, and J. L. Huang. 2011. Effective treatment of severe steroid-resistant acute graftversus-host disease with umbilical cord-derived mesenchymal stem cells. Transplantation 91:1412.

86. Le Blanc, K., F. Frassoni, L. Ball, F. Locatelli, H. Roelofs, I. Lewis, E. Lanino, B. Sundberg, M. E. Bernardo, M. Remberger, G. Dini, R. M. Egeler, A. Bacigalupo, W. Fibbe, and O. Ringden. 2008. Mesenchymal stem cells for treatment of steroid-resistant, severe, acute graft-versus-host disease: a phase II study. Lancet 371:1579.

87. Sun, L., D. Wang, J. Liang, H. Zhang, X. Feng, H. Wang, B. Hua, B. Liu, S. Ye, X. Hu, W. Xu, X. Zeng, Y. Hou, G. S. Gilkeson, R. M. Silver, L. Lu, and S. Shi. 2010. Umbilical cord mesenchymal stem cell transplantation in severe and refractory systemic lupus erythematosus. Arthritis Rheum 62:2467.

88. Carrion, F., E. Nova, C. Ruiz, F. Diaz, C. Inostroza, D. Rojo, G. Monckeberg, and F. E. Figueroa. 2010. Autologous mesenchymal stem cell treatment increased T regulatory cells with no effect on disease activity in two systemic lupus erythematosus patients. Lupus 19:317.

89. Duijvestein, M., A. C. Vos, H. Roelofs, M. E. Wildenberg, B. B. Wendrich, H. W. Verspaget, E. M. Kooy-Winkelaar, F. Koning, J. J. Zwaginga, H. H. Fidder, A. P. Verhaar, W. E. Fibbe, G. R. van den Brink, and D. W. Hommes. 2010. Autologous bone marrowderived mesenchymal stromal cell treatment for refractory luminal Crohn's disease: results of a phase I study. Gut 59:1662.

90. Ciccocioppo, R., M. E. Bernardo, A. Sgarella, R. Maccario, M. A. Avanzini, C. Ubezio, A. Minelli, C. Alvisi, A. Vanoli, F. Calliada, P. Dionigi, C. Perotti, F. Locatelli, and G. R. 
Corazza. 2011. Autologous bone marrow-derived mesenchymal stromal cells in the treatment of fistulising Crohn's disease. Gut 60:788.

91. Le Blanc, K., C. Tammik, K. Rosendahl, E. Zetterberg, and O. Ringden. 2003. HLA expression and immunologic properties of differentiated and undifferentiated mesenchymal stem cells. Exp Hematol 31:890.

92. Inoue, S., F. C. Popp, G. E. Koehl, P. Piso, H. J. Schlitt, E. K. Geissler, and M. H. Dahlke. 2006. Immunomodulatory effects of mesenchymal stem cells in a rat organ transplant model. Transplantation 81:1589.

93. Tokita, D., H. Ohdan, T. Onoe, H. Hara, Y. Tanaka, and T. Asahara. 2005. Liver sinusoidal endothelial cells contribute to alloreactive T-cell tolerance induced by portal venous injection of donor splenocytes. Transpl Int 18:237.

94. Kamei, T., M. P. Callery, and M. W. Flye. 1990. Pretransplant portal venous administration of donor antigen and portal venous allograft drainage synergistically prolong rat cardiac allograft survival. Surgery 108:415.

95. Nauta, A. J., G. Westerhuis, A. B. Kruisselbrink, E. G. Lurvink, R. Willemze, and W. E. Fibbe. 2006. Donor-derived mesenchymal stem cells are immunogenic in an allogeneic host and stimulate donor graft rejection in a nonmyeloablative setting. Blood 108:2114.

96. Eliopoulos, N., J. Stagg, L. Lejeune, S. Pommey, and J. Galipeau. 2005. Allogeneic marrow stromal cells are immune rejected by MHC class I- and class II-mismatched recipient mice. Blood 106:4057.

97. Zangi, L., R. Margalit, S. Reich-Zeliger, E. Bachar-Lustig, A. Beilhack, R. Negrin, and Y. Reisner. 2009. Direct imaging of immune rejection and memory induction by allogeneic mesenchymal stromal cells. Stem Cells 27:2865.

98. Li, Y., J. Chen, L. Wang, L. Zhang, M. Lu, and M. Chopp. 2001. Intracerebral transplantation of bone marrow stromal cells in a 1-methyl-4-phenyl-1,2,3,6tetrahydropyridine mouse model of Parkinson's disease. Neurosci Lett 316:67.

99. Spaeth, E., A. Klopp, J. Dembinski, M. Andreeff, and F. Marini. 2008. Inflammation and tumor microenvironments: defining the migratory itinerary of mesenchymal stem cells. Gene Ther 15:730.

100. Kawada, H., J. Fujita, K. Kinjo, Y. Matsuzaki, M. Tsuma, H. Miyatake, Y. Muguruma, K. Tsuboi, Y. Itabashi, Y. Ikeda, S. Ogawa, H. Okano, T. Hotta, K. Ando, and K. Fukuda. 2004. Nonhematopoietic mesenchymal stem cells can be mobilized and differentiate into cardiomyocytes after myocardial infarction. Blood 104:3581.

101. Herrera, M. B., B. Bussolati, S. Bruno, L. Morando, G. Mauriello-Romanazzi, F. Sanavio, I. Stamenkovic, L. Biancone, and G. Camussi. 2007. Exogenous mesenchymal stem cells localize to the kidney by means of CD44 following acute tubular injury. Kidney Int 72:430.

102. Waterman, R. S., S. L. Tomchuck, S. L. Henkle, and A. M. Betancourt. 2010. A new mesenchymal stem cell (MSC) paradigm: polarization into a pro-inflammatory MSC1 or an Immunosuppressive MSC2 phenotype. PLoS One 5:e10088.

103. Romieu-Mourez, R., M. Francois, M. N. Boivin, M. Bouchentouf, D. E. Spaner, and J. Galipeau. 2009. Cytokine modulation of TLR expression and activation in mesenchymal stromal cells leads to a proinflammatory phenotype. J Immunol 182:7963.

104. Moll, G., R. Jitschin, L. von Bahr, I. Rasmusson-Duprez, B. Sundberg, L. Lonnies, G. Elgue, K. Nilsson-Ekdahl, D. Mougiakakos, J. D. Lambris, O. Ringden, K. Le Blanc, and B. Nilsson. 2011. Mesenchymal stromal cells engage complement and complement receptor bearing innate effector cells to modulate immune responses. PLoS One 6:e21703.

105. Koch, M., A. Lehnhardt, X. Hu, B. Brunswig-Spickenheier, M. Stolk, V. Brocker, M. Noriega, M. Seifert, and C. Lange. 2013. Isogeneic MSC application in a rat model of acute renal allograft rejection modulates immune response but does not prolong allograft survival. Transpl Immunol 29:43. 
106. Parekkadan, B., A. W. Tilles, and M. L. Yarmush. 2008. Bone marrow-derived mesenchymal stem cells ameliorate autoimmune enteropathy independently of regulatory $\mathrm{T}$ cells. Stem Cells 26:1913.

107. Bluestone, J. A., W. Liu, J. M. Yabu, Z. G. Laszik, A. Putnam, M. Belingheri, D. M. Gross, R. M. Townsend, and F. Vincenti. 2008. The effect of costimulatory and interleukin 2 receptor blockade on regulatory T cells in renal transplantation. Am J Transplant 8:2086.

108. Tan, J., W. Wu, X. Xu, L. Liao, F. Zheng, S. Messinger, X. Sun, J. Chen, S. Yang, J. Cai, X. Gao, A. Pileggi, and C. Ricordi. 2012. Induction therapy with autologous mesenchymal stem cells in living-related kidney transplants: a randomized controlled trial. Jama 307:1169.

109. Reinders, M. E., J. W. de Fijter, H. Roelofs, I. M. Bajema, D. K. de Vries, A. F. Schaapherder, F. H. Claas, P. P. van Miert, D. L. Roelen, C. van Kooten, W. E. Fibbe, and T. J. Rabelink. 2013. Autologous bone marrow-derived mesenchymal stromal cells for the treatment of allograft rejection after renal transplantation: results of a phase I study. Stem Cells Transl Med 2:107.

110. Bohne, F., M. Martinez-Llordella, J. J. Lozano, R. Miquel, C. Benitez, M. C. Londono, T. M. Manzia, R. Angelico, D. W. Swinkels, H. Tjalsma, M. Lopez, J. G. Abraldes, E. Bonaccorsi-Riani, E. Jaeckel, R. Taubert, J. Pirenne, A. Rimola, G. Tisone, and A. SanchezFueyo. 2012. Intra-graft expression of genes involved in iron homeostasis predicts the development of operational tolerance in human liver transplantation. $J$ Clin Invest 122:368 


\section{CURRICULUM VITAE}

Federica Casiraghi was born in Merate (LC), Italy in 1969. She has obtained her degree in Industrial Chemistry in 1988 at ITIS "G. Natta" in Bergamo, Italy. She has obtained the degree in Clinical Monitoring and in Biochemical Research in 1993-1994 at Mario Negri Institute for Pharmacological Research, Bergamo, Italy.

From 1989 to 1994 she was a research fellow at Mario Negri Institute, Bergamo within Laboratory of Immunology and Genetics of Rare Disease and Organ Transplantation. Since 2006 she is Head of the Unit of Cellular and Molecolar Biology of Transplantation Tolerance at the Transplant Research Center "Chiara Cucchi de Alessandri e Gilberto Crespi” in Ranica (BG), Italy.

She is involved in the field of transplant immunology with particular interest on pharmacological and cellular therapies for induction and maintenance of transplantation tolerance as well as in the characterization of regulatory $\mathrm{T}$ cells in renal transplant patients given different immunosuppressive drugs and in experimental models of allograft tolerance.

She has authored and co-authored more than 30 articles for publication in scientific journals especially in the field of transplant immunology and experimental lupus nephritis. 


\section{ACKNOWLEDGEMENTS}

First and foremost, I wish to thank Maastricht University which gave me the possibility to defend this thesis to obtain the degree of Doctor, and in particular Prof. Karel Leunissen, who took charge of my application, kindly provided helpful advices and revised the current thesis.

I'm very indebted and especially grateful to Prof Giuseppe Remuzzi. He encouraged me since the beginning to pursue the research work and continuously favoured my self-confidence. He was always available to discuss the results and was an unlimited source of research ideas.

Special thanks to Drs Marina Noris, Norberto Perico and Ariela Benigni who dedicated to me their precious time and efforts teaching how to be a researcher, from laboratory methods, experimental design, interpretation of the results, and writing a scientific report.

I am also very grateful to all present and past colleagues with whom I have shared research activity and with whom it is really a pleasure to work and spent time, in particular Marta and Nadia for always being supportive.

Last but not least, I wish to thank my husband Tiziano who daily support my research work, my sons Tommaso and Filippo, my mother Cesarina and my sister Cosetta. 